$10 / 9590$



United States Department of Energy

July 1995

Office of Energy Research

Office of Health and Environmental Research

Environmental Sciences Division

Washington, DC 20585

\title{
Graduate Student Theses Supported by \\ DOE's Environmental Sciences Division
}

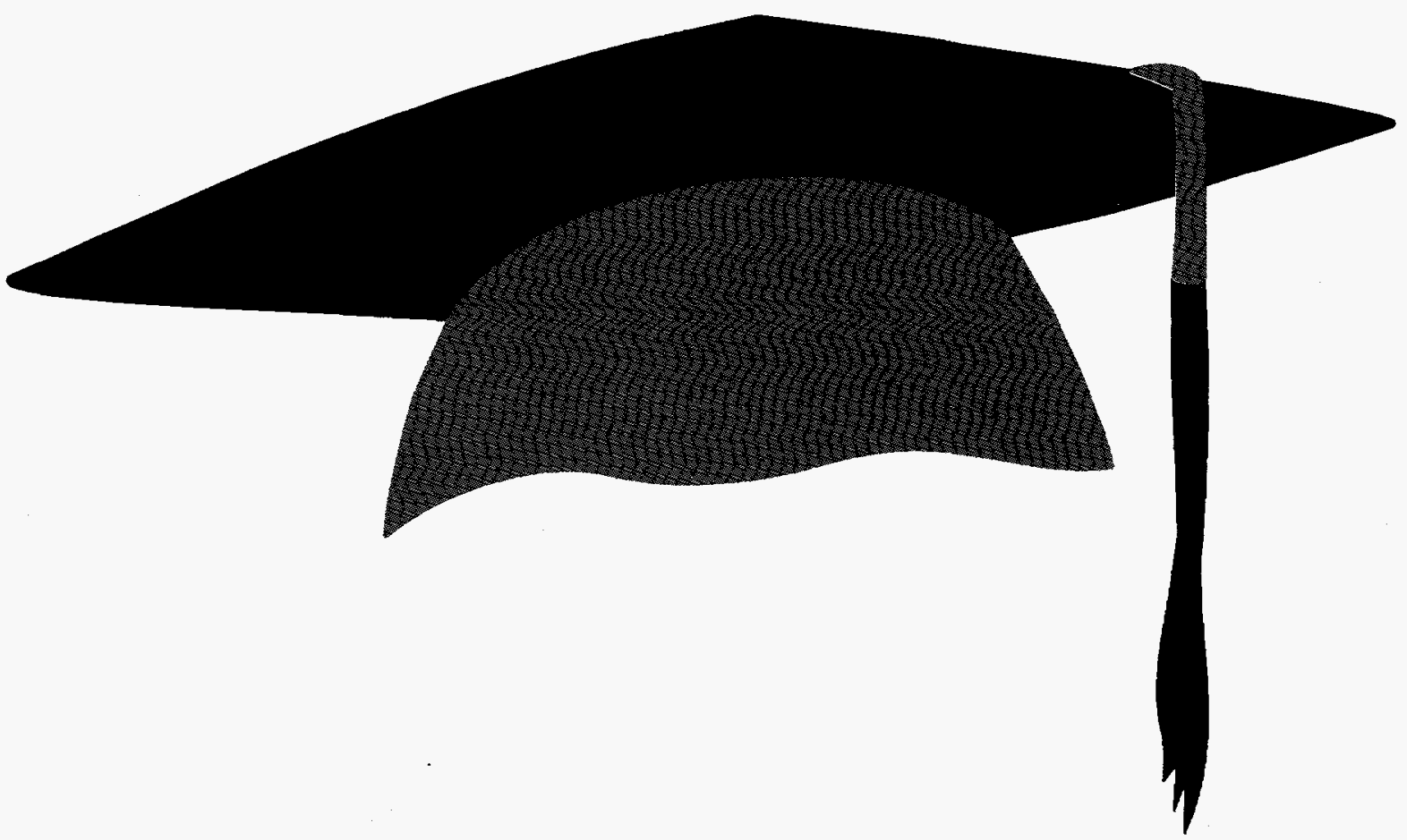


This report has been reproduced directly from the best available copy.

Available to DOE and DOE Contractors from the Office of Scientific and Technical Information, P.O. Box 62, Oak Ridge, TN 37831; prices available from (615) 576-8401.

Available to the public from the U.S. Department of Commerce, Technology Administration, National Technical Information Service, Springfield, VA 22161, (703) $487-4650$. 


\section{DISCLAIMER}

This report was prepared as an account of work sponsored by an agency of the United States Government. Neither the United States Government nor any agency thereof, nor any of their employees, make any warranty, express or implied, or assumes any legal liability or responsibility for the accuracy, completeness, or usefulness of any information, apparatus, product, or process disclosed, or represents that its use would not infringe privately owned rights. Reference herein to any specific commercial product, process, or service by trade name, trademark, manufacturer, or otherwise does not necessarily constitute or imply its endorsement, recommendation, or favoring by the United States Government or any agency thereof. The views and opinions of authors expressed herein do not necessarily state or reflect those of the United States Government or any agency thereof. 


\section{DISCLAIMER}

Portions of this document may be illegible in electronic image products. Images are produced from the best available original document. 


\section{Graduate Student Theses}

Supported by

DOE's Environmental

Sciences Division

Compiled by:

Robert M. Cushman

Carbon Dioxide Information Analysis Center

Environmental Sciences Division

Oak Ridge National Laboratory

Oak Ridge, Tennessee 37831-6335

Bobbi M. Parra

Environmental Sciences Division

Office of Health and Environmental Research

Office of Energy Research

U.S. Department of Energy

19901 Germantown Road

Germantown, Maryland 20874-1290 

TABLE OF CONTENTS

Page

LIST OF FIGURES $\ldots \ldots \ldots \ldots \ldots \ldots \ldots \ldots \ldots \ldots \ldots \ldots \ldots \ldots \ldots \ldots \ldots \ldots, \mathrm{v}$



ACKNOWLEDGMENTS $\ldots \ldots \ldots \ldots \ldots \ldots \ldots \ldots \ldots \ldots \ldots \ldots \ldots \ldots \ldots \ldots$ ix

PREFACE $\ldots \ldots \ldots \ldots \ldots \ldots \ldots \ldots \ldots \ldots \ldots \ldots \ldots \ldots \ldots \ldots \ldots \ldots \ldots \ldots \ldots \ldots$



BIBLIOGRAPHY $\ldots \ldots \ldots \ldots \ldots \ldots \ldots \ldots \ldots \ldots \ldots \ldots \ldots \ldots \ldots \ldots \ldots \ldots \ldots \ldots$

MAJOR PROFESSOR INDEX $\ldots \ldots \ldots \ldots \ldots \ldots \ldots \ldots \ldots \ldots \ldots \ldots \ldots \ldots \ldots \ldots \ldots \ldots$

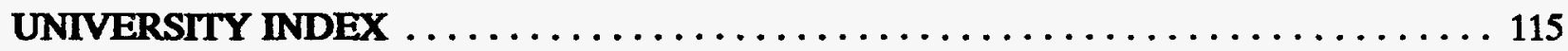

PRINCIPAL INVESTIGATOR INDEX $\ldots \ldots \ldots \ldots \ldots \ldots \ldots \ldots \ldots \ldots \ldots \ldots \ldots \ldots \ldots$

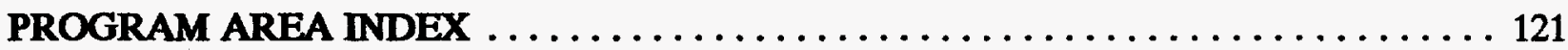

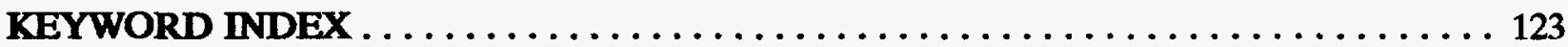





\section{LIST OF FIGURES}

\section{Fipure}

1. Number of graduate student theses, by year of completion, supported by the DOE Environmental Sciences Division (and its predecessor divisions). . . . . . . . . xiii

2. Number of graduate student theses, by Program Area, supported by the DOE Environmental Sciences Division (and its predecessor divisions). . . . . . . . xiv 



\begin{abstract}
This report provides complete bibliographic citations, abstracts, and keywords for 212 doctoral and master's theses supported fully or partly by the U.S. Department of Energy's Environmental Sciences Division (and its predecessors) in the following areas: Atmospheric Sciences; Marine Transport; Terrestrial Transport; Ecosystems Function and Response; Carbon, Climate, and Vegetation; Information; Computer Hardware, Advanced Mathematics, and Model Physics (CHAMMP); Atmospheric Radiation Measurement (ARM); Oceans; National Institute for Global Environmental Change (NIGEC); Unmanned Aerial Vehicles (UAV); Integrated Assessment; Graduate Fellowships for Global Change; and Quantitative Links. Information on the major professor, department, principal investigator, and program area is given for each abstract. Indexes are provided for major professor, university, principal investigator, program area, and keywords. This bibliography is also available in various machine-readable formats (ASCII text file, WordPerfect $^{\circ}$ files, and PAPYRUS ${ }^{\mathrm{Tm}}$ files).
\end{abstract}





\section{ACKNOWLEDGMENTS}

We thank all the DOE-funded investigators who provided the details of graduate student theses completed under their projects.

We thank Penny Sullenberger of the Carbon Dioxide Information Analysis Center (CDIAC) for compiling a list of DOE-funded investigators, Deborah Shepherd (CDIAC) and Julia Watts (Environmental Sciences Division, Oak Ridge National Laboratory) for providing technical comments on a draft version of this report, and Julie Bommarito (Information Management Services, Oak Ridge National Laboratory) for her suggestions for improvement of this report.

CDIAC is supported by the U.S. Department of Energy's Office of Health and Environmental Research, Environmental Sciences Division. CDIAC is housed in the Environmental Sciences Division of Oak Ridge National Laboratory, which is managed by Lockheed Martin Energy Systems, Inc., for the U.S. Department of Energy under Contract DE-AC05-84OR21400. Publication No. 4428, Environmental Sciences Division, Oak Ridge National Laboratory. 



\section{PREFACE}

The U.S. Department of Energy's Environmental Sciences Division (ESD), located within the Office of Health and Environmental Research, Office of Energy Research, has a strong commitment to graduate education. In 1987, the Carbon Dioxide Information Analysis Center (CDIAC) published Graduate Student Theses Supported by Carbon Diaxide Research Division, Office of Basic Energy Sciences, U.S. Department of Energy (ORNL/CDIAC-21, Raymond E. Millemann, ed.), which summarized $25 \mathrm{Ph} . \mathrm{D}$. and 23 master's theses that had been written between 1981 and 1987 , based on research supported fully or partly with funds from the Carbon Dioxide Research Division (CDRD). ESD now includes research supported by the former CDRD, as well as ESD's other predecessor divisions: the Atmospheric and Climate Research Division, the Carbon Dioxide Effects Research Division, the Ecological Research Division, the Physical and Technological Research Division, and the Pollutant Characterization and Safety Research Division. This update to the 1987 report covers theses and dissertations through early 1995, including those summarized in the earlier report. This report covers the following areas:

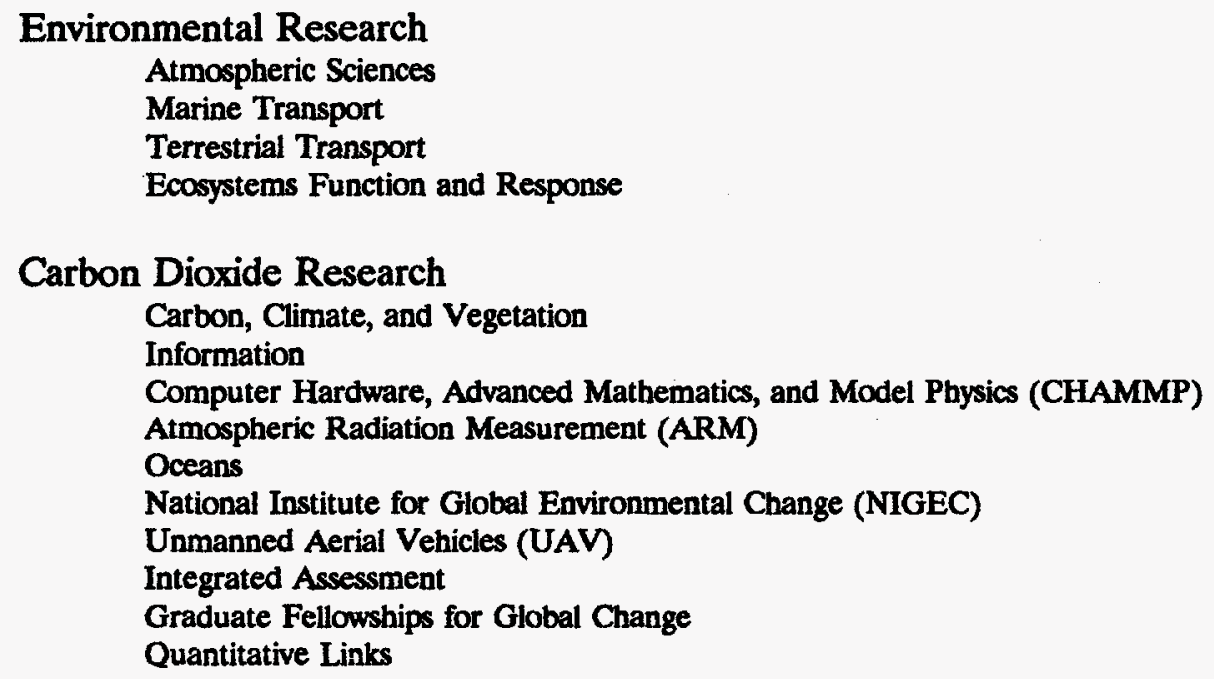

A summary with figures shows the breakdown of the theses by degree, year, and program area. The body of the bibliography provides a complete bibliographic citation (author, year, title, degree, university, number of pages), along with abstract, major professor, department, principal investigator, program area, and keywords. The bibliographic listing is followed by major professor, university, principal investigator, program area, and keyword indexes.

This report was compiled by CDIAC using PAPYRUS ${ }^{\mathrm{mm}}$ Bibliography System, version 7.0.3 (Research Software Design, 2718 SW Kelly Street, Suite 181, Portland, OR 97201). PAPYRUS produced formatted output files that were imported into WordPerfect ${ }^{\circ}$, version 5.1 (WordPerfect Corporation, $1555 \mathrm{~N}$. Technology Way, Orem, UT 84057) for final document preparation. The keyword index was produced within PAPYRUS; to create the major professor, university, principal investigator, and program area indexes, additional database operations were performed using Lotus $1-2-3^{\circ}$. 
This bibliography is also available, free of charge, in various machine-readable formats from CDIAC, Oak Ridge National Laboratory, Mail Stop 6335, P.O. Box 2008, Oak Ridge, TN 378316335; telephone 615-574-3645; fax 615-574-2232; e-mail cdiac@ornl.gov. The formats include ASCII text file, WordPerfect files, and PAPYRUS files. For additional information on bibliographic software, users are referred to articles such as "Bibliography Formatting Software: A Buying Guide," by Sue Stigleman (which appeared on pages 15-27 of the February 1992 issue of $D A T A B A S E$ ) and "Personal Bibliographic Software Programs-A Comparative Review," by Paul R. Neal (pages 44-51 of the January 1993 issue of BioScience). The PAPYRUS Retriever, a limited version of PAPYRUS that may be used to manipulate and access this database, is available directly from Research Software Design's $\mathrm{ftp}$ area at ftp.teleport.com/vendors/rsd. 


\section{SUMMARY}

To date, $\mathbf{2 1 2}$ graduate theses have been written based on research supported fully or partly with funds from the DOE Environmental Sciences Division or its predecessors. Sixty-three universities, including three foreign universities (in Australia, Switzerland, and the United Kingdom), awarded degrees for the thesis research reported here. There were 102 doctoral degrees (Ph.D. and D.Sci.) and 110 master's degrees (M.S., M.A., M.En., M.Eng., M.P.P., and M.P.A.) awarded for this thesis work. The greatest number of degrees (53) were awarded in 1994 (Fig. 1), although 1995 was not yet complete when this bibliographic database was compiled. The program areas accounting for the greatest number of theses and dissertations were Carbon, Climate, and Vegetation (104); Atmospheric Radiation Measurement, Marine Transport, and National Institute for Global Environmental Change (18 each); and Atmospheric Sciences (15) (Fig. 2).

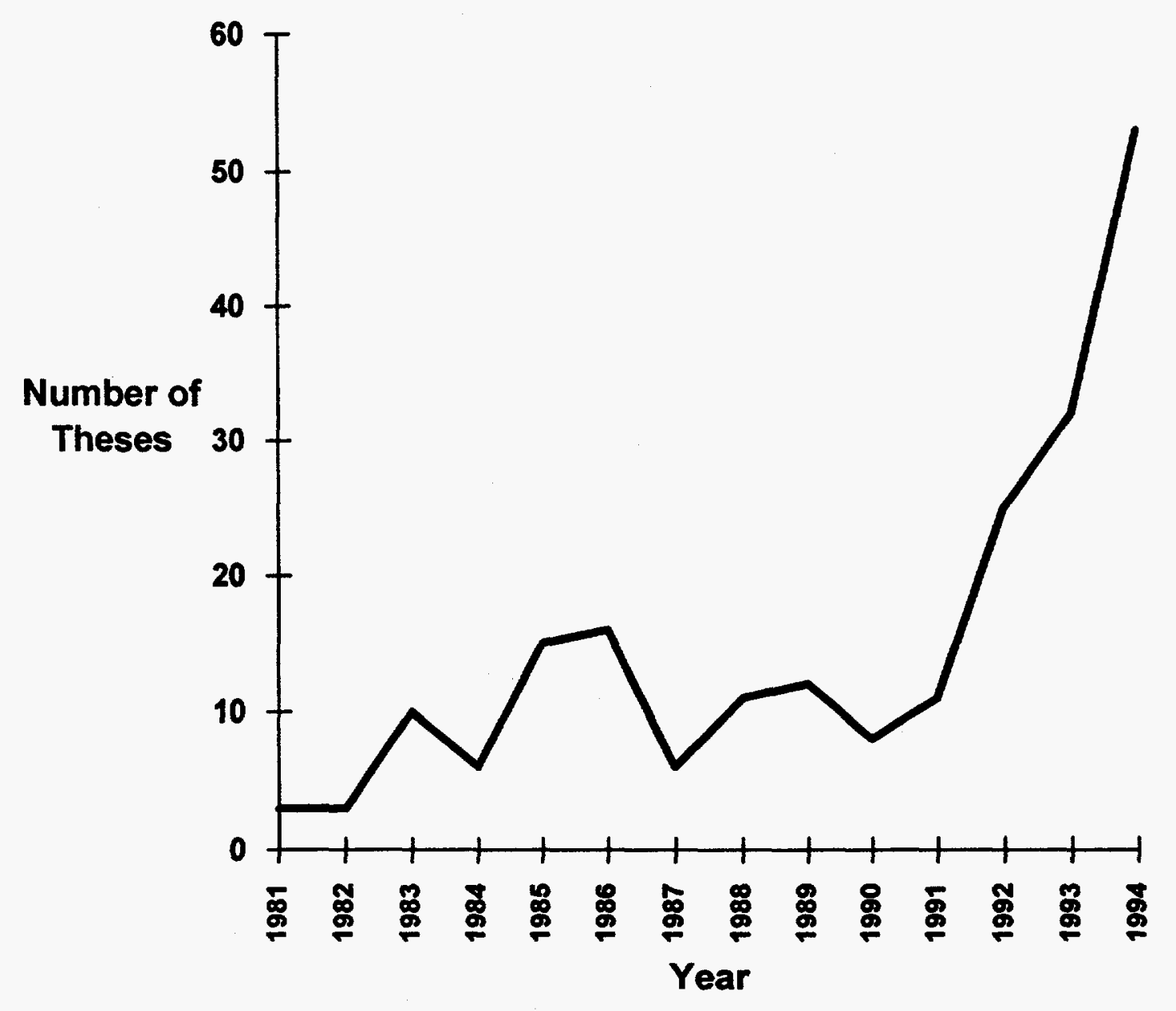

Fig. 1. Number of graduate student theses, by year of completion, supported by the DOE Environmental Sciences Division (and its predecessor divisions). 




Fig. 2. Number of graduate student theses, by Program Area, supported by the DOE Environmental Sciences Division (and its predecessor divisions). 


\section{BIBLIOGRAPHY}

1

Acter, Richard H 1994. The Quiet (Energy)

Revolution: Analyzing the Dissemination of Photovoltaic Systems in Kenya. M.P.A. Thesis, Princeton University, 107 pages.

The widespread introduction and adoption of renewable energy technologies remains high on virtually every national development policy agenda; renewable energies can assist national energy autonomy, decentralize resource management, promote environmental conservation, and serve as a means to reduce global warming. The track-record of efforts to turn this noble ideology into successful technology transfer and dissemination, however, remains very mixed. It is a story of a few successes amid many failures. Here we document and examine the diffusion of small-scale photovoltaic (PV) systems in Kenya. At the same time that integrated energy plans and top-down models championing renewable energy futures are becoming increasingly common, a new power base, divorced from these grand schemes, has begun to emerge. Over the past decade, some 20,000 to 40,000 small PV systems, essentially all privately financed, have been installed in Kenya. Many valuable lessons for renewable energy research can be found here. The Kenyan case richly illustrates the dramatic role that actors on every scale, from grass-roots to international, can have in accelerating - or when mismanaged, impeding -technology transfer and the elevation of renewable energy systems from niche applications to a prominent role in housebold empowerment, and decentralized and sustainable development initiatives.

Major Professor(s): Kammen, Daniel M. Department: Woodrow Wilson School of Public and International Affairs

Principal Investigator(s): Kammen, Daniel M. Program Area: National Institute for Global Environmental Change (NIGEC)

\section{KEYWORDS: AFRICA, POLICY, SOLAR ENERGY}

2

Acterman, Andrew S. 1994. A Numerical Modeling Study of the Effects of Variations in Aerosol Concentrations on Stratiform Clouds in the Marine Boundary Layer. Ph.D. Dissertation, University of Washington, 230 pages.

Marine stratiform clouds play an important role in the global radiative heat budget of the Earth because they overlie about a third of the oceans and they reflect much more sunlight than the ocean surface. The reflectivity of these clouds depends in part on the concentrations of cloud condensation nuclei (CCN) on which cloud droplets form. Here a numerical model is used to investigate interactions between aerosol and cloud microphysics, radiative transfer, and turbulent mixing in the stratiform cloud-topped marine boundary layer. Results from model simulations are found to be in general agreement with airborne measurements of marine stratocumulus clouds. However, the model underpredicts the concentrations of small cloud droplets in the lower region of the cloud layer. This is consistent with the lack of a peak supersaturation near cloud base in the model results, which is attributable to horizontal averaging in the model. The model simulations indicate that equilibrium $\mathrm{CCN}$ concentrations are sensitive to their formation rate. The times required to reach equilibrium were found to increase with increasing $\mathrm{CCN}$ concentration, suggesting that cloud layers can maintain high $\mathrm{CCN}$ concentrations long after the supply of $\mathrm{CCN}$ is reduced. The results of the model show cloud albedo to be more sensitive to cloud droplet concentrations than under the assumptions that cloud water is fixed and unactivated haze particles are ignored. Increased droplet concentrations generally (but not always) produce increased cloud water due to reduced drizzle. The number of haze particles increases with droplet concentrations due to decreased peak supersaturations in the cloud. The model simulations show that when droplet collisions reduce droplet concentrations to extremely low values, a cloud layer can become so optically thin that cloud-top radiative cooling is unable to drive vertical mixing. The stratocumulus-topped marine boundary layer can then collapse to a shallow fog layer over the course of a day or more. The model was also used to investigate long-lived, linear regions of enhanced cloud reflectivity that appear in satellite imagery downwind of ships. We have found that injections of CCN, which are present in ship exhaust, can account for many of the observed properties of ship tracks. Ship tracks are classified as Type 1, which are observed in visible satellite imagery, and Type 2, which are more common and are observed in near-infrared imagery. The distinction between the two types is attributed to differences in ambient concentrations of CCN that cause variations in turbulent mixing in the marine boundary layer, through the effect of cloud droplet concentrations on cloud-top longwave radiative cooling.

Major Professor(s): Hobbs, Peter V. Department: Atmospheric Sciences 
Principal Investigator(s): Toon, Owen B., and Douglas L. Westphal Program Area: Atmospheric Radiation Measurement (ARM)

\section{KEYWORDS: AEROSOLS, BOUNDARY LAYER, CLOUDS, CONDENSATION, MARINE ENVIRONMENT, MICROPHYSICS, PARTICULATES, REFLECTANCE}

\section{3}

Ahmed, Faisal Elgasim. 1992. Heat Injury to Reproductive Development in Cowpea (Vigna unguiculata (L.) Walp.) Under Ambient and Elevated Carbon Dioxide Concentrations. Ph.D. Dissertation, University of California at Riverside, 100 pages.

Physiological basis of heat injury during reproductive development was studied using contrasting cowpea (Vigna unguiculata L. Walp.) genotypes subjected to different night temperatures and light qualities under ambient and elevated levels of $\mathrm{CO}_{2}$ in growth chambers. The objectives were to: determine the stages of reproductive development when damage due to heat stress occurs; test whether specific tissues or developmental processes are damaged during the periods of sensitivity to heat; evaluate the interactive effects of temperature and light quality during the day on floral development; and test for possible associations between carbohydrate limitations and sensitivity to heat during reproductive development. High night temperature during the vegetative and early reproductive states causes complete suppression of floral buds on the main stem. Transfer experiments demonstrated that plants were not sensitive to heat at a particular stage of development but that the duration of beat experience is critical for floral bud development. Two weeks or more of continuous or interrupted heat caused complete suppression of all floral buds suggesting that the heat stress effect was cumulative over time. The degree to which high night temperature suppressed floral bud development depended on the R/FR ratio during the day and values of 1.3 to 1.6 were required to elicit the same responses as occur under natural sunlight. High night temperature during anther development causes male-sterility and results in no pod set due to low pollen viability and anther indehiscence. The stage of floral development most sensitive to heat occurred nine to seven days before anthesis. During this period, premature degeneration of the tapetal tissue and lack of endothecial formation were detected in heat stressed plants. These two abnormalities may be responsible for the low pollen viability, low anther dehiscence and low pod set observed under heat stress. Under high night temperature, different heat sensitive genotypes either produced no flowers or set no pods at either ambient or elevated $\mathrm{CO}_{2}$, whereas the heat tolerant genotype abundantly set pods. The high pod set of the heat tolerant genotype was associated with higher levels of sugars in peduncles compared with the heat sensitive genotypes. Elevated $\mathrm{CO}_{2}$ resulted in higher overall carbohydrate levels in heat sensitive genotypes but sugar levels in peduncles were not improved indicating that heat stress affects assimilate demand to a greater extent than assimilate supply. It is hypothesized that sensitivity to heat during reproductive development is due to developmental lesions that are not overcome by enhanced carbohydrate supplies through $\mathrm{CO}_{2}$ enrichment. A heat tolerant genotype was most responsive to $\mathrm{CO}_{2}$ enrichment, with respect to pod production, under either high or intermediate temperatures.

Major Professor(s): Hall, Anthony E.

Department: Botany and Plant Sciences Principal Investigator(s): Hall, Anthony E. Program Area: National Institute for Global Environmental Change (NIGEC)

KEYWORDS: CARBON DIOXIDE, FERTILIZATION, GROWTH AND DEVELOPMENT, HEAT STRESS, REPRODUCTION, VEGETATION

\section{4}

Altearappuram, Anto Francis. 1988. Air-Sea Exchange Processes off the Carolinas During the 1986 East Coast Winter Storms - GALE (Genesis of Atlantic Lows Experiment). M.S. Thesis, North Carolina State University, 105 pages.

GALE, a national and multi-institutional project to study the physical mechanisms causing the formation and development of winter storms, was centered around the eastern Carolinas along the east coast of the United States from 15 January to 15 March, 1986. Data from six moored buoys in the coastal waters off the Carolinas and two research vessels mostly stationed at the western boundary of the Gulf Stream (GS) were used to study air-sea interaction processes. Data selection for the period of 20 January to 13 February, 1986 included several cases of cold air outbreaks, cold front passages, coastal frontogenesis, and offshore cyclogenesis. Prevalence of non-neutral conditions during the entire time period of GALE necessitated the selection of an appropriate method to account for the diabatic effects for computing the surface fluxes from the routine surface GALE data. An Iterative Bulk Aerodynamic Method (IBAM) is compared with the eddy correlationand energy dissipation method to obtain surface fluxes of momentum and heat during the non-neutral 
boundary layer conditions and high winds $\left(-22 \mathrm{~ms}^{-1}\right)$. After the intercomparisons of IBAMs, the IBAM of Liu, et al. (1979) was selected as a good indirect bulk method to use with the GALE data sets. Fluxes of momentum and heat from the mesascale network of buoys and ships show significant temporal- and spatial variations in the coastal waters and along the western boundary of the GS with the south to north and crossstream gradients. Spatial and temporal variations of these fluxes depend on the formation, location, intensity, and path of large-scale disturbances. During GALE, the highest fluxes, as measured from research vessels and buoys, occurred off the coast of South Carolina where high wind speeds and air-sea temperature differences were recorded frequently. For example, a momentum flux of $1.03 \mathrm{NM}^{-2}$ and a total heat flux of $1243 \mathrm{WM}^{-2}$ with an air-sea temperature difference of about $-22^{\circ} \mathrm{C}$ in the vicinity of the highly baroclinic GS front were observed in this area during the offshore cyclogenesis with cold air outbreak on 27 January/ at 0900 UTC. A salient feature of the spatial variation across the western boundary of the GS front is the prevailing accelerating effect that causes large deviations in the surface fluxes. Time series data for the depth of Oceanic Mixed Layer (OML) from a stationary location during $26 / 0000$ to 27 January/1100 UTC show the response of the depth of OML with a lag of about two hours to the modulations of surface fluxes induced by the synoptic-/mesascale atmospheric disturbances. The range of variations of OML depth is from 50 to $76 \mathrm{~m}$ when the variations of momentum, sensible heat, and latent heat are from 0.15 to 1.03 $\mathrm{NM}^{-2}, 24$ to $367 \mathrm{WM}^{-2}$, and 214 to $874 \mathrm{WM}^{-2}$ respectively. OML observations are far less than those obtained using one-dimensional models and the comparison shows that the models do not work well at the western boundary of the GS front probably because of strong horizontal advection.

Major Professor(s): Raman, Sethu

Department: Marine, Earth and Atmospheric Sciences Principal Investigator(s): Pietrafesa, Leonard J. Program Area: Marine Transport

KEYWORDS: ATMOSPHERE, CIRCULATION, CLIMATE, COASTAL ENVIRONMENT, HEAT FLUX, MOMENTUM, OCEANS, SPATLAL DISTRIBUTION, STORMS, TEMPORAL DISTRIBUTION

5 Aliss, Randall Jamil. 1992. The Utilization of SSMI/ Data in the Analysis of Tropical and Extra-Tropical Cyclones. M.S. Thesis, North Carolina State University, 143 pages.
Recently, remote sensing of tropical and extra-tropical storms has been enhanced via data from the Special Sensor Microwave/Imager (SSM/I) launched by the Defense Meteorological Satellite Program (DMSP) in June 1987. Data obtained from SSM/I was analyzed and used to infer important meteorological parameters of Hurricanes Hugo (1989) and Florence (1988) as well as a mid-latitude cyclone which developed during Intensive Observational Period (IOP) -4 of the Experiment on Rapidly Intensifying Cyclones over the Atlantic (ERICA). These parameters include rainfall rates, integrated water vapor, marine surface wind speeds and 85 Gigahertz brightness temperatures used for center fixing the tropical cyclones. In this study, the utility of the SSM/I as a supplemental source of data in tropical and extra-tropical cyclones is evaluated. Results indicate that increases in SSM/ $/$ derived total latent heat release and increases in heavier rainfall rates near the center are associated with the intensification of both Hugo and Florence. SSM/I winds give a good description of the surface wind field of both Florence and the IOP-4 storm, outside areas of deep convection. SSM/I integrated water vapor is found to be particularly useful in locating the surface fronts associated with the IOP-4 cyclone. In addition, storm structure characteristics inferred from SSM $/ 1$ of the ERICA IOP4 storm compare well with the numerical results produced by the Naval Research Laboratory mesoscale model. Because SSM/I parameters were useful in observing the structure of these storms and compared well with in situ observations and model simulations, the applications described herein could be valuable in augmenting current analysis techniques of tropical and extra-tropical cyclones.

Major Professor(s): Raman, Sethu

Department: Marine, Earth and Atmospheric Sciences Principal Investigator(s): Raman, Sethu Program Area: Atmospheric Radiation Measurement (ARM)

KEYWORDS: CLIMATE, EXTRATROPICS, HEAT FLUX, PRECIPITATION, REMOTE SENSING, STORMS, TROPICS, WATER VAPOR, WNDS

6

Angevine, Wayne. 1993. Heat and Momentum Flux Measurements in the Planetary Boundary Layer with a Wind Profiling Radar/Radio Acoustic Sounding System. Ph.D. Dissertation, University of Colorado, 85 pages.

The planetary or atmospheric boundary layer is the lowest $100-2000 \mathrm{~m}$ of the atmosphere, and contains the sources of most energy and pollutarts that affect the entire atmosphere. Boundary layer structure and 
dynamics are key to understanding, modeling, and predicting climate, weather and pollution. New and improved techniques for measuring the dynamics of the boundary layer are needed. Existing methods involving towers, surface measurements, or aircraft have limited flexibility or are expensive. This dissertation describes methods for measuring heat flux (virtual temperature flux) and momentum flux in convective boundary layers. The instrument used is the $915 \mathrm{MHz}$ boundary layer radar wind profiler Radio Acoustic Sounding System (profiler/RASS). As the name suggests, the profiler was developed to make wind measurements, and this work is an expansion of its capabilities. The radio acoustic sounding system uses the profiler and attachments to measure virtual temperature. Before the profiler/RASS could be used to make flux measurements, the ability to make simultaneous measurements of wind velocity and temperature had to be developed. A feasibility study was conducted in Platteville, CO in June 1991 to determine if flux measurements were a practical application of the profiler, with encouraging results. The Rural Oxidants in the Southern Environment II (ROSE II) experiment in Alabama in June 1992 provided the opportunity to compare flux measurements from the profiler/RASS to those made by a surface sonic anemometer and an aircraft, The National Center for Atmospheric Research (NCAR) King Air. The results indicate that the profiler/RASS is capable of making heat flux measurements that compare well with aircraft and surface measurements. The primary limitation on the precision of the measurements is the sampling uncertainty of the turbulence, a limitation that is the same for any fixed instrument. The feasibility of making momentum flux measurements needs to be explored further in more favorable conditions. In the course of analyzing the flux measurements, methods of determining the mixing depth (boundary layer height) and improved data quality control techniques were developed.

Major Professor(s): Avery, Susan

Department: Electrical and Computer Engineering Principal Investigator(s): Gage, Ken Program Area: Atmospheric Radiation Measurement (ARM)

KEYWORDS: BOUNDARY LAYER, HEAT FLUX, MOMENTUM, RADIO ACOUSTIC SOUNDING SYSTEM (RASS), TURBULENCE, WINDS

7

Amosti, Carol 1983. Structural Characterization and Bacterial Degradation of Marine Carbohydrates. Ph.D. Thesis, Massachusetts Institute of Technology and Woods Hole Oceanographic Institution, 239 pages.
The goal of this thesis was to develop and apply an integrated chemical and microbial approach to study the effects of chemical structure on the rates and patterns of carbohydrate degradation by anaerobic marine bacteria. Polysaccharides produced by five species of marine plankton, Dunaliella tertiolecta, Emiliania huxdeyi, Stephanopixis palmeri, a Phaeocystis sp., and Synechococcus WH7335, were surveyed using one- and two-dimensional nuclear magnetic resonance spectroscopy (NMR). Two carbohydrates from Synechococcus WH7335 were characterized in detail. Synechococcus produced an $a(1,4)$ glucose polysaccharide with $a(1,6)$ branches, which probably function as an energy reserve. The nominal molecular weight of the polysaccharide was $\approx 5000$ daltons. Large quantities of a glycerol-polysaccharide, which was tentatively identified as a teichoic acid similar in structure to teichoic acids found in cell walls of grampositive bacteria, were also produced by Synechococcus WH7335. This is the first report of teichoic acids in cyanobacteria. Enrichment of bacteria from anoxic marine sediments on specific carbohydrate yielded reproducible model systems with which to study the degradation of chemically well-defined substrates. Headspace gases $\left(\mathrm{CO}_{2}, \mathrm{H}_{2}, \mathrm{CH}_{4}, \mathrm{H}_{2} \mathrm{~S}\right)$ were monitored by gas chromatography, and carbohydrate substrates and intermediates were separated and quantified via gel-permeation chromatography and high-pressure liquid chromatography. The transfer of carbon from substrates through to end products was followed quantitatively. Nuclear magnetic resonance spectroscopy was used to check for selective structural alterations (such as preferential cleavage of specific linkage types or positions) of the substrates. A series of enrichment experiments showed that mixed cultures of marine bacteria distinguish even between small, very closelyrelated substrates which do not require extracellular hydrolysis prior to uptake. A galactose-B(1,3)-arabinose dimer was degraded at half the rate of seven other similar disaccharides and three larger oligosaccharides. A further series of degradation experiments with polysaccharides (pullulan, laminarin) showed that they are degraded by bacteria at virtually the same rate as structurally related substrates in the molecular weight range of 300-600 daltons. Degradation of the branched glucan and the teichoic acid-type pclysaccharide from Synechococcus WH7335 was also very rapid. The timecourse of bacterial hydrolysis of pullulan was examined with gel permeation chromatography and NMR to provide the first molecular-level evidence in marine systems of the bacterial extracellular transformation of high molecular weight organic matter to lower molecular weight organic matter. NMR spectra provided evidence that the pulluian was hydrolyzed by pullulanase, an endo-acting extracellular enzyme which preferentially hydrolyzes $\alpha(1,6)$ linkages. This is the first 
experimental evidence of pullulanase activity among marine mesophilic bacteria. The culture results suggest that enzymatic hydrolysis of macromolecular carbohydrates to transportable pieces is not the slow step in bacterial degradation of at least some types of polysaccharides. The results from the oligosaccharide experiments suggest that certain heteropolysaccharides may not be degraded as quickly. Chemical structure can be more important than molecular weight in determining degradation rates of carbohydrates. Varying rates of organic polymer degradation in anoxic sediments may be largely determined by the sensitivity of bacterial enzymatic and transport systems to structural features.

Major Professor(s): Repeta, Daniel J. Department: Joint Program in Oceanography Principal Investigator(s): Repeta, Daniel J., and Timothy I. Eglinton Program Area: Marine Transport

\section{KEYWORDS: BACTERLA, CARBOHYDRATES, CARBON CYCLE, DEGRADATION, MARINE ENURONMENT, PLANKTON, SEDIMENTS}

8

Arshy, Natalie. 1994. Prediction of the Generalized Ecotypes with COLA GCM Using Four Different Bioclimatic Schemes. M.S. Thesis, University of Maryland at College Park, 22 pages.

The problem of interactive coupling of the AGCM to the biospheric model is examined. Four different bioclimatic schemes, which relate the atmospheric parameters like annual temperature and precipitation to the vegetation distribution, were implemented. The schemes were applied to two global climate data sets. One represents the result of the COLA (Center for Ocean-Land-Atmosphere Interactions) model R-15 version simulation of the present-day climate (without coupled ocean). Ten years monthly averages of nearsurface temperature, total precipitation, soil wetness, net long-wave radiation and short-wave radiation absorbed at the surface were used for schemes calculations. Another data set represents climatological temperature and precipitation data (Jaeger data set, NCAR). The main result is that all four models are able to reproduce the main features of the vegetation distribution. Thus, the schemes can be used as a first step in coupling of atmospheric GCM with biosphere, e.g. "interactive biosphere". In addition, they can be a useful tool in interpreting of the GCM results of future and past climates simulations and a diagnostic tool for verification of the model performance in a simulation of the present-day climate.
Major Professor(s): Baer, Ferdinand

Department: Meteorology

Principal Investigator(s): Baer, Ferdinand

Program Area: Atmospheric Radiation Measurement (ARM)

\section{KEYWORDS: CLIMATE, MODELS, RADLATIVE} PROCESSES

9

Atherton, Cynthia Shaver. 1994. Predicting

Tropospheric Ozone and Hydroxyl Radical in a Global, Three-Dimensional, Chemistry, Transport, and Deposition Model. Ph.D. Dissertation, University of California at Davis, 209 pages.

Two of the most important chemically reactive tropospheric gases are ozone $\left(\mathrm{O}_{3}\right)$ and the hydroxyl radical $(\mathrm{OH})$. Although ozone in the stratosphere is a necessary protector against the sun's radiation, tropospheric ozone is actually a pollutant which damages materials and vegetation, acts as a respiratory irritant, and is a greenhouse gas. One of the two main sources of ozone in the troposphere is photochemical production. The photochemistry is initiated when hydrocarbons and carbon monoxide $(\mathrm{CO})$ react with nitrogen oxides $\left(\mathrm{NO}_{\mathrm{x}}=\mathrm{NO}+\mathrm{NO}_{2}\right)$ in the presence of sunlight. Reaction with the hydroxyl radical, $\mathrm{OH}$, is the main sink for many tropospheric gases. The hydroxyl radical is highly reactive and has a lifetime on the order of seconds. Its formation is initiated by the photolysis of tropospheric ozone. Tropospheric chemistry involves a complex, non-linear set of chemical reactions between atmospheric species that vary substantially in time and space. To model these and other species on a global scale requires the use of a global, three-dimensional chemistry, transport, and deposition (CTD) model. In this work, I developed two such three dimensional CTD models. The first model incorporated the chemistry necessary to model tropospheric ozone production from the reactions of nitrogen oxides with carbon monoxide (CO) and methane $\left(\mathrm{CH}_{4}\right)$. The second aiso included longer-lived alkane species and the biogenic hydrocarbon isoprene, which is emitted by growing plants and trees. The models' ability to predict a number of key variables (including the concentration of $\mathrm{O}_{3}, \mathrm{OH}$, and other species) were evaluated. Then, several scenarios were simulated to understand the change in the chemistry of the troposphere since preindustrial times and the role of anthropogenic $\mathrm{NO}_{x}$ on present day conditions.

Major Professor(s): Soong, Su-Tsai Department: Land, Air \& Water Resources Principal Investigator(s): Penner, Joyce E. 
Program Area: Atmospheric Sciences

KEYWORDS: ATMOSPHERE, CARBON MONOXIDE, CHEMISTRY, DEPOSITION, HYDROCARBONS, HYDROXYL RADICAL, METHANE, MODELS, NITROGEN SPECIES, OZONE, TRANSPORT

\section{0}

Baik, Jong-Jin. 1989. Tropical Cyclone Simulations with the Betts Convective Adjustment Scheme. Ph.D. Dissertation, North Carolina State University, 159 pages.

A new convective adjustment scheme proposed by Betts (1986) is incorporated into a tropical cyclone model. The convective parameterization scheme adjusts the local temperature and moisture structures towards the observed quasi-equilibrium thermodynamic state and includes non-precipitating shallow convection as well as deep convection. The numerical model used for this study is an axisymmetric, primitive equation, hydrostatic, finite difference model with 15 vertical layers and a horizontal resolution of $20 \mathrm{~km}$. The model domain covers $1000 \mathrm{~km}$ and the spectral radiation boundary condition, which uses a different gravity wave speed for each vertical mode, is implemented in the model. It is shown that the convective scheme is capable of simulating the developing, rapidly intensifying and mature stages of a tropical cyclone from a weak vortex. During the early developing stage, the latent heat release is from the convective parameterization, but at the mature stage the latent heat release is mainly due to the grid-scale phase change. It is demonstrated that the increasing inertial stability and symmetric instability near the radius of the maximum wind in the lower troposphere can play important roles in the rapid intensification of the storm. For comparison, an experiment is conducted with the parameterized convection excluded, leaving only the grid-scale condensation and evaporation. The results show that the development of a tropical cyclone can be modeled with crude grid-scale condensation and evaporation processes for the $20 \mathrm{~km}$ horizontal resolution similar to other studies. However, the storm with the explicit convective latent heat release is considerably less intense than that with the parameterized convective latent heat release. The sensitivity of the model storm evolution to the convective adjustment parameters is investigated. These results show that the model storm develops earlier as the adjustment time scale becomes small and as the stability weight on the moist adiabat in the lower atmosphere is increased. The model storm evolution is very sensitive to variations in the saturation pressure departure at the lowest model integer level and the storm at the mature stage has a lower central pressure as the magnitude of the saturation pressure departure is increased. The adjustment parameters affect the gridscale precipitation as well as the convective precipitation and the precipitation is especially sensitive to changes in the saturation pressure departure. Sensitivity of the model to variations in the sea surface temperature, latitude, initial vortex amplitude, initial moisture distribution and radiation is studied. The results of the numerical simulations are similar to previous studied. Sensitivity studies with various horizontal resolutions show that the subgrid-scale heating becomes a larger fraction of the total heating as the horizontal grid size is increased. The role of shallow convection in the tropical cyclone development is investigated. The simulation with both deep and shallow convection results in earlier development of the storm than that without shallow convection, but the intensity at the mature stage is similar in both cases. Finally, comparison of the Betts deep convective adjustment scheme with the Kuo convective parameterization is made. The result shows that the storm with the Kuo scheme intensifies earlier than the storm with the Betts scheme.

Major Professor(s): Raman, Sethu Department: Marine, Earth and Atmospheric Sciences Principal Investigator(s): Pietrafesa, Leonard J. Program Area: Marine Transport

\section{KEYWORDS: CLIMATE, CONDENSATION, CONVECTION, EVAPORATION, MODELS, STORMS, TROPICS}

11

Benkovity, Carmen M. 1994. Development and Testing of a High-Resolution Model for Tropospheric Sulfate Driven by Observation-Derived Meteorology. Ph.D. Dissertation, New York University, 265 pages.

A high-resolution three-dimensional Eulerian transport and transformation model has been developed to simulate concentrations of tropospheric sulfate for specific times and locations; it was applied over the North Atlantic and adjacent continental regions during October and November, 1986. The model represents emissions of anthropogenic $\mathrm{SO}_{2}$ and sulfate and of biogenic sulfur species, horizontal and vertical transport, gas-phase oxidation of $\mathrm{SO}_{2}$ and dimethyisulfide, aqueous-phase oxidation of $\mathrm{SO}_{2}$, and wet and dry deposition of $\mathrm{SO}_{2}$, sulfate, and methanesulfonic acid (MSA). The meteorological driver is the 6-hour output from the forecast model of the European Centre for Medium-Range Weather Forecasts. Calculated sulfate concentrations and column burdens, examined in detail for October 15 and October 22 at $6 \mathrm{Z}$, are related to existing weather patterns. These results exhibit rich temporal and spatial structure; the characteristic (1/e) 
temporal autocorrelation time for the sulfate column burdens over the central North Atlantic averages 10 hours; $95 \%$ of the values were 25 hours or less. The characteristic distance of spatial autocorrelation over this region depends on direction and averages $1600 \mathrm{~km}$; with $10 \mathrm{th}$ percentile value of $400 \mathrm{~km}$ and $90 \mathrm{th}$ percentile value of $1700 \mathrm{~km}$. Daily average model sulfate concentrations at the lowest vertical level accurately represent the spatial variability, temporal episodicity, and absolute magnitudes of surface concentrations measured by monitoring stations in Europe, Canada and Barbados; over $50 \%$ of model concentrations are within a factor of 3 of the observations. Over $50 \%$ of weekly model sulfate wet deposition amounts are within a factor of 3 of observations from US monitoring stations. Over the 34day period modeled, contributions from anthropogenic emissions to the sulfate over the mid North Atlantic Ocean ranged from 44 to $66 \%$, contributions from biogenic emissions were between 6 and $12 \%$. Calculated average yields for sulfate (47 to $72 \%$ ) and MSA (13\%), and turnover times for $\mathrm{SO}_{2}$ ( 2 to 3 days) and sulfate and MSA ( 4 to 8 days) are comparable to previous estimates; however, these quantities depend on meteorological conditions and on the geographic and vertical distributions.

Major Professor(s): Hoffert, Martin I.

Department: Earth System Science

Principal Investigator(s): Schwartz, Stephen E.

Program Area: Atmospheric Sciences

\section{KEYWORDS: EMISSIONS, MODELS, SPATLAL DISTRIBUTION, SULFUR SPECIES, TEMPORAL DISTRIBUTION, TRANSFORMATION, TRANSPORT}

\section{2}

Bermudez, Alejandra Paez 1982. Carbon Dioxide Enrichment: Its Direct Effects and Its Interaction with Water Stress Relative to Apical Dominance and Growth of Pea and Tomato Plants. Ph.D. Dissertation, Duke University, 171 pages.

A continued increase in atmospheric carbon dioxide could have a profound effect upon plant growth, resulting in a change in composition and structure of agricultural and native ecosystems. The objectives of this study using increased atmospheric $\mathrm{CO}_{2}$ were: 1) to determine its effects on apical dominance; 2) to obtain information on changes in growth response for species and cultivars; 3) to investigate the interacting effect with water stress on plant growth and development. Alaska and Snow pea (Pisum sativum) and New Yorker and Better Boy tomato (Lycopersicum esculentum) plants, were grown from seeds under controlled environments in the Duke University Phytotron. The results produced by $\mathrm{CO}_{2}$ enrichment were: 1) Apical dominance was not altered, 2) Seedling emergence was unaffected.

However, the growth response in terms of plant height, leaf thickness, dry matter production and flowering varied with the species and the cultivars within species and was inconsistent for determinate and indeterminate cultivars. While even determinate and indeterminate plants were not consistent in their response, growth form of indeterminate plants was more affected. 3) The water status was usually not affecter by the $\mathrm{CO}_{2}$ level when the plants were well-watered. When water was withheld both total leaf water and osmotic potential decreased, with a slower decrease under high $\mathrm{CO}_{2}$. Plants maintained a positive turgor potential under high $\mathrm{CO}_{2}$ and did not wilt when water-stressed. The differences in water potentials apparently were due to reduced stomatal conductance and transpiration rate. Additional $\mathrm{CO}_{2}$ caused no effect on branch number in stressed or non-stressed plants. Water stress completely inhibited branch development in pea and significantly reduced it in tomato. Elevated $\mathrm{CO}_{2}$ partially compensated for this inhibiting effect and resulted in more rapid recovery of water-stressed plants. These results are of ecological significance. They indicated that as atmospheric $\mathrm{CO}_{2}$ increases, there will be improved water use efficiency, and also, changes in canopy shape may occur in crop stands and native ecosystems. This would be due to response differences of species, varieties and cultivars.

Major Professor(s): Hellmers, Henry

Department: Botany

Principal Investigator(s): Strain, Boyd R.

Program Area: Carbon, Climate, and Vegetation

KEYWORDS: ATMOSPHERE, CARBON DIOXIDE, FERTILIZATION, GROWTH AND DEVELOPMENT, VEGETATION, WATER STRESS

13

Bisbal, Evelin Cabrera. 1987. Effects of Subambient and Superambient $\mathrm{CO}_{2}$ Levels on Growth, Development and Total Nonstructural Carbohydrate of Soybean. M.S. Thesis, University of Florida, 144 pages.

Atmospheric carbon dioxide $\left(\mathrm{CO}_{2}\right)$ concentration has been increasing for the past 100 years and may double by the year 2030 according to some scenarios. Carbon dioxide enrichment studies can provide information on future crop yield responses as well as quantify the limitation of low concentration of atmospheric $\mathrm{CO}_{2}$ on crop photosynthetic capacity. Soybeans [Glycine max (L.) Merr. 'Bragg'] were grown from seedling to 
maturity in sunlit environmentally controlled growth chambers under subambient $(160,220,280 \mu \mathrm{mol}$ $\mathrm{mol}^{-1}$ ), ambient ( $330 \mu \mathrm{mol} \mathrm{mol}^{-1}$ ) and superambient $\left(660,990 \mu \mathrm{mol} \mathrm{mol}^{-1}\right) \mathrm{CO}_{2}$ concentrations. The objectives were to determine the effects of subambient and superambient $\mathrm{CO}_{2}$ concentration on (1) seasonal pattern of dry matter distribution, leaf growth, and development stages, and (2) seasonal and diurnal patterns of total nonstructural carbohydrate (TNC) concentration. Morning and evening plant samples were taken at eight dates. The plants were separated into components to determine dry matter accumulation and leaf area extension, and then analyzed for TNC concentration in each plant component. Carbon dioxide enrichment increased dry matter accumulation in all the vegetative plant parts as well as seed yield. Total plant dry weight increased more rapidly and to a greater final biomass in plants that were exposed to superambient $\mathrm{CO}_{2}$ treatment. Plant height and leaf area were also increased by elevated $\mathrm{CO}_{2}$ concentrations. Mainstem height increase in superambient $\mathrm{CO}_{2}$ concentration resulted from greater node number and internode elongation. The increased sizes of plants in superambient $\mathrm{CO}_{2}$ concentrations were due to higher absolute growth rates, which were associated with higher rates of leaf area development. Superambient $\mathrm{CO}_{2}$ caused a significant increase in the number of nodes and branches, which represented additional sites for pod initiation and leaf area to support pod development. The yield increase arose primarily because of increased seed number rather than seed size. However, harvest index was not altered by increase of $\mathrm{CO}_{2}$ and apparently dry matter partitioning between the seeds and other plant parts was not responsive to $\mathrm{CO}_{2}$ increase. Plants in superambient $\mathrm{CO}_{2}$ accumulated more TNC than ambient and subambient throughout their development. These carbohydrates were presumably utilized to support the growth of greater number of seeds. However, leaves of plants in superambient $\mathrm{CO}_{2}$ contained large pools of TNC at plant maturity, indicating that not all of the photosynthetically derived carbohydrate reserves were utilized for seed yield.

Major Professor(s): Allen, Leon H., Jr.

Department: Agronomy

Principal Investigator(s): Allen, Leon H., Jr.

Program Area: Carbon, Climate, and Vegetation

KEYWORDS: ATMOSPHERE, BIOMASS, CARBOHYDRATES, CARBON DIOXIDE, FERTILIZATION, GROWTH AND DEVELOPMENT, LEAVES, SEEDS, VEGETATION, YIELD
14

Blasch, Kyle W. 1994. Analysis of the Earth's Schumann resonance. M.S. Thesis, Massachusetts Institute of Technology, 192 pages.

Descriptions of two formulations describing the Earth's Schumann resonance were investigated to provide a quantitative analysis of the resonance. The convective instability approach predicted higher values for the resonance than the absolute instability approaches. Ratios methods for determining the frequency dependent source term, $M(w)$, and attenuation were developed for the single source case. The geometric structure of the resonance was used to isolate time periods and locations when the ratios closely approximated the single source case. Quantitative comparisons were made with observed Schumann Resonance data from Table Mountain, California and N.W. Cape, Australia. Agreement was within an order of magnitude for features in the first three modes, although ratios near the singularities tended to overestimate the observed values.

Major Professor(s): Williams, Earle

Department: Earth, Atmospheric, and Planetary

Sciences

Principal Investigator(s): Williams, Earle

Program Area: National Institute for Global

Environmental Change (NIGEC)

KEYWORDS: SCHUMANN RESONANCE

15

Boden, Thomas A 1985. An Internship with the Carbon Dioxide Information Center at Oak Ridge National Laboratory. M.En Report, Miami University, 115 pages.

The objective of the Carbon Dioxide Information Center (CDIC) at Oak Ridge Naticnal Laboratory is to compile and distribute $\mathrm{CO}_{2}$-related information under systematic quality control to international researchers and policy makers evaluating direct and indirect effects of increased $\mathrm{CO}_{2}$ levels. During a one-year internship beginning July 31, 1984, I helped compile, evaluate, and distribute numeric data and computer model packages. These packages provide well-documented, retrievable $\mathrm{CO}_{2}$ databases and computer models to researchers and help assure the long-term availability of documented $\mathrm{CO}_{2}$ data. In compiling six packages, I read $\mathrm{CO}_{2}$ research papers, wrote abstracts to document $\mathrm{CO}_{2}$ databases, wrote FORTRAN retrieval programs, developed graphics, and synthesized materials into a document format. This experience helped me to develop programming and technical writing skills and to 
expand my scientific knowledge. One package is included in this report as an example

Major Professor(s): Vankat, John L. Department: Institute of Environmental Sciences Principal Investigator(s): Farrell, Michael P. Program Area: Information

\section{KEYWORDS: CARBON DIOXIDE, DATABASES, MODELS}

16 Bralte, Mary P. 1989. Gas Exchange and Growth Responses of Citrus Trees to Partial Irrigation, Soil Water, and Atmospheric Conditions. Ph.D. Dissertation, University of Florida, 181 pages.

Growth and yield of citrus trees in Florida have been reported to be closely related to the portion of rooting zone irrigated, contrary to conclusions of many partial irrigation studies conducted elsewhere. This study was conducted to clarify whole plant gas exchange and growth responses of young citrus trees to partial irrigation of the rooting zone and to investigate the influence of soil water and atmospheric factors on gas exchange through experiments in controlledenvironment growth chambers and model simulations of leaf conductance and transpiration. In an initial study with fully irrigated citrus and three dry-bulb temperature/vapor pressure deficit (DBT/NPD) treatment levels, photosynthetic rates and water-use efficiencies were greatest at the low DBTNPD $\left(24{ }^{\circ} \mathrm{C} / 1.7 \mathrm{kPa}\right)$ treatment and remained high when soil water content was low. Increases in DBT and VPD reduced photosynthetic rate and water-use efficiency and resulted in photosynthetic midday depression at the intermediate $\left(29^{\circ} \mathrm{C} / 2.4 \mathrm{kPa}\right)$ and high $\left(37^{\circ} \mathrm{C} / 3.6 \mathrm{kPa}\right)$ DBT/NPD levels when soil water content was low. In a subsequent study, photosynthetic rate and growth of partially irrigated trees on builders' sand declined significantly as the irrigated fraction of rooting volume was reduced 25,50 , and 75 percent. Trees at all levels of irrigation and soil water content experiences severe midday depression of photosynthesis. In both studies, transpiration increased, but not proportionally, as DBT/VPD increased and was attributed to stomatal closure. At elevated atmospheric carbon dioxide concentrations, midday depression of photosynthesis was observed in the second study, but not in the initial study. The combined findings suggest that midday depression of photosynthesis in citrus results in part from stomatal closure at elevated leaf-to-air humidity deficits, but perhaps more significantly, from increased mesophyll resistance induced by low soil water availability at DBT/VPD levels about $24^{\circ} \mathrm{C} / 1.7 \mathrm{kPa}$.
Simulated diurnal transpiration rates agreed closely with actual rates of trees with all or 3/4 of their rootingvolume irrigated but declined more rapidly than actual rates in 2/4 or 1.4 irrigated trees. Results of simulations suggest that soil type, evaporative demand, and rootlength density are important factors influencing transpiration of fully and partially irrigated citrus trees.

Major Professor(s): Allen, Leon H., Jr. Department: Agronomy

Principal Investigator(s): Allen, Leon H., Jr.

Program Area: Carbon, Climate, and Vegetation

\section{KEYWORDS: GROWTH AND DEVELOPMENT, LEAVES, MODELS, SOILS, TEMPERATURE, TRANSPIRATION, VAPOR PRESSURE, VEGETATION, WATER, WATER STRESS, WATER USE}

\section{7}

Bremer, D. J. 1994. Transpiration from a Tallgrass Prairie Exposed to Elevated and Ambient Atmospheric $\mathrm{CO}_{2}$. M.S. Thesis, Kansas State University, 110 pages.

Increasing concentrations of atmospheric $\mathrm{CO}_{2}$ may influence plant-water relations in natural and agricultural ecosystems. A tallgrass prairie near Manhattan, Kansas was exposed to elevated atmospheric $\mathrm{CO}_{2}$ using open-top chambers (OTC's). Heat balance sap flow gauges were used to measure transpiration in ironweed (Vemonia baldwini var. interior (Small) Schub.), a C3 forb; and on individual culms of big bluestem (Andropogon gerardii Vitman) and indiangrass (Sorghastrum nutans (L.) Nash), both C4 grasses, in each of three treatments: (1) CE (chamber enriched, $2 \mathrm{x}$ ambient $\mathrm{CO}_{2}$ ); (2) $\mathrm{CA}$ (chamber ambient, no $\mathrm{CO}_{2}$ enrichment); and (3) $\mathrm{NC}$ (no chamber, no $\mathrm{CO}_{2}$ enrichment). Sap flow data were combined with measurements of stomatal resistance and whole-chamber evapotranspiration (ET) to determine the effect of $\mathrm{CO}_{2}$ on water use at different scales. Because of frequent rainfall during the study, all data were collected under well-watered conditions. Sap flow was reduced by $33 \%$ in ironweed, $18 \%$ in big bluestem, and $22 \%$ in indiangrass under $\mathrm{CO}_{2}$ enrichment. Elevated $\mathrm{CO}_{2}$ reduced whole chamber ET by $23-27 \%$. The environmental effect of the OTC reduced transpiration by $21-24 \%$. Stomatal conductance declined from $6.6 \mathrm{~mm} \mathrm{~s}^{-1}$ to $3.2 \mathrm{~mm} \mathrm{~s}^{-1}$ in big bluestem, and from $5.0 \mathrm{~mm} \mathrm{~s}^{-1}$ to $3.1 \mathrm{~mm} \mathrm{~s}^{-1}$ in indiangrass, under $\mathrm{CO}_{2}$ enrichment. Whole-plant stomatal resistance to water vapor flux (rp) was calculated from sap flow measurements and environmental data collected in the chambers. Whole-plant stomatal resistance in big bluestem increased from $103 \mathrm{~s} \mathrm{~m}^{-1}$ to $194 \mathrm{~s} \mathrm{~m}^{-1}$ under 
elevated $\mathrm{CO}_{2}$ during sap flow measurements. Wholeplant stomatal resistance was scaled to the canopy level, but consistently underestimated the canopy resistance calculated from whole-chamber ET data, indicating that rp in big bluestem may not be representative of $\mathrm{rp}$ in other plants or species in the chamber. Elevated $\mathrm{CO}_{2}$ increased whole-chamber canopy resistance more than scaled-up canopy resistance. Thus, elevated $\mathrm{CO}_{2}$ probably increases stomatal resistance in other species in the OTC more than that of big bluestem. As atmospheric $\mathrm{CO}_{2}$ increases, $\mathrm{CO}_{2}$-induced stomatal closure may alter plant-water relations and the water balance of an ecosystem.

Major Professor(s): Ham, J.M.

Department: Agronomy

Principal Investigator(s): Owensby, C.E.

Program Area: Carbon, Climate, and Vegetation

\section{KEYWORDS: C3 METABOLISM, C4 METABOLISM, CARBON DIOXIDE, PRAIRIES, SAP, TRANSPIRATION, VEGETATION}

18

Bub, Frank Lee. 1993. The Structure of Water Mass, Salt, and Temperature Transports Within Intermediate Depths of the Western Tropical Atlantic Ocean. Ph.D. Dissertation, University of New Hampshire, 222 pages.

Water mass flow patterns within the $150-1300 \mathrm{~m}$ intermediate layer of the western tropical Atlantic were determined from observations during four 1990-1991 Pegasus velocity and CTD hydrographic surveys. Nondivergent flows were analyzed to determine transports. A survey-average 29 Sverdrups $\left(1 \mathrm{~Sv}=10^{6} \mathrm{~m}^{3} / \mathrm{s}\right)$ of southern hemisphere water masses flowed northwestward across $44^{\circ} \mathrm{W}$ near the equator as part of the subsurface South Equatorial Current (SEC). 21 Sv retroflected anticyclonically around the Amazon Eddy $\left(2^{\circ} \mathrm{N} 45^{\circ} \mathrm{W}\right)$ and flowed eastward toward the North Equatorial Undercurrent (NEUC). The other $8 \mathrm{~Sv}$ moved northwestward within a series of anticyclonic retroflection eddies which periodically separate from the Amazon Eddy. $61 \mathrm{~Sv}$ of a northern/southern water mass mixture flowed southeastward across $9^{\circ} \mathrm{N}$ as part of the North Equatorial Current (NEC) and bifurcated; $32 \mathrm{~Sv}$ turned anticycionically northwestward, and $29 \mathrm{~Sv}$ turned cyclonically around a low $\left(6^{\circ} \mathrm{N} 44^{\circ} \mathrm{W}\right)$, merged with the southern water, and flowed toward the NEUC. The 50 Sv NEUC, a mixture of mostly southern water, flowed eastward into the interior. The remaining NEC and SEC branches blended to form a $40 \mathrm{~Sv}$ northwestward transport across $53^{\circ} \mathrm{W}$. These observed transports were generally about three times larger than the wind-driven equatorial and tropical gyre return transports (Mayer and Weisberg 1993); suggesting the existence of subgyre-scale recirculation eddies in the western tropics. One of the retroflection eddies was measured during September 1990. Its structure was approximated by a $300 \mathrm{~km}$ diameter cylinder which extended vertically through the surface and intermediate layers to $1300 \mathrm{~m}$. During two other surveys, retroflection eddies were identified at the region's northwestern corner.

Instantaneous transport associated with an eddy which translated at $10 \mathrm{~cm} / \mathrm{s}$ was about $30 \mathrm{~Sv}$. Assuming three were generated each year, retroflection eddy translation could account for the $8 \mathrm{~Sv}$ alongshore flow through the region. According to water mass budgets, $21 \mathrm{~Sv}$ of northern water masses were transformed by mixing within the region. Temperature-salinity relationships indicated this mixing effectively transports the cool, low salinity Antarctic Intermediate Water into the North Atlantic by as yet unknown pathways.

Major Professor(s): Brown, Wendell S.

Department: Earth Sciences

Principal Investigator(s): Moore, Berrien

Program Area: Carbon, Climate, and Vegetation

KEYWORDS: CIRCULATION, MASS, OCEANS, SALINITY, TEMPERATURE, TROPICS, WATER

19

Burns, Kerry Lee. 1994. Cloud Microstructure, Acidity and Reflectivity: Case Studies and Implications for Regional Climate Change. M.S. Thesis, North Carolina State University, 36 pages.

A sensitivity analysis was performed to determine the effect of small fluctuations in cloud microphysical parameters on the cloud albedo. It is discovered that unpolluted marine clouds should have a greater radiative response to changes in cloud droplet spectra than more polluted continental clouds. It is further shown that increasing droplet concentration by a few percent can have a greatly increased cloud albedo and produce a cooling effect on regional climate. In situ cloud measurements were taken during 39 individual cloud events between June and October 1993 in Mount Mitchell State Park, North Carolina. Cloud droplet spectra were measured coincidentally with cloud water $\mathrm{pH}$ and chemical composition. A total of $\mathbf{1 1 3}$ hourly cases were recorded. Nine of these cases corresponded with satellite derived direct cloud albedo measurements. Scatter graphs were generated showing how albedo varies with cloud droplet concentration, cloud droplet size, cloud liquid water content, cloud water $\mathrm{pH}$, cloud thickness, and precursor cloud condensation nuclei concentration. 
Major Professor(s): Saxena, Vinod K.

Department: Marine, Earth and Atmospheric Sciences Principal Investigator(s): Saxena, Vinod $\mathbf{K}$

Program Area: National Institute for Global

Environmental Change (NIGEC)

\section{KEYWORDS: AEROSOLS, CHEMISTRY, CLIMATE, CLOUDS, CONDENSATION, MICROPHYSICS, PARTICULATES, REFLECTANCE, WATER}

\section{0}

Byun, Dae-Won. 1983. A Two-Dimensional Mesoscale Numerical Model of St. Louis Urban Mixed Layer. M.S. Thesis, North Carolina State University, 216 pages.

An urban boundary layer (UBL) is characterized by a smaller surface albedo than rural, large sensible heat flux due to the urban surface medium and small moisture availability, inhomogeneity of the surroundings, additional anthropogenic heat and considerably large surface roughness attributed to buildings and man made structures. A horizontal two dimensional numerical UBL model of St. Louis., which takes into account above differences of the urban from the rural, is developed based on the mixed layer assumption. For numerical integration, the time splitting technique is used in which the system is decomposed into an adjustment stage, a flux exchange stage and an advection stage. A cubic spline upstream advection scheme, which allows better choice of smoothing and boundary conditions than Mahrer and Pielke's (1978), is tested and utilized. The land use differences over the metropolitan area are characterized by the different proportions of the concrete and grassy soil surfaces. The thermal parameters of the vegetated soil are parameterized in terms of surface soil moisture content. From the homogeneous case studies. distinct urban and rural patterns of surface energy budget, which are typical of some observational studies, are obtained. It suggests that the simplification is successful in simulating the effects of different land use types on the atmosphere. Dynamics of a dome shaped model urban mixed layer is studied with the stationary balanced wind. It seems that the balanced wind can explain some important flow perturbations due to the urban heat island. Numerical simulation of the daytime boundary layer of St. Louis, Mo. on August 18, 1976, show some favorable results. The simulated wind field shows a heat island-related weak convergent area, complicated with the topographical effects, over the southwest side of the city in the morning. The model predicts surface temperature distributions similar to the observations showing a distinct surface urban heat island, although contour patterns differ from observations in detail. Downwind displacements of the mixed layer dome and urban plume phenomenon are simulated. However, influence of existing topography further complicated the mixed layer thickness patterns, especially in the morning. Further, the effects of only the urban heat island on the mixed layer evolution are studied by removing the topography in one simulation. The results of the run without topography show that the locations of local maxima and minima in mixed layer heights and temperatures coincide one another, suggesting existence of a direct relation between the two fields. In the morning, when the distinct mixed layer dome and high potential temperature region were present at the downwind side of the city, significant convergent flow is seen over that area. In the afternoon, the wind field is characterized by a nearly nondivergent and relatively homogeneous flow. The results here demonstrate the usefulness/potential of the vertically-integrated model for simulation of the clear day mixed layer. For such cases the present model can give increased understanding of the interrelationships between physical parameters determining the urban heat island phenomenon. For nighttime periods or morning and evening transition periods, a three-dimensional large eddy simulation model may be necessary.

Major Professor(s): Arya, S.P.S. Department: Marine, Earth and Atmospheric Sciences Principal Investigator(s): Pietrafesa, Leonard J. Program Area: Marine Transport

KEYWORDS: ATMOSPHERE, BOUNDARY LAYER, CLIMATE, LAND SURFACE, LAND USE, MODELS, SPATLAL DISTRIBUTION, URBAN ENVIRONMENT

21

Campbell, William J., Jr. 1986. Effects of Carbon Dioxide on the Physiology and Biochemistry of Photosynthesis in Soybean. Ph.D. Dissertation, University of Florida, 181 pages.

In three consecutive years $(1983,1984$, and 1985) soybeans (Glycine max L. Merr. cv Bragg) were grown from seed to maturity in six outdoor environmentally controlled plant growth chambers under natural solar irradiance. The $\mathrm{CO}_{2}$ concentrations inside the chambers were controlled to various levels during these studies. Both field and laboratory measurements were made to investigate the effects of $\mathrm{CO}_{2}$ concentration on photosynthesis. Emphasis was placed on the response to $\mathrm{CO}_{2}$ of ribulose 1,5-bisphosphate (RuBP) and RuBP carboxylase (RuBPCase), the substrate and enzyme of the carbon fixation reaction in soybean. Following growth at 330 (atmospheric concentration) or $660 \mu$ ] $\mathrm{CO}_{2} \mathbf{l}^{-1}$, leaflet photosynthetic rates were always greater for the elevated $\mathrm{CO}_{2}$ grown plants when measured over 
a wide range of $\mathrm{CO}_{2}$ concentrations. This enhanced capacity for photosynthesis was possibly a result of changes in internal leaf anatomy, or to greater assimilate demand, or both, in the high $\mathrm{CO}_{2}$ grown plants. The RuBP concentration decreased with increasing $\mathrm{CO}_{2}$, but still appeared to be greater than the active site concentration of RuBPCase. The RuBPCase activity, expressed on an area basis, was not affected by growth $\mathrm{CO}_{2}$ concentration. It appears that RuBPCase and RuBP are thus not involved significantly in the enhanced photosynthetic capacity. Evaporative cooling kept leaf temperatures from reaching the higher air temperatures during studies on temperature effects on soybean growth at atmospheric and twice atmospheric concentrations of $\mathrm{CO}_{2}$. Although air temperatures were increased by approximately 5 and $10^{\circ} \mathrm{C}$, leaf temperatures were usually not increased more than approximately 2.5 and $4.5^{\circ} \mathrm{C}$, respectively. These leaf temperature increases were not great enough to affect canopy photosynthesis or RuBPCase activity (on a chlorophyll basis) in either $\mathrm{CO}_{2}$ treatment. Canopy photosynthesis was, however, greater at the higher $\mathrm{CO}_{2}$ concentration. The concentration of RuBP was reduced at higher temperatures. Increasing growth $\mathrm{CO}_{2}$ concentrations (from 160 to $990 \mu \mathrm{CO}_{2} \mathrm{r}^{-1}$ ) resulted in decreasing RuBPCase activities and RuBP levels, when both were expressed on a chiorophyll basis. At the higher $\mathrm{CO}_{2}$ concentrations, the concentration of RuBP appeared to approach the concentration of RuBPCase active sites. Both the apparent $\mathrm{K}_{\mathrm{m}}\left(\mathrm{CO}_{2}\right)$ and $\mathrm{V}_{\max }$ of RuBPCase showed small, but statistically significant, decreases with increasing $\mathrm{CO}_{2}$.

Major Professor(s): Allen, Leon H., Jr. Department: Agronomy

Principal Investigator(s): Allen, Leon H., Jr. Program Area: Carbon, Climate, and Vegetation

KEYWORDS: ATMOSPHERE, CARBON DIOXIDE, ENZYMES, GROWTH AND DEVELOPMENT, LEAVES, PHOTOSYNTHESIS, RIBULOSE BISPHOSPHATE, TEMPERATURE, VEGETATION

22

Chaloupta, Kristin A 1994. Diagenetic Behavior of Arsenic in Amazon Shelf and Long Island Sound Sediments. M.S. Thesis, State University of New York at Stony Brook, 90 pages.

Arsenic cycling in sediments is influenced by a variety of physical and chemical processes. Anthropogenic activities are also potentially important. In order to help elucidate major controls on diagenetic behavior of arsenic, vertical profiles of total dissolved and solid phase arsenic were measured in two physically distinct environments; the Amazon shelf and Long Island Sound. The relative trends of arsenic distributions were similar in both study sites, with subsurface pore water maxima and surficial solid phase enrichment. In Amazon shelf sediments, these patterns reflect a strong redox association with iron whereby oxidized arsenic is adsorbed onto iron oxyhydroxides in surface sediments, which is then subsequently reduced and dissolved upon burial in the sub-oxic zone. Upward diffusion within the sediment is followed by readsorption or release to the water column. On the Amazon shelf, intense physical reworking of sediments often releases the dissolved arsenic fraction to the water column. In contrast, loss of arsenic from sediments in Long Island Sound does not reflect an energetic environment. Instead, it is linked to annual fluctuations in temperature and organic carbon inputs which, when high, deplete the axygenated zone within the sediment, and result in an upward shift in redox processes. In addition to iron, arsenic is also closely coupled to the manganese and phosphate cycles in Long Island Sound; relationships which deteriorate following a bloom event. Fluxes of dissolved arsenic from Long Island Sound sediment, calculated from pore water profiles during periods of elevated organic carbon deposition, are on the order of $0.025-0.634 \mu \mathrm{mol} / \mathrm{m}^{2} / \mathrm{d}$, while the flux from the solid phase into pore water is $1.42-11.5 \mu \mathrm{mol} / \mathrm{m}^{2} / \mathrm{d}$. Disparity between these rates may reflect the fact that the flux calculations exclude irrigation rates, adsorption onto adcitional mineral phases, physical reworking of sediments, among other model assumptions. Pore water As concentrations in Amazon shelf sediments are an order of magnitude greater than for sediments in Long Island Sound, and elevated concentrations extend several meters below the sediment surface. These expanded features are probably due to the combined effects of intense chemical weathering of riverine sediments and a turbulent physical regime present on the shelf, both of which promote Fe cycling. Annual fluctuations in river flow result in increased physical mixing of the sediments during higher flow, and a greater abundance of benthic biota during lower river flow, particularly away from the river mouth. This results in generally increasing arsenic pore water concentrations away from the river. Patterns of temporal variability are more difficult to discern, possibly due to differences in physical environments on the shelf. While some areas of the shelf are generally controlled by sediment transport processes, other areas are influenced more by benthic activity.

Major Professor(s): Aller, Robert C.

Department: Marine Sciences

Principal Investigator(s): Aller, R.C., J.K. Cochran, J.Y. Aller, and C. Lee

Program Area: Marine Transport 
KEYWORDS: DLAGENESIS, METALS, NORTH AMERICA, OCEANS, ORGANICS, PHOSPHATE, REMOBILIZATION, RIVERS, SEDIMENTS, SOUTH AMERICA, TEMPORAL DISTRIBUTION

\section{3}

Chanumalla, Neeraja Reddy. 1992. A Study of Mesoscale Circulation and the Structure of the Baroclinic Boundary Layer over a Gulf Stream Filament. M.S. Thesis, North Carolina State University, 148 pages.

Observations obtained from aircraft, buoys, ships and vertical soundings made from 9-11 February, 1986 during the Genesis of Allantic Lows Experiment (GALE) were used to study the mesoscale circulations and the mean and turbulent marine boundary layer structure over the cold coastal waters and the warm Gulf Stream. Different synoptic conditions prevailed on each day. The synoptic setting was characterized by prestorm conditions on 9 February, meso low development on 10 February and offshore cyclogenesis on 11 February. A Gulf Stream filament about $150 \mathrm{~km}$ long and $50 \mathrm{~km}$ wide was also formed during this period. Analysis of the data on 10 February indicates substantial increase in wind speed and change in direction across the filament up to a height of about $300 \mathrm{~m}$. Northeasterly synoptic winds changed to a northwesterly direction, with winds almost at right angles to the filament. This in combination with the effects of the horizontal temperature gradients between the coastal waters, the cold core of the filament and the Gulf Stream appears to have induced a mesoscale cyclonic circulation. Wind speeds indicated a low level convergence over the filament. This mesoscale circulation and the convergence appears to have caused a meso-low over the filament which later developed into a mid-latitude cyclone when a mid-tropospheric trough advected into the region on 11 February. Turbulence profiles indicated that the similarity relations are valid during undisturbed weather. During disturbed conditions on 10 February and 11 February variances do not seem to follow the free convection relations. Conventional similarity relations with the height normalized by the boundary layer height did not exist during meso-low development and offshore cyclogenesis.

Major Professor(s): Raman, Sethu Department: Marine, Earth and Atmospheric Sciences Principal Investigator(s): Raman, Sethu Program Area: Atmospheric Radiation Measurement (ARM)
KEYWORDS: ATMOSPHERE, BOUNDARY LAYER, CIRCULATION, CLIMATE, MARINE ENVRONMENT, OCEANS, PRESSURE, STORMS

\section{4}

Charney, Joseph J. 1992. Heating Rate Variability in Radiation Codes When Subjected to Different Vertical Discretizations. M.S. Thesis, University of Maryland at College Park, 43 pages.

A collection of seven radiation codes was acquired from various organizations and intercompared. Their variability with respect to each other was determined when performing heating rate calculations on different distributions of vertical levels. Specifically, two vertical discretizations with 30 and 18 levels were intercompared. Some significant differences were found to exist by performing simple statistical tests on the models. The statistical tests were based on sets of 100 heating rate calculations. Independent determinations were made at each model level. The parameterizations of water vapor absorptivities were found to cause the largest variability between the models. Other mechanical problems were highlighted and recommendations for future steps in the ongoing study were proposed.

Major Professor(s): Baer, Ferdinand

Department: Meteorology

Principal Investigator(s): Baer, Ferdinand

Program Area: Atmospheric Radiation Measurement (ARM)

KEYWORDS: CLIMATE, HEAT FLUX, MODELS, RADLATIVE PROCESSES

\section{5}

Chen, Liqiang 1994. The Simulation of Reflection Function of Clouds Using the Adding-Doubling Method. M.S. Thesis, South Dakota School of Mines and Technology, 57 pages.

Clouds reflect about $50 \%$ of the incident solar radiation and thus account for most of the planetary albedo. The investigation of energy reflected by clouds is very important to estimate the global climate change. The plane parallel assumption is widely used in both model and remote sensing studies for calculating cloud reflections. The objective of this study is to use AVHRR data to test the plane parallel assumption. The AVHRR Channel 1 data is used, which has the wavelength of $0.58 \mu \mathrm{m}-0.68 \mu \mathrm{m}$. In order to test the plane parallel assumption, a radiative transfer model is used. The model considers ozone absorption and the atmospheric molecular scattering. There are three layers 
in the model, in which layer ozone absorption, the molecular scattering and Mie scattering are independently processed. The reflection function, defined as the ratio of the reflected radiance to the incident solar radiance, is used to describe the angular dependence of the reflected radiation. The addingdoubling method is used to deal with multiple scattering. One month of the AVHRR data is averaged for different solar and satellite viewing zenith angles as well as relative azimuth angles in order to obtain an averaged reflection function. The model results show that the reflection function depends on the cloud optical thickness. The comparison between the model results and the AVHRR data shows that at larger solar zenith angle the plane parallel assumption causes larger error. However, on average, cloud optical thickness derived from plane parallel assumption does not show significant bias.

Major Professor(s): Han, Qingyuan

Department: Meteorology

Principal Investigator(s): Han, Qingyuan

Program Area: National Institute for Global

Environmental Change (NIGEC)

KEYWORDS: CLOUDS, MODELS, OZONE, RADLATIVE PROCESSES, REFLECTANCE, SCATTERING

26 Chen, Minghang 1993. Cloud Radiative Forcing Anomalies Associated with and Their Effects on the Atmospheric Response to Equatorial Pacific SST Anomalies. Ph.D. Dissertation, State University of New York at Stony Brook, 142 pages.

The NCAR CCM2 has been used in this study to investigate cloud radiative forcing (CRF) anomalies associated with equatorial Pacific SST anomalies, and the effects of the longwave CRF (LWCRF) anomalies on the atmospheric response to the SST anomalies. The SST anomalies cause large CRF anomalies, both longwave and shortwave, as well as latent heat anomalies at low latitudes on a global scale. The relative magnitude of the simulated longwave and shortwave CRF anomalies is consistent with the result of the Earth Radiation Budget Experiment (ERBE), which means cloud height and cloud radiative properties, such as emissivity and reflectivity, are well simulated by the model. The CRF anomalies, however, are underestimated in the CCM2. This underestimate of the CRF anomalies is due to the insufficient high cloud amount anomaly in the model. The LWCRF anomaly strongly enhances the precipitation anomaly in the whole tropical belt. The positive (negative) LWCRF anomaly warms (cools) the troposphere and destabilizes (stabilizes) the upper troposphere. The LWCRF anomaly enhances the Southern Oscillation, both the positive sea level pressure (SLP) anomaly in the Indonesia-Australia region and the negative SLP anomaly in the central and eastern Pacific, and the related Walker circulation anomaly. The effects of the LWCRF anomaly are essential to the NH extratropical circulation anomaly, the PNA pattern. The LWCRF anomaly has a large contribution to the three action centers of the PNA pattern, especially the positive anomaly center, at all levels. This large contribution results from the direct thermal effect of the tropical LWCRF anomaly and its strong positive interaction with tropical deep convection. As a consequence of the complex interaction between the forced wave train, orographic forcing and other factors, the contribution rates of the LWCRF anomaly to the three PNA action centers are different.

Major Professor(s): Cess, Robert D.

Department: Coastal Oceanography (Atmospheric

Sciences)

Principal Investigator(s): Cess, Robert $\mathbf{D}$.

Program Area: Carbon, Climate, and Vegetation

KEYWORDS: CLOUDS, RADIATIVE PROCESSES

27

Chen, M. 1994. Validation and Adjustment of Precipitation Simulated by CCM2/BATS over the Continental United States. M.S. Thesis, University of Arizona, 86 pages.

This study compares frequency, intensity and amount of precipitation simulated by NCAR CCM2/BATS with those observed over the continental United States. The emphasis is placed on both spatial and temporal variations. The analysis indicates that: a) The model simulates the seasonal variation of daily intensity reasonably well, while the seasonal variation of frequency is poorly produced. b) The model underestimates the amplitude of intensity, overestimates the amplitude of frequency, and distorts the distribution of phase in diurnal variations. c) The simulated maximum hourly precipitation has almost the same range as is observed. However, the model fails to simulate the overall pattern of maximum hourly precipitation, maximum wet and dry periods from observations. d) The model overestimates the frequency of hourly precipitation by a factor of 13-48 and underestimates intensity by about $90 \%$.These results demonstrate a necessity to adjust simulated precipitation for realistic surface simulation. After 
adjustment, the simulated intensity is in much closer agreement to the observed value.

Major Professor(s): Dickinson, Robert E. Department: Atmaspheric Sciences Principal Investigator(s): Dickinson, Robert E. Program Area: Computer Hardware, Advanced Mathematics, and Model Physics (CHAMMP)

KEYWORDS: CLIMATE, MODELS, PRECIPITATION, SPATLAL DISTRIBUTION, TEMPORAL DISTRIBUTION

\section{8}

Cione, Joseph Jerome. 1992. The Effects of Surface Forcing on Mid-Atlantic Winter Cyclones. M.S. Thesis, North Carolina State University, 120 pages.

Mid-latitude cyclones develop off the Carolinas during winters and move north producing gale force winds, ice and heavy snow. It is believed that boundary layer and air-sea interaction processes are very important during the pre-cyclonic and development stages of these east coast storms. Due to the presence of the Gulf Stream, the marine boundary layer just offshore is highly baroclinic caused by warmer sea surface temperatures relative to the coastal waters. The offshore flow during cold air outbreak (CAO) periods initiates a strong heat flux distribution in the Western Atlantic Ocean that, over time, acts to vertically warm and moisten the atmosphere from below (Whittmann, 1982; Vukovich et al., 1991; Wayland and Raman, 1989; Holt and Raman, 1990). This airmass modification has been observed to substantially reduce regional stabilities over a time scale of $\mathbf{3 6}$ to 48 hours. This thesis looks into the effects the presence of the Gulf Stream off the Virginia and Carolina coastlines during the pre-storm environment potentially has on the intensification of coastal cyclones. The examination of nine years of data on the Gulf Stream position and east coast winter storms seems to indicate that the degree of low level baroclinicity and modification existing prior to a cyclonic event significantly affects the rate of cyclonic deepening off the mid-Atlantic coastline.

Major Professor(s): Raman, Sethu

Department: Marine, Earth and Atmospheric Sciences Principal Investigator(s): Pietrafesa, Leonard J.

Program Area: Marine Transport

KEYWORDS: ATMOSPHERE, BOUNDARY LAYER, CIRCULATION, CLIMATE, COASTAL ENVIRONMENT, MARINE ENVIRONMENT, OCEANS, PRESSURE, STORMS
29

Collins, Dan C. 1992. An Evaluation with the Fourier Amplitude Sensitivity Test (FAST) of Which LandSurface Parameters Are of Greatest Importance for Atmospheric Models. M.S. Thesis, Rutgers University, 78 pages.

Land-surface parameterizations based on a statisticaldynamical approach have been suggested recently to improve the representation of the surface forcing from heterogeneous land in atmospheric models. With this approach, land-surface characteristics are prescribed by probability density functions (pdf's) rather than single "representative" values as in "big-leaf"

parameterizations. Yet the use of many pdfs results in an increased computational burden and requires the complex problem of representing covariances between pdf's to be addressed. In this study, a sensitivity analysis of a land-surface parameterization for atmospheric modeling was performed to evaluate the surface parameters most important to the variability of surface heat fluxes. The Fourier Amplitude Sensitivity Test (FAST) used for this analysis determines the relative contribution of individual input parameters to the variance of energy fluxes resulting from a heterogeneous surface. By simultaneously varying all parameters according to their individual probability density functions, the number of computations needed is very much reduced by this technique. This analysis demonstrates that most of the variability of surface heat fluxes may be described by the distributions of relative stomatal conductance and surface roughness. Thus, the statistical-dynamical approach may be simplified by the use of only these two probability density functions.

Major Professor(s): Avissar, Roni Department: Meteorology and Physical Oceanography Principal Investigator(s): Avissar, Roni Program Area: Computer Hardware, Advanced Mathematics, and Model Physics (CHAMMP)

KEYWORDS: ATMOSPHERE, FOURIER AMPLITUDE, HEAT FLUX, LAND SURFACE, MODELS, SOILS, TURBULENCE, VEGETATION

30

Comstock, Jonathan Paul 1985. Photosynthetic and Whole-Canopy Responses to Changing Plant Water status in Desert Shrub. M.S. Thesis, University of Utah, 80 pages.

The effects of changing plant water relations on plant carbon gain were studied in Encelia frutescens (Gray) with respect to both physiological performance during periods of slowly declining plant water potential, and the 
phenology of leaf production and death associated with natural rainfall in a warm desert. Physiological studies of the photosynthetic responses of individual leaves to increasing water stress were carried out on potted plants at the University of Utah. Light-saturated $\mathbf{C O}_{2}$ assimilation rates decreased from $42.6 \pm 1.6 \mu \mathrm{mol} \mathrm{CO}$ $\mathrm{m}^{-2} \mathrm{~s}^{-1}(\mathrm{x} \pm$ s.e. $)$ to $1.7 \pm 1.7 \mu \mathrm{mol} \mathrm{CO} \mathrm{m}^{-2} \mathrm{~s}^{-1}$ as leaf water potentials decreased from $-1.5 \mathrm{MPa}$ to $-4.0 \mathrm{MPa}$. This decline in net photosynthesis was shown to arise from both stomatal and nonstomatal effects, but not to equal degrees. The relative stomatal limitation, defined as the percent limitation in photosynthetic rate due to the presence of gas-phase diffusional barriers, increased from $11 \pm 2$ ( $x \pm$ s.e.) to $41 \pm 3 \%$ as water potentials became more negative. The importance of declining physiological capacity for photosynthesis in limiting whole-plant carbon gain was further studied in an experimental garden plot located in the Sonoran Desert at the Phoenix Desert Botanic Garden. The production and longevity of leaves of $E$. frutescens were followed under the natural rainfall regime during the summer and fall of 1984. The relationships between seasonally changing plant water status, extent of canopy development, and photosynthetic capacity per unit leaf area were determined. Maximum leaf life spans during a summer activity period were between 3 and 4 months, with the great majority living between 1 and 3 months. Leaf production occurred synchronously in well-defined cohorts triggered by precipitation events. Extensive leaf turnover occurred during the summer period even though the plants remained in continuous leaf. Turnover was most pronounced when precipitation triggered the production of new leaf cohorts. Five weeks were required for plants to reach maximum canopy development when renewed soil-water availability followed a prolonged drought.

Photosynthetic capacity per unit leaf area recovered much sooner than total leaf area, and submaximal leaf area development was the major factor limiting wholeplant carbon gain during a leaf-flushing period lasting several weeks. As the soil began to dry out, physiological capacity declined more rapidly than leaf area, and became the primary limiting factor to whole plant carbon gain.

Major Professor(s): Ehleringer, James R.

Department: Biology

Principal Investigator(s): Ehleringer, James R.

Program Area: Ecosystems Function and Response

KEYWORDS: CARBON CYCLE, DESERTS, GROWTH AND DEVELOPMENT, LEAVES, PHOTOSYNTHESIS, PRECIPITATION, SOILS, VEGETATION, WATER STRESS
31

Comstoct, Jonathan Paul 1989. Photosynthesis in Twigs. Ph.D. Dissertation, University of Utah, 132 pages.

Forty species from desert and adjacent riparian habitats were surveyed for twig photosynthetic activity. Photosynthetic capacity, as indicated by an increase in the net $\mathrm{CO}_{2}$ assimilation rate (A) in the light, was found in the twigs of all species. In most nondesert species, however, A was always negative. A was positive in the twigs of many desert species, which also exhibited specialized anatomies. The phenology and assimilation rates of leaves and twigs capable of positive net uptake were followed for one year. Both leaf and twig cohorts reached maximum values of surface area development and $A$ in spring. The degree of drought related dieback during summer varied among species for both leaves and twigs, but when $A$ was positive in twigs, they were often more drought resistant than leaves of that same species. A detailed comparison was made of leaves and twigs in a desert species with positive net photosynthetic twigs, Hymenoclea salsola. Leaves had higher values of $A$ and intercellular $\mathrm{CO}_{2}\left(c_{i}\right)$ than twigs when plants were well watered, and this may have been due to greater anatomical specialization in the leaves. When the twigs of a given species did not have high stomatal densities and conductances, they always operated in the light with $c_{i}$ above ambient and $A$ negative. As leaf size increased among species, twig respiration rates and gross photosynthetic rates increased. When twig respiration rates were high, photosynthetic nitrogen-useefficiency may have been maximized by having twigs recycle endogenous $\mathrm{CO}_{2}$ at high $c_{\mathrm{i}}$, and only leaves engaging in positive net uptake at $c_{1}$ below ambient.

Major Professor(s): Ehleringer, James R.

Department: Biology

Principal Investigator(s): Ehleringer, James R.

Program Area: Ecosystems Function and Response

\section{KEYWORDS: CARBON CYCLE, DESERTS, GROWTH AND DEVELOPMENT, LEAVES, PHOTOSYNTHESIS, PRECIPITATION, SOILS, VEGETATION, WATER STRESS}

32 Costigan, Keeley R. 1992. Large Eddy Simulations of the Atmospheric Boundary Layer East of the Colorado Rockies. Ph.D. Dissertation, Colorado State University, 142 pages.

Large eddy simulation, LES, has often been carried out for the idealized situation of a simple convective boundary layer. Studies of dual Doppler radar and aircraft data from the Phoenix II experiment indicate 
that the boundary layer of the Colorado High Plains is not a purely convective boundary layer and it is influenced by the mountains to the west. The purpose of this study is to investigate the atmospheric boundary layer on one particular day over the Colorado High Plains. This research applies a LES nested within larger grids, which contain realistic topography and can simulate the larger-scale circulations initiated by the presence of the mountain barrier. How and to what extent the atmospheric boundary layer of the Colorado High Plains is influenced by larger-scale circulations and other phenomena associated with the mountain barrier to the west is investigated.

Major Professor(s): Cotton, William

Department: Atmospheric Sciences

Principal Investigator(s): Porch, William M.

Program Area: Quantitative Links

KEYWORDS: BOUNDARY LAYER, CIRCULATION, DIFFUSION, LAND SURFACE

\section{3}

Cripe, Douglas G. 1994. Investigation of GCAPE Quasi-Equilibrium in the Midlatitudes. M.S. Thesis, Colorado State University, 230 pages.

Lorenz $(1955,1978,1979)$ developed the concept of the "moist available energy" (MAE) of the atmosphere. This he defined as the portion of non-kinetic energy (NKE) available for conversion to kinetic energy (KE). Randall and Wang (1992) and Wang and Randall (1994) showed that it is possible to consider the component of the MAE that resides in the vertical structure of the atmosphere as a "generalized convective available potential energy" (GCAPE). Using data from the tropics, they tested the GCAPE quasiequilibrium hypothesis (Arakawa and Schubert, 1974) which asserts that cumulus convection "consumes" GCAPE as quickly as it is produced by large-scale (nonconvective) forcing such that the convectively active atmosphere remains close to a state of conditional neutrality. The main purpose of this study is to also investigate the GCAPE quasi-equilibrium hypothesis, only this time in a midlatitude setting. This is a tougher test of the hypothesis given the significantly larger temperature and moisture fluctuations resulting in a stronger large-scale forcing in the midlatitudes, compared with the tropics. Data recently made available by the Atmospheric Radiation Measurement (ARM) program has been used. This new data comes from radiosonde measurements collected at ARM's Cloud and Radiation Testbed (CART) site located in northcentral Oklahoma during Intensive Operation Periods (IOPs) run periodically throughout the year. Since this is one of the first studies to make extensive use of this data, a further goal was to evaluate the quality of the wind and thermodynamic measurements being produced by the CART site. Additionally, analysis data from the Mesoscale Analysis and Prediction System (MAPS) was used, both as a check on the reasonableness of the ARM data, and also to detect any possible errors in the MAPS model output.

Major Professor(s): Randall, David A.

Department: Atmospheric Science

Principal Investigator(s): Randall, David A.

Program Area: Atmospheric Radiation Measurement (ARM)

\section{KEYWORDS: CLIMATE, CLOUDS, CONVECTION, WINDS}

\section{4}

Crowzet, Yoan. 1993. Equilibrium Vapor Pressure and Capillary Ring Formation of Adhering Spherical Aerosol Particles. M.S. Thesis, Texas A\&M University, 130 pages.

Liquid rings trapped by capillary condensation at the point of contact between two spherical particles present an interesting feature insofar as they often display negative curvatures, thereby inducing a lowering of the equilibrium vapor pressures according to the Kelvin equation. This thesis work is divided up into two parts, and each part corresponds to a specific approach of the problem and different objectives. The first part of this work dealt with the calculations of the mean curvature of the meniscus for any two spherical particles in contact. Results were interpreted in terms of equilibrium vapor pressure and applied to condensation nuclei activation. Critical supersaturations were defined and compared to the predictions of the heterogeneous nucleation model for the case of water. A few applications were listed. The second part of this thesis work attempted a different approach by taking into consideration the van der Waals interaction forces acting at a molecular level. The liquid was modeled as an assembly of one-nanometer liquid spheres, and a Monte Carlo code was developed in order to find the minimal energy configuration of the system. Energies were computed using Lifshitz theory between macroscopic spheres. A simulation was performed for a specific case: liquid water and two texadecane solid particles in contact. The final configuration of the assembly was first analyzed in order to estimate the contact angle; the interface was then compared to the predictions of the previous approach. A very encouraging agreement was found on a qualitative level. 
Major Professor(s): Marlow, William H.

Department: Nuclear Engineering

Principal Investigator(s): Marlow, William H.

Program Area: Atmospheric Sciences

\section{KEYWORDS: AEROSOLS, CAPILLARITY, CONDENSATION, VAPOR PRESSURE}

\section{5}

Daniek, R. C. 1991. An Internship with the Carbon Dioxide Information Analysis and Research Program at Oak Ridge National Laboratory: The Effects of Greenhouse Gas Induced Sea Level Rise on the South Carolina Coast. M.A. Report, Miami University, 174 pages.

This one-year internship was conducted at Oak Ridge National Laboratory, Oak Ridge, Tennessee, in the Environmental Sciences Division (ESD). The internship consisted of four projects conducted in the following two programs within ESD: the Carbon Dioxide Information Analysis Center (CDIAC) and the Resource Analysis Project. Two projects involved the production and/or updating of two digital data sets designed for use in global warming research for CDIAC. In the third several of CDIAC's data sets were used to examine the effects that volcanic aerosols and changes in solar irradiance could have on the Earth's global mean air temperature. The last project (the bulk of this report) studies the effects that predicted sea level rise and episodic inundation (from tropical cyclones) would have on two vulnerable areas in South Carolina in the year 2100.

Major Professor(s): Klink, John

Department: Geography

Principal Investigator(s): Kanciruk, Paul, and Robert M. Cushman

Program Area: Information; Carbon, Climate, and Vegetation

KEYWORDS: AEROSOLS, ATMOSPHERE, COASTAL ENVIRONMENT, DATABASES, RADLATIVE PROCESSES, SEA LEVEL, STORMS, TEMPERATURE, VOLCANOES

\section{6}

D'Arrigo, Rosanne Dorothy. 1989. Dendrochronologic Modeling and Reconstruction of Large-Scale Climate Variability in Recent Centuries and Its Relation to Atmospheric Forcing Functions. Ph.D. Dissertation, Columbia University, 216 pages.
Tree-ring chronologies from boreal treeline and other sites have been used to reconstruct patterns of climate variability, their relationship to known forcing functions, and climate as modeled using these forcings. Northern Hemisphere temperatures reconstructed for the past three hundred years agree with other proxy data and with temperature derived from a radiative-convective model incorporating volcanic, solar and $\mathrm{CO}_{2}$ forcings. Superposed epoch analysis shows the effects of volcanism on tree growth and spectral analysis indicates periodicities which might be related to solar or other cycles. Comparison of the reconstructed temperatures with recent instrumental records reveals that the temperature departures within the past decade of elevated atmospheric trace gases levels exceed the "natural" variations in the tree-ring data in past centuries. $\mathrm{A} \mathrm{CO}_{2}$ fertilization effect is not detected in this data through 1973. This issue is further investigated for a high-elevation lodgepole pine site from California. Climate response models indicate that a recent growth increase cannot be completely explained by past climate-growth relationships. The contribution of atmosphere-biosphere $\mathrm{CO}_{2}$ exchange of boreal forests to Pt. Barrow $\mathrm{CO}_{2}$ amplitudes is found to be significant using a 3-D tracer model which employs an exchange function based on remote sensing photosynthetic indices. Positive correlations between variations in those amplitudes and tree-ring data suggest that tree-rings may be used as indicators of $\mathrm{CO}_{2}$ uptake and remote sensing estimates of photosynthetic activity. The northern chronologies show patterns of variation which have climatic implications. Their coefficient of variation reveals periods of agreement/disagreement among the sites which in turn indicates varying periods of spatial coherence in atmospheric circulation patterns. Included among the years of highest variation is 1816 , one year following the Tambora eruption. The tree growth anomalies support the hypothesis of a shift in the atmospheric long wave pattern with enhanced meridional Arctic airflow at this time. Internal variations of the climate system include the global-scale interactions associated with the El Nino-Southern Oscillation and variations in the monsoon cycle. A Java teak tree-ring series shows a response to ENSO and monsoon precipitation.

Major Professor(s): Jacoby, G.

Department: Geology

Principal Investigator(s): Fung, Inez

Program Area: Carbon, Climate, and Vegetation

KEYWORDS: CARBON DIOXIDE, CLIMATE, EL NIÑO - SOUTHERN OSCILLATION (ENSO), FERTILIZATION, NORTHERN HEMISPHERE, RADLATIVE PROCESSES, STORMS, TEMPORAL DISTRIBUTION, TREE RINGS, VOLCANOES 
37

Dean, Caryn Lyn. 1993. Interactions Between a

Tropical Mixed Boundary Layer and Cumulus

Convection in a Radiative-Convective Model. M.S.

Thesis, Pennsylvania State University, 159 pages.

A radiative-convective model, combining previously developed cumulus, stable cloud and radiation parameterizations with a boundary layer scheme, was developed in the current study. The cloud model (Frank and Cohen, 1985) was modified to incorporate the effects of both small and large clouds. The boundary layer model, adapted from a mixed layer model (Albrecht et al. 1979), was only slightly modified to couple it with the more sophisticated cloud model. The model was tested for a variety of imposed divergence profiles, which simulate the regions of the tropical ocean from approximately the Intertropical Convergence Zone (ITCZ) to the subtropical high region. The sounding used to initialize the model for most of the runs is from the trade wind region of ATEX. For each experiment, the model was run with a timestep of $\mathbf{3 0 0}$ seconds for a period of seven (7) days. The model produced an inversion height of approximately $950 \mathrm{mb}$ for each region. As the subsidence increased, typical of conditions towards the subtropical high region, the boundary layer became moister and warmer, and the periods of deep convection became weaker and less frequent. Various cloud spectra were also introduced into the model to test for sensitivity to the number of cloud types represented. The model produced similar results whether one cloud or many clouds were used. However, the runs with more than one cloud generally displayed resultant inversion heights with more stable oscillations than the equivalent runs with only one cloud type. With the exception of higher mixing rates resulting in larger clouds, the specification of initial updraft vertical velocity and mixing rate made little difference to the final inversion height and boundary layer thermodynamic values. Finally, sensitivity tests were done for varying sea surface temperatures and surface wind velocities. The model responded well to changes. As sea surface temperature increased, the inversion height increased, the boundary layer became warmer and the moisture stayed approximately the same. As surface wind velocity increased, the inversion height decreased, and the boundary layer temperature and moisture decreased and increased, respectively. A FGGE sounding from a region closer to the equator was tested and the results were very similar, with an inversion height near $960 \mathrm{mb}$. Therefore, the model is thought to be physically representative of the physical area described above.

Major Professor(s): Frank, William
Department: Meteorology

Principal Investigator(s): Wohlpart, A.

Program Area: Graduate Fellowships for Global Change

KEYWORDS: BOUNDARY LAYER, CLOUDS, CONVECTION, OCEANS, RADLATIVE PROCESSES, TEMPERATURE, TROPICS, WATER VAPOR, WINDS

38

De Bruyn, Warren J. 1994. The Heterogeneous Chemistry of Carbonyl Halides, Haloacetyl Halides and Biogenic Sulfur Species. Ph.D. Dissertation, Boston College, 175 pages.

Heterogeneous reaction pathways involving aqueous droplets in clouds and fogs have been recognized as major mechanisms for the chemical transformation of atmospheric trace gases. Here we examine the heterogeneous chemistry of two atmospheric systems using a previously developed fast droplet experiment and a new bubble column apparatus. Gas-liquid uptake studies have been completed for the following series of carbonyl and haloacetyl halides: $\mathrm{CF}_{3} \mathrm{CFO}, \mathrm{CF}_{2} \mathrm{O}$, $\mathrm{CF}_{3} \mathrm{CClO}, \mathrm{CCl}_{2} \mathrm{O}$ and $\mathrm{CCl}_{3} \mathrm{CClO}$. Some of these species have been shown to be degradation products of hydrochlorofluorocarbons and hydrofluorocarbons which have been proposed as substitutes for ozone depleting chlorofluorocarbons. The experiments yielded values for the product of the Henry's law coefficient $(\mathrm{H})$ and the liquid phase hydrolysis rate constant $(\mathrm{k})$ in the form Hk. Results indicate that the tropospheric removal of the degradation products is fast enough not to contribute to the ozone depletion potential of their parent species. A series of aqueous phase uptake studies have also been completed for key biogenic sulfur species in the marine boundary layer. Reduced sulfur species of biogenic origin $\mathrm{CH}_{3} \mathrm{SCH}_{3}, \mathrm{H}_{2} \mathrm{~S}, \mathrm{CS}_{2}$, $\mathrm{CH}_{3} \mathrm{SH}$ and $\mathrm{OCS}$ are a major source of sulfur in the marine atmosphere. These species and their oxidation products $\mathrm{CH}_{3} \mathrm{SO}_{3} \mathrm{H}$ (MSA), $\left(\mathrm{CH}_{3}\right)_{2} \mathrm{SO}$ (DMSO), and $\left(\mathrm{CH}_{3}\right)_{2} \mathrm{SO}_{2}\left(\mathrm{DMSO}_{2}\right)$ dominate the production of aerosol and cloud condensation nuclei in the clean marine atmosphere. Henry's law coefficients and Sctchenow saltout coefficients have been obtained for the reduced sulfur species and mass accommodation coefficients have been obtained for the oxidized sulfur species. The atmospheric implications of the results have been examined. The species DMSO, $\mathrm{DMSO}_{2}$ and MSA which exhibit relatively large uptake were studied with the fast droplet apparatus previously described in detail. The other species studies in this work exhibited uptakes too small to be measured with the droplet apparatus. A new more sensitive bubble column apparatus was developed for the study of these 
molecules. In the bubble column apparatus, a low pressure gas flow, carrying trace gas diluted in helium carrier gas, is bubbled through a liquid. The bubbles and their transit through the liquid are carefully characterized. Measurements of gas depletion yield the desired characteristics.

Major Professor(s): Davidovits, Paul

Department: Chemistry

Principal Investigator(s): Davidovits, Paul

Program Area: Atmospheric Sciences

\section{KEYWORDS: ATMOSPHERE, CHEMISTRY, EMISSIONS, HALOGEN SPECIES, HENRY'S LAW, HYDROLYSIS, SULFUR SPECIES}

\section{9 \\ Delaney, Paul. 1991. Sensitivity of Atmospheric Radiation to Temperature, Water Vapor and Ozone Profiles. M.S. Thesis, University of Maryland at College Park, 23 pages.}

The sensitivity of the longwave spectral radiance incident on the surface to uncertainties in the measurement of temperature, water vapor and ozone have been examined with the use of the line-by-line radiation code FASCODE2. Spectrally averaged results at one wavenumber resolution were obtained for simulated random and systematic errors in the meteorological data under midlatitude summer conditions. As expected, temperature errors dominate the uncertainties in the opaque regions, whereas water vapor errors dominate the sensitivity in the atmospheric window. In general, the radiation field is most sensitive to uncertainties in water vapor, followed by temperature, tropospheric ozone then stratospheric ozone. Systematic errors dominate radiance uncertainties, with reasonable random errors in the meteorological data resulting in radiance errors that are of the of 0.25 to 0.5 the magnitude of the systematic effects. The maximum effects of systematic errors on the fractional radiance error at any spectral location in the 5 to 20 micron region is the order of $2 \%$ per degree Kelvin and $1.2 \%$ per percent water vapor mixing ratio error for temperature and water vapor uncertainties, respectively.

Major Professor(s): Ellingson, Robert G.

Department: Meteorology

Principal Investigator(s): Ellingson, Robert G.

Program Area: Quantitative Links

KEYWORDS: ABSORPTION, OZONE, RADLATIVE PROCESSES, TEMPERATURE, WATER VAPOR
40

Detwiler, Ralph Paul 1986. Tropical Forests and the Global Carbon Cycle. Ph.D. Thesis, Comell University, 415 pages.

The concentration of carbon dioxide in the atmosphere has increased from 280 parts per million circa 1750 to 345 parts per million in 1984. One cause of this increase, and the principal one in recent years, has been the combustion of fossil fuels. Another has been the destruction of forests and their replacement with agroecosystems, whose vegetation and soil contain much less carbon than the vegetation and soil of undisturbed forests. In the past, the destruction of temperate forests may have contributed significantly to the increase in atmospheric $\mathrm{CO}_{2}$. It now appears, however, that the clearing of tropical forests is the major source of $\mathrm{CO}_{2}$ from terrestrial ecasystem. Tropical forests are cleared for shifting cultivation, permanent agriculture, pasture, and timber. These land uses differ as to the amount of carbon stored in their vegetation and soil. To calculate the net release of $\mathrm{CO}_{2}$ from tropical forest clearing, one must determine: (1) the rates at which tropical forests are cleared for these various uses and the rate at which cleared areas are abandoned in shifting cultivation; (2) the carbon stored in the vegetation and soil of primary forests, logged forests, secondary forests, agricultural fields and pastures; and (3) the fate of carbon contained in cleared vegetation and soil. These date are used in computer model that simulates land use change in the tropies and its effects on vegetation and soil and calculates the net flux of $\mathrm{CO}_{2}$ between tropical ecosystems and the atmosphere. The model is useful because it permits testing the sensitivity of the calculated flux to uncertainties in the estimates of land use change, carbon storage, and the fate of cleared vegetation. The model has been used to calculate the net release in 1980 from the vegetation of four Latin American countries and from the vegetation and soil of the entire tropics. This research indicates that land use change in the tropics released at least $0.4 \times 10^{15} \mathrm{~g}$ but not more than $1.9 \times 10^{15} \mathrm{~g}$ of carbon in 1980 , with the more likely range being $0.4-1.6 \times 10^{15} \mathrm{~g}$. Decreases in soil organic matter were responsible for $0.1-0.3 \times 10^{15} \mathrm{~g}$ of the release, while the burning and decay of cleared vegetation accounted for $0.3-1.6 \times 10^{15} \mathrm{~g}$.

Major Professor(s): Hall, Charles A.S.

Department: Ecology and Systematics

Principal Investigator(s): Hall, Charles A.S.

Program Area: Carbon, Climate, and Vegetation

KEYWORDS: ATMOSPHERE, CARBON CYCLE, CARBON DIOXIDE, FORESTS, LAND USE, IATIN AMERICA, MODELS, ORGANICS, SOILS, TROPICS 
41

Deverver, Bric 1994. On the Dynamics of Extratropical Low-Frequency Atmospheric Variability. M.S. Thesis, University of Maryland at College Park, 33 pages.

The discovery of El Nino/Southern Oscillation (ENSO) as a dominant mode of interannual variability has lead to considerable optimism that circulation anomalies on seasonal timescales can be predicted. On the other hand, many studies have shown that extratropical lowfrequency variability is maintained by the convergence of momentum flux by synoptic-scale eddies. Further analysis shows that high-frequency eddies are organized and controlled by the low-frequency flow. If the lowfrequency flow does exert a dominant influence on the high-frequency eddies, it may be possible to construct a model in which the high-frequencies are parameterized in terms of the predicted low-frequency flow. Lowfrequency flow anomalies would then be directly attributable to slowly varying boundary forcing and strictly low-frequency dynamics. This research is intended as a contribution to the goal of constructing such a model. While our ultimate goal is to design a general low-frequency model, we have focussed on the specific case of seasonal streamfunction anomalies associated with tropical heating events. To examine these anomalies, we have constructed a steady-state barotropic diagnostic model. The model simulates the streamfunction anomaly between two seasons at a given level using the observed fields of divergence and transient vorticity flux convergence for the two seasons. Because the basic state of the model is the average of the flow for the two seasons, the model is automatically linear. Thus the global streamfunction anomaly can be thought of as the linear sum of the streamfunction anomalies forced from various regions by various processes.

Major Professor(s): Baer, Ferdinand

Department: Meteorology

Principal Investigator(s): Baer, Ferdinand

Program Area: Computer Hardware, Advanced

Mathematics, and Model Physics (CHAMMP)

KEYWORDS: ATMOSPHERE, CIRCULATION, EL NINO - SOUTHERN OSCILLATION (ENSO), EXTRATROPICS, TEMPORAL DISTRIBUTION

\section{2}

DeWitt, Craig A 1983. Soil Moisture Stress and Nitrogen Fixation in Soybeans. M.S. Thesis, Clemson University, 70 pages.
Symbiotic nitrogen fixation in legumes is an economically important source of biological nitrogen in the food chain. The rate of nitrogen fixation in soybean (Glycine max [L.] Merr. 'Bragg') is influenced by many environmental factors including soil water potential. This study was conducted to determine the effects of soil moisture stress on nitrogen $\left[\mathrm{C}_{2} \mathrm{H}_{2}\right]$-fixation in soybeans during early flowering. Nitrogen $\left[\mathrm{C}_{2} \mathrm{H}_{2}\right]$-fixation is a method of determining nitrogen fixation using the reduction of acetylene $\left(\mathrm{C}_{2} \mathrm{H}_{2}\right)$ to ethylene in a surrogate reaction utilizing the nitrogenase enzymes. Soybeans were grown in a Norfolk sandy loam topsoil at 27/15 C (day/night) in a controlled environment in Soil-PlantAtmosphere-Research (SPAR) units which were modified to permit in situ nitrogen $\left[\mathrm{C}_{2} \mathrm{H}_{2}\right]$-fixation measurements. At early flowering, three water stress treatments (wet soil, 0-50 $\mathrm{kPa}$, and 0-100 Kpa) were imposed for a minimum of three consecutive drydown/recovery cycles. Nitrogen $\left[\mathrm{C}_{2} \mathrm{H}_{2}\right]$-fixation in soybeans during early bloom decreased during the first dry-down cycle in each treatment. Nitrogen $\left[\mathrm{C}_{2} \mathrm{H}_{2}\right]-$ fixation increased upon rewetting in all treatments but not to pretreatment levels. Correlation coefficients of 0.63 and 0.58 were obtained for the first drydown in the dry and medium treatments, respectively. No significant correlation was found for any treatment after the first dry-down period. Pod dry weight and pod nitrogen contents at harvest were unaffected by any of the soil moisture treatments in this experiment. Total plant dry weight at harvest was $25 \%$ lower in the $0-100 \mathrm{kPa}$ treatment. The acetylene/ethylene system used in the determination of nitrogen $\left[\mathrm{C}_{2} \mathrm{H}_{2}\right]$-fixation proved to be nontoxic to the plants when sampled at 3-h intervals. This system in conjunction with SPAR units allowed semi-continuous measurements of nitrogen $\left[\mathrm{C}_{2} \mathrm{H}_{2}\right]-$ fixation and its response to water stress in soybeans.

Major Professor(s): Lambert, Jerry $\mathbf{R}$. Department: Agricultural Engineering Principal Investigator(s): Acock, Basil Program Area: Carbon, Climate, and Vegetation

KEYWORDS: ATMOSPHERE, NITROGEN CYCLE, SOILS, VEGETATION, WATER STRESS

43

Diaz, Henry Frank 1985. A Comparison of Twentieth Century Climatic Anomalies in Northern North America with Reconstructed Patterns of Temperature and Precipitation Based on Pollen and Tree-Ring Data. Ph.D. Dissertation, University of Colorado, 234 pages.

The possibility of significant climatic changes over the next century of two resulting from anthropogenic modification of atmospheric composition and vegetative 
alterations makes it important to determine the ranges associated with different climatic regimes that have occurred during the present interglacial (in particular, the climate of the Middle- and Late-Holocene). The area of interest in this study comprises northern North America going from Alaska in the west to western Greenland in the east. The approach taken in this study was to use the modern observational record to identify the surface anomaly patterns and the associated midtropospheric circulation features characteristic of the principal modes of interannual variance in this region. These anomaly patierns were analysed within the context of the annual cycle by looking at seasonal variations and by comparison with the mean season-toseason changes. Principal component analysis was one major tool used to derive objectively the characteristic anomaly fields at both the surface and upper levels and to assess their temporal relationships. Other techniques included differencing various periods based on the integrated anomaly field and calculating field correlations between surface temperature and $700 \mathrm{mb}$ heights. The surface patterns were contrasted to those derived using climate proxy data such as variations in tree-ring growth and fossil pollen variations in order to infer plausible circulation regimes based on the degree of pattern similarity. Areas of consistent response during warm and/or cold periods operating at time scales varying from years to decades to centuries and finally to the order of millennia were identified and their existence was explained in terms of the possible redistribution (i.e. changes in the mean position and strength) of the planetary-scale waves in this region. The finding that the zone of high amplitude response is located approximately along the mean present-day boundary between arctic and Pacific or interior continental airstreams may help in the identification and monitoring of areas in northern North America where early detection of climatic change due to increasing atmospheric $\mathrm{CO}_{2}$ concentration is likely. Furthermore, by relating such responses to specific changes in the structure of the atmospheric circulation, we may have greater confidence that those surface changes are indeed related to hemispheric-scale variations, and not to natural variability of the climate system.

Major Professor(s): Barry, Roger G.

Department: Geography

Principal Investigator(s): Diaz, Henry F.

Program Area: Carbon, Climate, and Vegetation

KEYWORDS: ATMOSPHERE, CIRCULATION, CLIMATE, HOLOCENE, NORTH AMERICA, POLLEN, PRECIPITATION, SURFACE LAYER, TEMPERATURE, TEMPORAL DISTRIBUTION, TREE RINGS, WAVES
44

Dietrich, William F. 1994. The Concept of Critical Levels: Should Climate Change Negotiators Use It? M.P.P. Thesis, Harvard University, 89 pages.

Germany will host the first conference of the Parties to the United Nations Framework Convention on Climate Change. As host, Germany is responsible for preparing background documents for use by the Parties. The German Federal Ministry for Environment, Nature Conservation and Nuclear Safety asked researchers at the Wuppertal Institute for Climate, Environment, and Energy to serve as the analytical round of international negotiations on climate change. This policy analysis is a background document for the negotiations. The paper addresses the question, "What can be learned from the use of critical levels in other international environmental negotiations that can be used in the climate change negotiations?" The paper examines the use of the critical level/oad concept in both the acid rain and stratospheric ozone negotiations, draws lessons from those experiences, and applies those lessons to the climate change negotiations. It finds that critical levels will be useful in the climate change if environmental regulation have tended to bring "unifactorial" explanations to bear on questions like the one asked by this study. Specifically, scholars most often employ four different explanatory models to explain divergences in national regulatory patterns: 1) the role of domestic political institutions; 2) the institutionalization, public trust, and political context of scientific information and advice; 3) the influence of international pressure, regimes, and institutions; and 4) the role played by divergent cultural perceptions of risk. In this study I examine the efficacy of each of these models in explaining the divergent regulatory histories of the two countries. I argue that, alone, none of these models is sufficient to account for the ten-year difference in the timing of measures to combat acid rain. Only by highlighting the complicated interplay among these factors can one illuminate the central question that guides this study. This conclusion emphasizes the power and usefulness of multifactorial analysis.

Major Professor(s): Clark, William C. Department: Kennedy School of Government Principal Investigator(s): Clark, William C. Program Area: National Institute for Global Environmental Change (NIGEC)

KEYWORDS: ACIDITY, CLIMATE, DEPOSITION, OZONE, POLICY, RISK 


\section{5}

Dignon, Jane Elizabeth. 1988. Time and Spatially Dependent Estimates of Pollutant Trace Gas Emissions and Their Effect on Tropospheric Ozone. Ph.D. Dissertation, State University of New York at Stony Brook, 180 pages.

Statistical models have been developed to relate the rate of pollutant emissions to the rate of fuel combustion. These models have been used to estimate global emissions of nitrogen and sulfur oxides in fossil fuel combustion since the year 1860 . When averaged over the 1860 to 1980 period, global sulfur emissions increased at a rate of 2.9 percent per year, and the nitrogen emissions increased at a rate of 3.4 percent per year. Using these statistical models along with population distribution estimates, high resolution geographical maps of emissions can be produced for each year which fuel consumption data are available. Global emissions of $\mathrm{NO}_{\mathrm{x}}$ and $\mathrm{SO}_{\mathrm{x}}$ emissions for 1966 and 1980 are illustrated on a latitude-longitude grid appropriate for general circulation models of the atmosphere. Emissions of carbon monoxide from fossil fuel, wood and biomass fuel, and open burning of vegetation, as well as emissions of nitrogen and sulfur oxides from wood and biomass fuel burning, are estimated for 1980 using emission factor methods. These trace gas sources are also mapped globally. The impact of increasing emissions of $\mathrm{NO}_{\mathrm{x}}$ on tropospheric ozone abundance is estimated by calculations with a one-dimensional (latitudinal) model which includes coupled tropospheric photochemistry and diffusive meridional transport. Steady-state photochemical calculations with the prescribed $\mathrm{NO}_{\mathrm{x}}$ emissions appropriate for 1966 and 1980 indicate an ozone increase of 8 to 11 percent in the Northern Hemisphere, a result which is compatible with the rise of about 12 percent between 1970 and 1981 suggested by recent observations.

Major Professor(s): Hameed, Sultan Department: Mechanical Engineering (Atmospheric Sciences)

Principal Investigator(s): Hameed, Sultan

Program Area: Carbon, Climate, and Vegetation

KEYWORDS: COMBUSTION, EMISSIONS, FOSSIL FUELS, SULFUR SPECIES

46

Ding, Ming 1992. Radiative Forcing Due to Observed Changes in Greenhouse Gases for the Period 19801990. M.S. Thesis, State University of New York at Albany, 52 pages.
Recently, satelite observation of global $\mathrm{O}_{3}$ distribution for the period 1980-1990 became available. The data indicated that statistically significant lower stratospheric $\mathrm{O}_{3}$ depletion occurred at middle to high latitudes in both hemispheres, which may perturb the radiative forcing of the troposphere-surface climate system. Here, we study the radiative forcing due to $\mathrm{O}_{3}$ changes and compare the value with those due to the increase in other major greenhouse gases, $\mathrm{CO}_{2}, \mathrm{CH}_{4}, \mathrm{~N}_{2} \mathrm{O}$ and CFCs over the same period. In addition, we study the direct forcing due to the $\mathrm{CH}_{4}$ increase and indirect due to increase in atmospheric $\mathrm{O}_{3}$ and stratospheric $\mathrm{H}_{2} \mathrm{O}$ associated with $\mathrm{CH}_{4}$ increase. Stratospheric $\mathrm{O}_{3}$ depletion has two compensating effects on the radiation balance at the tropopause: positive solar forcing and negative infrared forcing. On a global mean basis, the radiative forcing due to the well-mixed greenhouse gases $\left(\mathrm{CO}_{2}\right.$, $\mathrm{CH}_{4}, \mathrm{~N}_{2} \mathrm{O}$ and $\mathrm{CFCs}$ ), $\mathrm{CFCs}$ and $\mathrm{O}_{3}$ are $0.51,0.07$, and $0.03 \mathrm{Wm}^{-2}$, respectively. Although the forcing due to $\mathrm{O}_{3}$ depletion is comparable to that of CFCs increase, it is small compared with the well-mixed gases. However, the calculated $\mathrm{O}_{3}$ forcing can be large on the basis of seasons and latitudes. For example, it may reach a maximum of $0.2 \mathrm{Wm}^{-2}$ at middle latitude summer hemisphere, which is about $50 \%$ of the forcing due to well-mixed greenhouse gases. The results thus suggest that $\mathrm{O}_{3}$ changes can contribute significantly to the total radiative forcing. Increase in $\mathrm{CH}_{4}$ may lead to increases in tropospheric $\mathrm{O}_{3}$ and stratospheric $\mathrm{H}_{2} \mathrm{O}$, with subsequent effect on radiative forcing. We find that the radiative forcing due to the stratospheric $\mathrm{H}_{2} \mathrm{O}$ increase caused by doubling the $\mathrm{CH}_{4}$ surface emission may enhance the $\mathrm{CH}_{4}$ direct effect by more than $30 \%$. And the $\mathrm{CH}_{4}$-induced atmospheric $\mathrm{O}_{3}$ increase may decrease the $\mathrm{CH}_{4}$ direct forcing by $30 \%$ at middle latitude summer hemisphere, primarily caused by stratospheric $\mathrm{O}_{3}$ increase. These results suggest that indirect forcing needs to be considered when addressing $\mathrm{CH}_{4}$ climatic effect. Finally, we carry out radiation calculations to examine the sensitivity of the radiative forcing to the climate state and the $\mathrm{H}_{2} \mathrm{O}$ continuum treatment. The results indicate that both effects are small, for example, about $10 \%$ when different $\mathrm{H}_{2} \mathrm{O}$ continuum schemes are used.

Major Professor(s): Wang, Wei-Chyung

Department: Atmospheric Science

Principal Investigator(s): Wang, Wei-Chyung

Program Area: Carbon, Climate, and Vegetation

KEYWORDS: GASES, RADLATIVE PROCESSES 
47

Dippery, Joy Kirsten. 1993. Effects of Reduced and Elevated $\mathrm{CO}_{2}$ Partial Pressure on $\mathrm{C} 3$ and $\mathrm{C} 4$ Plant Growth. M.S. Thesis, Duke University, 52 pages.

In order to study $\mathrm{C}_{3}$ and $\mathrm{C}_{4}$ plant growth in atmospheric $\mathrm{CO}_{2}$ levels ranging from Pleistocene through predicted future levels, Abutilon theophrasti $\left(C_{3}\right)$ and Amaranthus retroflexus $\left(C_{4}\right)$ were grown in growth chambers controlled at $\mathrm{CO}_{2}$ partial pressures of $15 \mathrm{~Pa}$ (approximate Pleistocene minimum), $27 \mathrm{~Pa}$ (preindustrial), $35 \mathrm{~Pa}$ (present) and $70 \mathrm{~Pa}$ (elevated). After 35 days of growth, $\mathrm{CO}_{2}$ had no effect on the relative growth rate, total biomass or partitioning of biomass in the $\mathrm{C}_{4}$ species. However, the $\mathrm{C}_{3}$ species showed increasing biomass with rising $\mathrm{CO}_{2}$ partial pressure. $\mathrm{C}_{3}$ plants grown in $15 \mathrm{~Pa} \mathrm{CO}$ had only $8 \%$ of the total biomass of plants grown in $35 \mathrm{~Pa} \mathrm{CO}_{2}$. In 15 $\mathrm{Pa} \mathrm{CO}_{2}, \mathrm{C}_{3}$ plants had lower relative growth rates, lower specific leaf weights and stunted reproduction relative to plants grown in higher $\mathrm{CO}_{2}$ partial pressures. $\mathrm{C}_{3}$ plants grown in $70 \mathrm{~Pa} \mathrm{CO}_{2}$ showed relatively greater partitioning of biomass to roots compared with plants grown in $15 \mathrm{~Pa} \mathrm{CO}$. This study suggests that 1) $\mathrm{C}_{3}$ species may acquire a competitive advantage over $\mathrm{C}_{4}$ species with increasing atmospheric $\mathrm{CO}_{2}$ partial pressure; 2) $\mathrm{C}_{4}$ species may have had a competitive advantage over $C_{3}$ species in the past when atmospheric $\mathrm{CO}_{2}$ partial pressure was substantially lower than current levels; 3) and supports the hypothesis that low $\mathrm{CO}_{2}$ partial pressures of the past may have been an important factor favoring the evolution of $\mathrm{C}_{4}$ species.

Major Professor(s): Strain, Boyd R.

Department: Botany

Principal Investigator(s): Strain, Boyd R.

Program Area: Carbon, Climate, and Vegetation

KEYWORDS: BIOMASS, C3 METABOLISM, C4 METABOLISM, CARBON DIOXIDE, COMPETITION, EVOLUTION, FERTILIZATION, GROWTH AND DEVELOPMENT, PLEISTOCENE EPOCH, PRE-INDUSTRLAL ERA, VEGETATION

\section{8}

Dibopolsty, Rose Marie. 1991. A Study of the Earth Radiation Budget Experiment Short Wave Measurements and Bidirectional Reflectance Models for the Ocean Surface. PhD. Dissertation, State University of New York at Stony Brook, 141 pages.

Shortwave radiances from the Earth Radiation Budget Experiment (ERBE) satellites are converted to fluxes using bidirectional reflectance models created from Nimbus 7 data. These models describe the dependence of a shortwave measurement on the angle at which a scene is being observed and the position of the sun relative to that scene and the satellite. In this study, reflectances are derived from Earth Radiation Budget Satellite (ERBS) shortwave radiances and sorted according to the range of angles at which they were measured. This range is called the angular bin size. The Nimbus 7 Bidirectional Reflectance Models were created using this same procedure. In this study, the size of the angular bins is made smaller than the sizes in the Nimbus 7 Bidirectional Reflectance Models in order to more accurately describe the angular dependence of the shortwave reflection. Results indicate that the size of the Nimbus 7 angular bins causes the ERBE shortwave fluxes to be overestimated when the satellite views specular reflection from the ocean surface. This is especially severe for solar zenith angles less than 25 degrees. Clear sky shortwave radiances measured under specular geometries are very large and are therefore not included in the processing. However, these radiances are sometimes identified as clouds and included in the data set. This occurs because shortwave radiances reflected from clouds do not exhibit as strong a dependence on viewing geometry as the clear sky ocean surface. Therefore, a large shortwave radiance is identified as a cloud. Examples are given where this affects the regional data.

Major Professor(s): Cess, Robert D.

Department: Mechanical Engineering (Atmospheric Sciences)

Principal Investigator(s): Hameed, Sultan

Program Area: Carbon, Climate, and Vegetation

KEYWORDS: MODELS, RADLATTVE PROCESSES, REFLECTANCE

49

Donato, Timothy Francis 1994. Radar Imaging of Oceanic Fronts at Low Grazing Angles. M.S. Thesis, North Carolina State University, 90 pages.

Over the past twenty years imaging radars, such as Synthetic Aperture Radar and Real Aperture Radar, have seen increasing use in the study of oceanic phenomena. The variety of ocean phenomena or features observed in radar images include (but are not limited to) western boundary currents, shallow water bathymetric influences of the sea surface, internal wave, atmospheric boundary layer variations, and surface wind waves. However, most of these investigations have relied on spaceborne and airborne platforms operating at small to moderate incidence angles $\left(0^{\circ}-60^{\circ}\right)$. Few studies have employed imaging radars operating at angles greater than $60^{\circ}$ incidence or low grazing angles. 
In this study a Real Aperture Radar operating at low grazing angles (approximately $65^{\circ}$ to $87^{\circ}$ ) is used to identify and interpret sub-mesoscale surface features associated with oceanic fronts. To facilitate this task airborne remote sensing and ship board sea truth activities conducted simultaneously. The research was conducted over a five day period between 1 and 5 October, 1990 off the north east coast of North Carolina. Data collection include airborne remote sensing data (radar imagery, sea surface temperature from a radiometer, inertia navigation system data and radar altimetry), ship board sea truth (acoustic Doppler current profiles, conductivity-temperature-depth profiles, expendable bathythermographs, radiosondes, and standard shipboard meteorological and oceanographic observations), and ancillary sea surface temperature data from NOAA polar orbiting satellites. Radar data was collected at a pulse repetition frequency of $100 \mathrm{~ns}$ and at $9.375 \mathrm{GHz}$. A total of six low resolution images were examined and compared with sea truth for this study. The observations and results of this study show that a localized mesoscale cyclonic flow existed within the boundary layer and is interpreted as a low level cold air advection towards the Gulf Stream. Wind speed and air temperature remained fairly consistent over the course of the study. Wind direction, however was observed to cyclonically rotate approximately $15^{\circ}$ upon crossing the Gulf Stream thermal front. This condition was a consequence of the strong sea surface temperature gradients associated with the Gulf Stream $\left(7^{\circ} \mathrm{C} \mathrm{km}^{-1}\right)$. Oceanic mixed layer measurements revealed a complex Guif Stream frontal region. A filament detected in sea surface temperature imagery was aiso apparent in the Acoustic Doppler profiles. Two frontal regions existed as a result of the presence of this filament. One front was dominated by the thermal contrast between the Gulf Stream and continental shelf waters. The other front was dominated by strong shears associated with the detaching filament and the main body of the Gulf Stream. Results from this investigation demonstrate that ocean features such as thermal fronts, shear zones, filaments, and boundary layer variations, observed in sea truth and radiometer data can be detected in low grazing angle radar images. Azimuthal variability with respect to wind and radar look direction was apparent. The study also demonstrated that frontal features can yield a backscatter return as high as the returns generated by hard targets, such as ships.

Major Professor(s): Morrison, J. Department: Marine, Earth and Atmospheric Sciences Principal Investigator(s): Pietrafesa, Leonard J. Program Area: Marine Transport

\section{KEYWORDS: ATMOSPHERE, BOUNDARY LAYER, CIRCULATTON, CLIMATE, MARINE ENVRONMENT, OCEANS, REFLECTANCE, REMOTE SENSING, WINDS}

50

Donowan, Lisa Alayne. 1992. A Chrysothamnus Affair: Surviving and Developing Roots in Utah. $P h . D$. Dissertation, University of Utah, 144 pages.

Water limits plant establishment and productivity in many arid and semi-arid habitats. This study investigated patterns of water-use characters in natural populations, and the relationships among water-use characters, growth and survival. The study concentrated on Chrysothamnus nauseosus, commonly known as rubber rabbitbrush, and emphasized differences between juveniles (smaller establishing plants), and adults (larger reproductively mature plants). Juveniles were found to differ from adults not only in size and rates of mortality, but also in their water status (xylem pressure potentials), rates of gas exchange (photosynthesis and stomatal conductance) and wateruse efficiency (WUE, ratio of photosynthetic carbon gain to transpirational water loss). The differences were due, in part, to soil moisture availability, with shallow rooted juveniles being more water stressed and more dependent on moisture from summer rain. Summer drought resulted in high rates of seedling mortality for C. nauseosus, but larger seedlings and juveniles were more likely to survive the drought. Though small plants were more water stress than large plants during each summer, they had lower WUE throughout the season, based on measurements of instantaneous gas exchanges and of leaf carbon isotope discrimination ( $\Delta$ ). This negative relationship between $\Delta$ and plant size in the natural population, as well as temporal shifts in $\Delta$ found under controlled environment conditions, suggested that there was a developmental component to variation in WUE in addition to environmentally induced variation. Quantitative genetic analysis indicated that there was also genetic variation for $\Delta$, though the estimates were relatively low, and hence some potential for genetic differentiation in $\Delta$ in response to natural selection. For C. nauseosus, lower WUE (higher $\Delta$ ) was not necessarily associated with greater biomass accumulation and growth,and both photosynthetic capacity and stomatal limitation appeared to contribute to the variation in the relationship between $\Delta$ and growth. Though there were stable differences between juveniles and adults for water-use characters, and in particular WUE, the functional significance of these differences remains unknown.

Major Professor(s): Ehleringer, James R. 
Department: Biology

Principal Investigator(s): Ehleringer, James R.

Program Area: Ecosystems Function and Response

\section{KEYWORDS: CARBON CYCLE, DESERTS, GENETICS, GROWTH AND DEVELOPMENT, LEAVES, MORTALITY, PHOTOSYNTHESIS, PRECIPITATION, SOILS, TEMPORAL DISTRIBUTION, VEGETATION, WATER STRESS, WATER USE}

\section{1 \\ Duda, David P. 1994. Macrophysical and Microphysical Influences on Radiative Transfer in Two Dimensional Marine Stratus. Ph.D. Dissertation, Colorado State University, 202 pages.}

Recent estimates of the effects of increasing amounts of anthropogenic sulfate aerosol on global climate have indicated that its impact on the radiative forcing of the atmosphere may be comparable in magnitude to the effect from increases in $\mathrm{CO}_{2}$. Much of this impact is expected from the indirect effects of the aerosol on global cloud microphysics and the subsequent impact on cloud albedo. However, internal horizontal variations in cloud optical properties are also known to affect cloud albedo and reflectance, and thus affect the remote sensing of cloud microphysics. A broadband solar radiative transfer model (SHSG) capable of simulating the radiances and fluxes in a medium that varies both vertically and horizontally was used to quantify the effects of both cloud microphysical changes and cloud inhomogeneity changes on the radiative properties of marine stratus. Two dimensional cross sections of cloud physics data taken from a set of three dimensional RAMS/LES simulations of marine stratus provided realistic optical property data for radiative transfer simulations. Along with a control run using typical marine $\mathrm{CCN}$ concentrations, two studies using enhanced concentrations of $\mathrm{CCN}$ were examined. The results of the radiative transfer calculations indicated that in unbroken marine stratus clouds the net horizontal transport of photons over a domain of a few $\mathrm{km}$ was nearly zero, and the domain average broadband albedo computed in a two dimensional cross section was nearly identical to the domain average calculated from a series of independent pixel approximation (IPA) calculations of the same cross section. This matches the findings from Cahalan et al. (1994) for monochromatic calculations in a simple cloud model, and suggests that accurate computations of domain averaged albedo in unbroken marine stratus can be made using IPA calculations with one dimensional radiative transfer models.
Major Professor(s): Stephens, Graene L. Department: Atmospheric Science Principal Investigator(s): Stephens, Graeme L. Program Area: National Institute for Global Environmental Change (NIGEC)

KEYWORDS: CLOUDS, MARINE ENVRONMENT, MICROPHYSICS, RADLATIVE PROCESSES, REFLECTANCE, REMOTE SENSING

52

Dugue, Charles Pierre Michel 1989. Colloidal Behavior in Natural Waters as Described by Ultrafiltration. M.S. Thesis, Illinois Institute of Technology, 52 pages.

The properties of colloidal substances and their possible correlation with other materials present in the natural waters help explain their movement in the environment. Ultrafiltration using hollow fiber filters was used to separate colloids from natural water into different size fractions. These size fractions were used in competitive binding experiments with a trace metal (yttrium) and a suspended solid (silica gel). The distribution coefficient of the metal between the suspended solid and the colloidal organics was found to be linearly related to the amount of organic in solution. This relationship was found to be strongly influenced by solution $\mathrm{pH}$, the nature of the suspended solids as well as the amount of other natural cations present in the system.

Major Professor(s): Holsen, Thomas M.

Department: Environmental Engineering

Principal Investigator(s): Gaffney, Jeffrey S., and Nancy A. Marley

Program Area: Terrestrial Transport

KEYWORDS: COLLOIDS, FULVC ACIDS, HUMIC ACIDS, WATER QUALITY

53

Dutton, Todd H. 1994. The Effects of Temperature, Atmospheric $\mathrm{CO}_{2}$ Concentrations and Arbuscular Mycorrhizal Populations from Two Disparate Biomes on Growth and Biomass Accumulation of 'Eureka' Lemon (Cirnus limon (Hort.)). M.S. Thesis, Arizona State University, 38 pages.

Growth and biomass accumulation of rooted Citrus limon Hort. 'Eureka" cuttings, after inoculation with either arbuscular mycorrhizal fungal populations originating from a plains grassland or Sonoran desertscrub biome, were measured after 3 monihs of growth in factorial combinations of near-optimal (29.4 C day max/21.1 C night min.) or supraoptimal (40.5 C 
day max. $32.2 \mathrm{C}$ night min.) diurnal temperature cycles and ambient (350-380 $\left.\mu \mathrm{mol} \mathrm{mol}{ }^{-1}\right)$ or enriched $(650$ $\mu \mathrm{mol} \mathrm{mol}{ }^{-1}$ ) atmospheric $\mathrm{CO}_{2}$ concentrations. Shoot growth and root to shoot ratio were affected by an interaction of temperature and $\mathrm{CO}_{2}$ treatments. Supraoptimal temperatures suppressed shoot extension growth and leaf accumulation; however, this heatinduced growth suppression was alleviated by a near doubling of atmospheric $\mathrm{CO}_{2}$. At near-optimal temperatures, shoot growth of $\mathrm{CO}_{2}$-enriched trees and those grown under ambient $\mathrm{CO}_{2}$ condition was similar. At near-optimal temperatures, root to shoot ratio was less for $\mathrm{CO}_{2}$-enrichment trees compared with trees grown at ambient $\mathrm{CO}_{2}$. Conversely, root to shoot ratio at supraoptimal temperatures of $\mathrm{CO}_{2}$-enriched and trees grown under ambient $\mathrm{CO}_{2}$ conditions was similar. Temperature was the sole factor affecting mycorrhizal colonization of 'Eureka' lemon tree roots. Supraoptimal temperatures decreased total root colonization but increased arbuscular colonization relative to nearoptimal temperatures. Shoot and root growth were also affected by an interaction of temperature and different ecotype populations of arbuscular mycorrhizal fungi. At near-optimal temperatures, lemon tree leaf area to root length ratio was not affected by mycorrhizal treatments, but at supraoptimal temperatures, there was a $37 \%$ greater leaf area to root length ratio in trees inoculated with the plains grassland population of AM fungi compared with those trees inoculated with the Sonoran desertscrub population of AM fungi. These data suggest that benefits of the mycorrhizal symbiosis may not necessarily be based on growth enhancement of the host plant.

\author{
Major Professor(s): Martin, Chris \\ Department: Botany \\ Principal Investigator(s): Acock, Basil, Leon H. Allen, \\ Jr., and Bruce. A. Kimball \\ Program Area: Carbon, Climate, and Vegetation
} KEYWORDS: CARBON DIOXIDE, CLIMATE,
FUNGI, GROWTH AND DEVELOPMENT, LEAVES,
ROOTS, TEMPERATURE, VEGETATION

\section{4}

Batman, Joe Fredrick 1986. The Effects of Elevated Levels of $\mathrm{CO}_{2}$ on the Conversion of Cellulose for Biomass Fuel Production. M.S. Thesis, Tuskegee University, 61 pages.

The burning of fossil fuel is a main contribution of $\mathrm{CO}_{2}$ to the atmosphere. The release of fossil carbon as $\mathrm{CO}_{2}$ has been increasing at an exponential rate since the beginning of the industrial revolution about 100 years ago. As a resuit the concentration of $\mathrm{CO}_{2}$ in the atmosphere, which thus far has grown only about $12 \%$, may double in the next 60 years. Sweet potatoes (Ipomoea batatas L.) were selected as experimental plants because they represent a major agricultural crop in the southern United States. In ardition, sweet potato is one of the world's major food crops. The stems and leaves of sweet potatoes are an attractive source of alcohol fuels because at the present time they do not have much agricultural value and are considered a waste a potato harvest. With this thought in mind, the major objective of this study was to evaluate the effect of elevated levels of $\mathrm{CO}_{2}$ on the conversion of cellulosic biomass into fermentable sugars from sweet potato leaves and stems. The results of this investigation indicates that increase in $\mathrm{CO}_{2}$ concentration in the atmosphere would increase the cellulosic biomass of sweet potato. This increase in cellulosic biomass resulted in increased conversion of cellulose into fermentable sugars for the formation of ethanol. The conversion of cellulose was higher in stems than in leaves possibly due to higher cellulose content in stems than leaves. Pretreatment of stems or leaves did not increase the extent the hydrolysis, as untreated and sieved biomass of sweet biomass were highly susceptible to cellulolysis.

Major Professor(s): Biswas, P.K.

Department: Agricultural Sciences

Principal Investigator(s): Biswas, P.K.

Program Area: Carbon, Climate, and Vegetation

\section{KEYWORDS: BIOMASS, CARBOHYDRATES, CARBON DIOXIDE, CELLULOSE, FERTILIZATION, FUEL, VEGETATION}

\section{5}

Eischeid, Jon K 1986. Precipitation Variations over Northern Hemisphere Land Areas and Major WheatProducing Regions: 1851-1980. M.S. Thesis, University of Massachusetts, 195 pages.

A statistical analysis of seasonal precipitation from reporting stations over Northern Hemisphere land areas and five major wheat-producing regions covering the interval $1851-1980$ is performed. The regions defined were as follows: Soviet West, Soviet East, Upper USA, Lower USA, and China. Monthly precipitation totals are initially converted to probabilities of the gamma distribution after which these values are interpolated to an equidistant grid with an exponential weighting function. Regional monthly probabilities were then culled from the gridded set and averaged over the appropriate months to arrive at seasonal values. The seasonal probabilities were then subjected to several tests in order to describe temporal variability: trend 
tests utilizing the method of least squares; persistence tests using the simple autocorrelation function; and tests for the detection of periodicities using the power spectrum method of Jenkins and Watts (1968). In addition, a gaussian low-pass filter was applied to each series as well as identifying extreme wet and dry seasons over the course of each record. The secular variability of seasonal precipitation is discussed for each region with reference to the prevailing mode of atmospheric circulation. Interregional comparisons, on a seasonal and annual basis, were also accomplished. Persistence from one season to the next could be defined only in the Soviet West region and only in the annual and winter series. The predominant spectral peak was in the 2-5 year range. A periodicity in the 10-13 year range, in the summer series, was noted in every region, including the Northern Hemisphere, except China. Over the Northern Hemisphere continental areas, taken as an aggregate, precipitation probabilities are seen to be rising since the late 1920 's-early 1930 's in every season. Persistence for the standard seasons was essentially nonexistent, but, the annual spectrum noted positive autocorrelations from lags one to five being significant at lag five. Periodicities, as with the regional series, were in the 2-5 year range, in addition to a near 13 year cycle in the summer spectrum.

Major Professor(s): Bradley, Raymond S. Department: Geology and Geography Principal Investigator(s): Bradley, Raymond S. Program Area: Carbon, Climate, and Vegetation

\section{KEYWORDS: ASIA, EUROPE, NORTH AMERICA, NORTHERN HEMISPHERE, PRECIPITATION, REGIONAL ANALYSIS, SOVIET UNION, TEMPORAL DISTRIBUTION, VEGETATION}

\section{6}

Bntwistle, Clarence Bruce. 1992. Analysis of the Nature of Zero Feedback in the Climate System Using a Multilayer Radiative-Convective Model. M.S. Thesis, University of Illinois at Urbana-Champaign, 201 pages.

The radiative-transfer-model (RT) feedback analysis method [Manabe and Wetherald (1980), Wetherald and Manabe (1980, 1988)] described by Schlesinger (1989) can provide an economical means of ranking the feedback processes in general circulation models (GCMs). To test the accuracy of this method a radiative-convective model ( $\mathrm{RCM}$ ), which can provide a true measure of feedback, is used. However, results of the RT method using a two-layer RCM developed from the radiative transfer parameterization of the Oregon State University two-layer GCM raise fundamental questions concerning the definition and nature of zero feedback. To answer these questions a multi-layer RCM was developed based upon the radiative transfer parameterization of the University of Illinois multi-layer GCM (Oh, 1989). Introduction of forward time marching to the multi-layer radiative transfer code revealed the need for modification. Accordingly, the radiative transfer code was modified and evaluated in comparison with 37 other such models that participated in the Intercomparison of Radiation Codes in Climate Models (ICRCCM) study. To answer the fundamental questions on the nature of zero feedback in the climate system, the MLRCM was run for two perturbation experiments, a one percent increase in the solar constant and a doubling of the $\mathrm{CO}_{2}$ concentration. Results from these experiments show that the nonvertically resolving, zero-dimensional planetary energy balance model prediction of the zero-feedback surface temperature change due to a change in external forcing gives the correct answer for a vertically resolving, onedimensional model, provided that the change in planetary emissivity as the climate system responds to that forcing is included. Also, it is concluded that the zero-feedback climate system includes the processes of radiative transfer, surface convection and temperatureindependent convective adjustment in the free atmosphere. Temperature-dependent convective adjustment is not included, as it creates a feedback. Additionally, it is found that the vertical profile of the zero-feedback temperature change is not uniform with height, and depends upon the perturbation applied to the climate system.

Major Professor(s): Schlesinger, Michael

Department: Atmospheric Sciences

Principal Investigator(s): Schlesinger, Michael

Program Area: Carbon, Climate, and Vegetation

\section{KEYWORDS: ATMOSPHERE, CARBON DIOXIDE, CLIMATE, CONVECTION, MODELS, RADIATIVE PROCESSES}

\section{7}

Everham, Edwin Mctay. 1994. Hurricane Disturbance and Recovery: An Empirical and Simulation Study of Vegetation Dynamics in the Luquillo Experimental Forest, Puerto Rico. PhD. Dissertation, State University of New York at Syracuse, 278 pages.

Hurricanes and other catastrophic wind events impact forests over most of the globe. These disturbances are predicted to increase in frequency and intensity if ocean temperatures rise as the result of global warming. I examined spatial patterns of damage and the factors that influence these patterns, and the resulting dynamics of recovery in a subtropical wet forest following 
hurricane disturbance. I developed an approach to modeling disturbance dynamics in which any point in geographical space can be represented as a position in a multiple gradient space of abiotic factors; and disturbance and recovery are quantified as movements within this gradient space. Spatial pattern analysis indicates a significant clumping of hurricane damage. Canonical correlation analysis is used to compare the relative influence of abiotic factors to biotic factors in determining the severity of damage. Spatial patterns of hurricane damage are most strongly correlated to biotic factors, i.e., species of trees. Recovery is quantified in terms of vegetation community dynamics, rates of biomass accrual, and restructuring of the canopy; and is predicted based on gradients of abiotic factors and severity of hurricane disturbance. A two-dimensional gradient space of damage severity, quantified as structural damage (percent of stems downed) and compositional damage (percent of stems killed), is effective in delineating the two major paths to recovery: regeneration (sprouting of surviving trees) and recruitment (establishment of pioneer species). A threedimensional gradient space, of structural damage and simulated light and soil moisture, allows prediction of rates of biomass accrual. Post-disturbance biomass increases are maximized under high levels of light and moderate levels of soil moisture and damage. The vertical restructuring of vegetation is associated with community dynamics of recovery, as predicted by damage severity, and by light available to the understory, as associated with topographic position. These responses are integrated into a spatially-explicit computer model (RECOVER) which simulates patterns of damage and recovery from a hurricane of a given intensity and track. This model is used to investigate the implications of changing the hurricane disturbance regime.

Major Professor(s): Hall, Charles A.S. Department: College of Environmental Science and Forestry Principal Investigator(s): Wohlpart, A. Program Area: Graduate Fellowships for Giobal Change

KEYWORDS: BIOMASS, DISTURBANCE, FORESTS, MODELS, RECOVERY, STORMS, SUBTROPICS

\section{8}

Fan, Song-mizo. 1991. Atmosphere-Biosphere Exchange of $\mathrm{CH}_{4}, \mathrm{CO}_{2}$, and $\mathrm{O}_{3}$. Ph.D. Dissertation, Harvard University, 223 pages.

The atmosphere-biosphere exchange was measured of $\mathrm{CO}_{2}$ and $\mathrm{O}_{3}$ in a tropical rain forest near Manaus,
Brazil during April and May 1987, and of $\mathrm{CO}_{2}, \mathrm{CH}_{4}$, and $\mathrm{O}_{3}$ in an arctic tundra of southwestern Alaska during July and August 1988. Vertical fluxes were measured directly using the eddy correlation technique in the surface layer; concentrations of the trace gases were also measured sequentially at eight altitudes from near the ground to about 10 meters above canopy. Forest floor respiration was measured using soil enclosures in the tropical forest. Nocturnal respiration averaged $6.2 \pm 0.7$ (s.e.) $\mathrm{gC} / \mathrm{m}^{2} / \mathrm{d}$ by the forest ecosystem ( $-85 \%$ from the forest floor) but $0.73+0.07 \mathrm{gC} / \mathrm{m}^{2} / \mathrm{d}$ by the tundra ecosystem. Net ecosystem exchange (NEE) of $\mathrm{CO}_{2}$ increased almost linearly with intensity of light by $0.036\left(\mathrm{gC} / \mathrm{m}^{2} / \mathrm{d}\right) /\left(\mathrm{W} / \mathrm{m}^{2}\right)$ in the forest, suggesting that canopy photosynthesis of a well-watered forest is primarily controlled by photosynthetically active radiation. Solar irradiance also provided the primary control on the NEE of $\mathrm{CO}_{2}$ in the disparate tundra ecosystem, although the relationship was curvilinear and photosynthesis was quickly light saturated (Pmax $~ 2.5$ $\left.\mathrm{gC} / \mathrm{m}^{2} / \mathrm{d}, \mathrm{I}_{1 / 2}-60 \mathrm{~W} / \mathrm{m}^{2}\right)$. Changes in the distribution of cloud cover, associated for example with climatic change, might induce globally significant changes in primary productivity and carbon storage. Methane emission averaged $25 \pm 1 \mathrm{mgCH}_{4} / \mathrm{m}^{2} / \mathrm{d}$ from the site of tundra ecosystem. Methane fluxes were apportioned to various habitats, using a SPOT satellite image of the site to classify surface vegetation at $20 \times 20 \mathrm{~m}$ resolution. Dry tundra (water level $5 \mathrm{~cm}$ below soil surface) was found to emit $11 \pm 3 \mathrm{mgCH}_{4} / \mathrm{m}^{2} / \mathrm{d}$ and wet tundra (water near the surface) $29 \pm 3 \mathrm{mgCH} / / \mathrm{m}^{2} / \mathrm{d}$. Fluxes from lakes depended on wind speed, averaging $57 \pm 6 \mathrm{mgCH}_{4} / \mathrm{m}^{2} / \mathrm{d}$, where wind speed was $5 \mathrm{~ms}^{-1}$. Results were used to assess errors accrued in scaling up the chamber data to larger scales. Methane emission from global tundra may be estimated with an error of $50 \%$ because the satellite could not fully resolve heterogeneous methane producing habitats. Mean ozone deposition flux was $\sim 1.0 \times 10^{11}$ molecules $\mathrm{cm}^{-2} \mathrm{~s}^{-1}$ in the tropical rain forest and in the arctic tundra, although daytime concentrations of $\mathrm{O}_{3}$ in the surface layer averaged 5 $\mathrm{ppb}$ over the forest and $25 \mathrm{ppb}$ over the tundra. The mean ozone deposition velocity at $\sim 10 \mathrm{~m}$ above canopy of the forest was $0.26 \mathrm{~cm} \mathrm{~s}^{-1}$ in the night and $1.8 \mathrm{~cm} \mathrm{~s}^{-1}$ in the day, regulated by turbulent transport and stomatal activity. The ozone deposition velocity measured at $12 \mathrm{~m}$ above the tundra was found inversely proportional to wind speed, averaging $0.13 \mathrm{~cm} \mathrm{~s}^{-1}$ in the night and $0.25 \mathrm{~cm} \mathrm{~s}^{-1}$ in the day.

Major Professor(s): Wofsy, Steven C. Department: Division of Applied Sciences Principal Investigator(s): Wofsy, Steven C. Program Area: National Institute for Global Environmental Change (NIGEC) 
KEYWORDS: ATMOSPHERE, BIOSPHERE, CARBON CYCLE, CARBON DIOXIDE, DIFFUSION, LAKES, METHANE, NORTH AMERICA, OZONE, PHOTOSYNTHESIS, RESPIRATION, SOUTH AMERICA, TROPICS, TUNDRA, TURBULENCE, WINDS

\section{9}

Fowler, David E 1985. An Internship with the Carbon Dioxide Information Center. M.En Report, Miami University, 34 pages.

To fulfill one of my requirements for the degree of Master of Environmental Science at the Institute of Environmental Sciences (IES), Miami University, Oxford, Ohio, I performed an internship at the Carbon Dioxide Information Center (CDIC) in Oak Ridge, Tennessee. I had two primary projects: producing a newsletter and preparing a computer demonstration of a program management tool called Coordination, Control, and Communication $\left(\mathrm{C}^{3}\right)$ system for the Department of Energy's Carbon Dioxide Research Division (CDRD). The newsletter, CDIC

Communications, is distributed to more than 1900 carbon dioxide $\left(\mathrm{CO}_{2}\right)$ researchers and policy makers in 47 countries to inform them of major $\mathrm{CO}_{2}$ issues and events. My responsibilities included all aspects of producing CDIC Communications: writing a production schedule, writing or editing the articles, doing the layout, and ensuring that the newsletter was mailed by its deadline. Before I could prepare a demonstration for $\mathrm{C}^{3}$, I had to learn about each of the components in the system. Then, I wrote drafts of the demonstration, which were discussed with the CDRD program managers. The final draft will be programmed on an IBM personal computer using the IBM "PC Storyboard" software package. Overall, I believe that I had a successful internship. I attribute much of the success to the skills that I developed and practiced in some of the IES core courses such as statistics and Environmental Methodology and the Public Information courses such as technical writing and independent studies in news writing and newsletter analysis.

Major Professor(s): Morgan, Hugh Department: Institute of Environmental Sciences Principal Investigator(s): Farrell, Michael P. Program Area: Information

KEYWORDS: NEWS MEDLA, PROGRAM MANAGEMENT
60

Franson, Raymond L. 1989. Mechanisms of Belowground Interactions among Plantago lanceolata, Phleum pratense and Glomus monosponum. Ph.D. Dissertation, University of Chicago, 108 pages.

A study of belowground interactions between two oldfield herbs was conducted to determine which of the many possible mechanisms of interactions between plants occur and what is the relative importance and interrelationship of those that do occur? Although mechanisms of plant interactions cannot be directly observed, the mechanisms by which plants are allowed to interact can be manipulated and then the net result can be quantified. The experimental design is a complete factorial composed of two plant species (Plantago lanceolata, Phleum pratense), two levels of fungal inoculation (addition of Glomus monosponum, without addition of $G$. monosporum), four levels of belowground barrier between plants (no barrier, 20 micron mesh, 1 micron mesh, solid barrier), and three potential partners (Plantago, Phleum, no neighbor), and four replicates. We found Glomus partiaily alleviates the depressive effects of increasing density in Plantago in monoculture. Phleum shows no response to Glomus colonization. Without Glomus, Plantago achieves a larger gain in biomass while Phleum is suppressed only minimally. When Glomus is added the net result of Plantago-Phleum interactions changes from competitive to commensal. Plantago achieves a higher growth rate while growing with Phleum than it can when grown alone while Phleum achieves nearly the same biomass whether growing alone, in monoculture or with Plantago. This suggests that Phleum acts as a "root promoter" causing an increase in root mass, root length and specific root length of any plant growing with it. The use of meshes allows determination that all mechanisms of interaction in the experiment involved chemicals or microbes of less than 1 micron in diameter.

Major Professor(s): Miller, R. Michael Department: Committee on Evolutionary Biology Principal Investigator(s): Miller, R. Michael Program Area: Ecosystems Function and Response

KEYWORDS: COMPETITION, FUNGI, ROOTS

61

Freer, Michael E. 1994. Temporal and Spatial Variations of Methane Emissions from the Sabine River Floodplain of Southeast Texas; The Role of Dissolved Organic Carbon (DOC) and Other Physicochemical Parameters. M.S. Thesis, Lamar University, 65 pages. 
The Sabine River floodplain is a flat broad watershed containing a diverse assemblage of blackwater wetland habitats. Concentrations of dissolved organic carbon (DOC) in the floodplain as well as the estuary are typically very high $(15-20 \mathrm{mg} /)$. In this study we compared methane fluxes across a gradient of three different habitats, within the floodplain, that extended from the outer reaches of the basin to the river proper (i.e., blackgum Nyssa aquatica, cypress Taxodium distichum, and arrowhead Sagittaria spp.), as well as a fourth station (a Spartina marsh) within the SabineNeches estuary. Methane emissions were highly variable and range from -0.0007 to $1640 \mathrm{mg} \mathrm{m}^{-2} \mathrm{~d}^{-1}$, with the highest rates in July 1993 . Fluxes were significantly correlated (both positively and negatively) with precipitation ( $p<0.01$ ); natural periods of flooding and drought were primarily responsible for the wide range of emissions. Methane consumption rates had little effect on total emissions due to ebullition and plant mediated transport mechanisms. Laboratory incubation experiments indicated that UV-B treated humic substances were preferentially utilized by methanogens over untreated humics. Thus, variability of light penetrance across the floodplain may affect the quality of DOC.

Major Professor(s): Bianchi, Thomas S. Department: Biology

Principal Investigator(s): Bianchi, Thomas S. Program Area: National Institute for Global Environmental Change (NIGEC)

KEYWORDS: EMISSIONS, HUMIC ACIDS, METHANE, NORTH AMERICA, ORGANICS, PRECIPITATION, WATER STRESS, WETLANDS

62

Frolling, Stephen E. 1993. Modeling Soil Climate Controls on the Exchange of Trace Gases Between the Terrestrial Biosphere and the Atmosphere. $P h . D$. Dissertation, University of New Hampshire, 231 pages.

Soil temperature and moisture profiles (soil climate) have a strong influence on the rate of trace gas exchange between the terrestrial biosphere and the atmosphere through the controls exerted on microbial processes and the physical exchange of gases. Principal controls of biological denitrification in mineral soils are the availability of carbon and nitrogen substrates and the soil anaerobic status. A process-oriented model of decomposition and denitrification in soils (DNDC) was modified to have a more detailed portrayal of these controls. In particular, a diffusive soil gas phase was added, along with a method for determining anaerobic and aerobic fractional volume within a soil profile. The model generally overestimated $\mathrm{N}_{2} \mathrm{O}$ fluxes when compared to field data from a sandy soil in Costa Rica, but captured the timing and shape of the brief flux episodes. Several modeling shortcomings are discussed, including the nature of the carbon substrates and the nature and dynamics of soil anaerobic fractional volume. Methane flux from wetland soils is generally correlated with soil temperature and depth to water table. A model of peat soil climate was developed and applied to a small poor fen in southern New Hampshire. Temperature profiles and ice depth are in good agreement with field data, but depth to water table is more problematic. Field-based flux correlations to soil temperature, depth to water table, and weighted recent precipitation were developed. When used with the wetland soil climate model, much of the seasonal and shorter period flux variability was captured. The model was then driven by local weather data for 1926 1986; flux variability was dependent on both summer season temperatures and summer precipitation patterns. It is estimated that a five-year field study would capture most of the inter-annual variability. Sensitivity of northern peatland methane flux to climate variability was studied by combining data on flux rates, inundation areas. and summer temperature anomalies (1900-1986) for the eight major northern peatland regions. Spatial and temporal variability in summer temperature anomalies caused regional methane flux anomalies to be small, and not likely to provide a strong feedback to initial climate change.

Major Professor(s): Harris, Robert C.

Department: Earth Sciences

Principal Investigator(s): Moore, Berrien

Program Area: Carbon, Climate, and Vegetation

KEYWORDS: ATMOSPHERE, BIOSPHERE, CLIMATE, DECOMPOSITION, DIFFUSION, EMISSIONS, GASES, ICE, METHANE, MODELS, NITROGEN CYCLE, NITROGEN SPECIES, PRECIPITATION, SOILS, SPATLAL DISTRIBUTION, TEMPERATURE, TEMPORAL DISTRIBUTION, WATER, WETLANDS

63

Fukui, Yoshika 1994. Measurements of Biogenic NonMethane Organic Compound Emissions from Grasslands. Ph. D. Dissertation, University of Illinois at Chicago, 201 pages.

Non-methane organic compounds (NMOCs) play an important role in the formation of photochemical oxidants in the troposphere. NMOCs originate from both anthropogenic and biogenic sources. Many organic compounds of biogenic origins are more reactive than 
those of anthropogenic origin because of the presence of internal double bonds within their molecular structure. The objective of this investigation was to examine the seasonal variation of NMOC emissions from grasslands and determine the environmental factors that control the emissions. An enclosure system was chosen as the most appropriate sampling technique for measuring emissions from herbaceous vegetation, and an analysis method using cryogenic preconcentration/high resolution gas chromatography was established. Emission rates were measured at a fixed location in a natural grassland during 1992 and 1993. Measurements were also made at various locations within the same site where the vegetation was harvested after the emission rates were determined. Emission rates of NMOCs for grasslands are not as large as those reported for forests. However the emissions of oxygenated hydrocarbons exceeded the emissions of monoterpenes and have not previously been identified as important forest-type emissions. A framework for parameterizing the NMOC emissions from grasslands based on seasonal and instantaneous variations of the emission rate measurements was developed. Temperature, hypoxia induced by water saturated soil, and frost were key environmental factors affecting both the composition and magnitude of NMOC emissions.

Major Professor(s): Gose, Earl E.

Department: Electrical Engineering and Computer Science

Principal Investigator(s): Wesely, Marvin L.

Program Area: Atmospheric Sciences

\section{KEYWORDS: EMISSIONS, GRASSLANDS,} ORGANICS

64

Gafin, Stuart Roger. 1986. Variable Seafloor Spreading Rates and Global Sea-Level: Introducing a Ridge Volume Inversion Technique. Ph.D. Dissertation, New York University, 122 pages.

The basic quantitative distinction between global cceanic ridge volume and the global rate of seafloor generation is made fully explicit. From this, the question of inversion over time from the former quantity into the latter is then posed using a generalized expression to approximate the global subduction zone distribution. Two numerical methods are described. Then, assuming the bypothesis that long term $\left(10^{8} \mathrm{yr}\right)$ eustatic sea level change is due primarily to changing ridge volume, an inversion of a widely cited Phanerozoic sea level curve (Vail) is also presented. The approach taken here is expected to be of direct importance for quantitative models of the carbonate-silicate cycle which seek to develop scenarios for atmospheric carbon dioxide variations over geologic time scales. Indeed, the testing of sea level inversion, as performed here, may ultimately come from the degree of correspondence with past climate variation.

Major Professor(s): Hoffert, Martin I.

Department: Applied Science

Principal Investigator(s): Hoffert, Martin I.

Program Area: Carbon, Climate, and Vegetation

KEYWORDS: CARBON CYCLE, CLIMATE, SEA FLOOR, SEA LEVEL

65

Gale, William J. 1988. Canopy Net Carbon Dioxide Exchange by Burned and Unburned Tallgrass Prairie. M.S. Thesis, Kansas State University, 79 pages.

Net carbon exchange (NCE) was measured on a burned and unburned tallgrass prairie canopy during a four month period in 1987. NCE rates were higher on the burned treatment $\left(0.66 \mathrm{mg} \mathrm{CO} \mathrm{m}^{-2} \mathrm{sec}^{-1}\right)$ compared to the unburned treatment $\left(0.47 \mathrm{mg} \mathrm{CO} \mathrm{m}^{-2} \mathrm{sec}^{-1}\right)$ on 11 July. On 20 July NCE rates were higher in the unburned treatment $0.64 \mathrm{mg} \mathrm{CO} \mathrm{m}^{-2} \mathrm{sec}^{-1}$ ) than the burned treatment $\left(0.38 \mathrm{mg} \mathrm{CO} \mathrm{m}^{-2} \mathrm{sec}^{-1}\right)$. Maximum NCE rates on 15 August were $0.37 \mathrm{mg} \mathrm{CO} \mathrm{m}^{-2} \mathrm{sec}^{-1}$ and $0.47 \mathrm{mg} \mathrm{CO} \mathrm{m}^{-2} \mathrm{sec}^{-1}$ in the burned and unburned treatments, respectively, but not significant differences existed between treatments. Plants were not light saturated at $1900 \mu \mathrm{E} \mathrm{m} \mathrm{mec}^{-2}$ on 15 August. Canopy NCE rates were generally lower than rates measured on individual leaves of Andropogon gerardii (big bluestem). No consistent differences in soil water content or leaf water potential were measured between burned and unburned treatments. The highest measured midday leaf water potential was $-1.56 \mathrm{MPa}$ in the unburned treatment on $14 \mathrm{July}$, but had declined to $<-4.0 \mathrm{MPa}$ in both treatments by 21 July. Soil $\mathrm{CO}_{2}$ flux decreased as soil water content declined, reaching a low of $0.06 \mathrm{mg}$ $\mathrm{CO}_{2} \mathrm{~m}^{-2} \mathrm{sec}^{-1}$, but increasing under ligher soil water content to $0.16 \mathrm{mg} \mathrm{CO}_{2} \mathrm{~m}^{-2} \mathrm{sec}^{-1}$. Soil $\mathrm{CO}_{2}$ flux was 7 to $28 \%$ of the net photosynthetic flux. Differences in photosynthetic rate can probably be attributed to differences in incident solar radiation as well as morphological differences between plants emerging in sun (burned) or shade (unburned) environments.

Major Professor(s): Kirkham, M.B. Department: Agronomy (Evapotranspiration Laboratory)

Principal Investigator(s): Kirkham, M.B. Program Area: Carbon, Climate, and Vegetation 
KEYWORDS: CARBON CYCLE, CARBON DIOXIDE, PRAIRIES, PRODUCTIVTY, SOILS, VEGETATION, WATER

\section{6}

Chan, Steven John. 1988. Unstable RadiativeDynamical Interactions. D.Sci Thesis, Massachusetts Institute of Technology, 180 pages.

The interaction between trace shortwave radiative absorbers and the dynamical circulation is shown to be linearly unstable for horizontally uniform basic states with a vertical gradient in the basic state absorber mixing ratio. Two types of instability are identified, described as the advective mode and the propagating mode. The advective mode is usually unstable when the basic state absorber mixing ratio decreases with height. Upward motion, high absorber concentration and warm temperatures are typically in phase for this mode. Growth rates, which can be competitive with those associated with baroclinic instability, are largest for perturbations that are much shorter than the internal deformation radius. Thus, the requirement that the basic state be horizontally uniform is often satisfied for the advective mode. The propagating mode is normally unstable when the basic state absorber mixing ratio increases with altitude. Propagating waves such as Rossby and inertia-gravity waves are amplified by the feedback with absorber transport and radiative heating. Growth rates for the propagating mode are usually bounded by the frequency of oscillation of the ambient wave, an important limitation for slowly propagating waves such as Rossby waves. Vertical transport of the absorber by the amplifying mode is down the basic state absorber gradient in each case. Complicating factors such as the effects of dissipative processes, vertical shear, and scattering of sunlight are also considered. The competition between vertical transport of absorber due to the modal instability mechanism described above and that due to initial horizontal patchiness of an absorber injection is also examined. For patches with horizontal scales much larger than the deformation radius the modal form of absorber transport is shown to be important, while for smaller patch scales the nonmodal form dominates.

Major Professor(s): Stone, Peter H. Department: Earth, Atmospheric and Planetary Sciences Principal Investigator(s): MacCracken, Michael C. Program Area: Carbon, Climate, and Vegetation

KEYWORDS: ATMOSPHERE, CIRCULATION, RADLATIVE PROCESSES, TRANSPORT, WAVES
67

Glectler, Peter John. 1993. The Partitioning of Meridional Energy Transport Between the Ocean and the Atmosphere. Ph.D. Dissertation, University of California at Davis, 160 pages.

The partitioning of meridional energy transport between the ocean and the atmosphere is a fundamental feature of the climate system, and unfortunately one that remains poorly understood. Observationally-based estimates of atmospheric and oceanic meridional energy transport (respectively, AMET and OMET) resulting from various methods have been intercompared. Energy fluxes at the top of the atmosphere and at the ocean surface have also been studied because they are required by several methods used to estimate meridional energy transport. The resulting intercomparison has demonstrated that estimates of oceanic and atmospheric energy transport are inconsistent with one another. The uncertainties associated with OMET estimates made with several methods have been established, but uncertainties in AMET estimates appear too complex to accurately quantify. Much of this study has focused on ocean surface energy fluxes because annual mean estimates of AMET and OMET could be inferred if they were accurately known. Two methods have been established to improve our understanding of OMET (and thus indirectly AMET). Both involve combining the same independent data and their associated uncertainties. All evidence suggests that the most commonly cited estimates of Northern Hemisphere AMET based on radiosonde data are systematically too low. Lesser known estimates which make use of dynamical constraints are much more consistent with the various independent estimates of OMET. At most latitudes in the Southern Hemisphere, it is not even clear whether the global ocean OMET is northward or southward. Meridional energy transport has also been examined in three atmospheric GCM simulations. There are considerable differences among the various models, particularly in the Southern Hemisphere OMET. It has been demonstrated that the implied transports in the models are strongly linked to the simulated cloud radiative forcing. The results of this study suggest that the most practical way to significantly improve our understanding AMET and OMET is with a small number of strategically placed high quality hydrographic transects. It has been recommended that the utility of the methods developed in this research which combine independent observationally-based data and their estimated uncertainties be considered in the planning of future global climate research programs.

Major Professor(s): Weare, Bryan C. Department: Land, Air \& Water Resources 
Principal Investigator(s): Gates, W. Lawrence Program Area: Carbon, Climate, and Vegetation

\section{KEYWORDS: ATMOSPHERE, ENERGY TRANSPORT, OCEANS}

\section{8}

Gluberynsti, A 1983. The Effects of Land Use on Soil Organic Carbon in Subtropical Forest Life Zones in Puerto Rico. M.S. Thesis, University of Illinois at Urbana-Champaign, 81 pages.

Soil samples from forested and agriculture sites in three subtropical forest life zones were analyzed for soil organic carbon in an effort to determine the effects of land use and life zone on soil carbon content. In general, soil carbon was highest in the mature forest sites (70.6-125.6 t/ha, $0-50 \mathrm{~cm}$ deep), particularly those in wet forest life zones. Agricultural sites had lower soil carbon contents than those in the mature forests. The magnitude of the differences between the cultivated sites and the mature forests varied by life zone, and ranged from $50 \%$ in the wet forest life zone to $75 \%$ in the dry ones. Pasture sites had levels of soil carbon comparable to those of the mature forests (71.0-111.7 t/ha, $0-50 \mathrm{~cm}$ deep). The soil carbon content of secondary forests was progressively higher in progressively older stands. By approximately $30-40 \mathrm{yr}$, the soil carbon content of secondary forests was similar to that of mature forests in both wet and dry life zones. Conversion of forests to permanent cultivation results in a net release of carbon to the atmosphere. However, the increase in soil carbon in pasture and through forest succession may off-set this loss to an extent, but ultimately more carbon will be lost of the atmosphere than is being stored by the soil in the tropics due to deforestation.

Major Professor(s): Brown, Sandra

Department: Forestry

Principal Investigator(s): Brown, Sandra

Program Area: Carbon, Climate, and Vegetation

KEYWORDS: AGRICULTURE, CARBON CYCLE, FORESTS, ISLANDS, LAND USE, NORTH AMERICA, ORGANICS, PASTURES, PUERTO RICO, SOILS, SUBTROPICS

69

Goldstein, Allen Hyman. 1994. Non-Methane Hydrocarbons Above a Midlatitude Forest: Biogenic Emissions and Seasonal Concentration Variations. PhD. Dissertation, Harvard University, 133 pages.
This dissertation presents observations of 1) nonmethane hydrocarbon emissions from a northern midlatitude forest, and 2) C2-C6 hydrocarbon concentrations over an annual cycle. The observations are analyzed to determine the dependence of biogenic olefin fluxes on temperature, light, and season and to obtain a measure of the annual mean and seasonal variation of $\mathrm{OH}$ concentration in the Northern Hemisphere. An automated system measuring hydrocarbon concentrations and vertical gradients was constructed. Measurements were obtained continuously from July 1992 to November 1993 at Harvard Forest, Petersham, Massachusetts. The longest gap in the data was eight days. Mean emission rates for isoprene, ethene, propene and 1-butene were 11.8, 2.63, 0.97, and $0.37 \times 10^{10} \mathrm{molec} / \mathrm{cm}^{2} / \mathrm{s}$ respectively, in summer 1993, derived using a micrometeorological gradient technique. Isoprene emission began several weeks after canopy photosynthesis, and decreased rapidly at leaf senescence. Emissions of ethene, propene and 1-butene had a longer seasonal cycle than isoprene. Fluxes of ethene increased relative to the other olefins during leaf senescence. Emissions of ethene, propene and 1-butene were correlated with incident sunlight, while isoprene rose in the morning with temperature and declined in the afternoon with light. These emission patterns indicate above-ground biomass sources for all species. The observations challenge the assumption that propene and 1-butene global inventories are dominated by oceans, biomass burning and fossil fuel combustion, suggesting instead they are dominated by the terrestrial biosphere. Seasonal variations of background concentrations for $\mathrm{C} 2-\mathrm{C} 6$ alkanes, and acetylene, were defined by the 0.1 quantile in $\mathbf{3 0}$ day periods. Maxima occurred in winter and minima in summer. Species that react fastest with $\mathrm{OH}$ reached their winter peak earliest, and declined earliest in the spring. The ratios of winter to summer concentration were observed to be uniform for the shortest lived hydrocarbons. We argue that the uniform ratios reflect seasonal steady-state conditions, and provide a direct measure of the mean ratio of $\mathrm{OH}$ concentrations in summer to winter at northern midlatitudes, $10 \pm 2$. Simulations of ethane data using a three-dimensional chemical tracer model and a box model constrain $\mathrm{OH}$ at northern midlatitudes to a mass weighted annual mean of $7 \times 10^{5}$ molec $/ \mathrm{cm}^{3} \pm 50 \%$.

Major Professor(s): Wofsy, Steven C. Department: Chemistry

Principal Investigator(s): Wohlpart, A, and Steven C. Wofsy

Program Area: Graduate Fellowships for Global Change; National Institute for Global Environmental Change (NIGEC) 
KEYWORDS: EMISSIONS, FORESTS, HYDROCARBONS, MIDLATITUDES, NORTHERN HEMISPHERE, ORGANICS, TEMPORAL DISTRIBUTION

\section{0}

Gomes de Azevedo, Antonio Expedito. 1981. Atmospheric Distribution of Carbon Dioxide and Its Exchange with the Biosphere and the Oceans. PhD. Dissertation, Columbia University, 144 pages.

The global carbon cycle is analyzed from the point of view of the distribution and exchange between the reservoirs of atmosphere, biosphere, and oceans. The partition of excess $\mathrm{CO}_{2}$ between the atmosphere and the oceans, introduced in the atmosphere as a perturbation over a previous steady state reached by the atmosphere-ocean system, is examined with a boxdiffusion model. This model considers vertical diffusion below the mixed layer and also isopycnal diffusion from the cold parts of the ocean surface as the mechanisms that control the removal of the perturbation from the mixed layer into the deep sea. The calibration of the ocean model is made by inspecting the predicted distribution of natural carbon-14 and bomb carbon-14 and Tritium. As a global average the model reproduces the basic patterns of the distribution of these tracers. For a perturbation source that grows exponentially at the same rate as the industrial releases of $\mathrm{CO}_{2}$ in the last few decades it is calculated that a little over $50 \%$ of the excess $\mathrm{CO}_{2}$ would remain in the atmosphere. This result suggests that no significant net source or sink, besides the industrial perturbation and ocean up-take, are involved in the evolution of the $\mathrm{CO}_{2}$ atmospheric concentration for the last few decades. The atmospheric distribution is investigated using a box model for latitudinal belts of 10 degrees. The mixing inside the atmosphere is parameterized by a constant meridional eddy diffusivity with a restriction in the exchange across the ITCZ. The ITCZ is assumed to move with the seasons between $10^{\circ} \mathrm{N}$ and $10^{\circ} \mathrm{S}$. The atmospheric model is calibrated by the consideration of the distribution of some halocarbons, excess carbon-14 from the nuclear tests and strong gradients in the $\mathrm{CO}_{2}$ concentration across the ITCZ. The considered values for the meridional eddy diffusivity is $3 \pm 1 \times 10^{10} \mathrm{~cm}^{2} / \mathrm{sec}$ and the exchange across the ITCZ is decreased by a Restriction Factor of 0.1. The exchange with the oceans is taken as proportional to the difference in partial pressure of $\mathrm{CO}_{2}$ in the atmosphere and in the surface of the ocean. The distribution of the ocean surface $\mathrm{pCO}_{2}$ is based on GEOSECS data. The exchange with the biosphere is divided into two components, the seasonal variations in the balance between the uptake and release of carbon and local secular variations in the biomass. The seasonal component is modeled as proportional to the net primary productivity in each latitudinal belt coupled with a scheme that describes the variations in the uptake and release of carbon. The basic structure of the latitudinal variation in the amplitude of the seasonal oscillation is approximately reproduced. The local secular variations in the land biomass is treated as a residual component in the atmospheric model. To reproduce the trends in the observed evolution of concentration for the last two decades a scenario is proposed that involves a recovery in the biomass in northern temperate zone and a decrease in equatorial and southern latitudes. The proposed scenario assumes an overall balance between the northern sink and southern source, both with a magnitude of about $1 \times 10^{15} \mathrm{gC} / \mathrm{y}$.

Major Professor(s): Takahashi, Taro

Department: Geochemistry

Principal Investigator(s): Takahashi, Taro

Program Area: Carbon, Climate, and Vegetation

KEYWORDS: ATMOSPHERE, BIOMASS, BIOSPHERE, CARBON CYCLE, CARBON DIOXIDE, CARBON ISOTOPES, DIFFUSION, EMISSIONS, INTERTROPICAL CONVERGENCE ZONE (ITCZ), MODELS, OCEANS, TERRESTRLAL ENVIRONMENT, TRACERS

71

Gould, Timothy R. 1993. Pollutant Concentrations and Deposition Rates: Interpretation of Dry Deposition Mechanisms at an Urban Tall Building. M.S. Thesis, Carnegie Mellon University, 67 pages.

Dry deposition is an important mechanism for the transfer of air pollutants to the surface of the earth. The delivery of acidic compounds is of special interest for their potential to cause damage to natural vegetation and human-made structures following deposition. In this thesis, deposition mechanisms are investigated by analysis of uncertainty in models of deposition to vegetation, and through a program of field measurements in an urban setting. The overall goal of the field experiments is to improve the understanding of dry deposition to structures. Dry deposition is viewed as a process that overcomes three series resistances to mass transfer: aerodynamic, boundary layer, and surface resistance. Field measurements at different heights of the Cathedral of Learning in Pittsburgh are designed to quantify the atmospheric, pollutant, and surface properties that affect these resistances. Aerosol concentrations and fluxes are measured to calculate deposition velocities for acidic species and elemental carbon. Meteorological 
variables are monitored using data acquisition systems to characterize their influence on the concentrations and depasition fluxes. Airborne concentration results vary considerably over time and exhibit a weak vertical gradient. A limited number of deposition experiments produced large variations in measured deposition velocity. Vertical deposition results exhibit even greater variability than horizontal measurements. The deposition velocity of elemental carbon, a potential indicator for vehicle emissions, was found to be greater than that of sulfate or nitrate. Analysis of uncertainty propagation in a deposition model for vegetation joentifies the inputs that are most critical for predicting deposition velocity. Natural variability in wind speed was found to contribute most to uncertainty in the predicted output. Vegetation collector size is important in assessing uncertainty for $1 \mu \mathrm{m}$ to $10 \mu \mathrm{m}$ diameter particles. A framework is presented for developing a model of dry deposition to building material surfaces that builds upon the series resistance concept. Developing a model with capabilities similar to the vegetation deposition model requires better resolution of surface moisture data, and improved characterization of air flow patterns around the building. Separating measured data according to whether the surface resistance is effectively zero is one strategy for isolating the surface resistance for separate consideration. Uncertainty in predictions of depasition models should be recognized as originating from either (1) "natural" variability or (2) measurement error and/or inadequacies in our knowledge of governing processes.

Major Professor(s): Davidson, Cliff

Department: Engineering \& Public Policy/Civil Engineering

Principal Investigator(s): Wohlpart, A.

Program Area: Graduate Fellowships for Global Change

KEYWORDS: AEROSOLS, DEPOSITION, MODELS, URBAN ENVIRONMENT, WINDS

\section{$\boldsymbol{n}$}

Griffin, Kevin Lee. 1994. Effects of Resource Availability on Carbon Utilization in Pinus taeda L. and Pinus ponderosa Dougl. ex Laws. Seedlings. Ph.D. Dissertation, Duke University, 169 pages.

The growth and development of tree seedlings is often regulated by the availability of resources such as atmospheric $\mathrm{CO}_{2}$ and soil nitrogen. Our ability to predict the effects of resource availability on plant growth is limited by our poor understanding of the control of carbon flow during plant growth and development. Traditionally, biomass has been used to describe carbon and energy allocation; yet, the reduction state of carbon in this biomass may be more informative. I analyzed data from the primary literature to characterize the range, mean and amount of variation in construction cost; the amount of glucose required to provide carbon skeletons, reductant and ATP for biosynthesis. Resources that are actively taken up (i.e. nitrogen) require the construction and maintenance of expensive biochemical machinery, increasing construction cost. Carbon uptake requires energetically expensive machinery but can lead to the formation of inexpensive carbohydrates, diluting construction cost. I manipulated $\mathrm{CO}_{2}$ and nitrogen resource availability in a phytotron to examine the nature of carbon and nitrogen interactions in loblolly and ponderosa pine seedings. Oxygen bomb calorimetry was used to determine construction cost. The relationships between resource availability and construction cost were mechanistically analyzed by comparing cost with photosynthesis, respiration, leaf carbon-, nitrogen, soluble sugar-, starch-, and total nonstructural carbohydrate-concentration, leaf mass, specific leaf mass, total plant mass and carbon allocation. A sensitivity analysis of the response of construction cost to changes in the biochemical fractionation of pine leaves was performed with a simple model and supported the empirical results. Over a wide range of carbon and nitrogen availabilities small differences were found in leaf construction costs. Elevated $\mathrm{CO}_{2}$ decreased, and elevated $\mathrm{N}$ increased leaf construction cost ( $\mathrm{g}$ glucose $\mathrm{g}^{-1}$ ). Carbon and nitrogen resources were interactive, reflecting whole plant source-sink relationships. $\mathrm{CO}_{2}$ effects on construction cost were correlated with increased nonstructural carbohydrates, and $\mathrm{N}$ effects were correlated with leaf $\mathbf{N}$ (protein). The response of leaf construction cost is consistent with our understanding of basic plant response to resource availability, yet the absolute differences observed were small, suggesting that carbon partitioning and allocation are controlling plant energy dynamics.

Major Professor(s): Strain, Boyd R.

Department: Botany

Principal Investigator(s): Strain, Boyd R.

Program Area: Carbon, Climate, and Vegetation

KEYWORDS: CARBON DIOXIDE, CARBON USE, FERTILIZATION, GROWTH AND DEVELOPMENT, PHOTOSYNTHESIS, RESPIRATION, VEGETATION

73

Grovenstein, John David. 1993. The Role of Cloud Condensation Nuclei in Understanding Climate Change. M.S. Thesis, North Carolina State University, 46 pages. 
It has been suggested that reducing fossil fuel emissions could cause global warming. Observed increases in sulfate derived cloud droplet number concentration indicate a cooling of $2-3 \mathrm{Wm}^{-2}$ in eastern North America. Reduction of $\mathrm{SO}_{2}$ derived from fossil fuels as mandated by the amended Clean Air Act would cancel this cooling. When $\mathrm{SO}_{2}$ is released it will form Cloud Condensation Nuclei (CCN). CCN have been implicated in climate regulation through their role in cloud-mediated albedo. $\mathrm{SO}_{2}$ derived cooling is obtained by a simple diagnostic model based on the relationship between $\mathrm{SO}_{2}$ emissions and cloud reflectivity. Increased $\mathrm{SO}_{2}$ emissions will decrease cloud droplet size. Could droplet size influences cloud albedo. Increased $\mathrm{SO}_{2}$ emissions will increase cloud albedo by decreasing cloud droplet size. Reducing $\mathrm{SO}_{2}$ emissions will have the opposite effect. We use three scenarios to assess the impact of fossil fuel emissions. These scenarios, after scenarios suggested by the Intergovernmental Panel on Climate Change (IPCC), are growth of emissions by $2 \%$ per year, a reduction by $2 \%$ per year, and a "business as usual" scenario of $0 \%$ per year. Model results of these three scenarios are presented. A $2 \%$ per year reduction of fossil fuel emission indicates a $\mathbf{3 0 \%}$ reduction in $\mathrm{SO}_{2}$ derived cooling in the next 50 years. Two percent growth per year for 50 years will cause a $40 \%$ increase in $\mathrm{SO}_{2}$ derived cooling. We will also discuss the sensitivity of regional climate to changes in fossil fuel emissions. There exist three possible mechanisms for the enhancement of cloud condensation nuclei (CCN) in the vicinity of and within clouds. Firstly, when clouds form due to enhancement although this explanation is far from satisfactory and precludes the observed $\mathrm{CCN}$ enhancement in clear moist layers above the cloud tops.

Major Professor(s): Saxena, Vinod K. Department: Marine, Earth and Atmospheric Sciences Principal Investigator(s): Saxena, Vinod K.

Program Area: National Institute for Global Environmental Change (NIGEC)

\section{KEYWORDS: CLIMATE, CLOUDS, CONDENSATION, DROPLETS, EMISSIONS, FOSSIL FUELS, MODELS, PARTICULATES, REFLECTANCE, REGIONAL ANALYSIS, SULFUR SPECIES}

\section{4}

Gupton, Frank Marcus. 1987. The Baroclinicity of the $\mathrm{M}_{2}$ Tide in the Georgia Bight. M.S. Thesis, North Carolina State University, 136 pages.

The importance of the $\mathrm{M}_{2}$ tide in the Georgia Bight is described. The tidal energy distribution of the Georgia
Bight is discussed from two experiments, GABEX I (February - June 1980) and GABEX II (June October 1981). Also the stability and coherency of the tidal particle motion is analyzed. Finally, the possible occurrence of an internal tidal wave using Fofonoff's (1969) criteria for the existence of an internal wave is shown using the GABEX I and GABEX II data.

Major Professor(s): Curtin, T.B.

Department: Marine, Earth and Atmospheric Sciences Principal Investigator(s): Pietrafesa, Leonard J. Program Area: Marine Transport

\section{KEYWORDS: CIRCULATION, OCEANS, PRESSURE, TIDES, WAVES}

75

Han, Dejiang. 1993. Derivation of Cloud Fraction from Surface-Based Longwave Flux Observations. M.S. Thesis, University of Maryland at College Park, 18 pages.

Theoretical studies have shown that cloud geometrical factors have a significant impact on longwave fluxes and heating rates, yet most models used in climate studies employ rather crude approximations of these effects. This study was designed to determine the possibility of estimating such geometrical effects with the use of surface-based infrared flux observations as might be obtained during the Atmospheric Radiation Measurement (ARM) program. The results show that pyrgeometer measurements can be used to determine the effective cloud fraction in a manner useful for geometrical parameterizations if the error variance of the observations is less than about 5 Watts per meter squared. In general, the uncertainties associated with such determinations increase with increasing water vapor burden. Overall, the pyrgeometer error restrictions are difficult to meet, but they may be possible with careful monitoring and control.

Major Professor(s): Ellingson, Robert G.

Department: Meteorology

Principal Investigator(s): Ellingson, Robert G.

Program Area: Atmospheric Radiation Measurement (ARM)

\section{KEYWORDS: CLOUDS, PYRGEOMETER, RADLATIVE PROCESSES}

76

Harrison, Kevin Geyer. 1993. The Impact of $\mathrm{CO}_{2}$ Fertilization, Changing Land Use and N-Deposition on Soil Carbon Storage. Ph.D. Dissertation, Columbia University, 134 pages. 
Fossil fuel combustion and changing land use have increased atmospheric and oceanic carbon inventories less dramatically than expected. This discrepancy has been termed the "missing sink." $\mathrm{CO}_{2}$ fertilization and $\mathrm{N}$ deposition processes could be sequestering some of this missing carbon. An improved understanding of disturbance and recovery carbon dynamics associated with changing land use may reduce this discrepancy by lowering biospheric release estimates. This research explores how these perturbations alter soil carbon inventories. Soil carbon responds to perturbations to a greater or lesser extent, depending on the turnover time of the soil organic material. Using radiocarbon measurements and a simple model, I have modelled soil organic material's turnover times, which range from decades to millennia, as a binary system having active and passive components. $\mathrm{CO}_{2}$ fertilization, the plant net primary productivity increase observed at elevated $\mathrm{CO}_{2}$ levels, increases soil carbon inventories. This research introduces a "greening" model to estimate this increase, using a $\mathrm{CO}_{2}$ fertilization factor, active soil carbon inventory, and turnover time. This research also uses radiocarbon measurements to examine how cultivation reduces the inventory of active soil carbon. Further, the relationships between carbon loss and vegetation type, farming technique, and the clay content of soil have been examined to identify patterns that can be used to develop strategies for mitigating future carbon loss. Formerly cultivated lands that are undergoing secondary succession can sequester atmospheric carbon. This research extends previous work in this area. One coniferous site in this study had a higher soil carbon inventory than its native deciduous counterpart. Anthropogenic nitrogen deposition, like $\mathrm{CO}_{2}$ fertilization, may also increase soil carbon storage. This research sets limits on the amount of carbon sequestered by nitrogen deposition by determining the amount and fate of anthropogenic nitrogen. In summary, $\mathrm{CO}_{2}$ fertilization and $\mathrm{N}$-deposition can potentially sequester a major portion of the so-called missing sink. This research identifies ways to limit biospheric carbon loss and enhance carbon recovery on formerly disturbed lands.

Major Professor(s): Broecker, Wallace S. Department: Lamont-Doherty Earth Observatory Principal Investigator(s): Broecker, Wallace S. Program Area: Carbon, Climate, and Vegetation

KEYWORDS: CARBON CYCLE, CARBON DIOXIDE, FERTILIZATION, LAND USE, NITROGEN CYCLE, SOILS
77

Hattemer-Fney, Holly A 1986. An Internship with the Carbon Dioxide Information Center. M.En. Report, Miami University, 50 pages.

To fulfill one of the requirements for a Master of Environmental Science degree from the Institute of Environmental Sciences (IES), Miami University, Oxford, Ohio, an internship with the Carbon Dioxide Information Center (CDIC) at Oak Ridge National Laboratory, Oak Ridge, Tennessee, which lasted from August 1, 1985, through Juty 31, 1986. My internship responsibilities included two primary research projects: 1) producing the climatic indices publication, and 2) evaluating the feasibility of using computer-generated sound to analyze long-term climate data. The climatic indices publication concisely describes 35 prominent indices to help meet the information needs of researchers who are evaluating the effects of increased atmospheric carbon dioxide levels. Five major steps were involved in producing the publication: 1) compiling an extensive collection of indices from nine climate subject areas; 2) determining citation totals for each reference included in the climatic indices bibliography; 3) writing descriptions of 35 prominent indices; 4) sending out surveys to climate researchers and analyzing the results; and 5) completing the tasks associated with publishing the document. Using sound to analyze data is based on the premise that one can hear differences in data patterns more easily than one can perceive these differences visually. Three objectives associated with this project included: 1) determining how CDIC could adapt this technique to analyze climate data; 2) identifying and purchasing the appropriate equipment necessary to establish a computer driven sound-generating system; and 3) outlining recommendations for using sound to analyze complex, multivariate data. Much of the success of my internship may be attributed much skills developed in IES core and area concentration courses and to the guidance and assistance provided by CDIC staff members.

Major Professor(s): Vankat, John L. Department: Institute of Environmental Sciences Principal Investigator(s): Farrell, Michael P.

Program Area: Information

KEYWORDS: CLIMATE, DATABASES, SOUND

78

Heikes, Ross P. 1993. The Shallow Water Equations on a Spherical Geodesic Grid. M.S. Thesis, Colorado State University, 175 pages. 
A computer model is presented that solves the stream function/velocity potential form of the shallow water equations using a new spherical geodesic grid that covers the sphere more homogeneously and isotropically than latitude-longitude grids. The geometric properties of the grid are considered. Following Masuda, the finite difference methods discretize line integrals to time-step the prognostic equations. Multigrid methods are used to solve the diagnostic equations for the stream function and velocity potential. The model is compared with the Arakawa-Lamb shallow water model and the NCAR spectral transform shallow water model using the suite of seven test cases proposed by Williamson. The model performance characteristics are presented. The test cases show that the evolution of the fields is independent of the relative orientations of the computational grid and the flow pattern. This is particularly true when flow is directed over the pole of the grid. Also, the new model is tested using a RassbyHaurwitz wave as initial conditions. The initial disturbance breaks down towards lower wavenumbers, but remains symmetric across the equator.

Major Professor(s): Randall, David A. Department: Atmospheric Science Principal Investigator(s): Randall, David A. Program Area: Computer Hardware, Advanced Mathematics, and Model Physics (CHAMMP)

\section{KEYWORDS: CLIMATE, MODELS, WATER}

79

Hendler, Albert H. 1983. Cloud Condensation Nuclei from Urban-Industrial Sources and Their Impacts on Cloud Chemistry and Microphysics. M.S. Thesis, North Carolina State University, 96 pages.

The results from two field experiments dealing with cloud-aerosol interactions in the urban environment are presented. In one of the experiments, real-time in situ measurements of the cloud nuclei activation spectra over St. Louis, obtained as part of METROMEX (Metropolitan Meteorological Experiment), as used to identify industrial sources of cloud condensation nuclei (CCN). The effluents of coal burning power plants are found to dominate the regional $\mathrm{CCN}$ production. Other major industrial producers of $\mathrm{CCN}$ are found to be steel mills, copper and zinc smelters, and oil refineries. Since St. Louis is a city of a large and diverse industrial base, these sources would likely dominate the anthropogenic $\mathrm{CCN}$ production in most urban-industrial areas. A natural source of $\mathrm{CCN}$ is also identified for the first time in the swampy marshlands northwest of St. Louis. In the second experiment, measurements of cloud nuclei activity, subcloud air chemistry, and cloud water sulfate concentrations are used to investigate the contribution of the cloud nucleation process to the sulfate content of cloud water. Results show that in only one of four cases nucleation by subcloud sulfate aerosol can account for the entire sulfate content detected in cloud water samples. In all cases, substantial production of $\mathrm{CCN}$ is observed in the subcloud layer.

Major Professor(s): Saxena, Vinod $\mathbf{K}$.

Department: Marine, Earth and Atmospheric Sciences Principal Investigator(s): Saxena, Vinod K.

Program Area: Atmospheric Sciences

KEYWORDS: AEROSOLS, CHEMISTRY, CLOUDS, CONDENSATION, EMISSIONS, FOSSIL FUELS, MICROPHYSICS, PARTICULATES, SULFUR SPECIES, URBAN ENVIRONMENT, WETLANDS

80

Herczeg, Andrew Leslie. 1985. Carbon Dioxide Equilibria and $\delta^{13} \mathrm{C}$ Studies in Some Soft Water Lakes. Ph.D. Dissertation, Columbia University, 263 pages.

A method for determining the hydrogen ion concentration of fresh waters is presented that involves total dissolved inorganic carbon measurements (DIC or $\left.\mathrm{XCO}_{2}\right)$ and $\mathrm{CO}_{2}$ partial pressures $\left(\mathrm{P}_{\mathrm{CO}_{2}}\right)$ measurements rather than $\mathrm{pH}$ electrode measurements. Values of $\mathrm{pH}$ calculated from DIC and $\mathrm{P}_{\mathrm{CO}_{2}}$ measurements in some softwater lakes at the Experimental Lakes Area, northwest Ontario and experimentally determined values of $K_{1}$ (the first dissociation constant of carbonic acid) were consistently higher than those directly measured with the pH electrode. Laboratory experiments demonstrated that the high dissolved organic content of these waters appears to alter the electrode response yielding $\mathrm{pH}$ values lower than the true values. Determination of $\mathrm{pH}$ after additions of known amounts of strong acid to lake water were internally consistent only when done using the carbon dioxide equilibria calculation. A second observed phenomenon was that the alkalinity determined by the Gran linear extrapolation method was always greater than $\mathrm{HCO}_{3}$ ion concentration determined independently (i.e., $[\mathrm{DIC}]=\left[\mathrm{H}_{2} \mathrm{CO}_{3}{ }^{*}\right]$ ). Uptake of protons by weak organic acid ions appear to be the cause of the measured differences. The $\mathrm{pH}$ in dilute waters may vary in response to changes in $\mathrm{P}_{\mathrm{CO}_{2}}$ and with changes in the relative amounts of $\mathrm{HCO}_{3}{ }^{2}$ and weak organic acid anions. A method is presented for correcting calculated $\mathrm{pH}$ determinations (based on the method outlined above) for water samples not at equilibrium with respect to atmospheric $\mathbf{P}_{\mathrm{CO}_{2}}$ and thereby providing a sensitive means to detect temporal trends in fresh water acidity. The second part of this 
thesis investigates some aspects of the carbon budget and carbon cycling in a softwater lake using the stable carbon isotopes ${ }^{12} \mathrm{C}$ and ${ }^{13} \mathrm{C}$. Mass balance calculations show that for the two months following ice-out, the phytoplankton obtained most of their carbon from $\mathrm{CO}_{2}$ of a metabolic origin; that is from respired $\mathrm{CO}_{2}$ that had accumulated under ice and from plant and soil respiration in the terrestrial drainage basin. High midsummer rates of net photosynthesis $\left(18 \pm 5\right.$ mmoles $\mathrm{m}^{-2}$ $\mathrm{d}^{-1}$ ) were accompanied by large rates of net $\mathrm{CO}_{2}$ invasion from the atmosphere $\left(16 \pm 5\right.$ mmoles $\left.\mathrm{m}^{-2} \mathrm{~d}^{-1}\right)$. About 75 percent of the integrated net photosynthesis for the year occurred during a six week period (July 4 . August 17 along with approximately 80 percent of the total net invasion of $\mathrm{CO}_{2}$ from the atmosphere. Because of the very low $\mathrm{P}_{\mathrm{CO}_{2}}$ 's that occurred during the algal bloom, there was a temporary rise in the surface water $\mathrm{pH}$ which resulted in presumed chemical enhancement of $\mathrm{CO}_{2}$ invasion. The fractionation between $\mathrm{CO}_{2}(\mathrm{~g})$ and $\mathrm{HCO}_{3}{ }^{-}$during this period is approximated by invasion into a hydroxide solution (up to $-13 \%$ rather than the usual value of $+8 \%$. that is assumed in steady-state conditions. Mass balance calculations for the buildup of DIC in the hypolimnion over the spring and summer requires that the DIC have an average isotopic composition of $-22 \%$ which is somewhat heavier than DIC derived from the complete degradation of the autochthonous or allochthonous particulate organic matter $(\approx-26 \%$. Therefore there must be an additional source of isotopically heavy carbon which is likely to be $\mathrm{CO}_{2}$ produced as a by-product of methane fermentation.

Major Professor(s): Broecker, Wallace S.

Department: Geochemistry

Principal Investigator(s): Broecker, Wallace S.

Program Area: Carbon, Climate, and Vegetation

\section{KEYWORDS: ALKALINITY, CARBON DIOXIDE, CARBON ISOTOPES, LAKES, PH}

\section{1}

Hesla, Bret 1984. The Implications of Spatial Variations in Adult Performance for the Distribution Patterns of Two Perennial Halophytes in Tooele Valley, Utah. M.S. Thesis, University of Utah, 63 pages.

The perennials Allenrolfea occidentalis (Wats.) Kuntze and Sarcobatus vermiculatus (Hook.) Torr. dominate two adjacent shrub communities in many saline valleys of the Great Basin. In Tooele Valley, the populations of each species are largely restricted to within the communities they dominate, although rate individuals may be found within each adjacent community. In order to gain insight into the factors limiting these populations at their edges, spatial variations in several indices of adult performance were compared with spatial variations in population density, as well as with variations in the soil environment. The lower edge of the Allenrolfea population coincided with the bare mud flats of the valley center. The gradual decline in density (linear cover of hummocks) toward this edge was paralleled by a significant decline in the length, stomatal conductance, and reproduction (flowering frequency) of active twigs, the latter reaching zero at the edge. Since no other species occurred there, the decline in performance was probably a response to environmental changes. Indeed, these performance indices were significantly correlated with both the depth to the water table and the salinity of the water table. The lower edge of the Sarcobatus population roughly coincided with the sharp ecotone between the Sarcobatus- and Allenrolfeadominated communities. Shrub density $\left(\# / \mathrm{m}^{2}\right)$ dropped sharply at the lower edge (across the ecotone). Also declining toward this lower edge were individual height, leaf biomass, stomatal conductance, daily transpiration, water potential, and reproduction (the frequency of flowering individuals), the latter reashing zero at the edge. This spatial variation was maintained throughout the season. The removal of perennial competitors (Allenrolfea individuals within $3 \mathrm{~m}$ ) induced small increases in individual water status at the lower edge of the population, but failed to induce increases in leaf biomass or reproduction. The abrupt changes in plant performance across the ecotone were associated with abrupt changes in many soil properties, including water table depth, soil water salinity, phosphorus content, organic carbon content, and clay content. The salinity and water table differences were maintained throughout the season. The upper edge of the Allenrolfea population coincided with the ecotone between the Sarcobatus- and Allenrolfea-dominated communities. Density peaked at the ecotone, dropping significantly at the upper edge. In contrast, the length, stomatal conductance, daily transpiration, and water potential of twigs reached a maximum at the upper edge. However, like hummock cover, reproduction peaked at the ecotone, being very low at the upper edge of the population. The removal of perennial competitors slightly stimulated water relations, leaf biomass, and reproduction at all locations, but did not alter the spatial trends. Low adult reproduction may have kept densities low at the upper edge. Environmental variation may contribute to the spatial variations in biomass and water status, but not directly to the spatial variations in reproduction. The upper edge of the Sarcobatus population coincided with the ecotone between the Sarcobatus and grassland communities. Density declined gradually across the Sarcobatus population, then abruptly at the upper edge. In contrast, height and reproduction reached a striking 
maximum at the upper edge of the population, suggesting that adult performance had little bearing on the low densities there.

Major Professor(s): Ehleringer, James R.

Department: Biology

Principal Investigator(s): Ehleringer, James R.

Program Area: Ecosystems Function and Response

\author{
KEYWORDS: DESERTS, GROWTH AND \\ DEVELOPMENT, LEAVES, PHOTOSYNTHESIS, \\ PRECIPITATION, REPRODUCTION, SALINITY, \\ SOILS, SPATLAL DISTRIBUTION, \\ TRANSPIRATION, VEGETATION, WATER, WATER \\ STRESS
}

\section{2}

Hong, Xiaodong. 1993. A Numerical Modeling Study of Vegetation as a Surface Forcing for Mesoscale Circulation and Cloud Formation. M.S. Thesis, North Carolina State University, 98 pages.

The effects of variable vegetation coverage as a surface forcing are examined by incorporating a vegetation parameterization into a mesoscale numerical model. Variable vegetation coverage leads to differential surface forcing which then creates mesoscale circulation. The mesoscale circulation and the interaction of the circulation with cloud production processes are examined with various atmospheric stability and moisture conditions. The sensitivity to scale length of the surface forcing function is also investigated. Finally, a realistic vegetation coverage is used in threedimensional simulations, with results compared to observations from the Boardman Regional Flux Experiment. The intensity of the vegetation breeze circulation is directly related to the characteristics of the adjacent bare soil. There is a strong relationship between surface heat and moisture fluxes and the intensity of the vegetation breeze circulation. Greater sensible heat is transferred to the atmosphere over bare soil, while more soil moisture is transferred over the vegetated area than over the bare soil area. Clouds induced by vegetation forcing are investigated by varying the atmospheric stability and moisture in the boundary layer and the atmosphere above it. The magnitude of the vertical velocity due to the thermally induced mesoscale circulation decreases as the atmospheric stability increases. Two mesoscale circulation cells merge into one in the weak stability cases due to the smaller restoring force. Clouds are generated earlier for the less stable cases, but eventually dissipate because of enhanced mixing. In more stable cases, clouds are generated later in the simulation but persist longer as the vertical mixing is inhibited by the greater stability. Increased moisture in the lower layers strengthens the thermally induced mesoscale circulation by decreasing the stability. Increased moisture in the upper atmosphere leads to increased cloud water. The scale of surface horizontal heating affecting cloud formation is also examined. One convective cell forms with narrow surface heating; as the scale of the heating increases, eventually two cells form. The depth of turbulent mixing increases as the horizontal heating scale increases due to greater surface heating over the large horizontal area. When horizontal heating scale is narrow, increased evapotranspiration in the vegetated areas increases surface layer fog or cloud water. The temperature, moisture and velocity components from the three-dimensional simulations are related to the distribution of vegetation. The ground surface temperature is uniformly distributed over the irrigated area but is inhomogeneous over the steppe area due to the penetration of the vegetation breeze. The colder air over the irrigated area does not penetrate over the steppe when the vegetation breeze opposes the ambient wind. A sharp horizontal moisture gradient is created between the two areas due to evapotranspiration from the vegetation and greater vertical mixing over the steppe. Velocity perturbations at the interface between the steppe and irrigated land are largest when the vegetation breeze opposes the ambient wind.

Major Professor(s): Raman, Sethu Department: Marine, Earth and Atmospheric Sciences Principal Investigator(s): Raman, Sethu Program Area: Atmospheric Radiation Measurement (ARM)

KEYWORDS: ATMOSPHERE, CIRCULATION, CLIMATE, CLOUDS, EVAPORATION, HEAT FLUX, LAND SURFACE, MODELS, SOILS, SPATLAL DISTRIBUTION, TEMPERATURE, VEGETATION, WATER VAPOR, WINDS

83

Hsieh, Ching-Tzong. 1985. Three Reservoir Models for Climate Evolution with a Two-Dimensional World Ocean. Ph.D. Dissertation, New York University, 148 pages.

A three-reservoir parameterized climate model is formulated from the principle of energy balance. The system, composed of the atmosphere, ocean and land, covers pole-to- pole regions. Land-sea distribution along the latitudinal direction is taken into consideration to simulate climatic response in both hemispheres. The ocean part includes the mixed layer and deep sea which has isopycnal structure. The model is designed to investigate the climatic responses to external and 
internal perturbations. External perturbations mainly refer to the seasonally varying solar radiation, whereas internal perturbations to the change in $\mathrm{CO}_{2}$ concentration in the atmosphere. Seasonal responses to the seasonal variation of solar radiation for present $\mathrm{CO}_{2}$ level are tested to calibrate parameters of the model. Long-term responses to the change of $\mathrm{CO}_{2}$ level are also investigated. Steady-state and transient solutions are obtained to present pole-to-pole temperature fields. The model is coupled to the parameterized output of the LOWTRAN 5 longwave radiation code, which calculates outgoing and downward longwave radiation. Steady-state solutions are obtained by specifying step changes of $\mathrm{CO}_{2}$ level to the system; transient solutions are obtained by specifying the time history of $\mathrm{CO}_{2}$. Sensitivities to doubling $\mathrm{CO}_{2}$ and a $2 \%$ increase of the solar constant of the present model are compared with GCM results. Zonally averaged temperatures at different latitudes are calculated. Temperature fields are obtained for air, water and land. The calculated seasonal temperature fields are compared with the observed data to test the performance of the model.

Major Professor(s): Hoffert, Martin I.

Department: Applied Science

Principal Investigator(s): Hoffert, Martin I.

Program Area: Carbon, Climate, and Vegetation

KEYWORDS: CARBON DIOXIDE, CLIMATE, MODELS, OCEANS, RADLATIVE PROCESSES

\section{4}

Hu, Jianhong 1994. Uptake of a Series of Gas-Phase Halogenated-Acetic Acids and Halogen Molecules by Aqueous Droplet Surfaces. Ph.D. Dissertation, Boston College, 180 pages.

The importance of gas-liquid heterogeneous chemistry in the atmosphere has been recognized. It has been found that heterogeneous reactions could dramatically alter the chemical composition of the atmosphere. Here we examine the heterogeneous chemistry of two atmospheric systems using a well developed droplet apparatus. This method combines a monodisperse droplet stream with a low pressure flow reactor. The uptake of gas by the droplets is determined by measuring changes in gas phase density using a mass spectrometer as the droplet area is changed. Gas-liquid uptake studies have been performed for the following series of halo-acetic acids (as well as acetic acid itself): $\mathrm{CF}_{3} \mathrm{COOH}, \mathrm{CCl}_{3} \mathrm{COOH}, \mathrm{CCH}_{2} \mathrm{COOH}, \mathrm{CCl}_{2} \mathrm{HCOOH}$, $\mathrm{CF}_{2} \mathrm{ClCOOH}$, and $\mathrm{CH}_{3} \mathrm{COOH}$. These species (expect $\mathrm{CH}_{3} \mathrm{COOH}$ ) are the final degradation products of alternative chlorofluorocarbons. The mass accommodation coefficients for these species have been determined. Results indicate that the mass transfer of these halo-acids to atmospheric cloud droplets are not limited by mass accommodation. The studies of the uptake of gas phase $\mathrm{Cl}_{2}$ and $\mathrm{Br}_{2}$ by aqueous surfaces as a function of $\mathrm{Br}^{-}$and $\mathrm{I}^{-}$ion concentration have also been completed. Since the solubility of the halogen molecules $\mathrm{X}_{2}(\mathrm{X}=\mathrm{Cl}$ or $\mathrm{Br})$ is low, the measured uptake is primarily due to the aqueous reaction of the species with the halide ion $\mathbf{Y}^{-}(\mathrm{Y}=\mathrm{Br}$ or $\mathrm{I})$ via $\mathrm{X}_{2}+$ $\mathbf{Y}^{-}$.-.> XY + $\mathbf{Y}^{-}$. The magnitude of the measured uptake and its functional dependence on the ion concentration are not in accord with simple bulk phase reaction of the species. The data indicate that reactions at the gas-liquid interface play a significant role in the gas uptake process. The atmospheric implications of the results have been examined.

\author{
Major Professor(s): Davidovits, Paul \\ Department: Chemistry \\ Principal Investigator(s): Davidovits, Paul \\ Program Area: Atmospheric Sciences
}

\section{KEYWORDS: ATMOSPHERE, CHEMISTRY, DROPLETS, HALOGEN SPECIES}

85

Hu, Qi. 1992. Low Frequency Oscillations in RadiativeConvective Models. Ph.D. Dissertation, Colorado State University, 196 pages.

Although slow eastward propagation has long been considered one of the essential features of the $30-60$ day oscillations in the tropical atmosphere, recent observations have shown the presence of a stationary or quasi-stationary component in the ascillations. This stationary component is significant especially in the thermodynamic fields, e.g., the diabatic heating and the geopotential height. The theories for the low frequency oscillations, derived from the wave-CISK concept, generally have difficulties in explanation of the period and the vertical structure of these oscillations. On the other hand, numerical experiments are providing more and more evidence showing that low frequency waves in the atmosphere are very likely to be excited by cumulus convection which itself varies on long time scales. These numerical results are supported by the observations. In this study our hypothesis is that the low frequency oscillations are forced by a stationary oscillating heat source. Moreover, we propose that the low-frequency oscillating heat source can result from nonlinear interactions among radiation, cumulus convection, and surface moisture flux. Three one-dimensional models, two numerical and one conceptual, are developed to test our hypothesis. The physical processes included in these models are the same, i.e., the atmospheric 
radiation, cumulus convection, and the surface moisture flux. Results from all three models show the presence of low-frequency oscillations in cumulus convection and latent heat release. In addition, the oscillations disappear from the results when the interactions between radiation and cumulus convection are removed artificially from the models. No oscillations are obtained for the case of a dry atmosphere. Cumulus convection becomes active when the mixed layer moisture, or the mixed layer equivalent potential temperature, theta $\mathrm{e}$, are high. Active cumulus convection changes both the temperature and moisture distributions in the vertical, in a nonlinearly coupled manner. Cumulus convection intensifies and is able to maintain itself for a period of 10 to 20 days through a radiation feedback on the convection-induced temperature fluctuations and a positive feedback between moist convection and the surface moisture flux. This positive feedback is mostly active in the early stage of a convective episode. Intensification of cumulus convection results in a fast reduction of the mixed layer moisture. When cumulus convection weakens, the upper-level radiative cooling gradually drives the lapse rate back toward instability while the mixed layer is moistening, again. The period of these oscillations is around 20-60 days, depending on the choice of parameters. This mechanism is also supported by our results from an observational study, based on Truk Island data. The stationary lowfrequency oscillating heat source associated with the oscillating cumulus convection can force low frequency ascillations in the winds, and so can excite the observed 30-60 day oscillations in the tropics.

Major Professor(s): Randall, David A.

Department: Atmospheric Science

Principal Investigator(s): Randall, David A.

Program Area: Carbon, Climate, and Vegetation

KEYWORDS: CLIMATE, CONVECTION, MODELS, RADLATIVE PROCESSES, TEMPORAL DISTRIBUTION

\section{6}

Hu, Yong-Xiang. 1994. A Study of the Link Between Cloud Microphysics and Climate Change. Ph.D.

Dissertation, University of Alaska - Fairbanks, 121 pages.

The climate related cloud radiative properties (fluxes and heating rates) are found to be determined by the second and the third moments of the cloud droplet size distribution. The detailed distribution of the cloud droplet size is unnecessary to obtain for climate purposes. An accurate parameterization of cloud optical properties suitable for climate models is developed. A new radiative-convective model has been developed and used for studying cloud-climate interactions. The energy balance at the Earth-atmosphere interface is treated in a self-consistent manner which avoids artificial tuning. The cloud radiative properties are accurately incorporated and are suitable for sensitivity studies of cloud-radiation-climate interactions. A sensitivity study of role of the cloud microphysical properties in the climate system is performed by studying the impact of cloud radiative forcing on the equilibrium state temperature. The cloud equivalent radius is found to be a very important variable in the climate system. A climate sensitivity study is performed to highlight the important role of the cloud absorption. An adjoint radiative transfer method is developed for use in the cloudy and aerosol-loaded atmospheres. The physical meaning of the adjoint radiative properties are discussed. The method is expected to be useful in climate modeling and remote sensing studies. A preliminary study of the atmospheric irreversibility is performed to elucidate the connection between cloud microphysical properties and the macrophysical direction of global climate. A variational principle which describes the macrophysical character of the climate system is established.

Major Professor(s): Stamnes, Knut Department: Atmospheric Sciences, Geophysical Institute Principal Investigator(s): Stamnes, Knut Program Area: Quantitative Links

\section{KEYWORDS: CLIMATE, CLOUDS, ENERGY} BALANCE, MODELS, RADLATIVE PROCESSES

\section{7}

Huang, Ching-Yuang 1990. A Mesoscale Planetary Boundary Layer Numerical Model for Simulations of Topographically Induced Circulations. Ph.D.

Dissertation, North Carolina State University, 253 pages.

A mesoscale planetary boundary layer (PBL) numerical model is developed to investigate airflow over complex topography. The model physics includes PBL turbulent transfer, atmospheric longwave and shortwave radiation, diurnal energy budgets over ground, cloud microphysics and subgrid cumulus parameterization. The model utilizes a new fourth order Crowley advection scheme which preserves phase and amplitude much better than other Crowley schemes. Turbulence closures using the turbulent kinetic energy (TKE) and dissipation (6) equations are investigated with the level 2.5 scheme of Mellor and Yamada (1982) to better determine eddy diffusivities. One-dimensional (1-D) model results show that the PBL flows under various stability conditions are not significantly sensitive to the modified Blackadar's 
and Kolmogorov's eddy mixing length formations, although the latter yields excessively large mixing lengths in the entrainment region of the upper PBL. With the same prognostic TKE equation, the model results show insensitivity of the 1-D flow to the details of diagnostic formulations in the closures and to eddy Prandtl numbers. A 2-D model is used to simulate January 28 cold-air outbreak over the Gulf Stream region during the IOP-2 (Intensive Observation Period) of the 1986 Genesis of Atlantic Lows Experiment (GALE). The modeled 2-D circulation system is found to be sensitive to Prandtl number, in contrast to the 1D model results. Prandtl number becomes increasingly important as the clouds begin to interact with the marine boundary layer (MBL). Using the E-e closure, the model predicts the observed MBL structure that includes a low level jet west of the Gulf Stream warm core and a constrained boundary layer height due to the middle-level stable layer. The results also indicate that the high cloud streets observed downwind of the Gulf Stream are possible caused by the upper level baroclinic lee waves triggered by a density mountain. The density mountain waves, however, become evanescent as the baroclinicity of the flow (with a larger Scorer parameter) is removed, which agrees well with mountain wave theory. Two cases with 3-D idealized flow are also simulated for the same GALE IOP. For the easterly onshore ambient flow, a confluence zone appears near the coastline in response to the strong baroclinicity due to the Gulf Stream. This confluence zone is nearly parallel to the coastline and the SST isotherms. With the increased coastal confluence, a shallow coastal front (below $2 \mathrm{~km}$ ) begins to form. The northern part of the front later encroaches inland as the coal air intensity over ground weakens due to onshore warm air advection. Stationary rainbands are produced along the coastal front. For the northerly offshore ambient flow, the rainband first appears along the eastern edge of the Gulf Stream and moves slowly downstream. The fastest growth rate of the MBLinduced updrafts agrees with the theory of conditional symmetric instability. The model is also applied to simulate the 3-D airflow past Taiwan mountains. For both north-westerly and the south-westerly prevailing winds (with a Froude number of about 0.3 ), a mesoscale low pressure center occurs at the southeastern (downstream) slopes of the steep mountains. The formation of meso-low may be attributed to the combined effects of local confluence and adiabatic warming caused by the downslope wind. The role of the PBL effects in changing the flow separation and stagnation points is found to be more important for the upstream flow than the downstream flow. For the north-westerly flow, a downstream vortex pair can be generated near the two corners of the elongated island (with a smaller Rossby number). The geometry of the vortex pair is also determined by lateral mixing and thus is not greatly modified by the PBL destabilization. A strong downstream upslope wind is induced by the vortices and is further intensified by the PBL effects. This reversed flow results in greater precipitation than that produced by any upstream upslope flow.

Major Professor(s): Raman, Sethu Department: Marine, Earth and Atmospheric Sciences Principal Investigator(s): Pietrafesa, Leonard J. Program Area: Marine Transport

KEYWORDS: ASIA, ATMOSPHERE, BOUNDARY LAYER, CIRCULATION, CLIMATE, CLOUDS, COASTAL ENVIRONMENT, DIFFUSION, LAND SURFACE, MARINE ENIIRONMENT, MICROPHYSICS, MODELS, OCEANS, PRECIPITATION, RADLATIVE PROCESSES, TURBULENCE, WINDS

88

Hulbe, Christina Louise. 1994. Flow of Ice Stream B, West Antarctica, and a Method For Determining Ice Thickness Change at Remote Locations Using Differential GPS. M.S. Thesis, Ohio State University, 147 pages.

The flow style of the West Antarctic Ice Sheet is unlike that of other ice sheets on Earth today. Its drainage into the Ross Ice Shelf is almost entirely through fastflowing current called ice streams. The ice streams are thought to play a fundamental role in the stability of the ice sheet. The motivation of the work presented here is to measure and interpret flow variation of an antarctic ice stream. Interferometric Giobal Positioning System (GPS) surveys of a strain grid on Ice Stream B, West Antarctica, are used to study flow processes. Ice flow features are created locally and are changing over time. Existing ice flow models fail to explain those processes. Two new models, 'submerged-boulder' flow diversion, and vertical displacement along bands of 'weak' ice, are proposed. Two new uses of GPS are presented. One is a method for calculating strain rates directly from GPS observation. Another uses vertical velocity of the ice sheet surface to determine its rate of ice thickness change.

Major Professor(s): Whillans, Ian M.

Department: Geological Sciences

Principal Investigator(s): Wohlpart, A.

Program Area: Graduate Fellowships for Global Change

KEYWORDS: ANTARCTICA, FLOW, ICE, STREAMS 
89

Hussain, Mian Wajahat. 1992. Effect of Elevated $\mathrm{CO}_{2}$ and Temperature on Sucrose Phosphate Synthase Activity and Carbohydrate Metabolism in Rice. Ph.D. Dissertation, Univensity of Florida, 157 pages.

The kinetics of sucrose phosphate synthase (SPS) activity were studied in leaf extracts of rice (Oyza sativa L. cv. IR-30) grown for 21 days at a quantum irradiance of $450 \mu \mathrm{mol} \mathrm{m} \mathrm{m}^{-2} \mathrm{~s}^{-1}$ and $28^{\circ} \mathrm{C}$. The SPS activity showed hyperbolic and sigmoidal responses, respectively, as a function of concentration for its two substrates, UDPG and F6P. The $K_{m}(U D P G)$ and $S_{0.5}$ (F6P) were 2.7 and $2 \mathrm{mM}$ respectively. The enzyme was activated in an allosteric manner by G6P at low F6P concentrations, while $P_{i}$ inhibited it. From these data, saturating (for full activation) and limiting (to resemble the in vivo situation) conditions were derived for subsequent studied. Diel profiles indicated SPS was light activated and the activation was greatest under limiting assay conditions. Leaves were pretreated either with mannose to sequester endogenous $P_{i}$ or with exogenous $P_{i}$. Mannose pretreatment made the enzyme relatively insensitive to $P_{i}$ inhibition, whereas $P_{i}$ pretreatment enhanced the inhibitory effect. These data suggest that the rice SPS enzyme exists in two states, a light-active, $P_{1}$-insensitive form, and a dark form that is more $\mathbf{P}_{\mathbf{f}}$-sensitive. Based on these kinetic analyses, leaf SPS activity was examined as a function of $\mathrm{CO}_{2}$ enrichment and growth temperature for rice plants grown under natural irradiance at 330 and $660 \mu \mathrm{L} \mathrm{CO}_{2}$ $\mathrm{L}^{-1}$ and growth temperatures ranging from 25 to $37^{\circ} \mathrm{C}$. Leaf extracts were analyzed at 21,48 and 81 days after planting (DAP). $\mathrm{CO}_{2}$-enrichment at $28^{\circ} \mathrm{C}$ caused a season-long increase (18\%) in SPS activity measured under limiting or saturating assay conditions. It also increased the leaf starch and sucrose content, but lowered the total nitrogen. Sucrose content was higher than starch, suggesting rice is a sucrose and starch storer. In $\mathrm{CO}_{2}$-enriched plants, SPS activity increased with growth temperature up to $34^{\circ} \mathrm{C}$, but declined at $37^{\circ} \mathrm{C}$. Total nonstructural carbohydrates decreased linearly with increased growth temperature, except at 81 DAP. The increasing temperature caused a significant linear decrease in starch content, whereas sucrose was only slightly decreased, while fructose was increased. The data suggest that up-regulation of SPS activity is an acclimation response of rice to elevated $\mathrm{CO}_{2}$ and temperature.

Major Professor(s): Bowes, George E. Department: Botany

Principal Investigator(s): Allen, Leon $\mathrm{H}_{\text {., Jr. }}$ Program Area: Carbon, Climate, and Vegetation
KEYWORDS: ATMOSPHERE, CARBOHYDRATES, CARBON DIOXIDE, ENZYMES, FERTILIZATION, LEAVES, METABOLISM, PHOSPHATE, TEMPERATURE, VEGETATION

\section{0}

Jagtap, Shrikant Shantar. 1986. Theoretical Development, Analysis and Experimental Validation of an Evapotranspiration Model for Developing Crops. PhD. Dissertation, University of Florida, 239 pages.

Crop water use is a complex function of climatic conditions, stage of crop development, and soil water content. Using the principles of heat and mass balance, soil evaporation and plant transpiration models were developed. Subsequently, these models were mathematically integrated into a comprehensive evapotranspiration model to predict water use, soil evaporation, transpiration, and microclimate of a wellwatered developing crop where the soil may go through cycles of wetting and drying. Solutions were developed that will allow practical applications and evaluations of model using normally measured weather, plant, and soil data as inputs. Two experimental studies were conducted in outdoor controlled environment chambers. In the bare soil evaporation study parameters in an empirical of soil resistance of soil resistance were determined under daily and weekly irrigation treatments. Estimated soil evaporation values were in close agreement with the measured values in contrast to estimates made using conventional relationship between the cumulative evaporation and the square root of time. In the second study, 'Bragg' soybeans were grown in 330,660 and 990 ppm $\mathrm{CO}_{2}$ concentration under well watered conditions to obtain a data base to evaluate the ability of the model to predict water use during canopy development. Average daily error in the predicted water use was less than $6 \%$ and the differences between the measured and the simulated values were not significant at the $95 \%$ level of confidence. The model was used to study effect of increasing atmospheric $\mathrm{CO}_{2}$ concentration from 330 to 990 ppm ("Green House" effect) on water use of field grown soybeans. If the predicted increase in air temperature was ignored, higher $\mathrm{CO}_{2}$ may reduce seasonal water use by $10 \%$. However, when the effect of increased $\mathrm{CO}_{2}$ on stomatal resistance, leaf area development and a $5{ }^{\circ} \mathrm{C}$ temperature increase were considered, the model predicted a $19 \%$ increase in water use and possibly a $3^{\circ} \mathrm{C}$ rise in leaf temperature. Effects of variations in weather, irrigation frequencies, and planting dates on soybean crop coefficients were evaluated. The study showed that the use of published crop coefficient values for varying climate and growing practices may result in over or under prediction of crop water requirements by 
as much as 15 to $20 \%$. When better accuracy is required, the model can be used to adjust crop coefficients to more closely fit local weather and management conditions.

Major Professor(s): Jones, James W.

Department: Agricultural Engineering

Principal Investigator(s): Allen, Leon $\mathbf{H}$., Jr.

Program Area: Carbon, Climate, and Vegetation

KEYWORDS: AGRICULTURE, ATMOSPHERE, CARBON DIOXIDE, CLIMATE, EVAPORATION, FERTILIZATION, LEAVES, MODELS, SOILS, STOMATES, TEMPERATURE, TRANSPIRATION, VEGETATION, WATER USE

91

Jastrow, Julie D. 1994. Mechanisms of Aggregate Formation and Stabilization in Prairie Soils. Ph.D. Dissertation, University of Illinois at Chicago, 115 pages.

Water-stable soil aggregates were studied in mollisols recovering from long-term cultivation. The general hypothesis investigated was that plant roots and fungal hyphae provide a mechanical framework for the formation of soil aggregates and, thereby, create the conditions necessary for the accrual of organic matter, which serves to further stabilize the aggregates. This hypothesis was investigated in three ways. First, the contributions of roots and the external hyphae of mycorrhizal fungi to the formation and stabilization of macroaggregates ( $>0.25 \mathrm{~mm}$ in diameter) in restored tallgrass prairie were shown to be greater than the effects of microbial biomass, water-soluble carbon, and total soil organic carbon by using the statistical technique of path analysis. It was also demonstrated that the relative importance of different organic binding mechanisms was generally a function of the physical size of the mechanism relative to the spatial scale of the aggregate planes of weakness being bridged. Second, in a chronosequence of prairie restorations, the accrual of soil organic matter was facilitated by, but lagged behind, the formation of macroaggregates. Inputs of particulate organic matter appeared to be incorporated relatively rapidly into a mineral-associated fraction, which may be an important factor in aggregate stabilization. Third, carbon inputs and turnover rates in micro- and macroaggregates were compared by using the natural abundance of stable carbon isotopes, which clearly demonstrated a much slower turnover of old carbon in microaggregates. Measured increases in the net inputs of new carbon with increasing aggregate size confirmed the existence of an aggregate hierarchy created by the binding of microaggregates into increasingly larger macroaggregates. Unexpectedly, the stable isotope data indicated that microaggregate formation and degradation may be more rapid than suggested by the apparent stability of microaggregates in cultivated soils or by the turnover rates for old carbon.

Major Professor(s): Lussenhop, John

Department: Biological Sciences

Principal Investigator(s): Miller, R. Michael

Program Area: Ecosystems Function and Response

KEYWORDS: AGGREGATES, BIOMASS, FUNGI, MICROBES, ORGANICS, PRAIRIES, ROOTS, SOILS, STABLE ISOTOPES

\section{2}

Jensen, Deborah Bowne. 1993. Population Differentiation in Tree-Ring Growth Responses of White Fir (Abies concolor) to Climate: Implications for Predicting Forest Responses to Climate Change. Ph.D. Dissertation, University of California at Berkeley, 143 pages.

Forest succession models and correlative models have predicted 200-650 kilometer shifts in the geographic range of temperature forests and forest species as one response to global climate change. This study examines differences in tree-ring growth, and in the phenotypic plasticity of tree-ring growth in 16-year old white fir, Abies concolor, from ten populations grown in four common gardens in the Sierra Nevada of California. For each population, tree-ring growth under three scenarios of doubled $\mathrm{CO}_{2}$ climates was estimated. Clinal variation in growth responses of white fir populations was found. Population from cold sources were less plastic in their response to degree-day sums. Intermediate populations had intermediate responses. Differences between populations were more pronounced under the various warming scenarios than under current climate conditions. Under the warmest climate scenario, using output from UKMO. The growth response functions predicted that the most responsive population in the future and make more difficult the task of predicting the responses of forest to climate change. The substantial scientific uncertainties about the magnitude and rate of climate change and the responses of natural ecosystems to these changes makes formulating policy more difficult. This research indicates that a local phenomenon, population differentiation, may not affect predictions of forest responses to climate change, suggesting that further research may increase rather than decrease estimates of uncertainty about the effects of climate change. Policy responses to climate change will have to proceed in the face of such uncertainly. 
Major Professor(s): Harte, John

Department: Energy and Resources Group

Principal Investigator(s): Wohlpart, A.

Program Area: Graduate Fellowships for Global Change

KEYWORDS: CLIMATE, GROWTH AND DEVELOPMENT, TEMPERATURE, TREE RINGS, VEGETATION

\section{3}

Jiang, Xingiian. 1986. Role of Oceanic Heat Transport Processes in $\mathrm{CO}_{2}$-induced Warming: Analysis of Simulations by the OSU Coupled Atmosphere-Ocean General Circulation Model. M.S. Thesis, Oregon State University, 154 pages.

The OSU global coupled atmosphere/ocean general circulation model (A/O GCM) has been used to simulate the present $\left(1 \times \mathrm{CO}_{2}\right)$ climate and to investigate a $\mathrm{CO}_{2}$-induced $\left(2 \mathrm{xCO}_{2}\right)$ climate change. Previous analysis of the $1 \mathrm{xCO}_{2}$ simulation showed distinct errors in the simulated sea surface temperature (SST) and sea ice which were attributed primarily to the atmospheric GCM (AGCM). Analysis of the $2 \mathrm{xCO}_{2}$ simulation showed that the $\mathrm{CO}_{2}$-induced warming penetrated into the ocean; this caused a delay in the equilibration of the climate system with an estimated e-folding time of 50 75 years. The present study has two objectives. The principal objective is to answer the question: By what pathways and through which physical processes does the simulated ocean general circulation produce the penetration of the $\mathrm{CO}_{2}$-induced warming into the ocean? The secondary objective is to evaluate the performance of the oceanic GCM (OGCM) in the $\mathrm{XCO}_{2}$ simulation. The comparison of the simulated $1 \mathrm{xCO}_{2}$ internal oceanic fields with the corresponding observations shows that although they are basically similar, there are distinct errors. Further analysis shows that these errors were generated by the OGCM during its spin up integration prior to its coupling with the AGCM. This study thus shows that it is not sufficient to compare the simulated SST with the observed SST to evaluate the performance of the OGCM. It is also necessary to compare the simulated internal oceanic quantities with the corresponding observed quantities. The global mean analysis of the $\mathrm{CO}_{2}$-induced climate changes shows that the ocean gains heat at a rate of 3 $\mathrm{W} / \mathrm{m}^{2}$ due to the $\mathrm{CO}_{2}$ doubling. This heat penetrates downward into the ocean predominantly through the reduction in the convective overturning. The zonal mean analysis shows that the surface warming increased from the tropics toward the midlatitudes of both hemispheres and penetrated gradually to the deeper ocean. The oceanic warming penetrated to a greater depth in the subtropics and mid-latitudes than in the equatorial region. A zonal mean heat budget analysis shows that the $\mathrm{CO}_{2}$-induced warming of the ocean occurs predominantly through the downward transport of heat, with the meridional heat flux being only of secondary importance. In the tropics the penetration of the $\mathrm{CO}_{2}$-induced heating is minimized by the upwelling of cold water. In the subtropics the beating is transported downward more readily by the downwelling existing there. In the high latitudes the suppressed convection plays the dominant role in the downward penetration of the $\mathrm{CO}_{2}$-induced heating.

Major Professor(s): Schlesinger, Michael

Department: Atmospheric Sciences

Principal Investigator(s): Gates, W. Lawrence

Program Area: Carbon, Climate, and Vegetation

\section{KEYWORDS: CARBON DIOXIDE, CLIMATE, HEAT FLUX, MODELS, OCEANS}

\section{4}

Jiang, Xingiian. 1991. Carbon Dioxide Induced Ocean Climatic Change and Tracer Experiment with an Atmosphere-Ocean General Circulation Model. Ph.D. Dissertation, University of Illinois at Urbana-Champaign, 304 pages.

The characteristic response time of the climate system ranges 10-100 years for a $\mathrm{CO}_{2}$ doubling due to the heat penetration into the deep ocean. This delay is of fundamental importance in establishing when the greenhouse signal will emerge from the background noise due to the natural variability of the climate system. It is imperative that we validate a model's estimate of the response time of the climate system against observations. If the penetration of the greenhouse-gas-induced heating into the ocean is analogous to that of a passive tracer, then the latter may be used as a surrogate for the former and thereby establish the characteristic response time. The principal objective of this study is to determine whether or not the penetration of a passive tracer is analogous to the penetration of a greenhouse-gas-induced heating. The Atmosphere-Ocean General Circulation Model (A-O GCM) developed at Oregon State University has been used to study $\mathrm{CO}_{2}$-induced climate change and the penetration of passive tracers into the world ocean. The present climate and a $2 \mathrm{xCO}_{2}$ climate have been simulated. In this study, the passive tracers tritium, CFC-11, CFC-12 and a "passive $\mathrm{CO}_{2}$-induced heating" are simulated. A rudimentary carbon-cycle model is also included for the purpose of a preliminary determination of the amount of atmospheric $\mathrm{CO}_{2}$ taken up by the ocean. The $\mathrm{CO}_{2}$-induced active and passive warmings 
are larger in the subtropics and high latitudes than in the tropics. The largest difference between the active and passive $\mathrm{CO}_{2}$-induced heatings occur in the North Atlantic deep ocean, with maximum cooling about $-1.5^{\circ} \mathrm{C}$ for the active case in layer four of the ocean $(1150 \mathrm{~m})$. There is no hemispherically asymmetric warming as that found by Manabe et al. (1990) and Stouffer et al. (1990). The convective overturning and large-scale sinking motion are responsible for the large penetration of $\mathrm{CO}_{2}$-induced warming in high latitudes. The $\mathrm{CO}_{2}$-induced circulation changes show that the North Atlantic thermohaline circulation is significantly weakened due to the penetration of $\mathrm{CO}_{2}$-induced heating. Associated with this change, the strength of North Atlantic conveyor belt is reduced, which results in a large warming in the upper ocean and cooling in the deep layers. The characteristic response time ranges from 40-50 years for the active $\mathrm{CO}_{2}$-induced climate change, and 70-160 years for passive $\mathrm{CO}_{2}$-induced climate change. The physical processes controlling the geochemical tracer penetration are very similar to those for the $\mathrm{CO}_{2}$-induced heating. Detailed comparisons between the penetrations of the $\mathrm{CO}_{2}$-induced beating and passive tracers show that there is no a single tracer, whether tritium, CFC-11, CFC-12 or the passive $\mathrm{CO}_{2}$ induced heating, which penetrates into the ocean exactly like the active $\mathrm{CO}_{2}$-induced heating in terms of distribution, transport or physical process. The overall results indicate that $\mathrm{CFCs}$ may be the best candidate as a surrogate for the $\mathrm{CO}_{2}$-induced oceanic climate study. The carbon-cycle study shows that the model is capable of simulating the observed ocean-atmosphere $\mathrm{pCO}_{2}$ difference $\left(\triangle \mathrm{pCO}_{2}\right)$ in most areas. However, the model cannot simulate the observed magnitude and detailed geographical distribution of $\Delta \mathrm{pCO}_{2}$ because they are also determined by the organic and biological processes which are neglected in the present study. The modelsimulated ocean uptake of atmospheric $\mathrm{CO}_{2}$ is about $2.61 \mathrm{GtC}$ per year, which is about $38.6 \pm 5.6 \%$ of the anthropogenic atmospheric $\mathrm{CO}_{2}$ released during the last decade.

Major Profescor(s): Schlesinger, Michael

Department: Atmospheric Sciences

Principal Investigator(s): Schlesinger, Michael

Program Area: Carbon, Climate, and Vegetation

KEYWORDS: CARBON DIOXIDE, CLIMATE, HEAT FLUX, MODELS, OCEANS, TRACERS

\section{5}

Jones, Pierce. 1981. Dynamic Photosynthetic Response of Soybeans: Model Development and Elevated $\mathrm{CO}_{2}$ Experiments. Ph.D. Dissertation, University of Florida, 175 pages.
A biochemical photosynthesis model has been developed and experiments at the whole plant level have been conducted in a holistic investigation of photosynthetic rate controls. The model was based on known biochemical pathways and emphasized the role of starch, sucrose and inorganic phosphate in the feedback control of $\mathrm{CO}_{2}$ fixation. The experimental work was designed to investigate short term rate response to a sudden change in $\mathrm{CO}_{2}$ concentration and long term physical adaptation to distinctive environmental $\mathrm{CO}_{2}$ levels. In the experimental procedure different source-sink balances were established for each treatment and plant response was measured. In the model the mechanisms for source-sink feedback process were developed. The overall purpose of the work has been to demonstrate and clarify the role played by source-sink relations in the feedback regulation of photosynthesis. Comparison of model predictions with measurements from the literature have shown the model's individual response equations to behave well. Overall the model demonstrated the central role of inorganic phosphate as a regulator of the Calvin cycle via its effects on the ATP/ADP ratio and as a regulator, partitioning $\mathrm{CO}_{2}$ between starch and sucrose synthesis. In turn, the concentration of inorganic phosphate was modelled to depend inversely on cytoplasmic sucrose level which was modeled to depend on export. By functionally linking the export of sucrose from the cytoplasm to sink demand, the model qualitatively described the photosynthetic inhibition and enhancement observed in a variety of scenarios. The experimental results showed soybeans (Glycine max c.v. Bragg) to respond to elevated $\mathrm{CO}_{2}$ levels by increasing net photosynthesis and respiration in the short term and increasing leaf area and biomass in the long term. Close analysis of photosynthetic light response found morning enhancement and/or afternoon inhibition of $\mathrm{CO}_{2}$ fixation in plants exposed to high $\left[\mathrm{CO}_{2}\right]$. In the canopy switched to high $\mathrm{CO}_{2}$, the magnitude of afternoon inhibition was suppressed by rapidly enhanced sink strength. Reduced $\mathrm{CO}_{2}$ fixation corresponded to higher levels of soluble carbohydrates in the leaves. Taken together these results supported the proposed interdependence between leaf sucrose levels and photosynthesis. The experimental work showed the association between source-sink balancing and photosynthetic rate while the biochemical model demonstrated a linkage mechanism. The differences in detail of the biochemical and whole plant levels prevented direct quantitative comparisons between model and experimental results. Nevertheless the experimental and model results were qualitatively consistent and this work represented a necessary effort at a holistic explanation of photosynthetic rate regulation. 
Major Professor(s): Zachariah, G.L., and James W. Jones

Department: Mechanical Engineering

Principal Investigator(s): Allen, Leon H., Jr.

Program Area: Carbon, Climate, and Vegetation

\section{KEYWORDS: ATMOSPHERE, BIÒMASS, CARBOHYDRATES, CARBON DIOXIDE, FERTILIZATION, LEAVES, MODELS, PHOSPHATE, PHOTOSYNTHESIS, RESPIRATION, VEGETATION}

\section{6}

Joos, Fortunat. 1992. Modellierung der Verteilung von Spurenstoffen im Ozean und des globalen Kohlenstoffkreislaufes. Ph.D. Thesis, University of Bern, 131 pages.

A model for simulating the transport of $\mathrm{CO}_{2}$ and tracers in the ocean (HILDA-model) is studied. The model is latitudinally divided into two zones; in the low latitudes, transport into the deep ocean occurs by eddy diffusion, while the high-latitude zone consists of two boxes (surface and deep ocean). Different ways of calibration are compared and it is found that in order to reproduce the distribution of natural radiocarbon as well as bomb-produced radiocarbon, the vertical eddy diffusivity $\mathbf{K}$ must decrease with depth. The concept of eddy diffusion is discussed. The model is validated comparing model results of the oceanic distribution of CFCs and Ar-39 with observations. The oceanic uptake of anthropogenic $\mathrm{CO}_{2}$, biospheric $\mathrm{CO}_{2}$ emissions and isotopic perturbations are calculated, based on the observed atmospheric $\mathrm{CO}_{2}$ concentration history. The results indicate an oceanic uptake of $1.9 \mathrm{Gt}-\mathrm{C} / \mathrm{yr}$ in 1980, and a near-zero net contribution from the biota in the past several decades. The HILDA-model is compared with other models, and we find that its response to atmospheric $\mathrm{CO}_{2}$ perturbations is rather similar to that of a 3-D ocean carbon cycle model of the Princeton group. The possible impact of a hypothetical iron fertilization on atmospheric $\mathrm{CO}_{2}$ levels is studies with the HILDA model. Assuming as an upper limit scenario that it is possible to stimulate the uptake of abundant nutrients in the Southern Ocean, the maximum atmospheric $\mathrm{CO}_{2}$ depletion is $58 \mathrm{ppm}$ after 50 years and $107 \mathrm{ppm}$ after 100 years. This scenario requires completely effective Fe fertilization to be carried out over $16 \%$ of the world ocean area. If iron fertilization were terminated, $\mathrm{CO}_{2}$ would escape from the ocean and soon cancel the effect of the fertilization. The possible effect of fertilizing the ocean is small compared to the expected atmospheric $\mathrm{CO}_{2}$ increase over the next century, unless the increase is kept small by means of stringent measures to control $\mathrm{CO}_{2}$ emissions.
Major Professor(s): Oeschger, H., and U. Siegenthaler Department: Physics Institute Principal Investigator(s): Siegenthaler, U. Program Area: Carbon, Climate, and Vegetation

\section{KEYWORDS: CARBON CYCLE, CARBON ISOTOPES, DIFFUSION, EMISSIONS, FERTILIZATION, METALS, MODELS, OCEANS, TRACERS}

97

Kamuru, Freeman 1992. Ammonia Production by a Mutant Strain of Anabaena variabilis and Its Contribution to Growth and Yield of Rice (Onyza sativa L.). Ph.D. Dissertation, University of Florida, 155 pages.

The cyanobacteria-rice interaction in paddy rice fields contributes to the soil nitrogen required to grow a rice crop. Experiments were carried out to evaluate the performance of a nitrogenase derepressed mutant strain of the cyanobacterium Anabaena variabilis as a nitrogen supplier for the growth of rice plants. The plants were grown in pots in the field and inoculated with either the parent or mutant cyanobacterium. The ability of the mutant cyanobacterium to supply nitrogen to grow a rice crop was determined by comparison of the dry matter and total nitrogen contents of rice plants inoculated with the parent strain or supplied with three levels if fertilizer nitrogen $\left(25,50\right.$ and $\left.100 \mathrm{~kg} \mathrm{~N} \mathrm{ha}^{-1}\right)$. Both dry matter and total nitrogen contents of the rice plants were enhanced by inoculation with the cyanobacterium. The response of the cyanobacteria-rice interaction to elevated $\mathrm{CO}_{2}$ concentration was investigated. Exposure of the rice p'ants to $660 \mu \mathrm{mol}$ $\mathrm{mol}^{-1} \mathrm{CO}_{2}$ resulted in a higher biomass compared to the biomass of plants grown at the ambient $\mathrm{CO}_{2}$ concentration. Evidence from the nitrogen accumulated in the biomass of the inoculated plants suggests that the elevated $\mathrm{CO}_{2}$ concentration was favorable for the fixation of dinitrogen and its subsequent uptake by the rice plants. In a pulse-chase experiment using ${ }^{15} \mathrm{~N}_{2}$, the assimilation of newly fixed nitrogen by rice plants was demonstrated. By the eighth week of growth, as much as $21 \%$ of the nitrogen accumulated in the biomass of rice plants inoculated with the ammonia-excreting mutant was assimilated from biologically reduced nitrogen. The ability to reduce dinitrogen and excrete newly fixed nitrogen into the surrounding environment, even in the presence of a combined nitrogen source, makes the mutant cyanobacterium a potential nitrogen source for paddy rice production.

Major Professor(s): Allen, Leon H., Jr., and S.L. Albrecht Department: Agronomy 
Principal Investigator(s): Allen, Leon H., Jr. Program Area: Carbon, Climate, and Vegetation

KEYWORDS: ATMOSPHERE, BACTERIA, CARBON DIOXIDE, FERTILIZATION, GROWTH AND DEVELOPMENT, NITROGEN SPECIES, VEGETATTON, YIELD

98

Kowase, Mitsuhiro. 1986. Circulation and Nutrients in the Atlantic Ocean. Ph.D. Dissertation Princeton University, 145 pages.

A set of property distribution maps and propertyproperty plots on eighteen potential density surfaces that cover the depth range of the North and Tropical Atlantic Ocean are presented using the data from the Transient Tracers in the Ocean (TTO) cruises, Meteor Cruise 56 leg 5, Atlantic II cruise 109 legs 1 and 3, and the GEOSECS Atlantic Study. The properties studied are salinity, oxygen, apparent oxygen utilization (A.O.U.), nitrate and silica. The results are discussed in terms of the large scale oceanic circulation and mixing, and the nutrient dynamics. The Atlantic Ocean can be understood to consist of four layers, (1) the thermocline where there is a strong contrast between the oxygenrich subtropical gyre where patterns supporting the ventilated thermocline hypothesis and be observed and the nutrient-rich equatorial ocean, (2) the stagnant layer below (1) that features the Mediterranean Outflow, (3) the North Atlantic Deep Water layer which appears to be better ventilated than the layer above with a strong signal of the deep western boundary current, and (4) the bottom layer with the influence of the Antarctic Bottom Water. The Mediterranean Outflow appears capable of driving strong salt fingering over a wide area in the subtropical Atlantic, which may drive strong isopycnal flows. The deep western boundary current shows irregularities which may be interpreted as stagnation points, and is seen to separate eastward along the equator. The Antarctic Bottom Water that enters the northern western basin seems to upwell in a concentrated manner at about 25 degrees N. Propertyproperty plots are used to infer (1) a possibly significant cross-isopycnal mixing activity in the equatorial ocean at the Antarctic Intermediate Water level, (2) significant nutrient regeneration throughout the water column in the upwelling region off the west coast of Africa, and (3) the cessation of the entry of the Iceland-Scotland Overflow Water into the deep western basin prior to TTO and consequent freshening of the deep Labrador and Irminger Seas in the past decade.

Major Professor(s): Sarmiento, Jorge L. Department: Geophysical Fluid Dynamics Program
Principal Investigator(s): Sarmiento, Jorge L. Program Area: Carbon, Climate, and Vegetation

KEYWORDS: CIRCULATION, NITROGEN SPECIES, OCEANS, OXYGEN, SALINITY, SILICA

99

Kearney, Anne Regina. 1993. Promoting Ride Sharing: The Effect of Information on Knowledge Structure - A Cognitive Perspective. M.S. Thesis, University of Michigan, $99+$ pages.

Transportation sources are a dominant source of many air pollutants which contribute to eivironmental problems. They contribute $70 \%$ of carbon monoxide emissions, $45 \%$ of the nitrous oxides, $34 \%$ of hydrocarbon emissions, and $73 \%$ of lead emissions (EPA, 1991). These pollutants contribute significantly to ozone depletion, global warming, and acid rain, as well as cause many adverse health effects (Graedel and Crutzen, 1990; Schneider, 1990). A major component of transportation-related emissions can be attributed to work-related trips. The length and duration of these trips has continued to grow and greatly reduces any overall pollution reduction achieved through improved auto efficiency and cleaner fuels (Schreffler and Kuzmyak, 1991; EPA, 1991). The 1990 Amendments to the Clean Air Act were designed to address this problem by mandating the implementation of transportation control measures to reduce work- related vehicle trips. Specifically, all employers with at least 100 employees who are located in areas where emissions levels are above a set standard are required to implement a trip reduction program. However, while economic-based programs have often been successful at the macro-level (e.g., utilities, large manufacturers), they have generally failed to affect long-term changes at the micro-level (i.e. the individual energy consumer) (Dennis et al., 1990). Energy users have failed to adopt energy-conserving technology even when it is highly cost-effective (Ross and Williams, 1981) and the adoption of energy conservation practices has been described as unpredictable (Yates and Aronson, 1983). Behavioral changes which do occur are usually at the minimal acceptable level and discontinue when the economic incentive is removed (Cook and Berrenberg, 1981). Certainly for this category of programs, the rational economic model is not a good description of individual behavior; reliance on this model is likely to continue to produce programs and strategies which are ineffective. It appears unlikely that the rationaleconomic model can provide a useful framework for promoting energy conservation among individual consumers. A more descriptive model of decisionmaking has been proposed by Kaplan (1991) and is 
based on what is known about human cognition, human behavior, and human evolution. While this model recognizes that economic incentives are one factor in the decision- making process, emphasis is also placed on the role of knowledge in the decision-making process. Support for this position is derived from numerous other studies pointing to the importance of knowledge and the impact of a lack of knowledge when making decisions (e.g., DeYoung, 1988-89; Weigel and Amsterdam, 1976). It is hypothesized that this knowledge-based model will prove useful for the examination of individual decision-making with regards to employee ride-reduction behavior. The use of case studies or narratives (or "stories" as they will be referred to in this paper) which provide interesting, vivid, concrete, and personalized information has been suggested as an effective way to transfer information (Monroe and Kaplan, 1988). The characteristics of a good story (e.g., coherence, vivid and concrete detail, a sense of mystery) readily encourage a depth of cognitive processing which makes it likely that the information will be used when making future decisions. Stories have great potential for educating people about phenomena which cannot be directly experienced and for offering behavioral solutions to environmental problems. This study will use Kaplan's (1991) knowledge-based decision-making model to explore the impact of knowledge on attitudes and intended behavior towards carpooling. The model predicts that the knowledge an individual has about a particular subject has a significant effect on his/her decisions. In general, people with little or no knowledge about a behavior (or consequences of a behavior) will tend to avoid that behavior. People with a well developed knowledge structure about a particular behavior will feel more confident in their ability to carry out the behavior and will thus be more likely to engage in that behavior. This assumption is supported by empirical studies on the differences between solo drivers and users of alternative transportation (e.g., public transit, carpools). These studies (covered in the Literature Review) suggest that a major reason why drivers will not switch to alternative modes of transportation is because they lack information on how to switch and how to deal with problems which may be encountered while using an alternative mode. Another purpose of this study is to compare two different information campaigns on their effectiveness in imparting knowledge about carpooling to the study participants. Studies (covered by Literature Review) show that pallid, relatively abstract information (e.g., factsheet, factual brochures) are not very effective at transferring information. In contrast, using stories to transfer information may be very effective. In this study, a story-based information campaign will be compared to a factual-based information campaign. Both of the groups receiving the information campaigns will be compared to a control group. Carpooling was chosen as the target behavior because it traditionally has a low level of adoption and because of its wide applicability (e.g., as compared to public transit). Carpooling has been shown to be an effective means of reducing employee vehicle trips, thereby reducing environmental degradation due to commuting (EPA, 1991).

Major Professor(s): DeYoung, Raymond, and Stephen Kaplan

Department: School of Natural Resources and

Environment

Principal Investigator(s): Wohlpart, A.

Program Area: Graduate Fellowships for Global Change

\section{KEYWORDS: AIR QUALITY, EMISSIONS, TRANSPORTATION}

\section{0}

Kim, Yongseung 1991. Sulfate Impact upon Low-Level Cloud Albedo over Oceans. Ph.D. Dissertation, State University of New York at Stony Brook, 161 pages.

The Earth Radiation Budget Experiment (ERBE) NOAA-9 scanner measurements have been employed for the purpose of identifying cloud albedo change due to continental sulfur emissions in the Northern Hemisphere. Comparison of cloud albedo over two hemispheric oceans has been made based on the hemispheric imbalance of the anthropogenic sulfur emissions that exists. The present study shows that cloud albedo, particularly in the broad maximum region of sulfur emissions off the east coasts of North America and Asia, appears to be affected by the landtransported sulfate aerosols. Although the continental sulfate aerosols substantially modify the marine lowlevel cloud albedo off the coasts, their dominance over the central ocean appears to be uncertain. The primary source of cloud albedo variations over the central ocean are considered to be phytoplankton chlorophyll concentrations, sea surface temperature (SST) and solar zenith angle (SZA). The correlation analysis, using chlorophyll concentrations derived from the Coastal Zone Color Scanner (CZCS) and the climatological SST data, respectively demonstrates that these two variables explain substantial variations of cloud albedo over the central ocean. However, the SZA effect upon the cloud albedo vs. longitude pattern is shown to be negligible.

Major Professor(s): Cess, Robert D. Department: Mechanical Engineering (Atmospheric Sciences) Principal Investigator(s): Cess, Robert D. 
Program Area: Carbon, Climate, and Vegetation

\section{KEYWORDS: CLOUDS, REFLECTANCE}

\author{
101 \\ King, Anthony W. 1986. Using Ecosystem Models to \\ Predict Regional $\mathrm{CO}_{2}$ Exchange Between the \\ Atmosphere and the Terrestrial Biosphere. Ph.D. \\ Dissertation University of Tennessee, 273 pages.
}

Ecologically sound models of the terrestrial biosphere are needed in the investigation of the Earth system and global change. Traditional ecosystem models simulate many processes and dynamics relevant to the functioning of the Earth system, but their application is limited by their local, small-scale, often site-specific nature. We address this limitation by deriving a method for predicting regional biosphere dynamics by extrapolation from smaller-scale ecosystem models. We use models of local ecosystem carbon dynamics to predict the seasonal exchange of $\mathrm{CO}_{2}$ between the atmosphere and terrestrial ecosystems of $64 \mathrm{~N}$ to $90 \mathrm{~N}$ latitude. Monte Carlo simulation is used to integrate solutions of a tundra model and a coniferous forest model across within-biome heterogeneity in the models' climatic driving variables. The product of the expected value of each model's output and the area of the region occupied by that biome or ecosystem type is an estimate of biome-scale $\mathrm{CO}_{2}$ exchange. Regional $\mathrm{CO}_{2}$ exchange is the sum of the biome exchanges. Comparisons of the extrapolation's results with independent estimates of seasonal $\mathrm{CO}_{2}$ exchange and annual net primary production support the proposition that extrapolation of ecosystem models can be used to simulate regional biosphere dynamics.

Major Professor(s): DeAngelis, D.L. Department: Graduate Program in Ecology Principal Investigator(s): Emanuel, W.R. Program Area: Carbon, Climate, and Vegetation

KEYWORDS: BIOSPHERE, CARBON CYCLE, CARBON DIOXIDE, CLIMATE, FORESTS, MODELS, PRODUCTIVTTY, REGIONAL ANALYSIS, TERRESTRLAL ENVIRONMENT, TUNDRA

\section{2}

Kinnison, Douglas Edward. 1989. Effects of Trace Gases on Global Atmospheric Chemical and Physical Processes. Ph.D. Dissertation, University of California at Berkeley, 202 pages.

This study examines the effects that increased emissions of anthropogenic and naturally-occurring trace gases have on the chemical and physical processes in the global atmosphere. The Lawrence Livermore National Laboratory (LLNL) one- and two-dimensional chemical-radiative-transport models of the troposphere and stratosphere, are used to calculate the net effects that variations in these trace gases, either individually, or taken together have on the ozone distribution and temperature structure. Using the LLNL onedimensional model, calculations are made that include large changes of $\mathrm{NO}_{x} \mathrm{Cl}_{x}$ and $\mathrm{HO}_{x}$ The object was to see if any interesting or unexpected effects could be found. The nitrous oxide boundary value is varied from 4 to 8 times the reference $(1960)$ value of $300 \mathrm{ppb}$. Stratospheric $\mathrm{Cl}_{\mathrm{x}}$ is varied from 0 to $22 \mathrm{ppbv}$. Special atmospheres are considered in which all $\mathrm{HO}_{x} \mathrm{NO}_{x}$ and $\mathrm{Cl}_{x}$ or combinations of these are omitted from the reference atmosphere. A sensitivity study is carried out using the LLNL one- and two-dimensional chemicalradiative-transport models to examine possible effects of future aircraft $\mathrm{NO}_{x}$ emissions on stratospheric ozone. A broad range in magnitude, altitude, and latitude of the assumed $\mathrm{NO}_{\mathrm{x}}$ emissions is examined for various background $\mathrm{Cl}_{x}$ values. The change in column-ozone is calculated for each sensitivity scenario relative to a reference atmosphere. Comparisons between the oneand two-dimensional models are discussed. The effect on the ozone-column due to variations in the eddy diffusion representation ( $\mathrm{K}_{\mathrm{yy}}$ and $\mathrm{K}_{\mathrm{zz}}$ ) is shown for one aircraft scenario. The emissions and atmospheric concentrations of several trace gases $\left(\mathrm{N}_{2} \mathrm{O}, \mathrm{CH}_{4}, \mathrm{CO}_{2}\right.$, $\mathrm{CFCl}_{3}, \mathrm{CF}_{2} \mathrm{Cl}_{2}, \mathrm{CCl}_{4}$, and $\mathrm{CH}_{3} \mathrm{CCl}_{3}$, plus the effect of both the 11 year solar sunspot cycle and $\mathrm{NO}_{x}$ produced from the nuclear test series of the late 1950's and early 1960's are examined using the LLNL two-dimensional model. Changes in ozone-column, local ozone, temperature profiles, and various other species distributions are compared to observations made from the ground, balloons, aircraft, rockets, and satellites. By modeling the emissions of these trace gases on the chemical and physical processes in the global atmosphere, the potential accuracy of the twodimensional model can be estimated and the prospects of future perturbations can be more realistically assessed. The effect of the eddy diffusion representation $\left(\mathrm{K}_{\mathrm{yy}}\right.$ and $\mathrm{K}_{\mathrm{zz}}$ ) on the two-dimensional transport of trace constituents is investigated, using analyzed carbon-14 and strontium-90 data from the nuclear test series in the late 1950's and early 1960 's. Here various $K_{y y}$ and $K_{2 z}$ values, as a function of latitude and altitude, were used to see what values best represented or corresponded with short and long term transport of the above two tracers. In addition, the model was used to help verify which of the two available estimates for bomb stabilization cloud height, Seitz [1968] or Peterson [1970]. better represents the available data. The effect of varying the eddy transport is examined in 
terms of model-calculated change in $\mathrm{O}_{3}$ column distributions. The best eddy diffusion representation derived from the tracer study gave the best ozonecolumn distribution relative to observational data.

Major Professor(s): Johnston, Harold

Department: Chemistry

Principal Investigator(s): Wuebbles, Donald J.

Program Area: Atmospheric Sciences

KEYWORDS: AEROSOLS, CARBON ISOTOPES, DIFFUSION, EMISSIONS, GASES, HALOGEN SPECIES, MODELS, NITROGEN SPECIES, OZONE, PARTITIONING, RADLATIVE PROCESSES, STRONTIUM-90, TEMPORAL DISTRIBUTTON, TRACERS

103

Kirtyla, Kristina Irena 1988. Harmonic Analysis of Global Precipitation: A Comparison Between a General Circulation Model and Observations. M.S. Thesis, State University of New York at Stony Brook, 135 pages.

Using precipitation values obtained from a version of the Oregon State University General Circulation Models and observational gridded data, harmonic analysis has been employed to study the seasonal variation of precipitation over various regions of the globe, including conterminous United States, South and Central America, Europe, Asia, Australia and Africa. Maps of primarily the first and second harmonic amplitudes, and the corresponding maxima provide a useful source of comparison between model output and observational data. Results indicate that the method of harmonic analysis allows a more analytical comparison between model predictions and data than the conventional approach of representing the annual march in the form of a curve of mean monthly rainfall amounts. The method delineates regional boundaries of various precipitation regimes, highlighting regions of transition. It is seen that the GCM captures a significant amount of regional detail in precipitation climatology when its results are decomposed by harmonic analysis.

Major Professor(s): Hameed, Sultan

Department: Mechanical Engineering (Atmospheric Sciences)

Principal Investigator(s): Hameed, Sultan

Program Area: Carbon, Climate, and Vegetation

KEYWORDS: CLIMATE, MODELS, PRECIPITATION, TEMPORAL DISTRIBUTION
104

Kniph Lisa Anne. 1988. A Time Series Analysis of Precipitation Records in China from 1470-1979. M.S. Thesis, State University of New York at Stony Brook, 104 pages.

A time series analysis using the method of Fourier transforms is performed on twenty-six precipitation records from Northeast China over the period of 14701979. The large quantity of data present has permitted the detailed investigation of the nature of the background spectrum of the series and the distribution of the spectral density over particular frequencies. An analysis of the power spectra reveals that the background spectrum is more closely related to white noise than to red noise which is commonly used in the time series analysis of climatic variables. A Fourier analysis is performed on a large number of random series in order to examine the distribution of spectral estimates over a particular frequency. Experimentation shows that the distribution of spectral lines due to random fluctuations is indeed the theoretically proposed chi square distribution. This idea was then applied to certain frequencies of the Chinese precipitation data. The distribution of spectral estimates for frequencies corresponding to $18.6,22.2$, and 10.4 years was seen to be significantly different from that of chi square. Therefore it may be concluded that fluctuations in the Chinese precipitation at periods of $18.6,22.2$, and 10.4 years have some physical causes and are not random fluctuations.

Major Professor(s): Hameed, Sultan

Department: Mechanical Engineering (Atmospheric

Sciences)

Principal Investigator(s): Hameed, Sultan

Program Area: Carbon, Climate, and Vegetation

KEYWORDS: ASLA, PRECIPITATION, TEMPORAL DISTRIBUTION

105

Kwon, Tae-Yong 1993. An Examination of the Time/Space Averaging Process Used in the Earth Radiation Budget Experiment. Ph.D. Dissertation, State University of New York at Stony Brook, 99 pages.

This study examines the Time/Space Averaging (TSA) process applied to scanner measurements of the Earth Radiation Budget Experiment. The TSA process produces monthly averages from the temporally sparse flux measurements on a regional scale. The diurnal distribution of the ERBS flux measurements for a given month and region shows considerable bias in high latitudes due to the inclination of the ERBS satellite 
orbit. The ERBS measurements for 72 days (approximately the processing period of the ERBS satellite orbit) have a nearly complete diurnal distribution for each region between $60^{\circ} \mathrm{N}-60^{\circ} \mathrm{S}$. To examine the TSA process, simple averages obtained from two 72-day measurement sets in 1985 and 1986 are assumed as the expected true averages. For clearsky, simple averaging methods are employed to infer the true averages where one can expect a diumal sampling bias due to clouds. The TSA process is examined in detail for different data sets of ERBS and NOAA 9. This repurt shows that the TSA process is adequate to account for the diurnal variation of radiation for both ERBS and NOAA 9 clear-sky measurements. The monthly clear-sky longwave flux differences between ERBS and NOAA 9 are explained mostly by the ERBS diurnal sampling bias and the different scene identification procedures for daytime and nighttime. When applied to NOAA 9 cloudy-sky measurements, considerable errors result in the summer hemisphere. This is due to the substantial diurnal variations of cloud properties and the NOAA 9 sampling at only around $2: 30$ and 14:30 local time in most latitudes. For ERBS cloudy-sky measurements, the above errors are seen to be reduced significantly because of better diurnal sampling. A similar examination is suggested for the case of NOAA 10, the third ERBE satellite, which samples at around 7:30 and 19:30 local time in most latitudes.

Major Professor(s): Cess, Robert D.

Department: Mechanical Engineering (Atmospheric Sciences)

Principal Investigator(s): Cess, Robert D.

Program Area: Carbon, Climate, and Vegetation

\section{KEYWORDS: RADLATIVE PROCESSES}

\section{6}

LaFontaine, Carolyn Vada. 1988. Comparison of the Simulated Climate and Geologic Observations from Equatorial Land Regions for the Past 18,000 Years. M.S. Thesis, University of Wisconsin-Madison, 62 pages.

Equatorial land results of paleoclimate simulations by Kutzbach and Guetter (1986) were examined for three areas: New Guinea/northern Australia, eastern equatorial Africa and western equatorial South America. Area-averaged results were computed at $\mathbf{3 0 0 0}$ year intervals for the past 18,000 years. Results were compared with geologic data and the results of similar paleoclimatic experiments. Prescribed changes in orbital parameters (Milankovitch mechanism) had the greatest effects on the model results at 9 and $6 \mathrm{kyr}$ BP but at 18 and 15 kyr BP prescribed boundary conditions were more important in the results. Modeled results were compared with geologic data compiled from many sources. Much colder temperatures and drier conditions were shown by the geologic data at 18 and $15 \mathrm{kyr}$ BP than are simulated by the model. However, at $9 \mathrm{kyr}$ BP the agreement was better. Although the magnitude of the simulated changes did not agree with the geologic inferences, the trend of those changes agreed reasonably well with geologic data in each region. Results from the Kutzbach and Guetter climate simulation were also compared with similar climate simulations. The most direct comparison was with that of Rind and Peteet (1985). While the simulated surface temperature in each of the three regions was similar, precipitation results were more variable.

Major Professor(s): Kutzbach, John E.

Department: Meteorology

Principal Investigator(s): Kutzbach, John E.

Program Area: Carbon, Climate, and Vegetation

KEYWORDS: CLIMATE, EQUATORIAL REGION, GEOLOGY, ICE AGE, MODELS

107

Lamoureux, Scott F. 1994. Paleoclimatic

Reconstruction from Varved Lake Sediments, Lake C2, Ellesmere Island, Canada. M.S. Thesis, University of Massachusetts, 160 pages.

Varved sediments from High Arctic Lake C2 (82 ${ }^{\circ} 50^{\prime} \mathrm{N}$, $76^{\circ} 00^{\prime} \mathrm{W}$ ), a small, deep ( $84 \mathrm{~m}$ ), low-elevation meromictic lake, were investigated as a paleoclimatic proxy. The combination of a short runoff and sediment transport season with the strong density stratification of the lake lead to the formation of annual sediment couplets. The annual nature of the varves was confirmed by ${ }^{210} \mathrm{~Pb}$ determinations. Additionally, previous work established that intra-lake varve correlation was high. This study investigated varved sediments from seven distal sediment cores from depths ranging from 19 to $38 \mathrm{~m}$. The cores exhibited similar records of near-massive marine mud overlain by 20-60 $\mathrm{cm}$ of finely laminated mud. Physical measurements were relatively constant throughout the laminated portions of the cores studied. The cores were organicpoor, and did not provide sufficient material for radiocarbon determinations within the varved sections. A continuous record of the varved sediments was obtained by removing slabs of sediment from the unfrozen cores. The slabs were dehydrated with repeated applications of acetone followed by epoxy resin. The epoxy was cured and the slabs were thinsectioned for the counting and measuring the varves 
under a microscope. Well-defined marker beds were visually identified and correlated among the thin sections. Varve sequences between the marker beds were repeatedly counted and measured. Cross-dating was performed between core sections to identify and resolve identification errors. Cross-dating revealed that minor disturbances of the thin Lake $\mathrm{C} 2$ varves lead to varying amounts of identification error. Thin varves were most frequently missed during measurement, and were subsequently identified during cross-dating with other cores. Additionally, sublaminations were occasionally incorrectly identified as separate (extra) couplets. The weighted whole-core mean errors were 1.1-11.5\% for missed varves and $0.3-1.4 \%$ for extra varves. The net of both types of error (5.92\%) estimates the error associated with varve sequences that are not cross-dated. Comparison between proximal and distal sediments measured by independent workers revealed no errors for a 200 year period, suggesting that varve chronology error after cross-dating was minimal. A composite, detrended varve chronology was constructed from the cross-dated varve sequences in this study. Approximately 950 years of the varve composite were not cross-dated owing to disturbances in the sediment cores. The error due to counting errors is estimated at \pm 57 years. A good relationship between upper air temperatures $(500 \mathrm{~m})$ and sediment transport into Lake $\mathrm{C} 2$ permits a tentative calibration between varve sedimentation and climate. This relationship suggests that meltwater production in the upper watershed is more important to sedimentation than low elevation conditions. The $\mathbf{3 3 0 0}$ year composite record reveals low frequency events similar to the d180 variations in the Agassiz, Devon, and Camp Century ice cores. Additionally, the varved record from Lake C2 shows similarity with other North American proxy records during the past 500 years. The good correlation between the varve record and other High Arctic proxies suggests that the tentative climatic interpretation of varve thickness is reasonable and that the chronology is accurate. These results also suggest that the Lake C2 varve sedimentation rate has been sensitive to High Arctic and hemispheric climatic forcings.

Major Professor(s): Bradley, Raymond S. Department: Geology \& Geography Principal Investigator(s): Bradley, Raymond S. Program Area: National Institute for Global Environmental Change (NIGEC)

KEYWORDS: ARCTIC, CLIMATE, LAKES, NORTH AMERICA, NORTHERN HEMISPHERE, SEDIMENTS, TRACERS
108

Leach, Martin. 1994. The Interactive Role of Clouds and Radiative Transfer in Maintaining Atmospheric Circulation. Ph.D. Dissertation, North Carolina State University, 150 pages.

Radiative flux divergence is one of the principal physical forcings for atmospheric circulation. It affects the temperature, winds, cloud evolution and structure, and the water budget on all time and space scales. In this study, numerical models are used to study the effects of radiative transfers on a variety of atmospheric circulation systems on time scales from several hours to several days, and on space scales of about 10 kilometers to 10 thousand kilometers. Shortwave and longwave radiative transfer are added to a mesoscale model which includes detailed microphysics and turbulence closure schemes. This model is used to study three cases where radiative transfer plats a role in the structure of the atmosphere. The first is stratocumulus clouds that form in the wake of thunderstorms. Longwave radiative flux divergence at the top of the boundary layer maintains the cloud layer by cooling at cloud iop, enhancing the inversion strength. Eventually, shortwave energy reaching the surface creates sufficient buoyancy to overcome the longwave forcing of the cloud layer, and the cloud dissipates. The same longwave forcing is responsible for the formation of boundary layer clouds in the second case studied, the coastal front. In that case, the presence of clouds also affects the horizontal heating of the atmosphere, as clouds effectively trap longwave energy below clouds, but also reflect shortwave energy, so that surface heating over land is less. The differences in radiative forcing changes the relative intensity of the thermal circulations that form over the Gulf Stream and at the coastline, with further feedback to the clouds, winds, temperature, and atmospheric water vapor. Finally, the third case was an examination of the effects of radiative transfer on low level cyclogenesis. Again, the longwave flux divergence at the top of the clouds maintained a cloud layer against the destructive force of mixing from below and entrainment from above. Once clouds form, horizontal thermal gradients lead to increased vorticity generation and a more intense circulation. A stronger circulation feedback to the cloud formation processes and water budget results. Finally, radiative transfer was added to a numerical weather prediction model to study the Indian summer monsoon. The length and time scales in this study were much longer, covering a 180 degree longitude by 90 degree latitude domain for 10 day forecasts. The conclusions however were remarkably similar to thase from the smaller model. Radiative transfer maintains the strengths and structure of the components of the monsoon circulation system with feedback to cloud and precipitation processes. 
Major Professor(s): Raman, Sethu

Department: Marine, Earth and Atmospheric Sciences

Principal Investigator(s): Raman, Sethu

Program Area: Atmospheric Radiation Measurement (ARM)

KEYWORDS: ATMOSPHERE, BOUNDARY LAYER, CIRCULATION, CLIMATE, CLOUDS, COASTAL ENVRONMENT, MICROPHYSICS, MODELS, OCEANS, PRECIPITATION, RADLATIVE PROCESSES, STORMS, TURBULENCE

\section{9}

Leadley, Paul W. 1985. Effects of Air Quality on Soybeans: (1) Effect of $\mathrm{CO}_{2}$ on Leaf Area Development and (2) Effect of $\mathrm{O}_{3}$ on Canopy Light Interception and Crop Growth Rate. M.S. Thesis, North Carolina State University, 129 pages.

The effects of air quality factors on soybean were studied using open-top field fumigation chambers. The study consisted of two parts: (1) the effects of elevated $\mathrm{CO}_{2}$ on mainstem leaf area development and relationships between leaflet length, width, area and dry weight in Ghcine max (L.) Merr. 'Bragg' and (2) the effects of ozone on light interception, conversion of light energy into shoot biomass and interaction with water stress in Glycine max (L.) Merr. 'Davis".

(1) Effects of $\mathrm{CO}_{2}$ on soybeans were studied using three $\mathrm{CO}_{2}$ concentrations: 349,502 and $645 \mathrm{ppm}$. Analysis of mainstem central leaflet growth indicated that the first leaflet grew faster and the second leaflet appeared earlier in elevated $\mathrm{CO}_{2}$ atmospheres. The rate of expansion, duration of expansion, rate of appearance and final area of subsequent leaflets were unaffected by $\mathrm{CO}_{2}$. Analysis of non-destructive estimates of leaf area and dry weight indicated that leaflet length times width was an excellent predictor of central leaflet area and trifoliolate area, and trifoliolate dry weight could be adequately predicted from leaf area if a linear model with $\mathrm{CO}_{2}$ concentration was incorporated. (2) There were five ozone treatments in the ozone study, ranging from $25 \mathrm{ppb}$ to $100 \mathrm{ppb}$ and two watering treatments providing water-stressed and non-stressed conditions. The effects of $\mathrm{O}_{3}$ were examined using light conversion analysis which resolves crop yield into the product of canopy light interception, fractional allocation of biomass to seed and the efficiency of conversion of light energy into biomass. Analysis of the non-stressed soybean growth indicated that high ozone levels reduced seed yield by decreasing the efficiency of conversion of intercepted light to biomass. Canopy light interception and fractional allocation were not affected by $\mathrm{CO}_{2}$. Comparison of results with an earlier study by Unsworth et al. (1984) suggests that utilization efficiency consistently decreases with ozone dose. Large differences in utilization efficiencies between the two studies were attributed to different light environments and water stress caused by an unusually hot and dry year. Analysis of the growth of water-stressed soybeans indicated that water stress reduces yield by reducing utilization efficiency and the fraction of incident light intercepted by the canopy. A modified light conversion model was used, which incorporated a dry weight loss term. Results from the application of this model indicated that ozone protected soybeans from water stress, but water stress did not keep ozone from reducing light conversion efficiencies.

Major Professor(s): Reynolds, James F. Department: Botany

Principal Investigator(s): Reynolds, James F. Program Area: Carbon, Climate, and Vegetation

KEYWORDS: CARBON DIOXIDE, GROWTH AND DEVELOPMENT, LEAVES, OZONE, WATER STRESS

\section{0}

Leavith, Steven Warren. 1982. Inference of Past Atmospheric $\delta^{13} \mathrm{C}$ and $\mathrm{P}_{\mathrm{CO} 2}$ from ${ }^{13} \mathrm{C} /{ }^{12} \mathrm{C}$ Measurements in Tree Rings. Ph.D. Dissertation, University of Arizona, 221 pages.

Carbon dioxide releases from fossil-fuel burning is significant enough that we may soon experience perceptible changes in climate with important human consequences. Man's activities involving deforestation and agricuiture have undoubtedly also affected atmospheric $\mathrm{CO}_{2}$, although quantitative, and even qualitative, net effects of these processes are incompletely understood relative to fossil-fuel production. An accurate reconstruction of past ${ }^{13} \mathrm{C} /{ }^{12} \mathrm{C}$ ratios of atmospheric $\mathrm{CO}_{2}$ may provide key constraints on the historical activity of the biosphere as $\mathrm{CO}_{2}$ source or sink. Tree rings appear to be a repository of this information but there is much noise in the collection of previous reconstructions, presumably associated with site selection, radial variability, choice of representative wood chemical constituents, and subtle effects of climate and fractionation. This study attempts to avoid these pitfalls and develop a $50-\mathrm{yr} \delta^{13} \mathrm{C}_{\mathrm{ATM}}$ record from juniper trees (genus Junipenus), in fact, by taking advantage of the influence of climate on fractionation. Trees were harvested from suitable sites in close proximity to weather stations with monthly records of temperature and precipitation. Ring material was then separated from each of the sections in 5-yr intervals from 1930 to 1979 around their full circumference, and cellulose was extracted from the wood. After measuring 
$\delta^{13} \mathrm{C}$ of the cellulose by standard mass-spectrometric techniques, a variety of $\delta^{13} \mathrm{C}$ vs. climate functions were examined for each interval. The most useful relationships for at most 7 of the 10 sites were $\delta^{13} \mathrm{C}$ with December temperature or precipitation, because the coefficients were nearly constant from one interval to the next (averaging $-0.27^{\circ} \%{ }^{\circ} \mathrm{C}^{-1}$ for temperature and $-0.04 \% \mathrm{~mm}^{-1}$ for precipitation) and the intercepts differed. Local pollution effects are believed responsible for the three anomalous sites. The separation of these regression lines of different intervals is interpreted as the response of trees to the changing $\delta^{13} \mathrm{C}$ of atmospheric $\mathrm{CO}_{2}$ so that $\delta^{13} \mathrm{C}_{\mathrm{ATM}}$ curves are constructed from this spacing. The shape of the best-fit reconstruction suggests the biosphere has acted as $\mathrm{CO}_{2}$ source to about 1965 and may now be a net sink. Although these conclusions are limited by certain assumptions and statistical restrictions, evidence from the recent scientific literature tends to support the increasing role of the biosphere as an important carbon sink.

Major Professor(s): Long, Austin

Department: Geosciences

Principal Investigator(s): Long, Austin

Program Area: Carbon, Climate, and Vegetation

\section{KEYWORDS: CARBON DIOXIDE, CARBON} ISOTOPES, TREE RINGS, VEGETATION

111

Lee, Jae Chul. 1989. Circulation in the Vicinity of the Shelf/Slope Front in the Mid-Atlantic Bight. PhD. Dissertation, North Carolina State University, 106 pages.

Subtidal variability of the shelf circulation in the MidAtlantic Bight was studied using a set of meteorological, coastal sea level, current velocity, temperature, salinity, chlorophyll content and light attenuation data obtained principally from a fixed array of SEEP-I moorings deployed from 16 February to 11 April 1984. A simple theoretical model with linear bottom friction and ascillating wind stress was developed in order to explain the phase relations between wind forcing and shelf circulation. The mean alongshelf current is in the downshelf direction. The vertical gradient of the alongshelf velocity $\left(v_{2}\right)$ is relatively small at the inner stations and greater at the outer stations due to the stronger horizontal density gradient $\left(p_{x}\right)$ in the vicinity of the shelf/slope front. In effect, the time series of $v_{z}$ at the outer stations and $p_{x}$ show high visual correlation. The mean cross-shelf circulation consists of onshore motion at the upper level and offshore flow near the bottom. An event which links onshore motions occurring at 84 meters depth in 124 meters of water and ridging of the frontal interface as predicted by $\mathrm{Ou}$ (1984) was observed. At the foot of the front, the temperature fluctuation is highly correlated with net displacement of cross-shelf flow. Phase lags of the alongshelf current in response to the longshore component of wind stress are found to be between $45^{\circ}$ and $90^{\circ}$ in the band of synoptic scale forcing corresponding to about 24 hours. A frictional adjustment time scale of about 40 hours in $100 \mathrm{~m}$ is obtained empirically by the application of a linear bottom stress model to the observed phases.

Major Professor(s): Pietrafesa, Leonard J. Department: Marine, Earth and Atmospheric Sciences Principal Investigator(s): Pietrafesa, Leonard J. Program Area: Marine Transport

KEYWORDS: CIRCULATION, MODELS, OCEANS, WINDS

112

Lewis, James D. 1994. Effects of Mycorrhizae and Phosphorus Supply on Response of Pinus taeda L. Seedlings to Elevated $\mathrm{CO}_{2}$. Ph.D. Dissertation, Duke University, 157 pages.

Mycorrhizal fungi play a critical role in nutrient uptake by most tree species, and the importance of this function in regulating the outcome of increasing atmospheric $\mathrm{CO}_{2}$ on natural ecosystems is widely assumed. However, few studies have considered whether the presence or absence of mycorrhizae differentially affects the response of nutrient-limited host trees to elevated $\mathrm{CO}_{2}$. Understanding the integration of leaf-level, root-level, and whole-plant processes is crucial to predicting the influence of mycorrhizal fungi on the response of host trees to elevated $\mathrm{CO}_{2}$ across a range of environments. I manipulated mycorrhizal status and phosphorus supply in a phytotron to investigate the role of the mycorrhizal fungus Pisolithus tinctorius (D. Marx isolate \#306) in the response of loblolly pine seedlings to elevated $\mathrm{CO}_{2}$ under different phosphorus regimes. Monthly measurements of biomass accumulation and allocation, relative growth rates and needle characteristics were used to examine whole-plant responses. Effects on rootlevel processes were examined by comparing root nutrient and carbohydrate concentrations with the extent of mycorrhizal colonization. Photosynthesis and non-destructive measurements of rubisco activity and ribulose 1,5-bisphosphate regeneration capacity were used to examine effects on leaf-level processes. Linkages among photosynthetic processes were examined using covariate analysis and used to infer photosynthetic regulation by the rate of carbohydrate 
utilization. Mycorrhizal colonization significantly increased phosphorus uptake and growth of phosphorus-limited seedlings, but did not affect the response of seedling photosynthesis or biomass to elevated $\mathrm{CO}_{2}$. In fact, phosphorus-limited seedlings showed the greatest relative responses to elevated $\mathrm{CO}_{2}$, apparently as a result of increased phosphorus uptake and increased phosphorus use efficiency. Additionally, elevated $\mathrm{CO}_{2}$ did not differentially affect seedlings grown from seeds obtained from Florida and coastal North Carolina populations. However, elevated $\mathrm{CO}_{2}$ reduced photosynthetic capacity and tissue phosphorus concentrations in seedlings supplied with phosphorus at levels adequate for maximum seedling growth in ambient $\mathrm{CO}_{2}$. These results suggest that phosphoruslimited loblolly pine seedlings initially will respond to elevated $\mathrm{CO}_{2}$ due to increases in phosphorus uptake and phosphorus use efficiency, but ultimately phosphorus-limitation will reduce or eliminate the fertilization effect of elevated $\mathrm{CO}_{2}$.

Major Professor(s): Strain, Boyd R.

Department: Botany

Principal Investigator(s): Strain, Boyd R.

Program Area: Carbon, Climate, and Vegetation

KEYWORDS: CARBON DIOXIDE, ELECTRON TRANSPORT CAPACITY, FERTILIZATION, FUNGI, PHOSPHATE, PHOTOSYNTHESIS, ROOTS, RUBISCO, VEGETATION

\section{3}

Li, Aigua 1994. Effects of Elevated $\mathrm{CO}_{2}$ on Rates and Durations of Apical Development of Spring Wheat. M.S. Thesis, University of Idaho, 62 pages.

Rates and durations of individual phases for wheat apex development are one of the most important factors that determine the yield. The relationship between rate and duration of each phase and $\mathrm{CO}_{2}$ concentrations are poorly documented in the literature. This study was conducted to determine the rates and durations of leaf, spikelet and floret primordium initiation in $\mathrm{CO}_{2}$ enrichment system called FACE for Free $A$ ir Carbon dioxide Enrichment (Lewin et al., 1992). Spring wheat (Triticum aestivum L. cv. Yecora Roja), was planted with split block design of four repetitions at the University of Arizona's Maricopa Agricultural Center located approximately $40 \mathrm{~km}$ south of Phoenix, AZ $(33.075 \mathrm{~N} 111.983 \mathrm{~W})$. The wholeplots were $550 \mu \mathrm{mol}$ mol ${ }^{-1}$ enriched- $\mathrm{CO}_{2}$ or ambient $\mathrm{CO}_{2}$ concentrations. The elevated $\mathrm{CO}_{2}$ concentration was maintained by FACE system. Subplots were two irrigation treatments, half of the plants received water equivalent to full water sufficiency (wet), the other half received $75 \%$ of its water needs (dry). Water was provided with sub-surface drip tube irrigation. Samples were collected about every 3 to 4 days. Two or three plants were randomly picked for apical dissection. I dissected main stem, Primary tillers: T0, T1, T2, T3, and secondary tillers: T00, T01, $\mathrm{TO2}, \mathrm{T} 10, \mathrm{~T} 11$, and $\mathrm{T} 12$. After dissection, the number of primordia was counted, and length and width of apical dome were measured. Apical dimension data were fitted into exponential models as the function of accumulated thermal units. The apex primordium data were regressed against accumulated thermal units with four-piece segmented regression models with SAS proc NLIN, method Marquardt. Length of T3 and T10 apices was significantly $(\mathrm{p}<0.05$ ) enhanced by $550 \mu \mathrm{mol}$ $\mathrm{mol}^{-1} \mathrm{CO}_{2}$ enrichment in this experiment. Width of main stem, T2, T3 and T11 apices was significantly $(p<0.05)$ increased by $\mathrm{CO}_{2}$ enrichment. The increased length was not accompanied by the increase in spikelet primordium number, but the width increase was accompanied by more floret primordia. I observed little or no response of leaf primordium initiation of main stem to elevated $\mathrm{CO}_{2}$ concentration, which might be due to low temperature at early stage, or alternatively, leaf primordium initiation was not affected by $550 \mu \mathrm{mol}$ $\mathrm{mol}^{-1} \mathrm{CO}_{2}$ enrichment. Within the spikelet initiation phase, $\mathrm{CO}_{2}$ enrichment significantly increased rates of spikelet primordium initiation of main stem by 0.0077 spikelets per ${ }^{\circ} \mathrm{C}$ day and diminished the durations of terminal spikelet phase by $39.43{ }^{\circ} \mathrm{C}$ day. Spikelet initiation rates of $\mathrm{T} 1, \mathrm{~T} 2, \mathrm{~T} 10$ and $\mathrm{T} 11$ were significantly $(p<0.05)$ enhanced and durations of $T 1$, $\mathrm{T} 2, \mathrm{~T} 3, \mathrm{~T} 10$ and $\mathrm{T} 11$, diminished by elevated $\mathrm{CO}_{2}$ concentrations. Within the floret phase, $\mathrm{CO}_{2}$ enrichment significantly increased rates of floret primordium initiation of main stem by 0.1186 florets per ${ }^{\circ} \mathrm{C}$ day and diminished the durations of floret primordium initiation by 28.5 per ${ }^{\circ} \mathrm{C}$ day. The rates of $\mathrm{T0}, \mathrm{T} 1, \mathrm{~T} 2$ and $\mathrm{T} 3$ were significantly increased and the durations of T0, T1, T3 and T11 were significantly decreased by $\mathrm{CO}_{2}$ enrichment. Comparing tillers on a given plant, it appears that the development of later-formed tillers is more sensitive to $\mathrm{CO}_{2}$ enrichment than that of earlyformed tillers. The floret primordium initiation phase is more sensitive to $\mathrm{CO}_{2}$ enrichment than spikelet primordium initiation phases.

Major Professor(s): Trent, Tony A.

Department: Plant Science

Principal Investigator(s): Acock, Basil, Leon H. Allen, Jr., and Bruce A. Kimball

Program Area: Carbon, Climate, and Vegetation

KEYWORDS: CARBON DIOXIDE, FERTILIZATION, GROWTH AND DEVELOPMENT, MORPHOLOGY, VEGETATION 
114

Li, Bin. 1993. The Impact of the Spatial Variability of Land-Surface Characteristies on Land-Surface Energy Fluxes. M.S. Thesis, Rutgers University, 39 pages.

The impact of subgrid-scale variability of land characteristics on land-surface energy fluxes simulated in atmospheric models (e.g., GCMs) was investigated with Patchy Land-Atmosphere Interactive Dynamics (PLAID), a land-surface scheme developed by Avissar and Pielke (1989), which represents the land surface as a mosaic of patches. Eleven different distributions of the five predominant characteristics of land-surface schemes (i.e., stomatal conductance, soil-surface wetness, leaf area index, surface roughness, and albedo) were considered. A total of 5,580,900 steady-state simulations was produced to analyze thoroughly this impact under a broad range of atmospheric conditions. We found that the more skewed is the distribution within the range of land-surface characteristics that is related nonlinearly to the energy fluxes, the largest was the difference between the energy fluxes calculated with the distribution and the corresponding mean. Among the various distributions considered in our study, the lognormal distribution produced the largest such difference, and negatively skewed beta distributions resulted in negligible difference. In general, the latent heat flux was the most sensitive to spatial variability and the radiative flux emitted by the surface was the least sensitive. Our results indicate that it is very important to consider the spatial variability of leaf area index, stomatal conductance, and, in bare land, soil-surface wetness. The spatial variability of surface roughness is mostly important under neutral and stable atmospheric conditions. It appears that the relationship between albedo and surface energy fluxes is almost linear and, therefore, using a mean value of this characteristic is appropriate. This analysis emphasizes the need to develop land-surface schemes able to account for spatial variability in atmospheric models, as well as the necessity to provide higher statistical moments when creating data sets of land-surface characteristics.

Major Professor(s): Avissar, Roni Department: Meteorology and Physical Oceanography Principal Investigator(s): Avissar, Roni Program Area: Computer Hardware, Advanced Mathematics, and Model Physics (CHAMMP)

KEYWORDS: ATMOSPHERE, LAND SURFACE, SOILS, TURBULENCE, VEGETATION
115

Li, Long. 1994. The Global Atmospheric Response to Low Frequency Tropical Forcing. Ph.D. Dissertation, University of California at Davis, 104 pages.

The tropical-extratropical interactions relevant to intraseasonal time scales (10-60 days) are investigated in a linearized non-divergent barotropic model on a sphere. The primary goal of this research is to study the role of tropical time varying forcing on the generation and maintenance of extratropical low frequency variability. Both zonally averaged and zonally varying basic flows are examined. WKB theory has been utilized to obtain analytical solutions for wave energy dispersion, wave ray paths, and wave amplitude variations along the rays. Both global and local energy budgets are carried out for the low frequency forced disturbances. The first part of this research (Chapter 2) deals with two types of zonal mean wind profiles: 1) solid body rotation flow;

2) flows with critical latitudes. An analytical analysis based on WKB and ray tracing methods shows that unlike stationary Rossby waves, westward moving, low frequency Rossby waves can propagate through the tropical easterlies into the extratropics. The difference between orientations of the stationary and low frequency ray paths is proportional to the forcing frequency and inversely proportional to the zonal wavenumber cubed. An expression for the disturbance amplitude is also derived, and shows that the ability of the forced waves to maintain their strength well into middle latitudes depends on their meridional wave scale and northward group velocity, both of which are functions of the slowly varying background flow. The analysis of the local energy budget demonstrates that the combination of energy dispersion from the forcing region and energy extraction from the equatorward flank of the midlatitude jet produces disturbances that have the greatest impact on the extratropical circulation. Under the assumption that the forcing amplitude is independent of frequency, this impact is largest when the tropical forcing period is in the 10-20 day range. The second part of this research (Chapter 3) studies the influence of zonally varying flows on energy propagation of tropically forced waves. A 9-year (1980-1988) averaged $300 \mathrm{mb}$ January basic flow is examined, which exhibits strong zonally varying jet streams in the Northern Hemisphere, and a nearly zonally uniform flow in the Southern Hemisphere. A two-dimensional WKB analysis shows that the group velocity depends on the sum of three terms: 1) the basic state wind vector; 2) a vector that is parallel to the absolute vorticity contours; and 3) the local wavevector. As the forcing frequency decreases, the ray paths approach the direction of the local wavevector. Generally, the changes of wave amplitude along ray paths are determined by the meridional variations of horizontal wave scales. 
However, the zonal variation of horizontal wave scale can still play an important role at the jet exit regions. A global energetics analysis demonstrates that the energy conversion from the basic flow becomes more important as forcing frequency decreases. A local energetics analysis shows that for long period ( $>30$ days) forced disturbances, the energy redistribution terms, i.e., the advection and the pressure work terms, are also significant along the extratropical jet streams in the Northern Hemisphere. Hence, long period disturbances are strongly influenced by the jet streams in the Northern Hemisphere, and are much less sensitive to the position of the tropical forcing than those of intermediate period ( $<30$ days). Consistent with observations, long (intermediate) period disturbances dominate in the Northern (Southern) Hemisphere, where the basic flow is more (less) zonally. varying.

Major Professor(s): Nathan, Terrance R. Department: Land, Air \& Water Resources Principal Investigator(s): Rotman, Douglas A. Program Area: Atmospheric Sciences

KEYWORDS: ATMOSPHERE, CIRCULATION, MODELS, TROPICS, WAVES, WINDS

\section{6}

Lia, Liang 1993. Ka-Band Radar Research

Applications for Ice and Water Clouds. $P h D$.

Dissertation, University of Utah, 220 pages.

To obtain scattering properties of nonspherical cloud particles, a description of the electric field integral equation and its solution procedure using the CG-FFT numerical scheme is given. The validity and accuracy of the CG-FFT results have been checked by comparing them with the Mie theory and experimental measurements. The range of the particle dimensions valid for the Rayleigh approximation is also determined. Scattering and polarization characteristics of ice particles with typical habits found in ice clouds are analyzed at Ka-band wavelength. The relationships between $\mathrm{Ka}$ band equivalent radar reflectivity factor $Z_{e}\left(\mathrm{~mm}^{6} / \mathrm{m}^{3}\right)$ and cirrus ice content and ice crystal precipitation content IWC $\left(\mathrm{mg} / \mathrm{m}^{3}\right)$ are developed through regression analysis on the results of the computed $\mathrm{Z}_{e}$ and IWC from measured ice particle size distributions. It is concluded that the $\mathrm{Z}_{e}$-IWC relationships depend only slightly on the polarization state and zenith angle of the radar beam as a result of oriented particle scattering effects. For vertically pointing operations, we find IWC $=7.49 \mathrm{Z}_{\mathrm{e}}{ }^{0.78}$ for aircraft-measured cirrus cloud compositions, and IWC $=21.8 \mathrm{Z}_{e}{ }^{a 79}$ for precipitating ice crystals measured in polar regions. In addition, comparisons between the Ka-band radar and lidar measurements for cirrus clouds are made using data collected from 17 July-30 November 1990 . Our findings reveal that the cloud-center altitude, cloud thickness and ice water content vary from 7 to $10 \mathrm{~km}, 1.6$ to $5.5 \mathrm{~km}$ and 0.5 to $30 \mathrm{mg} / \mathrm{m}^{3}$, respectively. The maximum ice water path from our observations is 38 $\mathrm{g} / \mathrm{m}^{2}$. The two-way lidar attenuation coefficient $A$ $(\mathrm{dB} / \mathrm{km})$ at the ruby wavelength, while traversing in cirrus clouds, is estimated from the derived equation $\mathbf{A}$ $=3.40 \mathrm{Z}_{\mathrm{e}}{ }^{0.79}$ by the simultaneous Ka-band radar measurements, and the lidar range-averaged backscatter-to-extinction ratio is derived from the lidar equation and determined from both the Ka-band radar and the lidar data. The numerical simulations of the Ka-band radar signal in the water phase clouds bave been performed in terms of the meteorological parameters from a one-dimensional adiabatic cloud model. The regression equations linking the radar reflectivity factor $Z$ to liquid water content $L W C\left(\mathrm{~g} / \mathrm{m}^{3}\right)$ and median volume diameter $\mathrm{D}_{0}(\mu \mathrm{m})$ are calculated from the results of simulations from an adiabatic cloud model, yielding $Z=\left(3.6 / N_{d}\right) L W C^{L .8}$ and $Z=(2.07 x$ $\left.10^{-12} \mathrm{~N}_{d}-1.37 \times 10^{-11}\right) \mathrm{D}_{0}^{5.83}$ respectively, where $\mathrm{N}_{\mathrm{d}}$ is the concentration of cloud droplets. Comparison with empirically-based relationships for cumulus and stratocumulus clouds shows the best agreement for $\mathbf{N}_{d}$ of about $100 \mathrm{~cm}^{-3}$.

Major Professor(s): Sassen, Kenneth

Department: Meteorology

Principal Investigator(s): Sassen, Kenneth

Program Area: Atmospheric Radiation Measurement (ARM)

\section{KEYWORDS: CLOUDS, SCATTERING}

117

Liso, Nien-Tsun. 1992. Spectral Analysis and Model Investigation of the Wind-Driven Midshelf Water Response from Cape Canaveral to Sape Fear During GABEX II. PhD. Dissertation, North Carolina State University, 156 pages.

The subtidal frequency responses of coastal sea level and alongshore currents to atmospheric forcing in the midshelf region between Cape Canaveral and Cape Fear is studied using data gathered during the GABEX II experiment, May 13 to October 15, 1981. It is found that wind field at synoptic period band (3-14 day) in the study area is well organized and propagates southward. In this highly barotropic region, it is also found that coastal seal level and current fluctuations are dominated by the response to the local wind forcing. The data indicate the lack of coastal trapped waves (CTWs) at 3- 
14 day period band although the phase speed in the alongshore current fluctuations at long period band (814 day) is $1.85 \mathrm{~m} \mathrm{~s}^{-1}$ with $87.4 \%$ of first mode fraction. A numerical model for coastal forced and free waves with realistic stratification and bottom topography is applied. The dispersion curves of first three modes for the barotropic and stratified cases at each single transect are obtained. It is found that the first mode long CTWs are highly barotropic, which is consistent with the large values of energy diagnostic $\mathbf{R}$ of these waves. The space-averaged phase speed of first mode long CTWs is $3.85 \mathrm{~m} \mathrm{~s}^{-1}$, and wave motions noted from alongshore current fluctuations are not CTWs. With the aid of frequency response function, a comparison between the empirical observation and the theoretical model response is undertaken. In the 3-6 day period band, the model response and frequency response of alongshore current provide reasonable fit in magnitude with relatively uniform phase lags although there is remote response component due to the alongshore pressure gradient produced elsewhere. This suggests that the free-wave resonant response is less in this period band. At 8-14 day period band, the remote response of alongshore current is small relative to the local response component, and it is hard to give rise to the CTWs. Moreover, the frictional decay time $T_{f}$ is short relative to the period of passible CTWs at this long period band, and the remotely induced energy is rapidly damped out in this broad and shallow continental shelf region. The linear bottom resistance coefficient $r$ in the midshelf region along each single cross-shelf transect is also determined by approaching the model response to the frequency response in magnitude and 3-6 day period band. And, they are 0.03, $0.05,0.055,0.08$, and $0.015 \mathrm{~cm} \mathrm{~s}^{-1}$ along the different transects with the values generally increase toward the north corresponding to the increasing width of continental shelf.

Major Professor(s): Janowitz, Gerald S. Department: Marine, Earth and Atmospheric Sciences Principal Investigator(s): Pietrafesa, Leonard J. Program Area: Marine Transport

KEYWORDS: CIRCULATION, COASTAL ENVRONMENT, MODELS, OCEANS, SEA LEVEL, TIDES, WAVES, WINDS

\section{8}

Lin, Guoging 1992. A Numerical Model of the Hydrodynamics of the Albemarle-Pamlico Croatan Sounds System, North Carolina. M.S. Thesis, North Carolina State University, 118 pages.
A linear, barotropic, three-dimensional, time-dependent, constant eddy viscosity model is developed for the entire Albemarle-Pamlico-Croatan sounds system. The study first analyzes the scales of time, velocity, and water level fluctuation of the flow field in the system. Analytical solutions under steady state are obtained to gain physical insight into the water motions. The factors influencing the flow fiedd, e.g., wind stress, river discharge, tidal effect. eddy viscosity, bottom friction, and Coriolis effect are examined in terms of their relative importance. The finite difference method is used to numerically solve the time-dependent governing equations. The numerical model incorporates a spatially and temporally varying atmospheric wind stress, a stress bottom condition, river discharges, and tidal exchanges as boundary conditions. The bottom topography is incorporated into the model by utilizing a $\sigma$-coordinate. The model is verified using the results of field measurements within the sounds system. Several case runs of the model show that the flow field in Pamlico Sound is dynamically coupled with that in Albemarle Sound via restricted flow through Croatan Sound. The sounds system fully responds to wind action in a period of about 6 hours for north/south direction and about 4 hours for east/west direction. The water parcels throughout the water column in Croatan Sound flow in the direction of a constant north/south wind for the first 14 hours after wind onset. The circulation response reaches quasi-steady state condition for a constant wind forcing in a period of about 24 hours for the north/south wind and about 18 hours for the east/west wind. The model is used to run a representative case of measured time series of wind stresses in three months of winter, which is believed to be the peak recruitment period for five commercially important estuarinedependent, migratory marine species to the sounds system. The results support the hypothesis that the dynamic coupling of Croatan Sound is unfavorable for the larval recruitment into Albemarle Sound. The model can also be used to forecast the water level fluctuations and to compute the water exchange rate of embayments along the periphery of the sounds system. The model results of the tropical storm surge simulation are satisfactory.

Major Professor(s): Pietrafesa, Leonard J. Department: Marine, Earth and Atmospheric Sciences Principal Investigator(s): Pietrafesa, Leonard J. Program Area: Marine Transport

KEYWORDS: CIRCULATION, COASTAL ENVIRONMENT, MODELS, OCEANS, WINDS 
119

Iin, Kaijun. 1986. Application of Linear Free Energy Relationship in Marine Chemistry and Analysis of the Wintertime Carbonate Data in the Northern North Atlantic Ocean. M.S. Thesis, Oregon State University, 143 pages.

Two topics are included in this thesis: (1) The application of linear free energy relationship (LFER) to marine chemistry is discussed and (2) winter carbonate data collected in the northern North Atlantic Ocean, mainly the Norwegian and Greenland seas, are analyzed. First, the occurrence of LFER has been confirmed by the stability constant data reported in the cited literature. Comparison of LFERs was made between the condition of zero ionic strength and that of 0.7 ionic strength which is considered similar to the condition in the marine environment. The application of LFERs yielded estimates of some undetermined stability constants, especially for carbonate and bicarbonate complexes and ion pairs, and adjustments to some data reported in the literature needed to be made. The goals achieved in the present work were: (1) to provide the evidence of LFERs in seawater in terms of the logarithms of stability constants (thermodynamic and stoichiometric at 0.7 ionic strength) at $25^{\circ} \mathrm{C}$ and 1 atmosphere; (2) to analyze the reason that the separate LFERs form and indicate their appearances occur only when $\log \mathrm{K}_{\mathrm{MF}}$ and $\log _{\mathrm{MF}}$ at 0.7 ionic strength are correlated with other logarithms of stability constants; (3) to suggest that separate LFERs are dependent on the type classification of metal ions according to Lewis' theory; (4) to provide the improved stability constants and compare them with the reported values from literature and to predict unknown stability constants, mainly for carbonate and bicarbonate complexes and ion pairs. Secondly, excess $\mathrm{CO}_{2}$ penetration in the northern North Atlantic Ocean in winter has been revealed based on carbonate data. The direct carbonate data in wintertime were collected on the HUDSON 82 cruise to the Norwegian and Greenland seas. The results indicate that the whole water column in the two seas has been contaminated by anthropogenic $\mathrm{CO}_{2}$, more so in the Greenland sea than in the Norwegian sea and more in the western basin than in the eastern basin. Observations of the apparent oxygen utilization and tritium data support this conclusion.

Major Professor(s): Chen, Chen-Tung A.

Department: Oceanography

Principal Investigator(s): Chen, Chen-Tung A.

Program Area: Carbon, Climate, and Vegetation
KEYWORDS: CARBON CYCLE, CARBON DIOXIDE, CHEMISTRY, METALS, OCEANS, OXYGEN, TRACERS

120

Little, Jackie. 1994. Patterns of Recovery in a Riverine Mangrove Forest. Ph.D. Dissertation, University of Tennessee, 183 pages.

This research forecasts the effect of variable hurricane intensity on mangrove forest structure and evaluates the role of species composition in recovery. Baseline data estimates were made along the Shark River in Everglades National Park, Florida, USA, in 1992, 32 years after Hurricane Donna ripped up the southwestern Florida coast. Hurricane disturbance and forest recovery were simulated in an individual-based model. Results were extrapolated to forecast the effects of two factors: windfall, in which $37.5 \%, 62.5 \%$, and $87.5 \%$ of stand density is blown over; and species composition, in which plots were categorized according to dominance by species which stump sprout [Avicennia germinans (AVGE) and Laguncularia racemosa (LARA)] vs dominance by the species not capable of sprouting [Rhizophora mangle (RHMA)]. Four stands were sampled along a $7 \mathrm{~km}$ transect adjacent to the Shark River and perpendicular to the path of Hurricane Donna. Mortality and recovery were inferred from diameter size-class density and basal area distributions. Analysis of the field data showed the presence of three cohorts post-hurricane recruits, and intermediate size class of stump sprouts and young survivors, and mature survivors of the hurricane. A major conclusion of the fieid data analysis was that sprouting and shade tolerance are effective recovery mechanisms that unexpectedly boost residual stem density in highly disturbed stands. To understand the structural patterns, plot data was back-calculated to prehurricane estimates and hurricane disturbance was simulated. The most simple explanation for the observed structure, variable wind intensity, was supported for plots without stump sprouting. However, in plots with sprouting, the relationship between intensity, and recruits and sprouts was positive from low to moderate intensity and leveled off from moderate to high intensity. The conceptual model that emerges is that hurricane disturbance, regardless of intensity, is filtered through a "grid" of species characteristics, and it is these traits which most influences stand structure. The recovery mechanism in plots dominated by AVGE/LARA, was survival, particularly below-ground, and site retention by individuals who were established before the disturbance. In plots dominated by RHMA, recovery following moderate and intense disturbance depended on the establishment of new recruits. 
Major Professor(s): Rennie, John

Department: Graduate Program in Ecology

Principal Investigator(s): Emanuel, W.R.

Program Area: Carbon, Climate, and Vegetation

KEYWORDS: DISTURBANCE, FORESTS,
MORTALITY, NORTH AMERICA, RECOVERY,
STORMS, STRUCTURE, VEGETATION

121

Lu, Cheng-Hsuan. 1992. Interaction of Coherent Structures with the Forest Canopy. M.S. Thesis, State University of New York at Albany, 109 pages.

Turbulence measurements obtained from instruments mounted on towers in a deciduous forest in central Massachusetts are analyzed to understand the statistical characteristics of coherent structures and how are these structures influenced by the biomass structure. A new technique, wavelet transforms, is used to study these time series data. This technique is recommended for detection of irregular patterns which are intermittent and contain sharp local gradients. Different wavelet functions are used and their results compared. The mean duration of events that contribute most to signal variance and turbulent fluxes are estimated by computing the wavelet spectra. The fraction of momentum and heat transport contributed by coherent structures are calculated over longer time periods by this objective detection method. A smaller fraction of transport contributed by the coherent structures suggests that previous studies based on idealized data sets may overestimate their importance. Composited flow pattern and flux structure associated with the coherent structures are displayed. Above the forest canopy, the coherent structures are characterized by ramp-downdraft pattern with twin peaks of fluxes surrounding the temperature microfront. Below the forest canopy, the horizontal wind leads the air flow aloft in the summer and winter periods, but the phase of temperature fluctuations related to the microfront are different during different seasons. This illustrates the air flow in the trunk space is influenced by the local environment (in-canopy stability for temperature fluctuation and surface pressure field for horizontal wind component) most of the time. Intermittently, strong gusts can transport the air far above the canopy and zero-gradient or counter-gradient fluxes are observed. Combined the filtering effect of forest canopy and the statistical characteristics of coherent structures, it is suggested that one can construct a parameterization model to simulate the atmosphereforest interaction.

Major Professor(s): Fitzjarrald, David R.
Department: Atmospheric Sciences Research Center

Principal Investigator(s): Fitzjarrald, David R. Program Area: National Institute for Global Environmental Change (NIGEC)

KEYWORDS: ATMOSPHERE, BOUNDARY LAYER, FORESTS, HEAT FLUX, TEMPORAL, DISTRIBUTION, TURBULENCE, WINDS

122

Lu, Yu. 1990. Modeling Tropospheric OH Chemistry. M.S. Thesis, Oregon Graduate Institute, Global Change Research Center, 244 pages.

The hydroxyl radical, $\mathrm{OH}$, is perhaps the most important reactive species in the troposphere, which reacts a wide range of trace gases and free radicals. The OH chemistry is coupled to almost all trace gas cycies. Environmentally important trace gases such as $\mathrm{CO}$, $\mathrm{CH}_{4}$, and many nonmethane hydrocarbons are removed principally by reacting with $\mathrm{OH}$. The distribution of the concentrations of the highly reactive $\mathrm{OH}$ radicals have been obtained with a detailed photochemical model. The model contains the information on the physical nature of the atmosphere such as temperature, pressure, and solar intensity as well as on the distributions of some key species, and chemical kinetic and photochemical data, and includes the cycles of $\mathrm{HO}_{\mathrm{z}} \mathrm{NO}_{\mathrm{v}}$ and other reactive compounds. Although the concentrations of a sequence of trace gases and free radicals were calculated with the model in this study, this thesis mainly covers the tropospheric distributions of the hydroxyl radical and its major buffer, the hydroperoxyl radical $\left(\mathrm{HO}_{2}\right)$. The model results, which are generally consistent with various measurements and model predictions, show that $\mathrm{OH}$ has a strong diurnal variations as well as clear vertical, seasonal, and latitudinal variations due to its high reactivity and short lifetime. As a special aspect of this thesis, the nighttime $\mathrm{OH}$, which has not been of concern in previous model calculations, are presented and discussed in detail. The model results show that the nighttime $\mathrm{OH}$ has also clear vertical, seasonal, and latitudinal variations, with its seasonally and globally averaged concentration of $9.6 \times 10^{+3}$ molecules $/ \mathrm{cm}^{3}$, which is two orders of magnitude less than the seasonally and globally averaged daytime $\mathrm{OH}$ concentration, $1.2 \times 10^{+6}$ molecules $/ \mathrm{cm}^{3}$. In addition, the nighttime $\mathrm{OH}$ assumes a more significant role in winter in the midlatitudes in the middie troposphere. The mechanism of production and destruction of hydroxyl radicals in the troposphere has been explored with two methods. First, by comparing the reactions directly affecting $\mathrm{OH}$, it is concluded that the mechanism for production of $\mathrm{OH}$ is significantly different between daytime and nighttime, 
while the mechanism for loss of $\mathrm{OH}$ is about the same between daytime and nighttime. During the daytime OH production is initiated and maintained by sunlight, and the reaction of $\mathrm{O}\left({ }^{1} \mathrm{D}\right)$ with $\mathrm{H}_{2} \mathrm{O}$ and reactions of $\mathrm{HO}_{2}$ with $\mathrm{NO}$ and with $\mathrm{O}_{3}$ produce most tropospheric $\mathrm{OH}$; however, the reaction of $\mathrm{HO}_{2}$ with $\mathrm{O}_{3}$ is the only significant source of nighttime $\mathrm{OH}$. The reactions of $\mathrm{OH}$ with $\mathrm{CO}$ and with $\mathrm{CH}_{4}$ consume most tropospheric OH during daytime as well as nighttime. Second, this thesis also presents a new method to further study the mechanism of $\mathrm{OH}$ by tracing a series of reactions activated by the key species and accounting for the effect on $\mathrm{OH}$ from each of the reactions. This method not only gives the conclusion that on the global scale $\mathrm{O}_{3}, \mathrm{H}_{2} \mathrm{O}$, and $\mathrm{NO}_{2}\left(\mathrm{NO}+\mathrm{NO}_{2}\right)$ produce the tropospheric $\mathrm{OH}$ which is mostly consumed by $\mathrm{CO}$ and $\mathrm{CH}_{4}$, but also quantitatively gives the contribution of each of these key species to the tropospheric concentration of $\mathrm{OH}$. The lifetime of a species represents the reactivity of a species. The lifetimes of $\mathrm{OH}$ and $\mathrm{HO}_{2}$ are illustrated and discussed in this thesis. The lifetime of $\mathrm{OH}$ is very short. The vertically and diurnally averaged lifetimes are 1.2 second at $45^{\circ} \mathrm{N}$ and 2.3 seconds at $45^{\circ} \mathrm{S}$, which are about two orders of magnitude smaller than those of $\mathrm{HO}_{2}$. Unlike $\mathrm{OH}$, the lifetime of $\mathrm{HO}_{2}$ shows a strong diurnal variation due to the strong diurnal variations of the concentrations of the species which remove tropospheric $\mathrm{HO}_{2}$. The sensitivity of the tropospheric hydroxyl radicals to the heterogeneous process was tested. It is shown that a strong heterogeneous process results in a much larger decrease of $\mathrm{OH}$ concentration in a polluted region at night than in a clean region during daytime. Finally the surface concentrations of $\mathrm{OH}$ over a wide range of climate conditions were investigated. It is concluded that on average the $\mathrm{OH}$ concentration decreases only slightly from the last glacial maximum (LGM, about 18,000 years ago) to the present despite the large changes of the concentrations of $\mathrm{CO}, \mathrm{CH}_{4}, \mathrm{O}_{3}$, and $\mathrm{NO}_{\mathbf{p}}$ however, the nighttime $\mathrm{OH}$ changes dramatically from the LGM to the present; the surface concentration of the nighttime $\mathrm{OH}$ at the LGM is about three times as large as that at the present.

Major Professor(s): Khalil, M. Aslam K. Department: Environmental Science and Engineering Principal Investigator(s): Rasmussen, R.A, and M.A.K. Khalil

Program Area: Carbon, Climate, and Vegetation

KEYWORDS: ATMOSPHERE, CHEMISTRY, HYDROXYL RADICAL, ICE AGE, MODELS, NIGHTTIME, SPATLAL DISTRIBUTION, TEMPORAL DISTRIBUTION
123

Lu, Yu. 1993. Model Calculations of Radiative Transfer and Tropospheric Chemistry. $P h D$. Dissertation, Oregon Graduate Institute, Global Change Research Center, 244 pages.

The tropospheric chemistry of $\mathrm{HO}_{x} \mathrm{NO}_{y}, \mathrm{O}_{x}$ and $\mathrm{CH}_{\mathrm{i}} \mathrm{O}_{\mathrm{j}}$ were studied with our time-ciependent multiple one-dimensional photochemical model. Besides its diurnal, vertical, seasonal, and latitudinal variations, the globally averaged $\mathrm{OH}$ level may decrease by about $40 \%$ from ice ages to the present and about $10 \%$ from the pre-industrial era to the present. However, the averaged nighttime $\mathrm{OH}$ in ice ages is about three times as large as the current nighttime $\mathrm{OH}, 1.3 \times 10^{4}$ molecules $/ \mathrm{cm}^{3}$, which is about two orders of magnitude smaller than the averaged daytime $\mathrm{OH}, 1.6 \times 10^{6}$ molecules $/ \mathrm{cm}^{3}$, at present. By tracing the reactions, which are initiated by the direct reactions of $\mathrm{OH}$ with $\mathrm{CO}$ and $\mathrm{CH}_{4}$, the total effects of $\mathrm{CH}_{4}$ and $\mathrm{CO}$ were calculated. Atmospheric methane, along with its feedbacks, may remove as much as or more atmospheric $\mathrm{OH}$ than carbon monoxide, although $\mathrm{CO}$ is widely accepted as the largest sink of the atmospheric $\mathrm{OH}$. A detailed radiative transfer model was developed for various atmospheric conditions by including the optical properties and other physical features of various types of clouds and aerosols. The model results indicates the variations of the synoptic and environmental conditions in the lower atmospheric affect not only the actinic fluxes locally but also the radiation field in the upper atmosphere. Finally coupling the radiative transfer model with the photochemical model shows the effect of aerosols on OH chemistry becomes important only in the atmospheric boundary layer. The $\mathrm{OH}$ concentrations could drop significantly below a cloud but increase above the cloud compared to the $\mathrm{OH}$ levels in a clear atmosphere. The averaged $\mathrm{OH}$ level for the whole troposphere could be increased by low clouds but decreased by high clouds. More importantly, the increase of tropospheric $\mathrm{OH}$ by low clouds could be larger than that due to stratospheric $\mathrm{O}_{3}$ depletion.

Major Professor(s): Khalil, M. Aslam K. Department: Environmental Science and Engineering, Applied Physics and Electrical Engineering Principal Investigator(s): Rasmussen, R.A., and M.A.K. Khalil

Program Area: Carbon, Climate, and Vegetation

KEYWORDS: AEROSOLS, ATMOSPHERE, BOUNDARY LAYER, CARBON MONOXIDE, CHEMISTRY, CLOUDS, HYDROXYL RADICAL, ICE AGE, METHANE, MODELS, NIGHTTIME, PREINDUSTRLAL ERA, RADLATIVE PROCESSES, 
SPATIAL DISTRIBUTION, TEMPORAL DISTRIBUTION

\section{4}

Luo, YaoHua. 1989. Responses of Well-Watered and Water-Stressed Abutilon theophrasti (C3) and Amaranthus hybridus (C4) to Long-Term Differences to $\mathrm{CO}_{2}$ and Humidity. Ph.D. Dissertation, Duke University, 192 pages.

Two dicotyledonous annuals, Abutilon theophrasti Medik. (C3) and Amaranthus hybridus L. (C4) were used to examine responses to differences in soil water (well-watered and slowly water-stressed for 20 days), atmospheric humidity ( $45 \%$ and $85 \% \mathrm{RH}$ at $30^{\circ} \mathrm{C}$ ), and $\mathrm{CO}_{2}(350$ and $650 \mu \mathrm{l} / \mathrm{l})$ in terms of water relations, gas exchange, and biomass production. A subirrigating system was used in growth chambers with $1000 \mu \mathrm{mol}$ photons $\mathrm{m}^{-2} \mathrm{~s}^{-1} 14 \mathrm{~h} / 30^{\circ} \mathrm{C}$ days and $10 \mathrm{~h} / 24^{\circ} \mathrm{C}$ nights. Water deficit was gradually induced in vermiculite by decreasing the osmotic potential with increasing concentrations of polyethylene glycol $(20,000 \mathrm{MW})$ in the subirrigating system. This allowed lowering relative humidity without directly inducing or aggravating soil water stress and provided conditions similar in time course to dry-down experienced in the field. Under the same light and temperature conditions as growth, photosynthetic rate for the $\mathrm{C} 3$ species (Abutilon theophrasti) tended to saturate after $650 \mu \mathrm{l} \mathrm{CO} \mathrm{CO}_{2} \mathrm{~A}$, whereas the $\mathrm{C} 4$ species (Amaranthus hybridus) reached the maximum rate before $350 \mu \mathrm{l} \mathrm{CO} / 1$. As a result, $\mathrm{CO}_{2}$ enrichment stimulated the $\mathrm{C} 3$ plant in biomass production but not the $\mathrm{C} 4$ species. Elevated leaf water potential due to a reduction in transpiration under $\mathrm{CO}_{2}$ enrichment alleviated the depression of low humidity on leaf expansion in both species. However, it did not prevent the depressive effect of the low humidityinduced decrease in photosynthesis in the $\mathrm{C} 3$ plant, so biomass production for the 32-day growth cycle was the highest in plants grown in $\mathrm{CO}_{2}$ enrichment and humid air. The dry air $\mathrm{C} 3$ plants had a higher leaf water content but lower biomass per plant than did the humid air plants and the $\mathrm{C} 4$ plant had a similar tendency. It indicates that absolute water content has relatively little influence on whole biomass production by the plant. After water stress, both species maintained their photosynthetic rates until leaf water potential declined to -1.1 to $-1.5 \mathrm{MPa}$. At later water stress, however, water potential declined more rapidly in the dry air plants than in the humid air plants yet their photosynthetic rates were similar. Assimilation versus internal $\mathrm{CO}_{2}$ concentration curves showed that the stomatal limitation of assimilation was dominant during early water stress while non-stomatal limitation of assimilation mainly occurred later in water stress.
Correspondingly, the ratio of intercellular $\mathrm{CO}_{2}$ to ambient $\mathrm{CO}_{2}$ concentration $(\mathrm{Ci} / \mathrm{Ca})$ decreased during early stress but increased later in water stress. Therefore, $\mathrm{Ci} / \mathrm{Ca}$ may be used as an indicator of stomatal or non-stomatal limitation of assimilation for water-stressed plants.

Major Professor(s): Strain, Boyd R.

Department: Botany

Principal Investigator(s): Strain, Boyd R.

Program Area: Carbon, Climate, and Vegetation

KEYWORDS: C3 METABOLISM, C4 METABOLISM, CARBON DIOXIDE, FERTILIZATION, INTERCELLULAR CONCENTRATIONS, PHOTOSYNTHESIS, RESPIRATION, SOILS, VEGETATION, WATER STRESS, WATER VAPOR

125

MacKay, Robert Malcolm. 1990. The Oregon Graduate Institute One Dimensional Time-Dependent Radiative Convective Model: Theory and Application. M.S. Thesis, Oregon Graduate Institute, Global Change Research Center, 229 pages.

A time dependent one dimensional radiative convective model (1D RCM) is developed to study the sensitivity of the Earth's vertical temperature structure to variations in external and internal components of the climate system. Special emphasis is given to the theory and development of the model so that it may be easily used and understood by others. The sensitivity of the Earth's surface temperature to variations in such parameters as the solar constant, surface albedo, cloud cover fraction, etc. is explored. The model developed is found to experience an approximate change in surface temperature of $2.0 \mathrm{~K}$ for a doubling of atmospheric $\mathrm{CO}_{2}$ concentration (from 320 to $640 \mathrm{ppm}$ ). This compares favorably with other previously published results for similar models. The influence on mean global temperature of variations in the atmospheric concentrations of $\mathrm{CO}_{2}, \mathrm{CH}_{4}, \mathrm{~N}_{2} \mathrm{O}, \mathrm{F} 11$, and $\mathrm{F} 12$ over the past century is simulated with the model and compared with the record of mean global temperature reconstructed from observations. In addition the effect of volcanic aerosols on the simulated record is explored. It is concluded that the OGI 1D RCM can serve as a valuable research tool in the future, for studying perturbations of the global average vertical thermal structure of the Earth-atmosphere system. It is also stressed that the 1D nature of the model is limited in that it offers no horizontal or seasonal resolution of the climate system.

Major Professor(s): Khalil, M. Aslam K. 
Department: Environmental Science and Engineering, Applied Physics and Electrical Engineering Principal Investigator(s): Rasmussen, R.A., and M.A.K. Khalil

Program Area: Carbon, Climate, and Vegetation

KEYWORDS: AEROSOLS, ATMOSPHERE, CARBON DIOXIDE, CLIMATE, CLOUDS, CONVECTION, HALOGENATED HYDROCARBONS, METHANE, MODELS, NITROGEN SPECIES, RADLATIVE PROCESSES, REFLECTANCE, TEMPERATURE, VOLCANOES

126

MacKay, Robert Malcolm. 1994. The GCRC TwoDimensional Zonally Averaged Statistical Dynamical Climate Model: Development, Model Performance, and Climate Sensitivity. Ph.D. Dissertation, Oregon Graduate Institute, Global Change Research Center, 258 pages.

The two-dimensional statistical dynamical climate model that has recently been developed at the Global Change Research Center and the Oregon Graduate Institute of Science \& Technology (GCRC 2D) is presented and several new results obtained using the model are discussed. The model solves the 2-D primitive equations in finite difference form (mass continuity, Newton's second law, and the first law of thermodynamics) for the prognostic variables zonal mean density, zonal mean velocity, zonal mean meridional velocity, and zonal mean temperature on a grid that has 18 nodes in latitude and 9 vertical nodes (plus the surface). The equation of state, $p=\rho R T$ and an assumed hydrostatic atmosphere, $\Delta p=-\rho g \Delta z$, are used to diagnostically calculate the zonal mean pressure and vertical velocity for each grid node, and the moisture balance equation is used to estimate the precipitation rate. The performance of the model at simulating the twodimensional temperature, zonal winds, and mass stream function is explored. The strengths and weaknesses of the model are highlighted and suggestions for future model improvements are given. The parameterization of the transient eddy fluxes of heat and momentum developed by Stone and Yao (1987 and 1990) are used with small modifications. These modifications are shown to help the performance of the model at simulating the observed climate system as well an increase the model's computational stability. Following earlier work that analyzed the response of the zonal wind fields predicted by three GCM simulations for a doubling of atmospheric $\mathrm{CO}_{2}$, the response of the GCRC 2D model's zonal wind fields is also explored for the same experiment. Unlike the GCM simulations, our 2D model results in distinct patterns of change. It is suggested that the observed changes in zonal winds for the $2 \mathrm{xCO}_{2}$ experiment are related to the increase in the upper level temperature gradients predicted by our model and most climate models of adequate sophistication and resolution. We thus suggest that the same mechanism controlling the changes in zonal winds for the $2 \mathrm{xCO}_{2}$ experiment in our model also contributes to the simulated changes in zonal winds of the more complex GCMs.

Major Professor(s): Khalil, M. Aslam K

Department: Environmental Science and Engineering, Applied Physics and Electrical Engineering Principal Investigator(s): Rasmussen, R.A., and M.A.K. Khalil

Program Area: Carbon, Climate, and Vegetation

KEYWORDS: ATMOSPHERE, CARBON DIOXIDE, CLIMATE, HEAT FLUX, MODELS, MOMENTUM, PRECIPITATION, PRESSURE, TEMPERATURE, WINDS

127

Manunta, Paolo. 1995. Respiration and Growth of Sorghum $\left(\mathrm{C}_{4}\right)$ and Sunflower $\left(\mathrm{C}_{3}\right)$ Under Predicted Increased Night Temperatures. M.S. Thesis, Kansas State University, 110 pages.

Due to global climate change, predictions are that night temperatures will become warmer than present, but day temperatures will not change. Little information exists concerning how crops will respond to asymmetrical temperature changes. The objective of this work, therefore, was to determine is the respiration rate of sorghum [Sorghum bicolor (L.) Moench] a $\mathrm{C}_{4}$ plant, and sunflower (Helianthus annuus L.), a $\mathrm{C}_{3}$ plant, is affected (increased or decreased) when the night temperature is increased by $5^{\circ} \mathrm{C}$ compared to the longterm (19 year) average night temperacure in June in Kansas. Sorghum and sunflower grew in walk-in growth chambers with either the ambient night temperature $\left(21^{\circ} \mathrm{C}\right)$ or a high night temperature $\left(26^{\circ} \mathrm{C}\right)$. Day temperature was the same for all plants $\left(27^{\circ} \mathrm{C}\right)$. Respiration, soluble carbohydrate concentration, and growth were measured. Both sunflower and sorghum had a higher respiration rate under the elevated night temperature than under the ambient temperature. On an average, respiration rates of sunflower under the high and ambient night temperatures were 0.817 and $0.672 \mu \mathrm{mol} \mathrm{m} \mathrm{m}^{-2} \mathrm{~s}^{-1}$, respectively; for sorghum, these values were 0.515 and $0.339 \mu \mathrm{mol} \mathrm{m} \mathrm{m}^{-2} \mathrm{~s}^{-1}$, respectively. Sunflower grown with the high night temperature had a higher concentration of carbohydrates than sunflower grown under the ambient night temperature. Carbohydrate concentration in sorghum grown with high night temperature was not consistently higher or 
lower than that in sorghum grown with ambient night temperature. Height of both sunflower and sorghum was reduced by elevated night temperature. After 74 days of exposure to the two different temperatures, sunflower grown under the ambient night temperature was about $30 \mathrm{~cm}$ taller than the sunflower grown under elevated night temperature; for sorghum, the difference was about $25 \mathrm{~cm}$. For sunflower, flowers of plants grown under the elevated night temperature appeared one week earlier than flowers of plants grown under the ambient temperature. For sorghum, no flowers formed under either treatment by harvest ( 74 days after planting). The results suggest that, if night temperatures do increase due to climate change, development of flowers of sunflower will be hastened.

Major Professor(s): Kirkham, M.B.

Department: Agronomy (Evapotranspiration

Laboratory)

Principal Investigator(s): Kirkham, M.B.

Program Area: Carbon, Climate, and Vegetation

KEYWORDS: C3 METABOLISM, C4 METABOLISM, CARBOHYDRATES, CLIMATE, GROWTH AND DEVELOPMENT, NIGHTTIME, RESPIRATION, TEMPERATURE, VEGETATION

\section{8}

Mbikayi, Nkonko T. 1985. Response of Cowpea (Vigna unguiculata) to Enriched Carbon Dioxide Environment. M.S. Thesis, Tuskegee University, 98 pages.

Response of cowpea (Vigna unguiculata) to enriched carbon dioxide environment was investigated in the summer of 1984 at the Tuskegee University George Washington Carver Agricultural Experiment Station. The experiment was carried out in one open field plot (345 $\mathrm{ppm} \mathrm{CO} \mathrm{CO}_{2}$ ) and three open top chambers (354, 506 and $655 \mathrm{ppm} \mathrm{CO}_{2}$ chambers). The objective of this study were to determine the long-term effects of increased $\mathrm{CO}_{2}$ concentration on vegetative growth, yield, protein nitrogen content in roots, shoots, and seeds of cowpeas. Physiological aspect was examined with emphasis on stomatal conductance, number of stomata and light intensity on leaflets of cowpeas. The study showed that the presence of the open top chamber had a small effect on cowpeas. Plants grown in chambers at ambient $\mathrm{CO}_{2}$ had fewer leaves and stomatal densities than plants grown in the open field. However, there were no differences between ambient chamber plants and open field plants in plant weight, height, leaflet area, nitrogen content and stomatal conductance. When comparing plants grown in chambers at different $\mathrm{CO}_{2}$ concentrations, most of the cowpea parameters studied showed significant responses to $\mathrm{CO}_{2}$ enrichment. Increasing $\mathrm{CO}_{2}$ was associated with increases in plant height and weight, total seed weight and number of leaves, root nodules and pods. Protein nitrogen content of the root at maturity decreased with increasing $\mathrm{CO}_{2}$.

Major Professor(s): Biswas, P.K.

Department: Agricultural Sciences

Principal Investigator(s): Biswas, P.K.

Program Area: Carbon, Climate, and Vegetation

KEYWORDS: CARBON DIOXIDE, FERTILIZATION, GROWTH AND DEVELOPMENT, LEAVES, PROTEINS, ROOTS, SEEDS, STOMATES, VEGETATION

\section{9}

McCann, Michael Paul. 1984. Physical Processes Influencing Temperature and Salinity on the North Carolina Cape Shoals. M.S. Thesis, North Carolina State University, 138 pages.

Cross-spectral analysis and a heat budget are used to relate atmospheric and river runoff data with seven years of daily surface temperature and salinity on the North Carolina continental shelf. Salinity on Diamond Shoals is highly correlated with alongshore wind stress implying wind driven advection of the front between Virginia Coastal Water and Carolina Coastal Water. In the presence of strong horizontal and vertical temperature gradients, temperature at Diamond Shoals quickly responds to cross-shelf winds. At Frying Pan Shoals, the plume of the Cape Fear River is detected when winds blow seaward. Atmospheric fluxes primarily control the cycle of heating and cooling at Frying Pan Shoals, but advection of heat buffers the water temperature in the winter and summer.

Major Professor(s): Pietrafesa, Leonard J. Department: Marine, Earth and Atmospheric Sciences Principal Investigator(s): Pietrafesa, Leonard J.

Program Area: Marine Transport

KEYWORDS: CIRCULATION, COASTAL ENVIRONMENT, HEAT FLUX, OCEANS, RIVERS, RUNOFF, SALINITY, TEMPERATURE, WINDS

\section{0}

McInnes, Barry John. 1984. Numerical Modelling of Ice Sheet Flow and Sliding. PhD. Thesis, University of Melbourne, 609 pages.

Due to the lack of precise, long-term measurements on glaciers and ice sheets, numerical modeling has become 
a major tool in probing the dynamical theory of ice masses. The available data can be used to test the theory of a model, and tune the various parameters included in the computation scheme. Various models of ice masses have been developed starting from a simple two-dimensional glacier flowline model. Numerous additions have been made to this basic theory which allows many options to be chosen to invoke temperature dependent deformation velocity schemes and compute either a stable or a surging sliding velocity component. The number of options allows many test cases to be completed which give information on many of the lesser known parameters in the computation scheme. The information gained from these sensitivity tests allows conclusions to be drawn regarding the current state or mode of flow in West Antarctica and Greenland. It also provides a base from which additional theory can be added and its effects noted. From these investigations the dynamics of the basal sliding of ice masses can be tested to the best of our current knowledge

Major Professor(s): Budd, W.F. Department: Meteorology Principal Investigator(s): Radok, Uwe Program Area: Carbon, Climate, and Vegetation

\section{KEYWORDS: GLACIOLOGY, SEA LEVEL, SURGING}

\section{1}

Medley, Steven D. 1993. Collection of Cloud

Condensation Nuclei for Chemical Analysis. M.S. Thesis, University of Missouri - Rolla, 70 pages.

The objective of this research is to build a sampling system to collect cloud condensation nuclei (CCN) in sufficient amounts for chemical analysis. The sampling system consists of three virtual impactors and two cloud chambers which are connected in series to collect a CCN sample within a critical supersaturation $\left(S_{c}\right)$ range of $0.16 \%$ to $1.0 \%$. The first cloud chamber, the haze chamber, subjects the air sample to $100 \%$ relative humidity in order to grow haze drops. The second virtual impactor then uses inertial separation to remove all particles with an $S_{c}$ of less than $0.16 \%$. The second impactor showed an $S_{c}$ cutoff of approximately $0.16 \%$ although the sharpness of the cutoff was less than expected. The second cloud chamber, the continuous flow diffusion chamber (CFD), subjects the sample to a $1.0 \%$ supersaturation such as found in clouds, and removes only particulates with an $S_{c}$ of less than $1.0 \%$. The CFD showed an $\mathrm{S}_{c}$ cutoff of close to $1.5 \%$. The slightly higher cutoff is likely due to temperature fluctuations within the CFD, but did not greatly affect the overall system performance. In general the sampling system gave an $S_{c}$ collection range close to the expected although the overall efficiency was lower than expected, which results in a longer sampling time to collect sufficient sample for chemical analysis.

Major Professor(s): Alofs, Darryl John

Department: Mechanical Engineering

Principal Investigator(s): Williams, Allen

Program Area: Quantitative Links

\section{KEYWORDS: CHEMISTRY, CLOUD CHAMBER, CLOUDS, CONDENSATION, PARTICULATES, VIRTUAL IMPACTOR}

\section{2}

Meehl, Gerald Allen. 1987. Interactions Between the Asian Monsoons, the Tropical Pacific, and the Southern Hemisphere Extratropics. Ph.D. Thesis, University of Colorado, 160 pages.

Relatively strong and weak years of Indian monsoon rainfall are selected and used as a starting point to follow the evolution of the annual cycle of precipitation in the tropical Indian and Pacific sectors. Analysis of observations shows that the dynamically coupled oceanatmosphere system in the Indian-Pacific region produces Southern Oscillation-type signals in atmosphere an ocean in many years, with extremes being manifested as Warm and Cold Events. Four different GCM simulations are analyzed. One is run with the specified annual cycle of ouserved sea surface temperatures (SPEC SST), and two are coupled to a simple $50 \mathrm{~m}$ deep slab ocean model with present $(1 \mathrm{x}$ $\mathrm{CO}_{2}$ ) and doubled $\left(2 \times \mathrm{CO}_{2}\right)$ amounts of atmospheric carbon dioxide. The $50 \mathrm{~m}$ slab ocean model acts as a simple heat reservoir with no provision for currents or upwelling. Due to these inherent limitations, the SPEC SST simulation most closely represents observed mean conditions, while the $1 \times \mathrm{CO}_{2}$ and $2 \times \mathrm{CO}_{2}$ integrations produce a progressively more Warm Event type of response in the tropics. The high southern latitudes in these mode runs show internally consistent circulation anomalies in the $2 \times \mathrm{CO}_{2}$ compared with the $1 \times \mathrm{CO}_{2}$ and SPEC SST. This involves a sensitivity to the annual cycle of SSTs at midlatitudes and sea ice extent at high latitudes, both of which have an effect on the semiannual oscillation at those latitudes. A fourth GCM experiment with an altered convective scheme but with SSTs and sea ice held constant produces a warmer tropical troposphere, an intensified equator-to-pole temperature gradient, and a deepened circumpolar trough year round. However, the observations show a seasonal evolution of anomalies in the Southern Hemisphere such that the circumpolar trough is deeper 
during southern winter the year of a Warm Event and shallower the following summer. The observed sequence of Warm minus Cold Event composites shows a poleward migration of anomalies with the tropies leading the high latitudes by about half a year. This poleward migration is most evident in the Pacific, and appears to be related to the annual cycle of the entire coupled ocean-atmosphere system in the Indian and Pacific sectors.

Major Professor(s): Barry, Roger G.

Department: Geography

Principal Investigator(s): Washington, Warren $\mathbf{M}$.

Program Area: Carbon, Climate, and Vegetation

\section{KEYWORDS: CLIMATE, EL NIÑO - SOUTHERN OSCILLATION (ENSO), MODELS, STORMS}

133

Meyer, Mary Kathryn. 1988. New Primary Productivity Estimates for the Last 18,000 Years Evaluated from Simulations by a Global Climate Model. M.S. Thesis, University of Wisconsin - Madison, 39 pages.

Net primary productivity (NPP) is estimated over land for the past 18,000 years using a simple model developed by Lieth (1973) and annual temperature as simulated by a climate model (Kutzbach and Guetter, 1986). Modern values of NPP are determined and summarized by area-average and by estimates in Walter's vegetation zones (1973). The modern evaluation serves as measure for studying past values of NPP. For the globe, the area-averaged value of modern NPP is about $995 \mathrm{~g} / \mathrm{m}^{2} /$ year. Sensitivity experiments performed by globally altering the modern temperature or precipitation illustrate that precipitation changes are most likely to affect equatorial and subtropical NPP values while both temperature and precipitation changes affect midlatitude NPP values and mainly temperature changes affect high latitude NPP values. The simulations of past climates lead to NPP estimates at $18 \mathrm{kyr}$ BP about $30 \%$ lower than modern over the northern hemisphere, due to the presence of the ice sheet. from 12 to $6 \mathrm{kyr}$ BP the NPP values, as compared to modern, were about $15 \%$ greater over the northern tropics and about $10-15 \%$ less over the southern tropics because northern summer monsoons were more intense and southern summer monsoons were weaker at this time (Kutzbach and Guetter, 1986).

Major Professor(s): Kutzbach, John E.

Department: Meteorology

Principal Investigator(s): Kutzbach, John E.

Program Area: Carbon, Climate, and Vegetation
KEYWORDS: CLIMATE, ICE AGE, MODELS, PRODUCTIVTY

\section{4}

Miller, Dennis B. 1987. An Internship with the Carbon Dioxide Information Analysis Center at Oak Ridge National Laboratory: Preliminary Development of a Seashore-Effects Analysis System. M.En. Report, Miami University, 168 pages.

As a result of increasing atmospheric $\mathrm{CO}_{2}$ concentrations and subsequent global temperature increases, the melting of polar ice sheets, mountain glaciers, and the thermal expansion of ocean water could lead to a rise in sea level. The coastal erosion and inundation caused by this event could create agricultural, economic, demographic, and ecological problems along coastal zones. A preliminary Sea Shore Effects Analysis System (SEAS) data base was developed to answer questions on the effects of the global sea level rise. Resources potentially affected by a rise in sea level were identified, resulting in the acquisition of eight data sets. Ten other sources of data were located, but are currently unavailable. The data are stored in SAS data sets. I propose that this information be analyzed using the Geographic Information System (GIS) of the Environmental Sciences Division at Oak Ridge National Laboratory (ORNL) and the newly developed Digital Line Graph Elevation Terrain Data of the U.S. Geological Survey. All SEAS data have longitude/latitude locational variables and, when merged with the terrain data on the GIS, they can be used for a detailed (e.g., $1 \mathrm{~m}$ increment) analysis of the effects of sea level rise. I recommend that development of the SEAS data base be continued with an emphasis on locating and obtaining additional data and using the GIS for analysis.

Major Professor(s): Kaufman, Donald G. Department: Institute of Environmental Sciences Principal Investigator(s): Farrell, Michael P. Program Area: Information

\section{KEYWORDS: COASTAL ENVIRONMENT, DATABASES, SEA LEVEL}

\section{5}

Mitchell, Connee S. 1985. The Use of Climate Classification Schemes to Assess the Performance of General Circulation Models. M.S. Thesis, Oregon State University, 145 pages.

Two climate classification schemes, W. Koppen's and C. W. Thornthwaite's, were used to analyze the 
performance of the OSU AGCM in simulating both the present climate (model verification) and the climatic change induced by an increase in the atmospheric $\mathrm{CO}_{2}$ (Sensitivity study). Climate classification maps were generated for each of the two schemes based on the observed data of Crutcher and Meserve (1970), Taljaard et al. (1969), and Jaeger (1976), as well as for each set of model simulation data. Both Koppen's and Thornthwaite's schemes showed that the model did well in simulating the observed climate, but no significant change in climate types was detected by either scheme for a quadrupling of atmospheric $\mathrm{CO}_{2}$ in the OSU AGCM with seasonally-varying insolation and prescribed sea-surface temperatures. Thornthwaite's scheme also detected no significant change in climate types in the OSU AGCM with annual-averaged insolation and a swamp ocean for a doubling of $\mathrm{CO}_{2}$. The interannual variability of the simulated climate types was also investigated. It was determined that the climate based on one year of model simulation data should not be taken as representative of the model climate because of the level of noise and the differing extents and intensities of the climate regions between simulation years. The climate classification schemes provide a different view of the GCM results by combining the raw data from the model to yield a description of the change in terms of what type of vegetation could be supported. They also have the potential for detecting climate change in GCM experiments, although the method for determining the significance of such changes needs to be developed.

Major Professor(s): Schlesinger, Michael

Department: Atmospheric Sciences

Principal Investigator(s): Gates, W. Lawrence

Program Area: Carbon, Climate, and Vegetation

KEYWORDS: CLIMATE, MODELS, SPATLAL DISTRIBUTION, TEMPORAL DISTRIBUTION

\section{6}

Moraes, Francis. 1992. Methane from a Destabilized Permafrost in a Warmer World. M.S. Thesis, Oregon Graduate Institute, Global Change Research Center, 53 pages.

A large amount of $\mathrm{CH}_{4}$ is sequestered in the upper layers of permafrost soils. This $\mathrm{CH}_{4}$ is likely to be released if the soil thaws due to increased surface air temperature as predicted by most climate models. This thesis describes the process of quantifying the $\mathrm{CH}_{4}$ release using available data from Alaskan soil cores, climate models, and a heat and gas transfer model. Based on this work, I conclude that permafrost will likely be a small though not negligible $\mathrm{CH}_{4}$ source in the future.

Major Professor(s): Khalil, M. Aslam K. Department: Environmental Science and Engineering, Applied Physics and Electrical Engineering Principal Investigator(s): Wohlpart, A. Program Area: Graduate Fellowships for Global Change

KEYWORDS: EMISSIONS, METHANE, PERMAFROST, SOILS

137

Moraes, Francis Perry, Jr. 1994. The Global Change Research Center Atmospheric Chemistry Model. Ph.D. Dissertation, Oregon Graduate Institute, Global Change Research Center, 200 pages.

A new 2.5-dimensional model of the chemistry of the troposphere has been developed. This model, the Global Change Research Center Atmospheric Chemistry Model (GCRC-ACM), is a general tool for the study of the chemistry of the natural atmosphere. It includes the $\mathrm{O}_{x}, \mathrm{HO}_{x}, \mathrm{NO}_{x}$, and methane cycles. Each of these cycles has been included in the model such that they may be included or excluded from a given model run. This makes it possible to determine the importance of each cycle under different circumstances. The model includes a new, fast and accurate cloud model that allows the effects of radiative changes due to clouds on atmospheric chemical processes to be assessed. The GCRC-ACM is used to assess the removal of $\mathrm{CH}_{4}, \mathrm{CO}$, the methyl halides, $\mathrm{HCFCs}, \mathrm{HFCs}$, and $\mathrm{CH}_{3} \mathrm{CCl}_{3}$. The lifetime of $\mathrm{CH}_{3} \mathrm{CCL}_{3}$ is 5.0 years and the global tropospheric $\mathrm{OH}$ concentration is $9.9 \cdot 10^{5} \mathrm{molec}^{-3}$. These values are lower and higher by roughly $10 \%$ than the values given by Prinn [personal communication]. This is due to the lack of non-methane hydrocarbon chemistry in the ACM. The radiative effects of clouds on tropospheric $\mathrm{HO}$ are discussed. Globally, clouds increase $\mathrm{HO}$ by roughly $10 \%$. Because clouds increase $\mathrm{HO}$ values in some areas and decrease $\mathrm{HO}$ in other areas they have almost no net effect on the removal of trace gases which are well mixing within the troposphere. For gases that are not well mixed, such as $\mathrm{CH}_{3} \mathrm{I}$, the effect can be quite large.

Major Professor(s): Khalil, M. Aslam K. Department: Environmental Science and Engineering, Applied Physics and Electrical Engineering Principal Investigator(s): Wohlpart, A. Program Area: Graduate Fellowships for Global Change 
KEYWORDS: ATMOSPHERE, CARBON MONOXIDE, CHEMISTRY, CLOUDS, HALOGENATED HYDROCARBONS, HYDROXYL RADICAL, METHANE, MODELS, NITROGEN SPECIES, RADLATIVE PROCESSES

138

Morris, Gary Allen. 1994. Demonstration and Evaluation of Trajectory Mapping. Ph.D. Dissertation, Rice University, 100 pages.

The problem of creating synoptic maps from asynoptically gathered data has prompted the development of a number of schemes. Most notable among these schemes are the Kalman filter, the SalbyFourier technique, and constituent reconstruction. This thesis presents a new technique, called trajectory mapping. Trajectory mapping employs a simple model of air parcel motion to create synoptic maps from asynoptically gathered data. To assess the applicability of the technique, four sources of trajectory mapping errors were analyzed. The analysis revealed that 1) the computational error is negligible; 2) measurement uncertainties can result in errors which grow with time scales on the order of a week; 3 ) isentropic approximations lead to errors characterized by time scales of a week; and 4) wind field inaccuracies can cause significant errors in individual parcel trajectories in a matter of hours. All the studies, however, indicated that while individual trajectory errors can grow rapidly, constituent distributions, such as those depicted in trajectory maps, are much more robust, maintaining a high level of accuracy for periods on the order of several weeks. The trajectory mapping technique has been successfully applied to a variety of problems. First, trajectory mapping was employed in the study of dynamical wave-breaking events. Second, trajectory mapping was applied in satellite data validation studies, both for the determination of instrument accuracy and precision. Third, trajectory mapping was used to assess the accuracy of the meteorological wind fields. Such demonstrations imply that trajectory mapping will become an important tool in answering questions of global change, particularly the issue of ozone depletion.

Major Professor(s): Few, Arthur, and Mark Schoeberl Department: Space Physics \& Astronomy Principal Investigator(s): Wohlpart, A. Program Area: Graduate Fellowships for Global Change

KEYWORDS: TRAJECTORIES, WINDS
139

Mummey, Daniel Lymn. 1993. Nitrous Oxide Emissions from a Shrub-Steppe Ecosystem: Sources, Regulation and Spatial and Temporal Variability. M.S. Thesis, Washington State University, 62 pages.

The first study was designed to examine the sources and regulation of $\mathrm{N}_{2} \mathrm{O}$ flux from an undisturbed shrubsteppe ecosystem. The second study was designed to determine how the factors which regulate $\mathrm{N}_{2} \mathrm{O}$ flux interact in the field to influence spatial patterns and temporal variability. Our results showed that nitrification is the dominant source of $\mathrm{N}_{2} \mathrm{O}$ in this ecosystem. Nitrous oxide flux is regulated by interactions between soil moisture content and $\mathrm{N}$ availability. Nitrous oxide flux was found to be largely spatially dependent at the scale of this study. The variability of $\mathrm{N}_{2} \mathrm{O}$ flux that could be accounted for by spatial dependence and the spatial association with vegetation increased with soil water content. Pulses of $\mathrm{N}_{2} \mathrm{O}$ and $\mathrm{N}$-mineralization occur after wetting of dry surface soil that are strongly correlated with plant associated soil. Approximately $21 \%$ of the annual $\mathrm{N}_{2} \mathrm{O}$ flux from this ecosystem can be attributed to periods within 48 hours after precipitation events.

Major Professor(s): Smith, Jeffrey L. Department: Crops and Soils Principal Investigator(s): Rogers, Lee E., and Harvey Bolton, Jr. Program Area: Ecosystems Function and Response

KEYWORDS: NITROGEN CYCLE, NITROGEN SPECIES, SHRUB-STEPPE, SPATIAL DISTRIBUTION, TEMPORAL DISTRIBUTION

140

Najjar, Raymond G. 1990. Simulations of the Phosphorus and Oxygen Cycles in the World Ocean Using a General Circulation Model. Ph.D. Dissertation, Princeton University, 190 pages.

The phosphorus cycle is simulated to determine the relative roles of dissolved and particulate organic matter in the "organic carbon pump". Experiments in which all of the new production is balanced by an export of fastsinking particles produce the following features: (1) higher-than-observed phosphate concentrations below regions of high surface upwelling (nutrient trapping), (2) new production in excess of primary production in the Southern Ocean, (3) regions where vertically-integrated new production is equal to zero, and (4) lower-than-observed phosphate concentration in the main thermocline. Nutrient trapping and low thermocline phosphate are especially severe when a 
particle-flux length scale consistent with sediment trap observations is used. When $80 \%$ of the new production is balanced by an export of DOM, and when this DOM has a lifetime which increases with depth, all of the above unrealistic features are either eliminated or become less prominent. This DOM model also reproduces fairly well meridional nitrate fluxes in the North Atlantic computed with inverse methods and the distribution of "new" DOC in the West Pacific, assuming a constant Redfield ratio of C:N:P = 105:16:1. It is suggested therefore, that DOM plays a major role in the downward transport of organic matter and that there is an as-yet undiscovered pool of DOP in the ocean. The oxygen cycle is simulated to determine the Redfield ratio of oxygen to phosphorus $\left(r_{\mathrm{O}_{2}: \mathrm{P}}\right)$. A model with $r_{\mathrm{O}_{2}: \mathrm{P}}=138$ predicts more realistically the distributions of $\mathrm{AOU}$ and denitrification than a model with $r_{\mathrm{O}_{2}: \mathrm{P}}=172$, suggesting that the classical value is closer to observed than the recent revision.

Major Professor(s): Sarmiento, Jorge L.

Department: Geological \& Geophysical Sciences Principal Investigator(s): Sarmiento, Jorge L. Program Area: Carbon, Climate, and Vegetation

KEYWORDS: CARBON CYCLE, MODELS, OCEANS, ORGANICS, OXYGEN, PARTICULATES, PHOSPHORUS, TRANSPORT

141

Nemesure, Seth. 1991. The Impact of Clouds on Atmospheric Shortwave Radiation at the South Pole. M.S. Thesis, State University of New York at Stony Brook, 60 pages.

Two separate datasets both of which provide measurements of net downward shortwave radiation have been combined, so as to provide a means for critically examining how antarctic clouds impact the shortwave radiation budget of the surface atmosphere system and also the atmospheric column. The nearsurface measurements are made by NOAA's Geophysical Monitoring for Climate Change at the South Pole Observatory while the top-of-atmosphere measurements are made by the Earth Radiation Budget Experiment aboard the NOAA-9 satellite. In addition, a delta-Eddington shortwave atmospheric radiation model is used to help interpret and understand these datasets. The datasets indicate that there is a negative correlation between planetary albedo and surface insolation within a small range of solar zenith angles. This implies that cloud-radiative forcing at the South Pole is negative. Using the linear slope-offset relation between net downward shortwave radiation at the top-of-atmosphere and at the surface, the shortwave radiative impact of clouds on the atmospheric column was also shown to be a cooling. Finally, this linear slope-offset relation has shown that clouds do not appear to effect the transfer of shortwave radiation from the top-of-atmosphere to the surface.

Major Professor(s): Cess, Robert D.

Department: Mechanical Engineering (Atmospheric Sciences)

Principal Investigator(s): Cess, Robert D.

Program Area: Carbon, Climate, and Vegetation

\section{KEYWORDS: ATMOSPHERE, RADLATIVE PROCESSES}

\section{2}

Nevison, Cynthia Dale. 1994. A Model Analysis of the Spatial Distribution and Temporal Trends of $\mathrm{N}_{2} \mathrm{O}$ Sources and Sinks. Ph.D. Dissertation, Stanford University, 239 pages.

Nitrous oxide $\left(\mathrm{N}_{2} \mathrm{O}\right)$, an atmospheric trace gas that contributes to both greenhouse warming and stratospheric ozone depletion, is increasing at an annual rate of about $0.25 \% / y$. By use of a global model of the changing terrestrial nitrogen cycle, the timing and magnitude of this increase are shown to be consistent with enhanced microbial $\mathrm{N}_{2} \mathrm{O}$ production due to fertilizer, land clearing, livestock manure, and human sewage. Fertilizer appears to be a particularly important source. Increasing emissions from additional anthropogenic $\mathrm{N}_{2} \mathrm{O}$ sources, including fossil fuel combustion and nylon production are also shown to coincide with and contribute to $\mathrm{N}_{2} \mathrm{O}$ 's annual atmospheric increase. Collectively, these industrial, combustion-related, and enhanced microbial $\mathrm{N}_{2} \mathrm{O}$ emissions add up to a total anthropogenic source of about $5 \mathrm{Tg} \mathrm{N} / \mathrm{yr}$. Natural $\mathrm{N}_{2} \mathrm{O}$ emissions from microbial activity in soils and oceans and from natural fires are estimated to produce an annual source of about $11 \mathrm{Tg}$ N/yr, of which the oceans contribute a substantially larger fraction than reported in most current budgets. In contrast to anthropogenic emissions, which are increasing rapidly, natural emissions are predicted to remain relatively constant from 1860 to 2050 , although this prediction ignores possible enhancements in microbial $\mathrm{N}_{2} \mathrm{O}$ production due to global warming. Also in contrast to anthropogenic emissions, which are heavily dominated by the northern hemisphere, the natural source is fairly evenly distributed over the Earth. The predicted magnitude of the natural source is checked against an estimate of the $\mathrm{N}_{2} \mathrm{O}$ stratospheric sink, while the predicted present day distribution of natural and anthropogenic sources is tested in a 3dimensional transport model run. This run reproduces 
the observed $1 \mathrm{ppb}$ interhemispheric gradient (higher in the north), and suggests that larger gradients may exist over strong continental source regions. Substantial increases in most anthropogenic $\mathrm{N}_{2} \mathrm{O}$ sources are projected for the future if current trends continue. In contrast to purely industrial greenhouse gases like the CFCs, which can be phased out fairly easily, attempts to control $\mathrm{N}_{2} \mathrm{O}$ emissions may conflict with efforts to reduce urban $s m o g$ (i.e., $\mathrm{NO}_{\mathrm{x}}$ emissions) and to feed the world's growing human population. These conflicts could be mitigated, however, by improved energy efficiency, decreased dependence on synthetic fertilizer, reduced numbers of livestock, and a slowdown in the rate of human population growth.

Major Professor(s): Street, Robert L. Department: Mechanical and Civil Engineering Principal Investigator(s): Penner, Joyce E. Program Area: Atmospheric Sciences

\section{KEYWORDS: EMISSIONS, NITROGEN CYCLE, NITROGEN SPECIES}

\section{3}

Nichok, Charles Reid 1991. Hydrodynamics of Oregon Inlet; Possible Mechanisms for Larval Fish Recruitment into the Pamlico Sound. M.S. Thesis, North Carolina State University, 253 pages.

Certain commercially significant fish species such as Atlantic spot, flounder, croaker and menhaden spawn in the continental shelf waters of North Carolina during late fall to early winter. Following spawning, the eggs and resultant larvae are transported shoreward. As the larvae are advected, they metamorphose into juveniles and those that successfully negotiate the continental shelf may subsequently migrate into the estuaries to primary nurseries to grow until they reach maturity. Hydrological data collected during this study indicates that larvae enter the northern part of the Pamlico Sound, a bar-built estuary, through Oregon Inlet via flood periods associated with enhanced inlet jetting. The hydrodynamics which exist between Pamlico Sound and the coastal ocean are such that the timing of larval arrival to the inlets and subsequent transport into the sound are in synchronization with winds from the north. The resulting ocean-to-estuary pressure gradient force, from the offshore passage of late winter weather systems, drives a rapid current through Oregon Inlet. The responses of Oregon Inlet currents to atmospheric forcing are analysed using time series analysis techniques to determine if larvae, acting as passive water particles, are transported through estuary inlets during favorable wind-enhanced jetting. First, exaggerated ebb and flood events are identified using data sets from Oregon Inlet and David Channels. Second, flood prisms are estimated to determine the volume of water available for larval transport through Oregon Inlet. Finally, the relationships between the atmospheric wind field and the inlet's water properties are evaluated for coherent relationships. Synoptic wind events in the vicinity of Oregon Inlet affect ocean and sound sea level as well as temperature and salinity. Multiple coherence analysis suggests that the flood events which are paramount to fish migration are attributed to local winds.

Major Professor(s): Pietrafesa, Leonard J. Department: Marine, Earth and Atmospheric Sciences Principal Investigator(s): Pietrafesa, Leonard J. Program Area: Marine Transport

KEYWORDS: CIRCULATION, COASTAL ENVIRONMENT, FISH, HYDROLOGY, WINDS

144

Oh, Jai-Ho. 1989. Physically-based General Circulation Model Parameterization of Clouds and their Radiative Interaction. Ph.D. Dissertation, Oregon State University, 315 pages.

A physically-based parameterization of clouds and their radiative interactions has been developed for a multilayer atmospheric general circulation model. The main purpose of this development is to enable the evaluation of cloud optical depth feedback, a feedback of potential importance for greenhouse-gas-induced climate change. In the cloud-radiation parameterization, cloud water is a prognostic variable; fractional cloud amount is predicted semi-prognostically; stratiform and cumuloform clouds can coexist in a vertical atmospheric column; clouds can exist either as liquid water, ice or mixed liquid water-ice clouds; the solar spectrum is subdivided into three bands, two for Rayleigh scattering and ozone absorption, and one for water vapor absorption which is further subdivided into six intervals for the k-distribution method; multiple scattering is calculated by the two-stream, delta-Eddington method; the longwave spectrum is divided into four regions based on the absorbers; the radiative properties of clouds depend on their predicted cloud liquid water and ice amounts; and the vertical distribution of clouds is considered to have maximum overlap for contiguous cloud layers and random overlap for noncontiguous cloud layers. The parameters for the stratiform-cloud parameterization and the values chosen are: (1) the characteristic time for the evaporation of cloud water, $\tau$ $=50$ minutes; (2) the autoconversion rate of cloud water into precipitation, $a=(3600 \mathrm{~s})^{-1}$; $(3)$ the threshold relative humidity of the environment at which 
condensation can begin, $U_{00}=0$; and (4) the threshold cloud water above which precipitation can begin, $\mathrm{m}_{\mathrm{c} w}=$ $0.5 \times 10^{-4} \mathrm{~g} / \mathrm{g}$ for water clouds; $m_{c i}=0.4 \times I_{c}\left(T_{c}\right)$ for ice clouds, where $I_{c}\left(T_{c}\right)$ are the values given by Heymsfield and Platt (1984) as a function of the cloud temperature $T_{c} ; m_{c, i}=1.2 x_{c}\left(T_{c}\right)$ for ice clouds formed from an antecedent cumuloform cloud. The parameters for the cumuloform-cloud parameterization and the values chosen are: (1) the characteristic time for the evaporation of cloud water, $\tau=50$ minutes; (2) the parameter in the diagnostic equation for the cloudiness in terms of the mass flux at the base of the detrainment layer, $\alpha=10$; and (3) the conversion rate of cloud water into precipitation, $\mathrm{C}_{0}=0.002 \mathrm{~m}^{-1}$. In addition, two radiation parameters were determined: (1) the mass absorption coefficient of cumuloform ice clouds, $a_{0}^{\dagger, t}=0.096$; and the multiple-scattering asymmetry factor for cumuloform clouds, $g=0.85$. An evaluation of the performance of the model shows that the cloudradiation parameterization is capable of successfully simulating many features of the observed cloud cover, the vertically integrated cloud water, precipitation, and the earth's radiation budget at the top of the atmosphere. The model is less successful in reproducing the cloud optical depths as given by the International Satellite Could Climatology Project observations. This apparent contradiction suggests that these optical depth observations may not be useful in validating a cloudradiation parameterization. The comparison of the simulated and observed climates also shows that the cloud parameterization is deficient in its reproduction of the subtropical stratocumulus clouds. To rectify this deficiency it is necessary to develop a model for stratocumulus clouds in the cloud-radiation parameterization.

Major Professor(s): Schlesinger, Michael

Department: Atmospheric Sciences

Principal Investigator(s): Schlesinger, Michael

Program Area: Carbon, Climate, and Vegetation

KEYWORDS: ATMOSPHERE, CLIMATE, CLOUDS, MODELS, RADLATIVE PROCESSES

\section{5}

Olaizola, Miguel. 1993. Laboratory and Field Studies of Diatoxanthin Cycling and Non-Photochemical Fluorescence Quenching in Marine Phytoplankton (Chaetoceros muelleri, Thalassiosira aestivalis, Phaeodactylum tricornutum, diatoms). Ph.D. Thesis, State University of New York at Stony Brook, 241 pages.

Laboratory experiments carried out with the diatoms Chaetoceros muelleri and Thalassiosira aestivalis showed that diatoms responded to changes in irradiance by changing their cellular concentration of diadinoxanthin (DD) and diatoxanthin (DT) via the diatoxanthin cycle. Those changes in pigmentation were accompanied by changes in fluorescence yield. Further experiments showed that light-induced diatoxanthin accumulation occurred on the same time scale as increases in the estimate for the rate for thermal de-excitation in the antenna of PSII. Reaction center fluorescence quenching was also evident from those experiments. Further evidence for involvement of the diatoxanthin cycle in energy dissipation was obtained from experiments with Phaeodactylum tricornutum and field samples. It was determined that dithiothreitol (DTT) inhibits the diadinoxanthin de-epoxidase. DTT inhibited DT accumulation as well as increases in DT accumulation resulting from de novo pigment synthesis had the same effect on fluorescence quenching. A large fraction of fluorescence quenching was found to occur independently of DT-cycling and was associated with dissipation processes occurring at the reaction center. Although the DT-cycle was associated with increases in energy dissipation, no evidence of photoprotection was found from measurements of photochemical efficiency or of reaction center protein. Nutrient stress $(\mathrm{N}, \mathrm{P}$, or $\mathrm{Fe}$ ) was found to induce accumulation of DD and DT in $P$. tricornutum. The dependency of quenching coefficients on DT accumulation changed according to the specific nutrient stress and the degree of starvation, estimated from Fv/Fm. The results were interpreted in view of structural changes in PSII known to occur under nutrient stress. Field investigetions of DT-cycling in Auke Bay, Alaska, showed that light induced changes in DT and DD concentration may be used to estimate vertical advection under certain circumstances, but that other factors besides irradiance may affect the cycle. Although it was attempted to measure DT concentrations in the subtropical Pacific ocean it was not possible. The time needed for sample preparation was found to be too long. However, phytoplankton pigment markers were used to estimate changes in the phytoplankton population produced by a wind-induced mesoscale eddy.

Major Professor(s): Falkowski, Paul G.

Department: Marine Science

Principal Investigator(s): Falkowski, Paul G.

Program Area: Oceans

KEYWORDS: DLATOXANTHIN, FLUORESCENCE, MARINE ENVIRONMENT, PLANKTON

146

Olson, Eric J. 1981. Calcium in the Equatorial Pacific Ocean. M.S. Thesis, Oregon State University, 84 pages. 
The calcium concentration of seawater was measured for samples obtained from the recent Hawaii-Tahiti Shuttle Experiment. The complexometric titration used for the determination of calcium was shown to be free of interference from other alkaline earth elements at the $0.1 \%$ level of accuracy obtained. However ratios of interferant to calcium larger than those found in seawater did cause significant loss of accuracy. The results of the investigation of the vertical distribution of calcium, in the equatorial region sampled, suggest that physical-circulation processes are more important that local-vertical production and dissolution of $\mathrm{CaCO}_{3}$ in creating the relative extreme observed. These samples from depths of $1000 \mathrm{~m}$ and less, have specific calcium values that inversely correlate with salinity and temperature. The lowest values of normalized (to $35 \%$ salinity) calcium are found in the warm surface waters of highest salinity and appear to reflect biological depletion in the relatively unmixed waters of the central gyre. The higher specific calcium values are found in less saline waters from higher latitudes and reflect the higher "preformed" calcium values found in colder waters near the polar fronts. This "preformed" dependence can been seen in cross-sectional comparison of calcium concentrations (normalized) across the equator. Here the calcium distribution has boundaries consistent with those between particular circulation features such as equatorial currents and possibly upwelled intermediate waters.

Major Professor(s): Chen, Chen-Tung A. Department: Oceanography Principal Investigator(s): Chen, Chen-Tung A. Program Area: Carbon, Climate, and Vegetation

\section{KEYWORDS: CHEMISTRY, CIRCULATION, EQUATORLAL REGION, METALS, OCEANS, SPATLAL DISTRIBUTION}

\section{7}

Palecki, Michael Anthony. 1986. An Empirical and Modelling Study of the Relationship Between Changes in Physical Variables of the Ocean Surface and the Global Carbon Cycle. $M A$. Thesis, University of Colorado, 160 pages.

Atmospheric $\mathrm{CO}_{2}$ content is measured accurately at a variety of locations around the world. These records reveal a seasonal $\mathrm{CO}_{2}$ cycle and interannual anomalies in $\mathrm{CO}_{2}$ levels. The purpose of this study is to examine the intra- and interannual $\mathrm{CO}_{2}$ variability at 13 stations from $20^{\circ} \mathrm{N}-90^{\circ} \mathrm{S}$, and make comparisons with physical variables of the ocean surface. Especially of interest are changes in atmospheric $\mathrm{CO}_{2}$ content that can be traced to climatic anomalies. Specifically, sea surface temperature (SST) and wind speed are crosscorrelated with $\mathrm{CO}_{2}$ rate-of-change (derivative) curves, with the fossil fuel-induced increase removed. In addition, supplementary crosscorrelation studies were conducted with land surface air temperatures and Antarctic sea ice area versus the $\mathrm{CO}_{2}$ derivative curves. A 2-D carbon cycle model was used to determine model sensitivity to changing SST and wind values in zonal model boxes. The analysis reveals a strong interannual periodicity 25 40 months in the longer $\mathrm{CO}_{2}$ records. All station $\mathrm{CO}_{2}$ records are clearly affected by the coupled atmosphereocean forcings of high and low soutnern oscillation events. Examinations of the climatically-forced variables indicate that the most important forcings of global atmospheric $\mathrm{CO}_{2}$ content are SST changes in the East Pacific Ocean, and land surface air temperature departures in tropical and sub-tropical regions. Ocean changes at higher latitude are more subtle in their effect on $\mathrm{CO}_{2}$ derivatives at most stations. Of the two main forcings, it appears that the land biosphere is most important in explaining interannual variance; very short phase lags and high positive correlations are observed between land surface air temperature departures and almost all the $\mathrm{CO}_{2}$ records examined. Increases in plant respiration and litter decay in response to warmer air temperatures must outweigh increased carbon fixing by plants (and vice versa) in order to explain the positive correlation. This finding is supported by model study results that indicate poor carbon cycle response to realistic ocean variable changes, without any biospheric $\mathrm{CO}_{2}$ flux alterations. A new positive feedback has been identified between air temperature and atmospheric $\mathrm{CO}_{2}$ content, through the land biosphere.

Major Professor(s): Barry, Roger G.

Department: Geography

Principal Investigator(s): Barry, Roger G.

Program Area: Carbon, Climate, and Vegetation

KEYWORDS: ANTARCTICA, ATMOSPHERE, BIOSPHERE, CARBON CYCLE, CARBON DIOXIDE, EL NIÑO - SOUTHERN OSCILLATION (ENSO), ICE, MODELS, OCEANS, SURFACE LAYER, TEMPERATURE, TEMPORAL DISTRIBUTION, WINDS

\section{8}

Pittahwala, Iqbal Ibrahim. 1988. Spatial and Temporal Variations in United States Sunshine. M.S. Thesis, State University of New York at Stony Brook, 85 pages.

Sunshine duration measurements have been made in the United States for about a hundred years, the data consisting mainly of monthly percentages of possible sunshine hours at more than 200 stations. Sunshine 
recording instruments were changed throughout the country to the photoelectric switch in 1953. The data were subjected to tests that investigated possible contamination of the time series due to changes in instrument. The results indicate that any inhomogeneities in the mean monthly, seasonal or annual values of sunshine duration, attributable to the instrument change, are not significant. Trend analysis was performed for nine climatic subdivisions of the United States for the period 1908-1984 to discern temporal and spatial changes in the availability of sunshine. Sunshine for a 30 year period in the nine subdivisions were compared with the Institute of Atmospheric Physics General Circulation Model regional sunshine predictions. A qualitative comparison has also been made with 1971-81 monthly and seasonal cloud cover data for the contiguous United States.

Major Professor(s): Hameed, Sultan

Department: Mechanical Engineering (Atmospheric Sciences)

Principal Investigator(s): Hameed, Sultan

Program Area: Carbon, Climate, and Vegetation

\section{KEYWORDS: NORTH AMERICA, SUNSHINE, TEMPORAL DISTRIBUTION}

\section{9}

Pittakwala, Iqbal Ibrahim 1993. Evolution of the North Atlantic Oscillation. Ph.D. Dissertation, State University of New York at Stony Brook, 202 pages.

The year-to-year variations of winter climate of the North Atlantic region including Northern Europe, northwest Africa and North America are largely influenced by the phases of the North Atlantic Oscillation (NAO). The NAO has been examined using winter sea-level pressure data and an index has been formulated that captures the variation of its intensity. The oscillation is shown to be detected in a coupled ocean-atmosphere general circulation model. The simulated teleconnections in the peripheral land masses of the North Atlantic Ocean are compared with observations. It is suggested that explanations of these climatic variations may be found through diagnoses of such model simulations. The evolution of the NAO has been investigated by inspecting the progression of seasurface temperature (SST) and sea-level pressure (SLP) anomalies for the high and low phases of the oscillation. The progression of the anomalies is found to be generally similar but with opposite sign in the two phases. The high phase is foreshadowed by a major reversal of sea-level pressure conditions in the Icelandic Low region in October. Analyses indicate that the high phase is characterized by a distribution of warm water in the central portion of the North Atlantic. This warm water is flanked by anomalously coll water is the north and in the tropics and subtropics. This distribution is explained as a consequence of the intensification of currents in the Atlantic gyres which is related to the strengthening of the Azores High and Icelandic Low. This explanation is supported by the OSU GCM simulation.

Major Professor(s): Hameed, Sultan Department: Mechanical Engineering (Atmospheric Sciences)

Principal Investigator(s): Hameed, Sultan

Program Area: Carbon, Climate, and Vegetation

KEYWORDS: CLIMATE, MODELS, NORTH ATLANTIC OSCILLATION, TELECONNECTIONS

\section{0}

Potvin, Catherine Jeanne. 1985. Responses of Two C4 Grasses to $\mathrm{CO}_{2}$ Enrichment and Temperature: Implication on Biogeographical Distribution of $\mathbf{C 4}$ Plants. Ph.D. Dissertation, Duke University, 156 pages.

This study was carried out to examine the responses of $\mathrm{C}_{4}$ plants to low temperature and to $\mathrm{CO}_{2}$ enrichment. Such information should help to understand the distributional limits of $\mathrm{C}_{4}$ plants in cool environments and to predict how a global increase in atmospheric $\mathrm{CO}_{2}$ concentration would affect $\mathrm{C}_{4}$ distribution. Two $\mathrm{C}_{4}$ grasses were analyzed, Echinochloa crus-galli and Eleusine indica. Echinochloa crus-galli was represented by 3 populations originating from contrasting thermal environments (Quebec, North Carolina, Mississippi) while a single population of Eleusine indica, from Mississippi, was included in the study. The results indicate clear physiological differences among northern and southern plants. Plants from Quebec have higher photosynthetic rates and a more efficient translocation of ${ }^{11} \mathrm{C}$ regardless of the temperature at which they are grown. Plants from the north have a better potential to adjust to chilling with or without light. The growth pattern of plants from Quebec is characterized by a shorter life cycle; the northern plants flower consistently before the other populations. Plants from all three populations were grown in field plots in North Carolina and in Quebec. While plants from Quebec do not survive through the summer in North Carolina, those from Mississippi fail to reproduce in Quebec. Thus, it appears that the various populations are ecotypically differentiated. The effects of $\mathrm{CO}_{2}$ enrichment on the physiology and growth of the two $\mathrm{C}_{4}$ grasses under study were minor. Plants respond to high $\mathrm{CO}_{2}$ concentration by a slight increase in photosynthesis, in export pool size and in net assimilation rates during the 
first $\mathbf{2 0}$ days of growth. There was a consistent temperature by $\mathrm{CO}_{2}$ interaction in both chilling experiments. $\mathrm{CO}_{2}$ enrichment partially ameliorates the deleterious effects of low temperature. The reasons for this interaction are only speculative but the existence of this relationship demonstrates the danger of assessing the effects of $\mathrm{CO}_{2}$ enrichment by photosynthesis and growth response to $\mathrm{CO}_{2}$ alone. Other environmental factors must be examined and understood. Prior studies have suggested that $C_{4}$ plants are best adapted to warm habitats and are unable to survive at higher latitudes or elevations. This study demonstrates, however that Echinochloa crus-galli has adapted to cool environments by ecotypic differentiation of populations. It seems possible that other $\mathbf{C}_{4}$ grass species will also eventually spread into cooler areas by genecological differentiation. Cool climate adaptations appear to involve the development of a faster phenological development and of an enhanced tolerance to chilling. Because of its stringent effects, chilling under high light is the most difficult challenge faced by $\mathrm{C}_{4}$ plants. With a global increase in $\mathrm{CO}_{2}$ concentration, the distribution of $\mathrm{C}_{4}$ plants is likely to extend to higher latitudes and elevations because of the temperature by $\mathrm{CO}_{2}$ interaction and the $\mathrm{CO}_{2}$-correlated global warming.

Major Professor(s): Strain, Boyd R.

Department: Botany

Principal Investigator(s): Strain, Boyd R.

Program Area: Carbon, Climate, and Vegetation

KEYWORDS: C4 METABOLISM, CARBON DIOXIDE, ECOTYPES, FERTILIZATION, GROWTH AND DEVELOPMENT, PHOTOSYNTHESIS, RESPIRATION, SPATIAL DISTRIBUTION, VEGETATION

\section{1}

Prentice, Katharine Culbertson 1986. The Influence of the Terrestrial Biosphere on Seasonal Atmospheric Carbon Dioxide: An Empirical Model. Ph.D. Dissertation, Columbia University, 247 pages.

A simple global model of the seasonal exchange of $\mathrm{CO}_{2}$ between the biosphere and the atmosphere has been developed. The model is climate-driven allowing vegetation types as well as carbon fluxes to adjust to perturbed climates. Output from the model consists of two fluxes - one directed toward the biosphere the other directed toward the atmosphere. The prescription for change in vegetation type in response to climate change is based on annual temperature and precipitation. The carbon fluxes are based on published field and laboratory measurements of photosynthesis and soil respiration, which have been empirically related to climate variables. The biosphere-atmosphere exchanges are tested by comparing predicted atmospheric $\mathrm{CO}_{2}$ concentrations with observations at a number of monitoring stations. Because the model incorporates spatial and temporal variability of vegetation at climate modeling resolution, the carbon fluxes are biologically more realistic than those of earlier global biospheric carbon models. This research is a first step toward relating climatic variables to seasonal properties of vegetation which influences atmospherically-important biospheric exchanges.

Major Professor(s): Zobler, Leonard

Department: Geography

Principal Investigator(s): Fung, Inez

Program Area: Carbon, Climate, and Vegetation

KEYWORDS: BIOMES, BIOSPHERE, CARBON CYCLE, MODELS, PHOTOSYNTHESIS, RESPIRATION, TERRESTRLAL ENVTRONMENT

152

Prestbo, Eric Wallace. 1992. Atmospheric Chemistry and Long Term Measurements of Peroxyacetyl Nitrate (PAN) and Ozone at a Remote Location in Northern New Mexico. Ph.D. Dissertation, University of Washington, 183 pages.

A field site was established at Frijoles Mesa in Northern New Mexico to study the tropospheric photochemical oxidants, ozone $\left(\mathrm{O}_{3}\right)$ and peroxyacetyl nitrate (PAN) in a non-urban environment. PAN was measured using gas-chromatography with electron capture detection (GC-ECD). An improved PAN calibration method for the GC-ECD was developed based on temperature controlled capillary diffusion of a laboratory synthesized PAN standard in a tridecane matrix. Ozone was measured using a constant referencing ultraviolet absorption detector. Ancillary measurements of $\mathrm{NO}_{\mathrm{y}}$ and meteorology were also made as part of this study. All of the field measurements were automated for continuous operation using computer interface for instrument control and data storage. The resulting 1.5 year continuous data set for $\mathrm{PAN}$ and $\mathrm{O}_{3}$ provided a first time investigation of PANs: 1) long range transport of $\mathrm{NO}_{\mathrm{x}}$ from urban locations with respect to seasonal frequency and magnitude, 2) seasonal budget in remote continental air in North America and 3) relationship to $\mathrm{O}_{3}$ in both remote continental and transported urban air. In remote continental air, identified by $\mathrm{NO}_{\mathrm{y}}$ mixing ratios and airmass back trajectories, the maximum monthly mean for PAN (203 pptv) and $\mathrm{O}_{3}$ (47.5 ppbv) occurs in the springtime. This supports the hypothesis of a photochemical mechanism for the hemispheric phenomenon of an $\mathrm{O}_{3}$ springtime maximum. The 
hypothesis is based on the fact that during the winter, longer lifetimes for both precursors and secondary photochemical oxidants compensates for the slow winter photochemical production rates, leading to a hemispheric winter-spring buildup in $\mathrm{O}_{3}$ and PAN free troposphere mixing ratios. Strong evidence suggests that $\mathrm{NO}_{x}$ is transported to Northern New Mexico from Southern California in the form of PAN. The longrange transport of PAN occurs almost exclusively during the fall and winter months when PAN thermal decomposition rates are at a minimum. The overall average mixing ratio of a long-range PAN transport episodes is nominally greater than $1.0 \mathrm{ppbv}$ with maximum values of $1.7 \mathrm{ppbv}$. The $\mathrm{PAN}$ to $\mathrm{O}_{3}$ ratio relationship appears to be dependent on the photochemical age of an airmass, while the photochemical age is also a function of season. In photochemically young air (fresh emissions) the $\left.[\mathrm{PAN}] / \mathrm{O}_{3}\right]$ ratio is greater than $0.020 \mathrm{ppbv}$ of $\mathrm{PAN}$ to ppov of $\mathrm{O}_{3}$, while in a photochemically aged airmass $\mathrm{PAN}$ and $\mathrm{O}_{3}$ are decoupled. PAN, $\mathrm{NO}_{4}$ and $\mathrm{O}_{3}$ were also investigated as apart of the Pacific Sulfur Investigation (PSI-1). Continental airflow during this investigation resulted in the observation of a PAN and $\mathrm{O}_{3}$ transport episode with maximum values of 1.7 and 80 ppbv respectively, similar to observations at Frijoles Mesa.

Major Professor(s): Zoller, William $\mathbf{H}$.

Department: Chemistry

Principal Investigator(s): Gaffney, Jeffrey S., and Nancy

A. Marley

Program Area: Atmospheric Sciences

KEYWORDS: AIR QUALITY, PEROXYACETYL NITRATES, REGIONAL ANALYSIS, REMOTE SENSING

153

Prior, Stephen Arthur. 1986. Field Studies of the Water Relations and Growth Response of Soybean (Glycine max (L.) Merr. 'Bragg') Grown under Different Water Regimes in $\mathrm{CO}_{2}$-Enriched Atmospheres. M.S. Thesis, North Carolina State University, 173 pages.

Soybean plants were grown from seeds in pots in open top field chambers under five $\mathrm{CO}_{2}$ concentrations (349 to $946 \mu \mathrm{LL}^{-1}$ ) and two water regimes. Differential watering was imposed after the seedling harvest (third node stage) and at this harvest $\mathrm{CO}_{2}$ enrichment had little effect on measured parameters. Harvests during reproductive growth [anthesis (T1) and late pod fill (T2)] showed that water stress inhibited growth, but, the relative increase in total branch length and number, leaf area and dry weight in response to elevated $\mathrm{CO}_{2}$ were greater under water-stressed (WS) conditions than under well-watered (WW) conditions. Water-stressed plants grown under $946 \mu \mathrm{LL}^{-1} \mathrm{CO}_{2}$ had a total dry matter production greater than WW plants at $349 \mu \mathrm{LL}^{-1} \mathrm{CO}_{2}$. Reproductive yield increases were represented by increases in seed number especially under WS conditions. However, weight per seed decreased with increasing $\mathrm{CO}_{2}$ level, thus the increase in total seed dry weight was not great. A phosphorus deficiency appeared to be restricting the seed response to elevated $\mathrm{CO}_{2}$. The mean relative growth rate (RGR) and mean net assimilation rate (NAR) increased with $\mathrm{CO}_{2}$ enrichment in the first interval (day 5 to 2 weeks after emergence) and diminished with time thereafter at each $\mathrm{CO}_{2}$ level. At the second interval ( 2 to 9 weeks), the direct effect of NAR was offset by lower leaf area ratio (LAR), however, since the LAR was greater for WS plants the response of $\mathrm{RGR}$ to $\mathrm{CO}_{2}$ was somewhat similar under both water treatments. At the third interval ( 9 to 14 weeks), the RGR for WS plants remained constant across $\mathrm{CO}_{2}$ treatments, whereas under WW conditions a constant response of NAR coupled with a negative response of $L A R$ resulted in decrease in RGR under $\mathrm{CO}_{2}$-enriched conditions. The decrease in LAR was attributed to a decrease in specific leaf area while leaf weight ratio was unaffected by $\mathrm{CO}_{2}$. Soil water depletion rates decreased at the high $\mathrm{CO}_{2}$ levels by anthesis and early pod formation for (WW) and (WS) treatments, respectively. Subsequently, plants grown under high $\mathrm{CO}_{2}$ required fewer irrigations. At (T1) and (T2), water use per plant either remained constant (WS plants at T1) or declined (WW plants and T1; WW and WS plants at T2) under $\mathrm{CO}_{2}$ enrichment despite an increase in leaf area. Leaf stomatal resistance increased with $\mathrm{CO}_{2}$ enrichment at $\mathrm{T} 1$, however under WS conditions this was apparently offset by greater leaf area, thus accounting for the constant rate of water use. At $\mathrm{T} 2, \mathrm{CO}_{2}$-enriched plants generally had higher leaf resistance, except at the end of the stress cycle where low $\mathrm{CO}_{2}$ grown plants exhibited a sharp increase in resistance. The xylem potential (XP) at $\mathrm{T} 1$ and $\mathrm{T} 2$ was lowered by stress. The XP for WS plants at T2 increased with increasing $\mathrm{CO}_{2}$ concentration.

Major Professor(s): Patterson, Robert P.

Department: Crop Science

Principal Investigator(s): Rogers, Hugo $\mathbf{H}$.

Program Area: Carbon, Climate, and Vegetation

KEYWORDS: CARBON DIOXIDE, FERTILIZATION, GROWTH AND DEVELOPMENT, LEAVES, VEGETATION, WATER STRESS, WATER USE 
154

Prior, Stephen Arthur. 1993. Cotton Root Response to Free-Air $\mathrm{CO}_{2}$ Enrichment. Ph.D. Dissertation, Auburn University, 136 pages.

Relative to aboveground responses of crops to elevated atmospheric $\mathrm{CO}_{2}$, data on belowground responses are scarce. Furthermore, little data under field conditions have been collected. Therefore, field studies were undertaken for two years to investigate the effect of $\mathrm{CO}_{2}$ concentration $\left(360\right.$ and $550 \mu \mathrm{mol} \mathrm{mol}^{-1}$ and soil water regime [wet, 100\% of evapotranspiration (ET) replaced and dry, $75 \%$ (1990) and $67 \%$ (1991) of ET replaced] on cotton root growth at two growth stages (vegetative and reproductive). A new exposure method called free-air $\mathrm{CO}_{2}$ enrichment (FACE) was used to create large-scale test atmospheres in the field with minimal disturbance of plant microclimate. A portable soil coring system was designed, constructed, tested and used to collect root soil samples. Soil root cores to a depth of $90 \mathrm{~cm}$ were collected within the crop row $(0$ $\mathrm{m})$ and interrow $(0.25$ and $0.5 \mathrm{~m})$ to evaluate vertical and horizontal rooting distribution. Root systems (taproot and attached laterals) were excavated to describe morphological patterns. Laterals were divided into four classes based on diameter size [Class 1 (1.0 $\mathrm{mm}<$ ); Class 2 (1.0-1.5 mm); Class 3 (1.5-2.0 mm); and Class $4(>2.0 \mathrm{~mm})$ ]. The effect of water stress or its interaction with $\mathrm{CO}_{2}$ were generally nonexistent with respect to root density (length and dry weight). At the second sampling (reproductive), root weight per unit length was usually greater under water stress throughout the soil profile. At the initial sampling (vegetative), whole profile root density (length and dry weight) and root weight per unit length were usually increased under high $\mathrm{CO}_{2}$ at all horizontal positions. The positive effects of $\mathrm{CO}_{2}$ on these measurements at the second sampling were limited to the $0.5 \mathrm{~m}$ position. At the first sampling, root dry weight density by depth increment were usually higher under FACE throughout the profile and at all horizontal positions, whereas increases in root length density were restricted to interrow positions. For most positions at the second sampling, enhancements in root weight per unit length and root length density occurred in the upper parts of the soil profile. At this period, FACE increased root dry weight density throughout the profile, especially at the interrow positions. Water stress had not effect on the taproot system (taproot plus laterals) at the initial period, but water stress at the second period resulted in reduced length, volume, and dry weight in the second year. At both samplings, most of the taproot measurements (volume, dry weight, lengths, and tissue density) were increased due to extra $\mathrm{CO}_{2}$. Similar responses were noted when taproot and laterals were measured separately. Significant $\mathrm{CO}_{2}$ by water interactions were detected when lateral roots were partitioned into classes based on diameter size. Interactions were detected in Class 1 (first sampling) and Class 3 (second sampling). In all cases, the positive effects of added $\mathrm{CO}_{2}$ occurred under water stress conditions. Results from this study clearly suggest enhancement of root growth of cotton in an elevated $\mathrm{CO}_{2}$ atmosphere.

Major Professor(s): Rogers, Hugo H.

Department: Agronomy and Soils Principal Investigator(s): Rogers, Hugo $\mathrm{H}$.

Program Area: Carbon, Climate, and Vegetation

KEYWORDS: CARBON DIOXIDE, FERTILIZATION, GROWTH AND DEVELOPMENT, ROOTS, SOILS, VEGETATION, WATER STRESS

155

Pulwarty, Roger S. 1994. Annual and Interannual Variability of Convection over Tropical South America: 1980-1989. Ph.D. Dissertation, University of Colorado, 220 pages.

Analyses of temporal (and spatial) variability in a wide range of ocean and atmospheric indices suggest that the annual cycle plays a central role in virtually all of the recognized principal modes of large-scale climatic variability (intraseasonal variability, tropospheric quasibiennial oscillation, El Nifo-Southern Oscillation (ENSO) events). The major research objective of this thesis is a study of the nature and controls of processes, associated with variability in convection on these timescales, over the region of the South American 'monsoon'. Variability on multiple timescales are examined using empirical orthogonal functions, lagged correlations and singular spectrum analysis. Unique aspects of the annual cycle of convection over tropical South America are documented in detail. The study shows that the controls of convection and circulation differ from the Northern Hemisphere summer maximum, over Panama and the eastern tropical Pacific, to that in the Amazon Basin (Southern Hemisphere maximum). Changes in the onset, longevity, and trajectory of key convective centers, associated with the annual cycle over different regions of tropical South America, appear to be modulated by sea surface temperature variations and gradients in the eastern Pacific and tropical Atlantic, location of the intertropical convergence zone, phase of the-quasibiennial oscillation etc. In particular, the southward and westward displacement of these centers, during strong ENSO 'warm' events, occur with widespread dryness over much of continental South America. Conversely, during strong 'cold' events, convection is restricted to 
locations north and eastward of the mean, resulting in higher rainfall over northern South America and Panama. The seasonal dependence of these influences, on climate and circulation over the region, is documented in detail. Interannual variability and trends are documented for rainfall over the central Amazon Basin, and for runoff in the Rio Negro/Amazon and Rio Parana/Paraguay river basins. Interactions and their evolution can lead to observed anomalies in circulation and seasonal precipitation, not always associated with ENSO, suggesting that 'wet' or 'dry' periods result from enhancement or suppression of the annual cycle. Further work is expected to include a study of the influence of ENSO events, with different development characteristics, on the seasonal cycle.

Major Professor(s): Barry, Roger G.

Department: Geography

Principal Investigator(s): Bradley, Raymond S., and

Henry F. Diaz

Program Area: Carbon, Climate, and Vegetation

KEYWORDS: ATMOSPHERE, CIRCULATION, CLIMATE, CONVECTION, EL NIÑO - SOUTHERN OSCILLATION (ENSO), PRECIPITATION, RUNOFF, SOUTH AMERICA, STORMS, TEMPORAL DISTRIBUTION

156

Purba, Mulia 1984. A Parametric Evaluation of Observations in the Georgia Bight, March - May, 1980. Ph.D. Dissertation, North Carolina State University, 159 pages.

An evaluation of the terms that appear in the equations governing the momentum balance have been made by using current meter data collected during a four month experiment (Feb. - June 1980) conducted in the Georgia Bight. Supplemental data sets, such as those of coastal sea level and continental shelf, marine meteorology also are utilized. Time and space difference approximations are used to estimate temporal rate of change and spatial gradients, respectively. Two sets of L-shaped mooring array triplets are chosen for this study. The results show that the diabathic (cross-shelf) momentum equation is basically geostrophic while the parabathic (alongshore) momentum balance is predominantly ageostrophic. Similar results are found for the case of temporally meaned momentum equations. However, the vertical Reynolds stress term is also important in the mean parabathic momentum balance. In the midshelf region evidence is found that subtidal frequency flow is influenced principally by local wind forcing. The geostrophic balance in the diabathic momentum equation could be best categorized as an Ekman frictional mechanism. The existence of the FloridaGeorgia-South Carolina wall effectively causes a sea level drop (rise) in the events of northward (southward) winds, establishing an onshore (offshore) diabathic pressure gradient force, which is balanced by the resulting north (south)ward geostrophic interior flows. The spatial and temporal variability of wind events along the coast, particularty the alignment of the meteorological "high" and "lows" with the coast, causes sea level to drop (rise) differentially along the coast, establishing the parabathic pressure gradient. As a corollary parabathic currents vary accordingly. Consequently, the time derivative of these parabathic currents becomes important in the parabathic momentum equation, yielding an ageostrophic balance. The parabathic pressure gradient force is found to be directed in the same direction as the parabathic wind stress because of the alignment of the weather systems relative to the curved coastline.

Major Professor(s): Pietrafesa, Leonard J., and Gerald S. Janowitz

Department: Marine, Earth and Atmospheric Sciences Principal Investigator(s): Pietrafesa, Leonard J. Program Area: Marine Transport

\section{KEYWORDS: CIRCULATION, COASTAL ENVIRONMENT, MOMENTUM, OCEANS, PRESSURE, SEA LEVEL, SPATLAL DISTRIBUTION, TEMPORAL DISTRIBUTION, TIDES, WINDS}

\section{7}

Ramankutty, Navin. 1994. An Empirical Estimate of Climate Sensitivity. M.S. Thesis, University of Illinois at Urbana-Champaign 167 pages.

The Intergovernmental Panel on Climate Change (IPCC) estimates the climate sensitivity to be in the range 1.5 to $4.5^{\circ} \mathrm{C}$, with a best guess of $2.5^{\circ} \mathrm{C}$ (Houghton et al., 1990, 1992), while Lindzen estimates $\Delta T_{2 x}=0.5^{\circ} \mathrm{C}$ (Lindzen, 1990). The IPCC estimate is based on equilibrium simulations using General Circulation Models (GCMs). This study presents an alternate method of estimating $\Delta T_{2 x}$ using an empirical approach combining simple climate/ocean model simulations with observations. The same procedure is applied to narrow the range of uncertainty in the estimate of radiative forcing due to some climate forcing agents. Our study yields an estimate of $\Delta T_{2 x}=2.9_{+2.3}^{-12} \mathrm{C}$, corresponding to estimated anthropogenic sulphate aerosol (ASA) forcing of $\Delta F_{\text {sos }}(1978)=-0.6_{-0.3}^{+0.5} \mathrm{Wm}^{-2}$. This range of sensitivity is $17 \%$ larger than the IPCC range, but our estimated 
range of ASA radiative forcing is much smaller than the estimates from direct radiative-transfer calculations of $-0.9 \pm 0.6 \mathrm{Wm}^{-2}$. Putative long-term solar-irradiance variations imply a range of $\Delta T_{2 x}=1.6_{+3.6}^{-0.6 \circ} \mathrm{C}$, corresponding to a range of $\Delta \mathrm{F}_{\mathrm{SO} 4}(1978)=$ $-0.5_{-a 6}^{+a 4} \mathrm{Wm}^{-2}$. A case is made for the plausibility of long-term solar-irradiance variations, but direct observational or physical evidence is still wanting. We use our simple model to detrend the observed temperature record and identify an ascillation of 65-70year timescale. The oscillation is confined to the North Atlantic and bounding Northern Hemisphere continental regions. We believe that it is caused by internal ocean dynamics rather than external forcing. We have explored the implications of volcanic aerosol forcing on global-mean surface temperatures. We estimate the cooling due to volcanic aerosols to be $-1.6_{-1.5}^{+0.8} \mathrm{C}$ per unit aerosol optical depth. We also find evidence for cumulative long-term cooling due to frequent occurrence of eruptions. However, this longterm cooling does not explain the warming-coolingwarming phases of the observed temperatures from 1910-1970, as has been conjectured by Lamb (1970), Robock $(1978,1979)$ and Bryson and Goodman (1980). We find that climate sensitivity has a significant influence on the temperature response to volcanic forcing, contradictory to the conclusion of Wigley and Raper (1990a).

Major Professor(s): Schlesinger, Michael Department: Atmospheric Sciences Principal Investigator(s): Schlesinger, Michael Program Area: Carbon, Climate, and Vegetation

KEYWORDS: ATMOSPHERE, CLIMATE, GASES, MODELS, OCEANS, RADLATIVE PROCESSES, SULFUR SPECIES, TEMPERATURE, TEMPORAL DISTRIBUTION, VOLCANOES

158

Reid, Chantal Danielle. 1990. The Carbon Balance of Shade-Tolerant Seedlings of Fagus grandifolia and Acer saccharum under Low Irradiance and $\mathrm{CO}_{2}$ Enrichment. PhD. Dissertation, Duke University, 180 pages.

The photosynthetic response to irradiance of beech (Fagus grandifolia) and sugar maple (Acer saccharum) was compared on seedlings grown at current and elevated atmospheric $\mathrm{CO}_{2}$ to determine the effects of $\mathrm{CO}_{2}$ enrichment on leaf carbon exchange. In both species, maximum photosynthesis was significantly increased with $\mathrm{CO}_{2}$ enrichment but leaf dark respiration was not significantly changed. Photosynthesis of beech was consistently lower than that of sugar maple while both species had similar leaf respiration rates. Beech experienced greater enhancement of growth with $\mathrm{CO}_{2}$ enrichment suggesting that photosynthetic capacity was not a good indicator of the net effect of $\mathrm{CO}_{2}$ enrichment. Whole-plant carbon balances were compared for seedlings grown under low irradiances and two atmospheric $\mathrm{CO}_{2}$ to determine if shadetolerant seedlings of these two species have similar patterns of carbon exchange rates, and how carbon exchange dynamics are affected by $\mathrm{CO}_{2}$ enrichment. Under current $\mathrm{CO}_{2}$, whole-seedlings of beech had lower carbon uptake during the daytime while carbon loss to root respiration and nighttime leaf dark respiration was similar for both species. A lower net carbon gain for beech resulted under current $\mathrm{CO}_{2}$. Under elevated $\mathrm{CO}_{2}$, both species showed similar whole-seedling carbon uptake, indicating a significant increase in CER with $\mathrm{CO}_{2}$ enrichment for beech. Total carbon loss to leaf respiration was decreased for beech only and carbon loss to root respiration was not changed by $\mathrm{CO}_{2}$ enrichment for either species. $\mathbf{A}$ greater net daily $\mathbf{C}$ gain for beech indicated an improvement of growth with $\mathrm{CO}_{2}$ enrichment relative to sugar maple. The carbon balances of beech and sugar maple suggest 2 types of carbon allocation contributing to growth and survival in low light: 1) a low carbon uptake coupled with low root respiration rate for slow growth (beech); and 2) a high carbon uptake with low root respiration cost allowing slow growth (sugar maple). $\mathrm{CO}_{2}$ enrichment enhances the first type by increasing photosynthesis and reducing respiration cost, and thus favoring growth of beech. This study suggests a potential change in species distribution in $\mathrm{CO}_{2}$ enriched atmospheres because of species specific responses such as a greater enhancement of beech versus sugar maple.

Major Professor(s): Strain, Boyd R.

Department: Botany

Principal Investigator(s): Strain, Boyd R.

Program Area: Carbon, Climate, and Vegetation

KEYWORDS: CARBON CYCLE, CARBON DIOXIDE, COMPETITION, FERTILIZATION, GROWTH AND

DEVELOPMENT, PHOTOSYNTHESIS, RESPIRATION, SHADE, VEGETATION

159

Reilly, John Matthew. 1983. An Economic Analysis of Global Energy and Carbon Dioxide Emissions. Ph.D. Dissertation, University of Pennsylvania, 173 pages.

A energy-economic model of possible future carbon dioxide emissions is presented and simulated to the year 2050. The model endogenously determines the set of energy prices that balance supply and demand for energy. Based on these simulations, energy use and 
carbon dioxide emissions are shown to increase substantially through the year 2050 , with an increasing share of emissions and energy use from outside the OECD countries. The model is simulated to consider the level of global emission taxes required to meet carbon dioxide concentration targets of 400,600 , and $\mathbf{8 0 0}$ parts per million (ppm) concentrations of atmospheric carbon dioxide and to control emissions to rates that would limit the temperature increase to $.2, .5$ and $.7 \mathrm{C}$. per decade. The fossil fuel taxes in constant 1975 dollars required by 2050 to meet concentration targets ranged from $\$ 107$ ( $800 \mathrm{ppm}$ constraint) to $\$ 372$ (400 ppm constraint) per ton of carbon and from $\$ 0$ (.7 C.) to $\$ 120(.2 \mathrm{C}$.) to limit the rate of increase in temperature. The required level of taxes increase over time. The United States acting alone to control emissions is shown to have very little effect on slowing the rate of climate change.

Major Professor(s): Adams, F. Gerard

Department: Economics

Principal Investigator(s): Edmonds, James A.

Program Area: Carbon, Climate, and Vegetation

KEYWORDS: ATMOSPHERE, CARBON DIOXIDE, CLIMATE, ECONOMICS, EMISSIONS, ENERGY USE, MODELS, POLICY, TEMPERATURE

160

Reinhardt, Debra R. 1989. Growing Season Dynamics of Vesicular Arbuscular Mycorrhizal Fungi in Prairie Versus Pasture Ecosystems. M.S. Thesis, University of Illinois at Chicago, 42 pages.

This study addresses the hypothesis that there is a community effect for levels of intraradical and extraradical vesicular-arbuscular mycorrhizal fungal colonization of fibrous roots, based on general root morphology and phenology. Two grassland communities, a reconstructed prairie characterized by a predominance of warm-season grasses and an ungrazed pasture composed of cool-season grasses, were chosen as the study sites because of their differences in root morphology as well as phenology. A community effect for the biomass of roots larger than $1.0 \mathrm{~mm}$ in diameter was found to occur. A significantly greater amount of root biomass was in this size class in the prairie as compared to the pasture. However, the biomass of fibrous roots, i.e., roots less than $1.0 \mathrm{~mm}$ diameter, did not differ significantly between the two communities. Fibrous root length was significantly greater in the pasture than in the prairie due to greater lengths of medium (0.075-0.2 $\mathrm{mm}$ diameter) and fine $(<0.075$ $\mathrm{mm}$ diameter) fibrous roots. Although a greater total length of total length of fibrous roots occurred in the pasture community, the amount of VAM fungus as represented by total length of roots colonized was similar for the prairie and pasture communities $(P=$ 0.34). However, the colonized lengths within the various size classes of fibrous roots differed between the two communities. Therefore, a pattern of fungal colonization which would explain the intraradical distribution among root size classes based on "susceptibility" of each size class to colonization was sought. A measure of "susceptibility to colonization" by VAM fungi for each size class of root was determined by dividing the proportion of total root length within a diameter size class by the proportion of total root length within that size class. These values demonstrated that the finer the fibrous root size class, the less susceptible it was to colonization. The susceptibility values for two of the three size classes were not significantly different for the two communities, indicating that the importance of root diameter in determining level of colonization is similar in the two communities.

Major Professor(s): Lussenhop, John

Department: Biological Sciences

Principal Investigator(s): Miller, R. Michael

Program Area: Ecosystems Function and Response

KEYWORDS: COLONIZATION, FUNGI, GRASSLANDS, MORPHOLOGY, ROOTS

161

Renn6, Nilton de Oliveira. 1992. Cumulus Convection Parameterization and Numerical Modelling of Moist Atmospheres. Ph.D. Thesis, Massachusetts Institute of Technology, 297 pages.

A hydrological cycle is explicitly included in a onedimensional radiative-convective equilibrium model which is coupled to a "swamp" surface and tested with various cumulus convection schemes: the Moist Convective Adjustment scheme (Manabe et al., 19656), the Kuo (1974) scheme, the GISS (1974) Model scheme, the GISS (1983) Model II scheme, and the Emanuel (1991) scheme. Our results show that when the flux of incoming solar radiation is above a critical value - dependent on the choice of the cumulus convection scheme - equilibrium is not possible (a runaway greenhouse occurs). When the atmosphere's relative humidity is kept fixed at climatological values, the runaway greenhouse is inhibited. Furthermore, while the mass flux schemes [GISS (1974), GISS (1983), and Emanuel (1991)] produce an abrupt runaway greenhouse - which occurs through a finite amplitude instability generated by the interaction of infrared radiation fluxes with detrained water vapor at 
the level of neutral buoyancy - the other schemes produce a smooth transition to the runaway greenhouse. In addition, our results show that the Moist Convective Adjustment scheme breaks down when the runaway greenhouse is approached, and that the various cumulus schemes tested produce a decrease in the relative humidity of the middle-upper troposphere when the atmosphere's $\mathrm{CO}_{2}$ content is doubled. These schemes are not consistent with each other since they not only lead to different critical solar forcing for a runaway greenhouse to occur, but also produce very different water vapor profiles in the equilibrium atmosphere and have different lapse-rate feedbacks. Finally, using the scheme proposed by Emanuel (1991), we show that the atmospheric water vapor content and, therefore, the sensitivity of the equilibrium temperature to changes in the solar forcing, as well as the critical solar forcing in order for the runaway greenhouse to occur, depend crucially on the microphysics of cumulus convection. These results indicate that a physically-based cumulus convection scheme is of crucial importance in climate simulations, and that a poor cumulus convection scheme can produce artificial sensitivities in numerical simulations of moist atmospheres.

Major Professor(s): Emanuel, Kerry A.

Department: Earth, Atmospheric, and Planetary

Sciences

Principal Investigator(s): Emanuel, Kerry A.

Program Area: Computer Hardware, Advanced

Mathematics, and Model Physics (CHAMMP)

KEYWORDS: CLIMATE, CONVECTION, MODELS, RADLATIVE PROCESSES, WATER VAPOR

\section{2}

Riechers, George Herman 1983. The Effects of Carbon Dioxide Enrichment on Two C-4 Grassland Species. Ph.D. Dissertation, Duke University, 92 pages.

The gradual, continuing $\mathrm{CO}_{2}$ enrichment of the global atmosphere is certain to have numerous effects on plants. It is well documented that these effects will not be uniform among species, but rather some species will be greatly affected, others relatively little. Because of this species specificity in the response to $\mathrm{CO}_{2}$ enrichment, effects on the competitive balances among species are anticipated. Photosynthetic pathway is one of the major factors upon which the response to $\mathrm{CO}_{2}$ depends. Plants with the $\mathrm{C}-3$ pathway are predicted to have larger growth responses than $\mathrm{C}-4$ species. However, most of the studies upon which this prediction is based were either short-term experiments, or were performed at low irradiances which may have severely limited the photosynthesis of the C.4's.
Therefore, in this study two C-4 species -- Andropogon scoparius and Bouteloua gracilis -- from the Great Plains grasslands were grown for an extended period, under irradiances of approximately $1000 \mu \mathrm{sec}^{-1} \mathrm{~m}^{-2}$ PPFD, and at three $\mathrm{CO}_{2}$ concentrations -- 350, 675 and $1000 \mu \mathrm{l} \mathrm{d}^{-1}$. A significant effect of enrichment to $675 \mu 11^{-1}$ on the growth of both species was demonstrated. After 9 weeks, Andropogon had nearly $50 \%$ more leaf area at $675 \mu \mathrm{H}^{-1}$ than at $350 \mu 1 \mathrm{H}^{-1}$. Bouteloua, after 7 weeks, had an $80 \%$ increase in leaf area. Well-watered plants grown at $1000 \mu \mathrm{l}^{-1}$ were generally no longer than those at $350 \mu \mathrm{l} \mathrm{H}^{-1}$. A period of drought stress was also imposed. The interaction between this stress and $\mathrm{CO}_{2}$ enrichment was such that elevated $\mathrm{CO}_{2}$ tended to reduce the severity of the stress, and that other under the stress treatment the $\mathrm{CO}_{2}$ effects may have been enhanced. Photosynthetic capacity of the plants grown at elevated $\mathrm{CO}_{2}$ was not reduced. Similarly, there was no evidence of excessive starch accumulation in the leaves grown at high $\mathrm{CO}_{2}$. For example, specific leaf weights were reduced in plants grown at 675 and $1000 \mu 1 \mathrm{~A}^{-1}$, not increased as would be the case with starch accumulation.

Major Professor(s): Strain, Boyd R.

Department: Botany

Principal Investigator(s): Strain, Boyd R.

Program Area: Carbon, Climate, and Vegetation

KEYWORDS: ATMOSPHERE, BIOMASS, C3

METABOLISM, C4 METABOLISM, CARBOHYDRATES, CARBON DIOXIDE, FERTILIZATION, GROWTH AND DEVELOPMENT, LEAVES, VEGETATION, WATER STRESS

163

Robaidek, Jerrold O. 1993. Comparison of Spherical Harmonic Coefficients of Long and Short Wave Heating Rates. M.S. Thesis, University of Maryland at College Park, 18 pages.

Radiation algorithms need to be improved to better simulate the atmosphere for long term climate variability studies. Part one of this paper looks at three different spectral models and compares the spherical harmonic coefficients of the long and short wave heating rate fields with observations. The CCM1 T42 and R15 models are used. In addition the CCM2 T42 model is used. The results indicate that the physics in the CCM1 does a poor job of matching observations. The CCM2's physics more closely matches the observations, but a T80 truncation may incorporate more valuable information than the T42 truncation. Part two of this paper compares the winter seasons of January and February of 1983 and 1987 from the 
NCAR CCM2 AMIP run with a short period of observations from January of 1987 . Both winters from the AMIP run appear to be quite similar. The observations, however show greater heating in the higher levels and much reduced heating in the lower levels. The January 87 observed data may be too short of a time period to adequately compare the data sets. The observed data may need to be run out further than the 12 and 36 hour runs that were performed.

Major Professor(s): Baer, Ferdinand

Department: Meteorology

Principal Investigator(s): Baer, Ferdinand

Program Area: Atmospheric Radiation Measurement (ARM)

KEYWORDS: CLIMATE, HEAT FLUX, MODELS, RADIATIVE PROCESSES

\section{4}

Rosa, Charies H. 1993. Modeling Investment Uncertainty in the Costs of Global $\mathrm{CO}_{2}$ Emission Policy. PhD. Dissertation, University of Michigan, 126 pages.

The dissertation investigates how the United States economy will evolve during the next 110 years if policies are implemented which limit the production of carbon dioxide as a by-product of economic activity. Increased concentrations of atmospheric carbon dioxide, a principal determinant of terrestrial weather patterns, have led many to conclude that governmental intervention is necessary to induce the world's economy to rely less upon carbon based fassil fuels. Many deterministic macroeconomic models have been developed to try and determine what specific policies are necessary to cause this shift away from fossil fuel use as well as what the cost of such measures are in terms of lost economic output. This dissertation develops a nonlinear stochastic macroeconomic model with continuously distributed random variables that determines optimal policy while explicitly modeling the uncertainty inherent in new technology development and exhaustible resource exploration. It compares the optimal policy developed in this stochastic model with non-optimal policy derived under the assumption of a certain future, and measures the resulting improvement in economic performance. Because the stochastic model with continuously distributed random variables is very difficult to solve, this dissertation bounds the true solution. It uses a parallel implementation of a nonlinear decomposition algorithm to obtain an upper bound and develops a new lower bounding method based on the linear response function technique for stochastic linear programs to derive a lower bound. The quality of the resulting bounds is explored as well as the benefits of parallelization as a means of improving solution times.

Major Professor(s): Birge, John R.

Department: Industrial and Operations Engineering

Principal Investigator(s): Wohlpart, A.

Program Area: Graduate Fellowships for Global Change

KEYWORDS: CLIMATE, ECONOMICS, EMISSIONS, GASES, MODELS, POLICY

165

Ross, John Alan. 1993. An Algebraic Stress Finite Element Model for Recirculating Turbulent Flows. Ph.D. Dissertation, University of California at Davis, 193 pages.

The momentum equations that describe laminar or turbulent flow are the Navier-Stokes equations. When these equations are time averaged, by a method outlined by $O$. Reynolds, new terms called Reynolds stresses appear in these equations. There are several ways to represent these Reynolds stresses, and the manner in which these terms are determined is called a turbulence model. In this research the standard K-€ and Rodi's algebraic stress models were used to calculate one-dimensional fully-developed turbulent channel flow, turbulent two-dimensional flow over a backward facing step, and turbulent two-dimensional flow around a rectangular cylinder. For fully developed channel flow the K-e model predicts equal normal Reynolds stresses, which has not been observed in laboratory measurements. The algeluraic stress model (ASM) correctly separates these normal stresses, which is a necessary condition for generating the secondary currents which are known to exist in rectangular duct flows. The K-e model for flow over a backward facing step predicts velocity distributions and separation lengths which are very good when they are compared with the experimental results. However, the normal Reynolds stresses were nearly identical, which has not been observed in laboratory studies. Results from Rodi's ASM for this test problem show a distribution of the normal Reynolds stresses that are separated and generally match the experimental data very well, especially near the step. The K-6 model for turbulent flow around a rectangular cylinder predicted vortex shedding at a lower frequency than was measured experimentally. Rodi's ASM produced more energy in the mean flow, and the vortex shedding frequency was almost identical to laboratory results. In conclusion, Rodi's ASM separated the normal Reynolds stresses and put more energy into the mean flow and is 
therefore considered to be a better turbulence model than the standard K-e model.

Major Professor(s): Larock, Bruce E. Department: Civil Engineering Principal Investigator(s): Lee, Robert L. Program Area: Atmospheric Sciences

\section{KEYWORDS: MODELS, REYNOLDS STRESSES, TURBULENCE}

166

Roj, Brian L 1988. Development and Evaluation of an Adaptive Control Procedure for Carbon Dioxide Control in Environmental Growth Chambers. M.Eng. Thesis, University of Florida, 130 pages.

The overall goal of this research was the development, implementation, and validation of a computer-based data acquisition and control system to regulate the $\mathrm{CO}_{2}$ concentration in a semi-closed environmental plant growth chamber. This included the overall conceptual design of the control system, a comparison of different control algorithms, and the development of an adaptive control procedure. The conceptual design was based on distributed processing and multi-tasking capabilities. The processing responsibilities in the developed system were shared by two serially connected microprocessors. A subprocessor handled short interval tasks such as real-time data collection as well as directly making and implementing control decisions. At longer intervals, data from sensors and on control actions were uploaded to a hostprocessor for storage and analysis. Multi-tasking in the hostprocessor allowed several independent tasks to run simultaneously. Three control algorithms were tested and compared for $\mathrm{CO}_{2}$ concentration control: a proportional (P), a proportional-integral (PI), and a modified PI controller using a model (PIM). Two tests were used to evaluate the response of the three controller algorithms to simulated diurnal light patterns and simulated cloud cover patterns. The PIM controller consistently maintained more stable $\mathrm{CO}_{2}$ levels in the chamber than either the P or the PI controllers for both simulated light patterns. Crop utilization of $\mathrm{CO}_{2}$ changes as plants develop throughout the growing season. Therefore, the model to predict plant $\mathrm{CO}_{2}$ uptake must also change. To provide the control system with the capability to make seasonal modifications a regressior procedure (R) was coupled to the PIM algorithm (PIMR). To evaluate PIMR a third test simulated plant growth by using different numbers of plants. The first diurnal simulation test ("day 1"), for a given number of plants in the chamber, used estimated control (model) parameters. On "day 2 ", the same plants were retested using control parameters generated through the automated regression analysis of data obtained on "day 1 ". The "day 1 "/"day 2 " sequence was repeated for 4 different plant loads. The adaptive controller (PIMR) proved to be very effective for automatically updating model coefficients and maintaining stable $\mathrm{CO}_{2}$ controls in a changing environment. The $\mathrm{CO}_{2}$ concentrations in the plant chamber were more precisely regulated after the adaptive regression procedure updated the control parameters. The standard deviation of the $\mathrm{CO}_{2}$ concentrations for one, two, three, and four plants comparing the values before/after regression were $14.09 / 5.62,12.06 / 7.40,10.42 / 5.39$, and $8.29 / 6.60 \mu / /$, respectively.

Major Professor(s): Jones, Pierce $\mathbf{H}$.

Department: Agricultural Engineering Principal Investigator(s): Allen, Leon $\mathrm{H}$., Jr. Program Area: Carbon, Climate, and Vegetation

\section{KEYWORDS: ATMOSPHERE, CARBON DIOXIDE ENVIRONMENTAL GROWTH CHAMBERS, MODELS}

\section{7}

Ruggiero, Frank Harrison. 1987. Experimental Studies of Clouds and Aerosols Along the Antarctic Coast. M.S. Thesis, North Carolina State University, 64 pages.

Results of a study of Antarctic coastal stratus clouds over the Ross Ice Shelf are presented The pristine nature of the Antarctic atmosphere provides a natural laboratory to learn the microphysical reactions to anthropogenic pollutants and aerosols. Bimodal droplet size spectra and spectral broadening increasing with height were detected. This bimodality although contrary to classical growth theory may be explained by entrainment within the cloud. The supersaturation in these clouds are rather high due to limited competition for water vapor caused by low concentrations of cloud condensation nuclei (CCN). Cloud water samples were taken from the Antarctic coastal clouds and analyzed for their acidity and ion contents. The $\mathrm{pH}$ of the cloud water ranged from 4.9-6.2. Total $\mathrm{SO}_{4}{ }^{2}$ concentration was found to increase with height inside the cloud although excess sulfate content showed a decrease with height. Average levels of total $\mathrm{SO}_{4}{ }^{-}$were found to be of the same magnitude as those in the regions surrounded by anthropogenic sources but $\mathrm{NO}_{3}^{-}$ concentration was much lower. Being devoid of influences from significant anthropogenic ground sources, Antarctic cloud water affords an unusual and unique opportunity to assess relative contribution of natural sources, such as marine vs. atmospheric, to the precipitation acidity. It is suggested that future 
measurements should include the determination of concentrations of ammonia, hydrogen peroxide and organic acids. Results are also presented of aerosol sampling that was done at Paimer Station on the Antarctic Peninsula during 1983. The sampling was accomplished by exposing nucleipore filters for periods of time ranging from two to nine days. The samples were later analyzed with an X-ray energy spectrometer (XES) in order to determine elemental composition. The importance of these samples derived from the fact that the adjacent Weddell Sea is believed to be the primary sources for the South Pole. Results reveal that sea salt aerosols from the oceans and crustal aerosols from exposed rocks are the principle components of the aerosol budgets at Palmer. Trace metals that are found highly enriched at the South Pole are not as enriched at Paimer. The reason for the change of enrichments is the preferential deposition of the sea salt and crustal aerosol.

Major Professor(s): Saxena, Vinod $\mathbf{K}$. Department: Marine, Earth and Atmospheric Sciences Principal Investigator(s): Saxena, Vinod $\mathrm{K}$. Program Area: Atmospheric Sciences

KEYWORDS: ACIDITY, AEROSOLS, ANTARCTICA, CHEMISTRY, CLOUDS, COASTAL ENVIRONMENT, CONDENSATION, METALS, PARTICULATES, SULFUR SPECIES, WATER

\section{8}

Sakai, Ricardo. 1994. Leaf Area Influence on Turbulent Exchange in a Deciduous Forest. M.S. Thesis, State University of New York at Albany, 128 pages.

A study over a deciduous forest has been performed to the examine the role of the leaves in the forestatmosphere interaction. Due to the seasonal presence of leaves, a deciduous forest is a good 'laboratory' to study this interaction. This study has two major parts. The first is concerned with the measurement of LAI (Leaf Area Index) using digital image processing. The second examines the effects of the leaves during the year and the impact of their presence on transition seasons (spring and autumn) during two study years. Comparison with satellite measurements is performed to use these relationships in models that require vegetation-atmosphere parameterizations such as GCMs, or mesoscale models. Even though digital images captured the transition from a leafless canopy to a foliated canopy and vice-versa, the digital images used in this study led to low estimates of LAI and PAI (Plant Area Index). Linear adjustments using LAI and PAI from direct measurements a PAR (Photosynthetically Active Radiation) due to absorption of visible light in the canopy. Water vapor concentration increases and the $\mathrm{CO}_{2}$ concentration decreases in the surface layer as the canopy starts tc be foliated. The physical presence of the leaves are felt in other quantities such as the global solar albedo and the subcanopy environment. Noticeable changes in the scalar profiles such as temperature, water vapor mixing ratio, and atmospheric $\mathrm{CO}_{2}$ concentration are also observed. Leaves also affect the energy partition at the top of the forest. The Bowen ratio decreases during the leaf out as the rate of evaporation increases. The canopy resistance continues to change as $\mathrm{LAI}$ increases slowly during summer, indicating that the canopy is not physiologically static during growing season. Canopy resistance starts to increase about one month before the leaf fall, and evaporation then is controlled as if the canopy were leafless. This suggests that physiological processes associated with leaves have a shorter annual period than their physical presence would suggest. NDVI (Normalized Difference Vegetation Index) relationships with some surface measurements indicate that tower based measurements can represent at least a satellite pixel region.

Major Professor(s): Fitzjarrald, David R. Department: Atmospheric Sciences Research Center Principal Investigator(s): Fitzjarrald, David R. Program Area: National Institute for Global Environmental Change (NIGEC)

KEYWORDS: FORESTS, LEAVES, PHOTOSYNTHESIS, RADLATIVE PROCESSES, REFLECTANCE, TEMPERATURE, TEMPORAL DISTRIBUTION, WATER VAPOR

169

Salathe, Eric. 1994. The Interaction of UpperTroposphere Water Vapor and the Earth's Infra-Red Radiation Field. Ph.D. Dissertation, Yale University, 128 pages.

A fundamental problem in predicting the response of the climate to anthropogenic perturbations to the atmospheric radiation field is understanding the role of water vapor. Water can provide a positive feedback to a temperature perturbation that is easily understood since a warmer atmosphere can contain more water and be more opaque. This feedback almost certainly occurs in the lower troposphere where shallow convection quickly transports water vapor into the boundary layer from the sea surface and maintains constant nigh relative humidity. The upper troposphere, however, is isolated from the underlying sea surface over large regions of the globe that are characterized by persistent sinking motion. Given the lack of a comprehensive long-term 
record of global upper-tropospheric water vapor, its role in climate processes is an unresolved question and is the underlying motivation for the work in this dissertation. The first two chapters present introductory material. In Chapter Three, the ability to measure moisture and to model the radiation field in the upper-troposphere is examined. Radiances observed by the GOES-VAS 6.7 um channel are compared to computations from simultaneous aircraft soundings of temperature and moisture. This comparison shows that all three models overestimate the observed brightness temperatures but reproduce the full range in observed brightness temperatures. Possible sources for this bias are investigated, and it is concluded that no one mechanism can alone account for the observed discrepancies. In Chapter Four, regional and seasonal characteristics of upper tropospheric moisture and the ability of a circulation model to capture them is examined. Largescale variability of moisture in the upper troposphere in 1989 is examined using ECMWF model analyses and TOVS satellite radiances. Radiances computed from the ECMWF analyses reproduce the general locations and seasonal cycle of the TOVS-observed moisture features, but lack the moisture gradients and seasonal contrasts than indicated by the TOVS observations. Dynamically, the TOVS-observed regions of significant subtropical dryness are correlated with persistent subsidence indicated by ECMWF $300 \mathrm{mb}$ vertical velocity analyses. In Chapter Five, the impact of infrared radiative heating on the evolution of observed atmospheric profiles and the vertical distribution of water vapor is considered. Gravity wave motions are explored as a mechanism to produce vertical layering of moisture and infra-red cooling is shown to slightly amplify the gravity wave. The static and dynamic stability of moist layers is explored.

Major Professor(s): Smith, Ronald B.

Department: Geology and Geophysics

Principal Investigator(s): Smith, Ronald B.

Program Area: National Institute for Global

Environmental Change (NIGEC)

KEYWORDS: ATMOSPHERE, MODELS, RADLATIVE PROCESSES, SPATLAL DISTRIBUTION, SUBTROPICS, TEMPERATURE, TEMPORAL DISTRIBUTION, WATER VAPOR

\section{0}

Santer, Benjamin David. 1988. Regional Validation of General Circulation Models. PhD. Dissertation, University of East Anglia 375 pages.

General Circulation Models (GCMs) of the atmosphere and ocean have been used for performing a variety of climate experiments, such as simulating the possible climatic effects of doubled or quadrupled $\mathrm{CO}_{2}$. Confidence in the reliability of experimental results can only be obtained by detailed validation of model control run results - e.g., by objective determination of how successfully GCMs perform in simulating present-day climate. It is generally accepted that current GCMs show considerable disagreement in terms of important regional and seasonal details of their control run climatologies, but there are few objective intercomparison studies to substantiate this. This study examines the regional and seasonal details of the mean sea-level pressure (MSLP) fields simulated by three GCMs - the OSU two-layer AGCM(in a 10-year control integration with fixed sea-surface temperature), the OSU CGCM (in years $11-20$ of a 20 -year control integration, in which the two-layer AGCM was synchronously-coupled with a six-layer ocean model), and the GISS nine-layer AGCM (in years 26-35 of a 35-year control integration with prescribed oceanic heat transport and mixed-layer depth). Model validation is performed in a North America/Atlantic/European study area. Prior to statistical significance testing, the principal seasonal characteristics of the observed Azores High (AH) and Iceland Low (IL) are analysed with the aid of time-averaged MSLP maps and objective locational and intensity indices. Dynamical explanations are proposed for the most important AH/HL seasonal cycle characteristics. These results are then used to test the performance of the three models in simulating center of action (COA) seasonal cycle characteristics. All three GCMs have large, systematic errors throughout the seasonal cycle in their simulation of AH/IL position and intensity, and all generate an unrealistic 'Greenland High'. The main focus of the investigation is on the statistical aspects of control run validation. Eighteen different statistics are used to test the significance of differences between observed and simulated means, variances and spatial patterns. Principal components analysis (PCA) and correlation analysis are applied in order to identify statistics which provide equivalent, overlapping or unique information. test statistic significance is determined using Preisendorfer and Barnett's permutation procedures, which provide a means of circumventing statistical problems commonly encountered in significance testing - notably multiplicity, spatial autocorrelation, unknown reference distributions and small time samples of model data. Statistics which measure the degree of spatial autocorrelation in latitudinal and longitudinal directions (and at different spatial lags) are also used to compare observed and simulated fields. Validation of the simulated seasonal cycles of MSLP (using observed data for the decade $1971-80$ ) indicates that all three models have statistically significant errors in the mean field, variances and spatial patterns. For the three models examined here, test 
statistic significance levels for observed/simulated differences in the mean field and spatial patterns are relatively insensitive to decadal time-scale variability in the observed MSLP data. Significance levels for the variance ratio results can depend critically on the choice of observed validation data.

Major Professor(s): Wigley, T.M.L.

Department: School of Environmental Sciences

Principal Investigator(s): Wigley, T.M.L.

Program Area: Carbon, Climate, and Vegetation

KEYWORDS: ATMOSPHERE, CLIMATE, EUROPE, MODELS, NORTH AMERICA, OCEANS, PRESSURE, SPATIAL DISTRIBUTION, TEMPORAL DISTRIBUTION

\section{1}

Santosa, Bdi. 1993. A Wind-Profile Relationship for the Unstable Surface-Jayer/Mixed-Layer System. M.S. Thesis, University of Wisconsin - Madison, 59 pages.

Simple expressions for wind-speed, $M$, profiles in a convective statically-unstable surface-layer/mixed-layer system are derived empirically. The wind-speed profiles are consistent across the top of the surface layer. Wind shear decreases rapidly with height, $z$, in the surface layer and becomes negligible at the top of the surface layer and in the mixed-layer interior. Thus, one may assume zero wind shear as a boundary condition and definition for the top of the surface layer. The depth of the surface layer, $z$, and the wind speed in the mixed layer interior, $\mathbf{M}_{\mathrm{ML}}$, can then be estimated. For the surface-layer/mixed-layer system, it is hypothesized that $\mathrm{z}_{1}$ and $\mathrm{M}_{\mathrm{ML}}$ may become relevant height and velocity scales in a similarity relationship, formulated as $M / M_{M L}$ $=\mathrm{f}\left(\mathrm{z} / \mathrm{z}_{\mathrm{z}}\right)$. Wind-speed data collected during the Minnesota atmospheric boundary-layer experiment are used to develop and evaluate alternative forms of the wind-speed profiles. All the data were measured during the late morning or mid afternoon, when the surface heat flux was positive and the depth of the mixed layer was nearly constant. Wind speeds near the surface increase rapidly with height, then become nearly constant in the mixed layer interior. Wind directions are nearly constant with height, with variations mostly less than 5 degrees for winds near the surface, and only some greater than 10 degrees for winds in the mixed layer. Based on close agreement with the data, there are two functional forms adopted in the surface layer $\left(\mathbf{z} \leq \mathbf{z}_{\mathbf{q}}\right)$ :

$M / M_{M L}=\left\{\left(z / z_{z}\right)^{A}\right\} \exp \left[A\left(1-z / z_{a}\right)\right]$ with $A=0.0975$

and

$\mathrm{M} / \mathrm{M}_{\mathrm{ML}}=\left(\mathrm{z} / \mathrm{z}_{1}\right)^{\left(\mathrm{A}\left(1-2 / \mathrm{z}_{2}\right)\right\}}$ with $\mathrm{A}=0.0840$.
Above the top of the surface layer $\left(z>z_{s}\right)$, the wind speed is simply equal to $M_{M L}$. These expressions give good agreement to the observations and approximate the data to within a few percent. The average depth of the surface layer, $z_{y}$, is found to approach the traditional definition of $\mathrm{z}_{\mathrm{a}}=0.1^{*} \mathrm{z}_{\mathrm{i}}$ (the depth of the mixed layer), but the relationship is weakly correlated. It is also found that the surface vertical momentum flux is highly correlated with $\mathrm{M}_{\mathrm{ML}}{ }^{2}$, as expected. The mixed-layer drag coefficient value is found to be $\mathrm{Cd}_{\mathrm{ML}}=0.0014$. While the Businger-Dyer formula that is extrapolated to the mixed-layer interior deviates when the height approaches the top of the surface layer, and usually is in error over all of the mixed layer, the functional forms proposed here can represent wind-profile data quite well within $99.9 \%$ of the whole surface-layer/mixed-layer domain. The functional forms above are not recommended for use below $z=1 \mathrm{~m}$, where they fail to represent the bottom portion of the $\log$ wind profile. This approach also does not work well when there is not a well-mixed layer of uniform wind speed, such as occurs with very weak convection and strong winds.

Major Professor(s): Stull, Roland B.

Department: Atmospheric and Oceanic Sciences Principal Investigator(s): Stull, Roland B.

Program Area: Atmospheric Radiation Measurement (ARM)

\section{KEYWORDS: MIXED LAYER, SURFACE LAYER, WINDS}

\section{2}

Sasek, Thomas William. 1983. Growth and Biomass Allocation Patterns of Lonicera japonica Thunb. and Lonicera sempervirens L. under Carbon Dioxide Enrichment. M.S. Thesis, Duke University, 80 pages.

Japanese honeysuckle (Lonicera japonica) and coral honeysuckle (Lonicera sempervirens) were compared in their responses to atmospheric carbon dioxide enrichment. The exotic Japanese species responded much more to $\mathrm{CO}_{2}$ than did the native coral honeysuckle. The relative increase in growth of the exotic was related to more efficient biomass utilization, earlier branching along the stem, and more carbon allocation to new leaf production. The compounding effects of branching, whether it occurs sooner or goes on longer into the growing season, are most important in producing differential growth of the two species and to increasing the competitive ability of the exotic over the native vine and of the vines over non-vine species. These intrinsic differences between the two Lonicera species would probably be even further magnified if other environmental stresses were present. This study suggests that Japanese honeysuckle will become more 
aggressive as an invading exotic as the atmospheric $\mathrm{CO}_{2}$ continues to increase.

\author{
Major Professor(s): Strain, Boyd R. \\ Department: Botany \\ Principal Investigator(s): Strain, Boyd R. \\ Program Area: Carbon, Climate, and Vegetation

\section{KEYWORDS: ATMOSPHERE, BIOMASS, CARBON DIOXIDE, FERTILIZATION, GROWTH AND DEVELOPMENT, INTRODUCED SPECIES, VEGETATION}

\section{3}

Sasek, Thomas William. 1985. The Implications of Atmospheric Carbon Dioxide Enrichment for the Physiological Ecology and Distribution of Two Introduced Woody Vines, Pueraria lobata Ohwi (Kudzu) and Lonicera japonica Thunb. (Japanese honeysuckle). PhD. Dissertation, Duke University, 203 pages.

The vine growth habit increases competitive potential for light capture. More biomass is allocated to height and leaf area because support structures are minimized. This study considered the effects of the continuing increase in atmospheric carbon dioxide concentration on the growth and morphology of vines. Vines were hypothesized to allocate $\mathrm{CO}_{2}$-induced increases in production to height and leaf area more efficiently than erect growth forms. Kudzu (Pueraria lobata Ohwi) and Japanese honeysuckle (Lonicera japonica Thunb.) are perennial woody vines, introduced into the United States from Japan. Both have become naturalized in the eastern US and are pernicious weeds in the Southeast capable of suppressing the native flora. Kudzu and honeysuckle were grown in controlled environment chambers in the Duke University phytotron at 350, 675 and $1000 \mu \mathrm{I} \mathrm{I}^{-1} \mathrm{CO}_{2}$, simulating double and triple current ambient $\mathrm{CO}_{2}$ concentration. Long-term growth at elevated $\mathrm{CO}_{2}$ concentrations resulted in less enhancement of photosynthesis than predicted by shortterm exposure. The reduction of photosynthetic capacity was not due to stomatal limitations. Rather, starch accumulation in the leaves at high $\mathrm{CO}_{2}$ probably reduces photosynthesis by biochemical feedback inhibition. Dry weight and leaf area were increased by $\mathrm{CO}_{2}$ enrichment especially in the young seedlings. Kudzu stems were $40 \%$ and $60 \%$ percent longer at double and triple $\mathrm{CO}_{2}$, respectively, than at current ambient $\mathrm{CO}_{2}$. Branching was enhanced by $50 \%$ with $\mathrm{CO}_{2}$ enrichment. Honeysuckle stem height was unaffected but branching was enhanced three-fold by $\mathrm{CO}_{2}$ enrichment. Height increase with $\mathrm{CO}_{2}$ enrichment was much greater than stem diameter increase, which is in contrast to erect growth forms. Vines maintain their favorable allocation patterns while still incorporating $\mathrm{CO}_{2}$-induced increases in productivity. Kudzu seedling establishment, currently rare, may be enhanced by $\mathrm{CO}_{2}$ enrichment due to improved growth at low irradiance and by increased water use efficiency. The geographic range of both species may be increased due to direct effects of $\mathrm{CO}_{2}$ enrichment and indirect climatic effects due to the Greenhouse Effect. Westward spread may occur due to enhanced water use efficiency. Northward spread may occur due to improved growth at low temperatures with $\mathrm{CO}_{2}$ enrichment and due to global warming that may increase minimum winter temperatures, reducing die-back of overwintering stems.

Major Professor(s): Strain, Boyd R.

Department: Botany

Principal Investigator(s): Strain, Boyd R.

Program Area: Carbon, Climate, and Vegetation

KEYWORDS: CARBON DIOXIDE, FERTILIZATION, GROWTH AND DEVELOPMENT, INTRODUCED SPECIES, PHOTOSYNTHESIS, RESPIRATION, SPATIAL DISTRIBUTION, VEGETATION

174

Schmitt, Christina C. 1990. The Effects of Surface Temperature and Clouds on the $\mathrm{CO}_{2}$ Forcing. M.S. Thesis, Colorado State University, 114 pages.

The effects of surface temperature and clouds on the $\mathrm{CO}_{2}$ forcing have been studied using the CSU General Circulation Model. The $\mathrm{CO}_{2}$ forcing is defined as the initial change in heating rate (with no feedbacks included) which is the direct response to the increase in the $\mathrm{CO}_{2}$ concentration in the atmosphere. Perpetual July simulations are made for a control run and a second run with the sea surface temperature increased by $4 \mathrm{~K}$. In the control run, the globally averaged reduction in upward longwave radiation due to a doubling of $\mathrm{CO}_{2}$ is $4.33 \mathrm{~W} \mathrm{~m}^{-2}$ at the level of maximum forcing, or the " $\mathrm{CO}_{2}$ tropopause." Above and below this level, the forcing decreases, resulting in a net warming of the troposphere by $0.0330 \mathrm{~K}$ day 1 , and a net cooling of $0.0134 \mathrm{~K} \mathrm{day}^{-1}$ in the stratosphere. The forcing at the $\mathrm{CO}_{2}$ tropopause in the warmer run is $4.59 \mathrm{~W} \mathrm{~m} 2$, and is associated with a warming of $0.0398 \mathrm{~K} \mathrm{day}^{-1}$ in the troposphere and cooling of $0.0146 \mathrm{~K} \mathrm{day}^{-1}$ in the stratosphere. The precipitable water is about 1.5 times larger in the warmer run (reaching $46 \mathrm{~mm}$ over the equator). The $\mathrm{H}_{2} \mathrm{O}$ amplifies the radiative effects of $\mathrm{CO}_{2}$, leading to the greater forcing in the warmer run. The clear sky $\mathrm{CO}_{2}$ forcing at the $\mathrm{CO}_{2}$ tropopause is $4.99 \mathrm{~W} \mathrm{~m}^{-2}$ in the control run, and $5.18 \mathrm{~W} \mathrm{~m}^{-2}$ in the $+4 \mathrm{~K}$ run. The clouds reduce the $\mathrm{CO}_{2}$ forcing by -0.070 
$\mathrm{K}$ day ${ }^{-1}$ in the control run, and by $-0.039 \mathrm{~K}^{-19 y^{-1}}$ in the $+4 \mathrm{~K}$ run. These maxima occur at low latitudes near the surface. The overall cloud effect on the $\mathrm{CO}_{2}$ forcing through the depth of the troposphere is about $50 \%$ greater in the warmer run than it is in the control run due to the reduced impact of the clouds on the $\mathrm{CO}_{2}$ forcing at the surface in the warmer run. Since the cloudiness values are similar in both runs (slightly more cloudy in the control run), these differences in the $\mathrm{CO}_{2}$ forcing are mostly attributed to the contribution of $\mathrm{H}_{2} \mathrm{O}$ to the effects of $\mathrm{CO}_{2}$ on the $\mathrm{LW}$ radiation balance.

Major Professor(s): Randall, David A.

Department: Atmospheric Science

Principal Investigator(s): Randall, David A.

Program Area: Carbon, Climate, and Vegetation

\section{KEYWORDS: CARBON DIOXIDE, CLIMATE, MODELS, RADLATIVE PROCESSES}

\section{5}

Schneicier, Timothy L 1994 . Backscattering by Nonspherical Ice Particles at Millimeter Wavelengths: A Theoretical Study. M.S. Thesis, Colorado State University, 98 pages.

The role of ice clouds in the hydrological cycle is uncertain. As a direct consequence, we do not fully understand the role of ice clouds in the atmospheric energy balance. It is therefore necessary to quantify the existence of ice clouds to understand their role in the upper tropospheric hydrologic cycle. This is primarily achieved with the aid of remote sensors. To extract information from remotely sensed data, it is necessary to understand how electromagnetic radiation interacts with cirrus ice particles. The work presented herein attempted to understand how ice particles of an arbitrary shape backscatter electromagnetic radiation at cloud radar wavelengths. The discrete dipole approximation (DDA) was applied to the backscattering of millimeter wave radiation by nonspherical ice particles. A simple analytical model of the DDA was developed to demonstrate the underlying physical principles and to understand the directional sensitivity of scattering. Backscattering by single particles was studied to test the use and validity of spheroidal models to model nonspheroidal hydrometeors which are characteristic of cirrus. Limitations of the Rayleigh approximation at millimeter wavelengths were also explored. It was found that for wavelengths on the order of or greater than $3 \mathrm{~mm}$, spheroidal shapes adequately represent hexagonal columns and plates. The Rayleigh approximation for spheroids begins to break down for wavelengths below $3 \mathrm{~mm}$ if the particles have major dimensions which are typical of cirrus ice crystals. The sensitivity of backscattered radiation to variations in microphysical properties were examined, based on DDA calculations for ensembles of ice particles. The most important factor was found to be the median diameter of the third moment $\left(D_{m}\right)$ of the ice crystal size distribution. In particular, if $D_{m}$ was relatively large, the contribution of small crystals (i.e. crystals whose major dimension was on the order of, or less than $100 \mu \mathrm{m}$ ) was masked by the signal of the larger crystals which possessed major dimensions of greater than approximately $400 \mu \mathrm{m}$. Simulations of effective radar reflectivity factor-ice water content relations $\left(Z_{c}-I W C\right)$ were also presented. Comparison with available empirical relations indicate a functional dependence of the IWC on the number of large crystals (i.e. $D_{m}$ ) and also suggest a set of reasonable limits for the parameter $D_{m}$. Implications for the remote sensing of ice clouds at millimeter wavelengths were discussed.

Major Professor(s): Stephens, Graeme L.

Department: Atmospheric Science Principal Investigator(s): Stephens, Graeme L. Program Area: Atmospheric Radiation Measurement (ARM)

KEYWORDS: CLOUDS, DISCRETE DIPOLE
APPROXIMATION (DPA), ICE, PARTICULATES,
REMOTE SENSING, SCATTERING

176

Schrieber, Kelly M. 1994. Observations of Surface-Layer Characteristics and Their Relationship to BoundaryLayer Cumulus. M.S. Thesis, University of Wisconsin Madison, 67 pages.

The subject of subgrid scale heterogeneity is one which has continued to pose problems for the numerical modeling community. Observations of meteorological and land use conditions which may account for these subgrid variations in the case of fair weather boundary layer cumulus (BL $\mathrm{Cu}$ ) are presented. Clear sky cases are examined from aircraft data from the HAPEX field experiment of 1987, in order to eliminate any further heterogeneities which may be caused by cloud shading, enabling a more accurate assessment of the relationship between atmospheric conditions and the underlying surface. To account for the physical processes involved in the formation of non-precipitation $\mathrm{BL} \mathrm{Cu}$, buoyancy and moisture variables are chosen. The virtual potential temperature and lifting condensation level (LCL) are calculated for each data point along the surface-layer flight path of the aircraft. The path is divided into segments according to general surface type categories, and the resulting segments are examined. The original heterogeneous surface characteristics can later be 
obtained by a weighted average of the homogeneous segment characteristics. Joint distributions of virtual potential temperature and LCL are presented and evaluated. These distributions are found to be primarily mono-modal over relatively homogeneous groundsurface subdomains, and exhibit a sharp peak which tails off quickly to a finite end. The mean value for each distribution is found to be representative of the desired characteristics. It has been determined that distributions of LCL and virtual potential temperature over homogeneous land surfaces are mono-modal and remain fairly consistent over time. This quality is therefore one which can be parameterized and provide reliable information about $\mathrm{BL}$ Cu onset time and coverage. The information required is readily available from both routine measurements and normal model output. Sub-grid variability of surface type can be obtained from satellite inventories and cataloged for future model use. Finally, a conceptual model for a simple cumulus parameterization is presented. Based on the calculated LCL and virtual potential temperature values for a given homogeneous patch, the cumulus cover can be diagnosed by comparison with an averaged area sounding. One would expect to find either the LCL to be higher than the measured inversion height (dry conditions), or the virtual potential temperature to be cooler than the environmental sounding values (nonbuoyant), for all of the clear-sky cases presented. It appears initially that this conceptual model was successful for the cases examined here.

Major Professor(s): Stull, Roland B. Department: Atmospheric and Oceanic Sciences Principal Investigator(s): Stull, Roland B.

Program Area: Atmospheric Radiation Measurement (ARM)

KEYWORDS: BOUNDARY LAYER, CLOUDS, LAND SURFACE

\section{7}

Seielstad, Carl A 1994. Holocene Environmental History at Chatterton Springs on the Southern Coastal Plain of Georgia. MA. Thesis, University of Georgia, 153 pages.

The Chatterton palaececological record provides the first evidence linking climate, fire, man, and the development of Coastal Plain ecosystems. Analysis of pollen, charcoal, and inorganic sediments from a peat deposit in Coffee County, Georgia reveals that the early Holocene (10,000-4,000 BP) experienced wetter conditions than present, while the late Holocene was slightly drier than present. Wetter periods were characterized by oak dominance and drier periods by pine dominance. Pine forest, eolian sand movement, fire, and human activity have been closely linked for the last 9,500 years. Palaeoecological evidence from the site supports the argument that the Middle Archaic period may have witnessed a general depopulation of the Chatterton area by indigenous peoples. Zea mays (corn) pollen was identified at $2,000 \mathrm{BP}, 1,300 \mathrm{BP}$, and 1,000 $\mathrm{BP}$, providing the first direct evidence of the presence of maize in the Woodland period on the inner Coastal Plain of Georgia.

Major Professor(s): Brook, George A. Department: Geography

Principal Investigator(s): Brook, George A. Program Area: National Institute for Global Environmental Change (NIGEC)

KEYWORDS: CHARCOAL, CLIMATE, HOLOCENE, NORTH AMERICA, PEAT, POLLEN, SEDIMENTS, VEGETATION

178

Shoo, Xuemei 1986. Long-Term Climatic Changes in Western Europe and East Asia. M.S. Thesis, University of Massachusetts, 133 pages.

Regional differences of climatic change are of importance in the study of climate history and in climate forecasting. In this research, long-term precipitation records and temperature records of western Europe and East Asia have been tested for homogeneity and analyzed for evidence of trend, periodicity, and disturbance on seasonal and annual basis using time series techniques. Polynomial regression analysis on this data set indicated that precipitation and temperature had been increased in the past 100 years in both areas. Power spectrum analysis showed some statistically significant high frequency fluctuations. One with 2 to 2.5 year period was most widespread in regions and in seasonal series. A comparison of the dates of the great volcanic eruptions and the climatic data suggested great volcanic eruptions could cause precipitation increase or decrease and temperature decrease. In conclusion, it can be stated that the general terms of climatic changes were of the same nature on a continental scale in recent historical time.

Major Professor(s): Bradley, Raymond S. Department: Geology and Geography Principal Investigator(s): Bradley, Raymond S. Program Area: Carbon, Climate, and Vegetation

KEYWORDS: ASLA, CLIMATE, DISTURBANCE, EUROPE, PRECIPITATION, REGIONAL ANALYSIS, TEMPERATURE, TEMPORAL DISTRIBUTION 
179

Shen, Karin Pauline. 1992. A Microclimate Model to Investigate Greenhouse Warming of a Sub-Alpine Ecosystem. M.S. Thesis, University of California at Berkeley, 64 pages.

Increasing concentrations of greenhouse gases in the earth's atmosphere are expected to result in a global warming of several degrees Celsius in the coming decades. This warming will have far-reaching impacts on the biosphere, and while General Circulation Models (GCMs) try to predict the magnitude and scope of the warming, there is little information regarding the potential impacts of greenhouse warming on natural systems. An experiment currently under way in a meadow in the Colorado Rocky Mountains attempts to investigate the many consequences of greenhouse warming for soil ecosystems. A mathematical model of the soil microclimate was developed to simulate the soil temperature and moisture content of the meadow. The model simulates both treatment and control scenarios so as to investigate the potential effects of warming. Results of model simulation studies indicate warmer, drier soils under treatment conditions showing the greatest temperature effects of warming occurring at night. These results could have several implications regarding the dynamics of the ecosystem, and future model studies will investigate these connections.

Major Professor(s): Harte, John

Department: Energy and Resources Group Principal Investigator(s): Wohlpart, A.

Program Area: Graduate Fellowships for Global Change

KEYWORDS: CLIMATE, MODELS, SOILS, SUBALPINE ENVIRONMENT, TEMPERATURE, WATER

\section{0}

Stole, David Lewis. 1992. Measurement of Deforestation in the Brazilian Amazon Using Satellite Remote Sensing. Ph.D. Dissertation, University of New Hampshire, 331 pages.

A clear understanding of the role of the biota in the global carbon cycle is limited by an absence of accurate measurements of deforestation rates in the tropics.

Thus study measures the rate and extent of deforestation in the Brazilian Amazon, a tropical forest biome approximately $5 \times 10^{6} \mathrm{~km}^{2}$ in size and the largest extant tropical forest biome in the world. The study focuses on remote sensing measurements of deforestation rates and the area of secondary vegetation, but also utilizes tabular data to document deforestation when satellite data are not available. The analysis concludes: (1) Regression analysis of SPOT, TM, and AVHRR measurements suggests that the AVHRR will greatly overestimate deforestation and be highly variable; the use of a brightness temperature threshold is highly sensitive and unreliable. The upward bias of AVHRR is a function of the density of deforestation. (2) An accurate measurement of deforestation requires Landsat TM data, and can be accomplished using low cost visual interpretation of photographic products at $1: 250,000$ scale, with accuracies within $10 \%$ if that obtained using digital image processing techniques employing supervised statistical classifiers. (3) Secondary growth in the Brazilian Amazon represents a large fraction of the total deforested area, and the abandonment of agricultural land is an important land cover transition. Abandonment rates were $70-83 \%$ of clearing rates from primary forests. At any one point in time, approximately $30 \%$ of the deforested area is in some stage of abandonment, and quite likely nearly all deforested land becomes abandoned after approximately 5 years.

(4) Previous estimates of the total area deforested in the Amazon, as well as the rate of deforestation, have been too high by as much as 4-fold. A complete assessment of the entire Legal Amazon using over 200 Landsat images measures $251 \times 10^{3} \mathrm{~km}^{2}$ deforestation as of 1988 , or approximately $6 \%$ of the closed forests of the region. The average annual rate of deforestation between 1978 and 1988 was $18 \times 10^{3} \mathrm{~km}^{2} \mathrm{yr}^{-1}$. These findings are important to carbon cycle research. They suggest the estimates of carbon emissions from the Amazon for the late 1980s have been too high, since the area of regrowth is large and rates of deforestation are lower than previously believed.

Major Professor(s): Aber, John

Department: Natural Resources

Principal Investigator(s): Moore, Berrien

Program Area: Carbon, Climate, and Vegetation

KEYWORDS: CARBON CYCLE, EMISSIONS, FORESTS, LAND USE, REMOTE SENSING, SOUTH AMERICA, TROPICS

181

Smith, William Scott. 1994. A Study of the

Cloud/Radiation Interaction Using a Second Order

Turbulence Closure Radiative/Convective Model. Ph.D. Dissertation, New Mexico State University at Las Cruces, 283 pages.

A high resolution one-dimensional version of a secondorder turbulence radiative/convective model, developed at Los Alamos National Laboratory, is used to simulate 
the diumal cycle of marine stratocumulus clouds with respect to their interaction with radiation and turbulent mixing. Particular attention is given to the role of shortwave heating in modulating the diurnal variation of the stratocumulus-capped boundary layer. The fidelity of the model to the underlying physics is assessed by comparing the model simulation against data taken at San Nicolas Island during the intensive field observation (IFO) of the First International Satellite Cloud Climatology Program (ISCCP) Regional Experiment (FIRE), conducted during June and July, 1987. The model is able to reproduce the observed diurnal cycle of the liquid water content, cloud base height, radiative heating or cooling rates, and the mean and turbulence variables fairly well. The mechanisms which cause the diurnal variation and the decoupling of the boundary layer are examined.

Major Professor(s): Chen, T.-W., and C.-Y. J. Kao Department: Physics

Principal Investigator(s): Kao, C.-Y. Jim Program Area: Atmospheric Radiation Measurement (ARM)

KEYWORDS: BOUNDARY LAYER, CLIMATE, CLOUDS, CONVECTION, ISLANDS, MARINE ENVIRONMENT, MODELS, NORTH AMERICA, RADLATIVE PROCESSES, REMOTE SENSING, TEMPORAL DISTRIBUTION, TURBULENCE

\section{2}

Sperber, Kenneth Robert 1985. Characteristics of Removal and Deposition of Soluble Species by Precipitation. M.S. Thesis, State University of New York at Stony Brook, 143 pages.

The scavenging coefficient in air, $\lambda$, for nitrate, sulfate and ammonium have been estimated under a variety of meteorological and seasonal conditions from comparing the respective deposition of the species in successive hours of precipitation samples taken over a six year period at Brookhaven National Laboratory, Long Island, New York. The square root transformation of the scavenging coefficients, $\lambda^{\text {/ }}$, yields an approximately normal distribution for each species. The mean value of the nitrate scavenging coefficient is $1.18 \times 10^{-4} \mathrm{sec}^{-1}$, for sulfate $0.92 \times 10^{-4} \mathrm{sec}^{-1}$, and for ammonium $1.41 \times 10^{-4}$ $\mathrm{sec}^{-1}$, in general agreement with previous experimental and theoretical estimates. An interesting property of the distribution of the scavenging coefficients is that the ratio of the mean value of $\lambda^{3 / 2}$ to its standard deviation varies little from 2.4 for nitrate, ammonium and sulfate for meteorological subsets of the data. This property may limit the choice of stochastic models which may describe the scavenging process. A trend analysis of the relationship between the scavenging coefficient and rainfall rate indicates that the nitrate scavenging rate increases with rainfall rate for rainfall rates $>3.4 \mathrm{~mm} / \mathrm{hr}$, qualitatively similar to model predictions in this region but based upon a small number of data points. The sulfate and ammonium scavenging coefficients are not simple functions of rainfall rate, their behavior is similar due to their prior association as $\left(\mathrm{NH}_{4}\right)_{2} \mathrm{SO}_{4}$. The length and variability of a mean precipitation period and dry period are approximately a factor of two greater at BNL as compared with Whiteface Mountain (WFM) from comparison of six years of precipitation data obtained at BNL and five years of data from WFM. The scavenging coefficient estimates combined with the precipitation and dry period data indicate residence time estimates for soluble pollutants are most sensitive to the mean length dry periods for estimates of $\lambda \approx 10^{-4} \mathrm{sec}^{-1}$. The deposition and concentration of nitrate, sulfate and ammonium with wind direction is investigated indicating greater concentration and deposition when hourly averaged winds are from the west.

Major Professor(s): Hameed, Sultan Department: Mechanical Engineering (Atmospheric Sciences)

Principal Investigator(s): Hameed, Sultan

Program Area: Carbon, Climate, and Vegetation

KEYWORDS: NITROGEN SPECIES, SCAVENGING, SULFUR SPECIES, TEMPORAL DISTRIBUTION

\section{3}

Sperber, Kenneth Robert. 1989. Southern Oscillation Simulation in Coupled Ocean/Atmosphere Global Climate Models. Ph.D. Dissertation, State University of New York at Stony Brook, 156 pages.

The Southern Oscillation is a major component in the interannual variations of global climate. The Oregon State University Global Climate Model with a dynamically interactive upper ocean reproduces in qualitatively correct fashion the major characteristics of the Southern Oscillation. This model simulates the observed anti-correlation of annually averaged sea-level pressure between the eastern Pacific and the Indonesian region, the primary atmospheric signal of the Southern Oscillation. During the first half of the calendar year positive sea-surface temperature (SST) anomalies propagate eastward towards South America from the tropical western Pacific. The SST anomalies develop in conjunction with the eastward mixed layer current anomalies in the tropical Pacific. In the late summer/early fall anomalously warm water near South America develops and moves westward to merge with 
the central Pacific anomalies. This lagged development in the eastern Pacific is qualitatively analogous to the 1982/83 El Nifo. The temperature of the thermocline layer also increases, with the slope of the equatorial Pacific thermocline decreasing in response to the relaxation of the trade winds. Enhanced precipitation occurs in the mid-Pacific while in Indian and Australian monsoon regions a deficit occurs. For this phase of the oscillation the model predicts anomalous currents in the Arabian Sea which oppose the usual flow. The decay of the warm phase occurs in mid/late northern winter, somewhat earlier than observed during El Nifos. The cold phase of the Southern Oscillation, enhancement of the zonal circulation, evolves in a fashion similar to the warm phase with the sign of the anomalies reversed, similar to the observations. Comparison with a slab version (no ocean dynamics) of the GCM indicates that the Southern Oscillation has its genesis in the atmosphere during northern spring and dynamic ocean interactions act to propagate this atmospheric impetus to other seasons. Southern Oscillation generation in the GCMs indicates that high frequency ocean waves are not necessary for this phenomenon to occur as suggested by Pacific Basin Models. These results also show that ocean/atmosphere global climate models are useful tools for investigation of time dependent changes on the interannual timescale in addition to their hitherto accepted use for studying equilibrium properties of climate.

Major Professor(s): Hameed, Sultan

Department: Mechanical Engineering (Atmospheric

Sciences)

Principal Investigator(s): Hameed, Sultan

Program Area: Carbon, Climate, and Vegetation

KEYWORDS: CLIMATE, EL NINOO - SOUTHERN OSCILLATION (ENSO)

\section{4}

Steig, Eric Julien 1992. A Gas Extraction System for the Measurement of Carbon Dioxide and Carbon Isotopes in Polar Ice Cores. M.S. Thesis, University of Washington, 52 pages.

Knowledge of the distribution of $\delta^{13} \mathrm{C}$ in the glacial ocean, atmosphere, and biosphere is important to understanding the causes of glacial/interglacial changes in atmospheric $\mathrm{CO}_{2}$ levels. Although, deep-ocean $\delta^{13} \mathrm{C}$ values are well-constrained by ocean sediment studies, model-based estimates of changes in the carbon budget for the biosphere vary considerably. Measurement of atmospheric $\delta^{13} \mathrm{C}$ in $\mathrm{CO}_{2}$ in ice cores will provide additional constraints on this budget and will also improve estimates of changes in the ocean surface layer $\delta^{13} \mathrm{C}$. Direct measurement of ancient atmospheric $\delta^{13} \mathrm{C}$ can be accomplished through polar ice cores studies. I have designed and constructed a gas-extraction line for ice cores with particular attention to the specific difficulties of measuring $\delta^{13} \mathrm{C}$ in $\mathrm{CO}_{2}$. The ice is shaved, rather than crushed, to minimize fractionation effects resulting from gas travel through long air-paths in the ice. To minimize the risk of isotopic contamination and fractionation within the vacuum line, $\mathrm{CO}_{2}$ is separated immediately from the air; the $\mathrm{CO}_{2}$ concentration is then measured by a simple pressure/volume comparison rather than by gas chromatography or spectroscopy. Measurements from Greenland ice core samples give an average value of $280 \pm 2 \mathrm{ppm} \mathrm{CO}$ for pre-industrial samples, demonstrating that the extraction system gives accurate, precise determinations of $\mathrm{CO}_{2}$ concentrations. Measurement of $\delta^{13} \mathrm{C}$ from polar ice samples has not been achieved at this time. However, results on standard air samples demonstrate a precision for $\delta^{13} \mathrm{C}$ of less than $0.2 \%$ at the $95 \%$ confidence level.

Major Professor(s): Stuiver, Minze

Department: Geological Sciences

Principal Investigator(s): Wohlpart, A.

Program Area: Graduate Fellowships for Global Change

KEYWORDS: CARBON DIOXIDE, CARBON ISOTOPES, CLIMATE, GREENLAND, ICE

185

Su, Kuo-Hsu. 1993. Low-Frequency Oscillations over the Continental Margin. Ph.D. Dissertation, North Carolina State University, 135 pages.

The objective of this dissertation is to study the characteristics, sources, effects and dates of lowfrequency oscillations over the continental margin east of North America. Current data from the Shelf Edge Exchange Processes Experiment (SEEP-II) in Spring 1988 are examined. The results from spectral analysis indicate that the characteristics of motions depend on the frequency of oscillation. In the low frequency band (periods from 12 to 24 days), the first empirical orthogonal function (EOF) mode of the alongshore current shows distinct offshore phase propagation from the outer shelf to the upper slope. The maximum amplitude occurs near the shelf break. At periods between 4.8 and 8 days, the amplitude of the oscillation is higher on the slope than on the shelf. In the highfrequency band of periods shorter than 4.8 days, the amplitude of the first EOF mode decreases rapidly offshore as in the case of shelf waves. Near the shelf break, data from Acoustic Doppler Current Profilers (ADCP) shows that the alongshore current is uniform 
in the vertical direction with an upward phase propagation between 6 and 24 days. A linear, forcedwave model, sinusoidal in the alongshore direction, is used to explain the observed phase propagation. It is found that offshore and upward phase propagation similar to that observed in SEEP-II data appears when currents are in resonance with vorticity forcing on the continental slope. For resonance to occur, it is essential that the thermohaline field by characterized by an upper ocean stratification on the slope. The phase difference near resonance is weakly dependent on the bottom frictional parameter and the alongshore length scale of forcing. It is suggested that the low-frequency ascillations on the outer shelf during the SEEP-II spring experiment are associated with vorticity sources on the upper slope. A three-dimensional semi-spectral primitive-equation model (SPEM) is used to further investigate the temporal and spatial variation of low frequency oscillations over the continental margins. Forcing is provided by an isolated, surface-intensified vorticity source with different frequencies and locations. At a period of 12 days, it is found that oscillations generated by forcing on the continental slope radiate away in the form of bottom-trapped topographic waves. Energy is mostly associated with the alongshore current and propagates in the direction of the phase velocity of topographic waves. Farther downstream, ascillations on the slope can penetrate onto the shelf and become barotropic. Trajectories of Lagrangian floats show that significant cross-isobath mixing occurs mainly near the forcing region. Outside of the forcing region, particles mostly follow in the along-isobath direction. For a shorter forcing period of 3 days, more energy leaks onto the continental shelf and propagates as shelf waves. These results are consistent with the low-frequency ascillations during the Shelf Edge Exchange Processes (SEEP-II) spring experiment. Furthermore, energy is transferred by long internal gravity waves in the vertical direction near the forcing region. As a result, increasing stratification induces ascillations, which have higher horizontal kinetic energy and shorter vertical wavelengths in the surface layers. Consequently, less energy is contributed to topographic waves when stratification is strong. The results suggest a mechanism by which surface-intensified forcing generates topographic waves during the winter and spring seasons over the continental margin.

Major Professor(s): Shaw, P.T., and Leonard J. Pietrafesa Department: Marine, Earth and Atmospheric Sciences Principal Investigator(s): Pietrafesa, Leonard J. Program Area: Marine Transport

KEYWORDS: CIRCULATION, COASTAL ENVIRONMENT, MODELS, NORTH AMERICA,
OCEANS, SPATLAL DISTRIBUTION, TEMPORAL DISTRIBUTION, WAVES

186

Subasilar, Bedrettin. 1991. The Broad Band Overlap

Problem in Atmospheric Trace Gases. PhD.

Dissertation, State University of New York at Stony

Brook, 118 pages.

In relation to a better understanding of climate change and the related greenhouse problem, one way of projecting for the next decades is through general circulation models (GCMs). The only input as a driving force in the changing atmospheric and oceanic circulation patterns is the amount of heat perturbation either due to natural or man-caused activities. Among these, $\mathrm{CO}_{2}$ concentrations resulting from the latter has been observed to be accelerating at alarmingly high rates especially after the advent of the industrialization which just began in the last century. In addition to that, collective effects of other greenhouse gases (freons, $\mathrm{SO}_{2}, \mathrm{H}_{2} \mathrm{O}, \mathrm{CH}_{4}$, etc.) are as important as $\mathrm{CO}_{2}$. Hence, it is evident from the above considerations that, in the predictions of climate models, the heat input which triggers changes in the atmospheric patterns, should be formulated accurately. In order to realize this objective, in this research,beginning with the available line parameter data, the problems of absorption have been investigated and attacked in the frame known as the broad band modeling since that is the only best and fastest manageable representation for GCMs. The first step was the construction of a full broad band (intra band overlap) model that was also flexible enough to accommodate the individual peculiarities of the bands. Before, the well known and very useful Ramanathan model had a limited applicability in the concentration scale, and it was also not systematically, or successfully incorporated into an inter band overlap picture. Then, the established ideas that served as bases up to present, have been employed but found to have a limited practical applicability when it came to predict the inter band overlaps. This followed by the clarification of the probabilistic approach, each of which are already shown to be expressible in terms of full broad bands, gave rise to the recognition of the transmittance multiplication principle being applicable to the wider than narrowband segments or the whole bands. At the end, an example of a flux application is added.

Major Professor(s): Cess, Robert D. Department: Mechanical Engineering (Atmospheric Sciences)

Principal Investigator(s): Cess, Robert $\mathbf{D}$.

Program Area: Carbon, Climate, and Vegetation 
KEYWORDS: ATMOSPHERE, GASES

187

Suzuli, Marcelino. 1994. The ARM Assay for the Measurement of Protistan Bacterivory Rates and Ammonium Regeneration Efficiencies. M.S. Thesis, Oregon State University, 106 pages.

Protists have a key role in pelagic systems, both as the main bacterivores and major nutrient regenerators. Thus, knowledge of protistan bacterivory rates and nutrient regeneration efficiencies is essential for studies concerning the structure and function of pelagic food webs. Current methods for the estimation of protistan bacterivory have methodological artifacts, especially when applied to open ocean communities. Also, measurements of regeneration rates for pelagic protists have been mainly limited to organisms in culture. Therefore, new methods should be developed for the measurement of protistan bacterivory and nutrient regeneration rates. I developed a method for simultaneous estimation of protistan bacterivory and regeneration efficiencies, based on a new approach for the study of microbial communities: the product release assays (PRAs). PRAs estimate grazing rates from the rate of excretion of labeled products resulting from the digestion of added pre-labeled prey. The product regeneration efficiency, which is assumed to be constant, can also be estimated as an index of trophic complexity in food webs origination with the prey of interest. I chose ammonium as the excretory product, since nitrogen is a major structural component of bacterial cells and ${ }^{15} \mathrm{~N}$, a stable isotope of nitrogen can be used as a tracer. The problems associated with the use of ${ }^{15} \mathrm{NH}_{4}{ }^{+}$include the difficulty of extracting ammonium from seawater, as well as the requirement of reasonably large sample sizes for the isotopic analysis. These problems limited the use of method for open ocean samples. In those cases where bacterial and protists abundances were high, I was able to calculate grazing rates and regeneration efficiencies that agreed with previously published values. In two of the experiments, protists and bacterial abundances varied during the incubation period, violating the assumption required for the calculation of rates as a simple negative exponential model, i.e., grazing rates are constant. Deterministic computer models designed to calculate rates which used bacteria and protist numbers as variables estimated grazing rates and nitrogen regeneration efficiencies in the range of previous reported values. The use of different tracers, as well as different prey types is recommended as the direction for future studies using the product release assay approach.

Major Professor(s): Sherr, Barry F.
Department: College of Oceanic and Atmospheric Sciences

Principal Investigator(s): Sherr, Barry F.

Program Area: Marine Transport

\section{KEYWORDS: BACTERIA, MODELS, NITROGEN CYCLE, PRODUCT RELEASE ASSAYS (PRA), PROTISTS}

\section{8}

Tissue, David T. 1984. Physiological and Growth Response of Eriophorum vaginatum to Elevated $\mathrm{CO}_{2}$ and Temperature in the Alaskan Tundra. M.S. Thesis, San Diego State University, 104 pages.

The long-term responses of an arctic sedge, Eriophorum vaginatum to elevated $\mathrm{CO}_{2}$ concentrations in the field differ from expected responses based on short-term lab experiments. Within three weeks, plants maintained at elevated $\mathrm{CO}_{2}$ exhibited a physiological adjustment of their photosynthetic rate so that ambient and elevated $\mathrm{CO}_{2}$ plants had similar rates at their maintenance $\mathrm{CO}_{2}$ concentrations. Plants maintained at elevated $\mathrm{CO}_{2}$ exhibited a reduced photosynthetic capacity per leaf area until late season. The reduction in photosynthetic capacity was not due to stomatal closure, but other possible mechanisms were not tested. There was no difference between $\mathrm{CO}_{2}$ treatments in transpiration, water-use efficiency or relative leaf growth rate. Plants in the $680 \mathrm{ppm} \mathrm{CO}_{2}$ treatment produced more tillers than ambient $\mathrm{CO}_{2}$ plants. Plants maintained at elevated temperature and elevated $\mathrm{CO}_{2}$ had the same photosynthetic capacity as plants maintained at ambient temperature and elevated $\mathrm{CO}_{2}$. There was no difference in transpiration, water-use efficiency, relative leaf growth rate or tiller production. On the basis of these measurements we predict that under future elevated $\mathrm{CO}_{2}$ and temperature conditions, plants may physiologically adjust so that carbon uptake and growth will not be significantly increased.

Major Professor(s): Oechel, Walter C.

Department: Systems Ecology

Principal Investigator(s): Oechel, Walter C.

Program Area: Carbon, Climate, and Vegetation

KEYWORDS: ARCTIC, CARBON DIOXIDE, FERTILIZATION, GROWTH AND DEVELOPMENT, PHOTOSYNTHESIS, TEMPERATURE, TRANSPIRATION, VEGETATION, WATER USE

189

Toggweiler, John Robert. 1983. A Multi-Tracer Study of the Abyssal Water Column of the Deep Bering Sea, 
Including Sediment Interactions; A Six Zone Regionalized Model for Bomb Radiotracers and $\mathrm{CO}_{2}$ in the Upper Kilometer of the Pacific Ocean. PhD. Dissertation, Columbia University, 421 pages.

This thesis is made up of two parts which are linked together by a common concern with the Pacific Ocean. Each part consists of five chapters which can be briefly summarized as follows. The abyssal waters of the Bering Sea lie in a high latitude marginal basin and are partially isolated behind the islands of the Aleutian Arc. Surface waters are characterized by very low salinities and high biological productivity. Sediments covering the abyssal plain are accumulating at a rate of about $\mathbf{3 0}$ $\mathrm{cm} / 1000$ yrs and have opal contents in excess of $30 \%$. In temperature and salinity properties deep Bering Sea water appears very similar to water in the adjacent Pacific. In chemical properties, however, Bering Sea water is distinctly labeled by very high dissolved silica concentrations and reduced oxygen content. The basin's simple geometry permits a straightforward parameterization of lateral exchange with the Pacific coupled with a standard one dimensional model, Munk (1966). Pacific water of sill-depth composition flows into the bottom layer. The distribution of bottom area is apportioned into various levels of the model to simulate sediment interactions. The model is designed to test for degree of lateral vs. vertical control of water column flux balances and to determine the bottom source strength of various geochemical tracers. Relative bottom and water column sources for the geochemical tracers are strongly correlated with lateral exchange. A solution is found which constrains the lateral exchange rate to be about $150-200$ years. The model predicts that $75 \%$ of the excess silica in the deep Bering Sea water column dissolves from the sediments, while $25 \%$ dissolves in situ. Including the sediment accumulation, only $15 \%$ of the particulate silica flux falling from below $1500 \mathrm{~m}$ dissolves in the water column. Half the flux reaching the sediments is buried. The model predicts an upwelling rate of $2.8 \mathrm{~m} / \mathrm{yr}$ in the deep basin with an inflow of $0.08 \mathrm{~Sv}$ at the sill, and a vertical mixing coefficient of $0.7 \mathrm{~cm}^{2} / \mathrm{sec}$. It is argued, however, that geothermal heating and radiocarbon constraints on the absolute time scale apply only in the lower part of the water column where the flushing by Pacific water is the critical factor. The importance of vertical mixing can only be assessed if the upwelling flux is truly nondivergent up to intermediate depth. The second half of this thesis presents initial results of a project to reconstruct the time histories of nuclear bombproduced ${ }^{90} \mathrm{Sr}$ and ${ }^{14} \mathrm{C}$ in ocean surface water through measurements of ${ }^{90} \mathrm{Sr}$ and ${ }^{14} \mathrm{C}$ in the annual growth bands of head-forming corals. One of the most important things to be learned from the coral time history reconstructions involves the early periods of the nuclear era when U.S. testing in the Marshall Islands introduced almost half of the present-day ${ }^{90} \mathrm{Sr}$ inventory into the Pacific Ocean. An upper ocean Pacific model with six latitudinal zones is developed to follow the vertical penetration of bomb tracers in the ocean and to examine exchanges between the equatorial region and shallow layers of the temperate thermocline. Parallel model runs for ${ }^{90} \mathrm{Sr}$ and tritium using a ${ }^{90} \mathrm{Sr}$ input function developed here and the Weiss and Roether (1980) tritium input function show that the tritium input is overestimated in both hemispheres and compromised in the northern hemisphere by a lack of 1950 's input. In modeling the input of ${ }^{90} \mathrm{Sr}$ to the surface mixed layer we find that a vertical mixing rate of $1.5 \mathrm{~cm}^{2} / \mathrm{sec}$ at the base of the mixed layer reproduces the observed time history. Given the vertical mixing calibration, the model predicts an average $\mathrm{CO}_{2}$ gas exchange rate of $18.2 \mathrm{moles} / \mathrm{m}^{3} / \mathrm{yr}$ by fitting radiocarbon time histories. In modeling the steady distribution of $\mathrm{CO}_{2}$ with a regional model of this type we show that it is possible to predict the net biological removal of carbon from the mixed layer by fitting ${ }^{13} \mathrm{C} /{ }^{12} \mathrm{C}$ ratios in surface water. The six-zone model represents the first attempt to couple the biological uptake of carbon with an upper ocean model in order to simulate the meridional variation in $\mathrm{pCO}_{2}$.

Major Professor(s): Broecker, Wallace S.

Department: Geochemistry

Principal Investigator(s): Broecker, Wallace S.

Program Area: Carbon, Climate, and Vegetation

KEYWORDS: CARBON DIOXIDE, CARBON ISOTOPES, CHEMISTRY, CIRCULATION, METALS, MIXED LAYER, MODELS, OCEANS, OXYGEN, SALINITY, SEDIMENTS, SILICA, TEMPERATURE, TRACERS

\section{0}

Tolley, Leslie Carroll 1982. The Effects of Atmospheric Carbon Dioxide Enrichment, Irradiance and Water Stress on Seedling Growth and Physiology of Liquidambar styraciftua and Pinus taeda. Ph.D. Dissertation, Duke University, 258 pages.

In order to predict possible effects of increasing atmospheric carbon dioxide on woody plant succession and community species composition, more detailed information is needed on the individual response of successional species to this changing environmental factor. The objective of this study was to investigate the growth and physiological response of two important successional woody species, Liquidambar styraciffua $\mathrm{L}$. (sweetgum) and Pinus taeda L. (loblolly pine) to long term $\mathrm{CO}_{2}$ enrichment. Carbon dioxide effects were 
studied under different irradiance and soil moisture conditions since these environmental factors, as well as nutrient availability, influence their pattern of invasion into abandoned fields and establishment under forest canopies in the North Carolina piedmont. Growth and physiological experiments were conducted in controlled environment facilities at the Duke University Phytotron. Elevated atmospheric $\mathrm{CO}_{2}$ concentration enhanced growth with the greatest increase in height, leaf area, basal stem diameter and total dry weight seen for sweetgum seedlings grown under high irradiance. Increases in dry matter accumulation were associated with early $\mathrm{CO}_{2}$ enhancement of net assimilation rate, with increases in amount of leaf surface area contributing more towards maintenance of larger size as seedlings aged. For sweetgum seedlings in particular reduction of growth by low irradiance and soil drought under normal atmospheric $\mathrm{CO}_{2}$ was compensated for by growing plants under elevated $\mathrm{CO}_{2}$. Photosynthetic acclimation of sweetgum and loblolly seedlings was not significantly altered by increasing atmospheric $\mathrm{CO}_{2}$. However, $\mathrm{CO}_{2}$ enrichment had a substantial differential effect on drought tolerance of these two species. Sweetgum seedlings grown at elevated $\mathrm{CO}_{2}$ maintained higher plant water potentials and net photosynthetic rates during a period of drought than when grown at present day $\mathrm{CO}_{2}$ level. In addition water use efficiency in these seedlings was also increased. In contrast $\mathrm{CO}_{2}$ enrichment had much smaller effects on total plant water potential, net photosynthesis, transpiration and water use efficiency of loblolly seedlings. Physiological and growth response data in this study strongly suggest that the continued increase in atmospheric $\mathrm{CO}_{2}$ may influence distribution patterns of these two species primarily in open fields.

Major Professor(s): Strain, Boyd R.

Department: Botany

Principal Investigator(s): Strain, Boyd R.

Program Area: Carbon, Climate, and Vegetation

KEYWORDS: ATMOSPHERE, BIOMASS, CARBON

DIOXIDE, FERTILIZATION, GROWTH AND

DEVELOPMENT, PHOTOSYNTHESIS, RADIATIVE

PROCESSES, VEGETATION, WATER STRESS, WATER USE

\section{1}

Tramoni, Florence. 1985. Lake Ice Occurrence as a Climatic Indicator in Studies of Carbon Dioxide Induced Warming: A Canadian Case Study. $M A$. Thesis, University of Colorado, 158 pages.

Recent consumption of fossil fuels is expected to lead to a doubling of $\mathrm{CO}_{2}$ concentration by about 2050. This may lead to a mean global warming of $2-3^{\circ} \mathrm{C}$. It is suggested that lake ice occurrence may be used as a first detection parameter of this warming, due to its relatively rapid integration of temperature, and the availability of freeze-up and break-up data. Two case studies are examined for the statistical relationship between ice patterns and daily temperature data. One study, for four lakes in Wisconsin, U.S.A, does not produce valuable results. The second study, for 27 lakes throughout Canada, statistically evaluates these relationships through regression analysis, and yields significant results. The effect of climate was well represented by the dates of freeze-up and break-up. Year to year variability decreased with increasing latitude, with break-up being generally more variable than freeze-up in all regions. The records of six lakes show a trend of closing earlier and opening later than average during the decade 1970-1980. Freezing degreedays had higher correlations with freeze-up than did thawing degree-days with break-up. For several Canadian lakes studied, a \pm 5 day variation in the date of freeze-up corresponds approximately to $\mathrm{a} \pm 1{ }^{\circ} \mathrm{C}$ change in temperature for the $\mathbf{3 0}$ days preceding this event. Future research should seek to obtain a wider distribution of lake ice datasets, as well as information on physical lake parameters (size, fetch, depth). Satellite observations of lake ice patterns could greatly enlarge the spatial network of data, which will become more and more valuable as we enter the era during which the $\mathrm{CO}_{2}$ signal should become detectable above the natural climatic noise.

Major Professor(s): Barry, Roger G.

Department: Geography

Principal Investigator(s): Barry, Roger G.

Program Area: Carbon, Climate, and Vegetation

KEYWORDS: CLIMATE, ICE, LAKES, NORTH

AMERICA, SPATLAL DISTRIBUTION, TEMPERATURE, TEMPORAL DISTRIBUTION

\section{2}

Ulman, James C. 1994. Impact of Air Mass History on the Chemical, Microphysical, and Radiative Properties of Clouds at Mount Mitchell, North Carolina. M.S. Thesis, North Carolina State University, 115 pages.

Cloud water acidity and ionic content, as measured at the Mount Mitchell State Park observing site (35" 44'05" N, 82" 17'15" W, 2038 m MSL -- highest peak in the eastern U.S.), using a passive cloud water collector, are directly influenced by the trajectories of cloud forming air masses which pass over areas of varying levels of pollutant emission. Regions of the United States which are emitters of high levels of 
pollutants, such as $\mathrm{SO}_{\mathrm{x}}$ and $\mathrm{NOx}$, will thus serve to reduce observed $\mathrm{pH}$ levels in cloud water samples and raise the levels of acidifying ions, such as sulfate and nitrate. Cloud water is one of the best indicators of pollution levels because all water soluble impurities in one cubic meter of air from an air mass are found condensed in typically one milliliter or less of the cloud water. The 48 -hr backward trajectories for all 39 cloud events during the 1993 field season (15 May 1993 . 14 October 1993) were computed using the Hybrid Single-Particle Lagrangian Integrated Trajectories (HYSPLIT) model. Three sectors, identified as the polluted sector, from $290^{\circ}$ to $65^{\circ}$ azimuth relative to the site, the continental sector, $240^{\circ}$ to $290^{\circ}$ azimuth, and the marine sector, $65^{\circ}$ to $240^{\circ}$ azimuth, were used to classify the cloud forming air masses. The polluted sector was associated with the lowest overall pH averages, with the marine sector following closely behind. The highest average $\mathrm{pH}$ values were received from air masses indicated as having crossed the continental and the marine sectors (in combination), with the largest portions of those air mass trajectories passing through the continental sector (exclusively continental sector air masses were also the most frequent). These observations are in agreement with findings in Colorado where aerosols produced by wind erosion were responsible for neutralizing the precipitation acidity.

Major Professor(s): Saxena, Vinod K. Department: Marine, Earth and Atmospheric Sciences Principal Investigator(s): Saxena, Vinod K. Program Area: National Institute for Global Environmental Change (NIGEC)

KEYWORDS: AEROSOLS, CHEMISTRY, CLIMATE, CLOUDS, EMISSIONS, MICROPHYSICS, MODELS, NITROGEN SPECIES, RADLATIVE PROCESSES, REGIONAL ANALYSIS, SULFUR SPECIES, WATER

\section{3}

Vorosmarty, Charles Joseph. 1991. Models of MacroScale Hydrology for Use in Global Change Research: Tests on Two Tropical River Systems. Ph.D.

Dissertation, University of New Hampshire, 255 pages.

The subject of this dissertation is the terrestrial water cycle and development of tools to study the issue of global hydrologic change. A rationale is developed to study the water cycle at regional and continental scales using macro-scale hydrology couples to Geographic Information Systems (GIS). A linked Water Balance/Water Transport Model (WBM/WTM) was constructed and tested as part of this research. The model was applied to two tropical river systems, the
Amazon River in South America and the Zambezi River in southern Africa. The WBM/WTM is a distributed parameter model, operating at $0.5^{\circ}$ (latitude $x$ longitude) spatial scale and with monthly timesteps. The WBM transforms spatially complex data on climate, vegetation, soils and topography into predictions of soil moisture, evapotranspiration and runoff. The WTM uses computed runoff, information on fluvial topology, linear transfer through river channels and a simple representation of floodplain storage to generate monthly discharge for any cell within a simulated catchment. For the Amazon, WBM/WTM results were checked against established data sources and found to be in good agreement. The Zambezi simulation was more problematic. This study identified and corrected errors in the precipitation, potential evapotranspiration, and soil water capacity data sets, and demonstrated the importance of checking such calculations against reliable discharge data. Simulations with data from the Amazon and Zambezi River systems identified fluvial transport parameters which best matched observed discharge. Similar parameters captured the dynamics of river flow in these strikingly different river systems. This suggests that large tropical rivers may have convergent properties that can be modeled using simple algorithms. This work produced a set of calibrated, macro-scale hydrology models for two large rivers prior to significant anthropogenic disturbance. Such simulations are prerequisites to the study of hydrologic change. The major impacts of such change, from shifting land use, climate change, and water resources management, can be simulated using macro-scale hydrology models. The dissertation offers a strategy to accomplish this goal.

Major Professor(s): Moore, Berrien

Department: Earth Sciences

Principal Investigator(s): Moore, Berrien

Program Area: Carbon, Climate, and Vegetation

KEYWORDS: AFRICA, CLIMATE, HYDROLOGY, LAND SURFACE, MODELS, PRECIPITATION, RIVERS, RUNOFF, SOILS, SOUTH AMERICA, TROPICS, WATER

\section{4}

Volk, Tyler. 1984. Multi-Property Modelling of the Marine Biosphere in Relation to Global Climate and Carbon Cycles. Ph.D. Dissertation, New York University, 348 pages.

A natural hierarchy of tracers based upon biological source-term complexity gives a systematic sequencing for a modeling procedure, which should be generally applicable to different types of models that need multi- 
property outputs. The procedure moves from dynamics to single-source tracers to double-source tracers. The surface water $\mathrm{pCO}_{2 m}$ and temperature relationship is examined seasonally, geographically and biologically. A meridional diffusive model reproduces the observed 1$2 \% \mathrm{pCO}_{2 \mathrm{~m}}$ per degree $\mathrm{C}$ of the Atlantic gyres. Differences in the seasonal orbit of $\mathrm{pCO}_{2} / \mathrm{T}$ potentially useful in field studies result from varying the magnitude and seasonality of biological productivity. The multiproperty procedure is used in a 1-D upwelling-diffusion model to produce simultaneous, globally-averaged profiles of temperaiure, phosphate, nitrate, oxygen, alkalinity, and total carbon dioxide. Depth-dependent source terms simulate the oxidation and dissolution processes. Traditional Redfield ratios coupling the organic source terms are adequate algorithmic proportionalities for the global profiles. Bottom and intermediate water formation is modeled both as a pipeline with parameterized fluxes of nutrients and as a buoyant plume that entrains water during descent. The model transfers $\mathrm{O}_{2}$ and $\mathrm{CO}_{2}$ between the surface mixed layer and the polar sea. The relative strengths of biology and dynamics as pumps that affect $\mathrm{pCO}_{2 \mathrm{~atm}}$ by creating surface-to-deep $\mathrm{CO}_{2}$ concentration differences are calculated. A full dynamic pump and no biology produces a $\mathrm{pCO}_{2}$ value of $460 \mathrm{ppmv}$. Also eliminating the dynamic pump by lowering the degree of polar $\mathrm{pCO}_{2}$ equilibrium raises $\mathrm{pCO}_{2 \mathrm{~atm}}$ to $720 \mathrm{ppmv}$. The model's usefulness in coupled multi-property transients is demonstrated by switching off biology and following all tracers toward their abiotic distributions. The mathematics of a 2-D isopycnal mixing model is presented. Along-and-across isopycnal diffusivities are rotated to horizontal-and-vertical diffusivities. Along with thermohaline circulation, equatorial upwelling represents a wind-driven circulation. The necessity for incorporating bottom water plumes and intermediate water is concluded from the 1-D modelling procedure.

Major Professor(s): Hoffert, Martin I.

Department: Applied Science

Principal Investigator(s): Hoffert, Martin I.

Program Area: Carbon, Climate, and Vegetation

KEYWORDS: ALKALINITY, CARBON CYCLE, CARBON DIOXIDE, CIRCULATION, DIFFUSION, MIXED LAYER, MODELS, NITROGEN SPECIES, OCEANS, OXYGEN, PHOSPHATE, TEMPERATURE, TRANSPORT

195

Walter, Robert Jeffrey. 1994. Sedimentary processes in the Neuse River estuary: Evidence from Chemical and Radiochemical Tracers. M.S. Thesis, University of North Carolina at Chapel Hill, 67 pages.
Radiochemical and chemical analyses were performed on fine-grained bottom sediments and interstitial waters from the main channel of the Neuse River estuary, NC. The primary purpose for undertaking these analyses was to establish a sedimentary context in which to interpret carbon isotope data $\left(\Delta^{14} \mathrm{C}, \delta^{13} \mathrm{C}\right)$.

Measurements of carbon isotopes will be performed at a later date. Activities of ${ }^{226} \mathrm{Ra},{ }^{228} \mathrm{Ra},{ }^{137} \mathrm{Cs}$, and ${ }^{40} \mathrm{~K}$ in the bottom sediments were measured by gamma spectrometry. Chloride concentrations in the interstitial waters were measured by ion chromatography. Six of the eight sampling locations are stations that were revisited from a previous study. Data profiles from these stations are compared with profiles from the previous study in an effort to obtain information on the nature of certain physical and chemical processes in the Neuse river estuary through time.

Major Professor(s): Benninger, Larry $\mathrm{K}$. Department: Geology

Principal Investigator(s): Benninger, Larry $\mathrm{K}$. Program Area: Marine Transport

\section{KEYWORDS: CARBON ISOTOPES, CHEMISTRY, ESTUARIES, HALOGEN SPECIES, METALS, RIVERS, SEDIMENTS}

\section{6}

Wanninthof, Richard Hendrit. 1986. Gas Exchange over the Air-Water Interface Determined with Man Made and Natural Tracers. Ph.D. Dissertation, Columbia University, 295 pages.

Gas exchange coefficients were determined on Rockland Lake, N.Y.; Crowley Lake, CA; and Mono Lake, CA which have surface areas of $1 \mathrm{~km}^{2}, 20 \mathrm{~km}^{2}$, and $190^{2}$, respectively, by injecting a small amount of man made tracer gas, sulfur hexafluoride $\left(\mathrm{SF}_{6}\right)$ into the lake and measuring the rate of concentration decrease in the water column with time. The dependency of gas exchange on wind speed is similar for the three lakes indicating that wind fetch is not a critical parameter for the gas exchange coefficient for lakes with sizes greater than $1 \mathrm{~km}^{2}$. Little gas exchange occurs for wind speeds less than $2.5 \mathrm{~m} / \mathrm{s}$ and gas exchange increases linearly with wind speed from 2.5 to $6 \mathrm{~m} / \mathrm{s}$. Average wind speeds, $u_{\mathrm{a}}$ and exchange coefficients, $k$, for the experiments which lasted 4 to 6 weeks, corrected to a Schmidt number of 1000 and to wind speeds at $10 \mathrm{~m}$ height, are: Rockland Lake $u_{\mathrm{wv}} 10 \mathrm{~m}=4.3 \mathrm{~m} / \mathrm{s}, \mathrm{k}=2.9$ $\mathrm{cm} / \mathrm{hr}$; Crowley Lake $u_{\mathrm{av}} 10 \mathrm{~m}=3.4 \mathrm{~m} / \mathrm{s}, \mathrm{k}=2.6 \mathrm{~cm} / \mathrm{hr}$; and Mono Lake $u_{\mathrm{w}} 10 \mathrm{~m}=3.5 \mathrm{~m} / \mathrm{s}, \mathrm{k}=2.7 \mathrm{~cm} / \mathrm{hr}$. The relationship of gas exchange and wind speed for the lakes agree well with a compilation of earlier single wind speed - exchange coefficient measurements on lakes 
and oceans but they are lower than most results obtained in wind tunnels. The kinetic fractionation of ${ }^{13} \mathrm{CO}_{2}$ and ${ }^{12} \mathrm{CO}_{2}$ during transfer from air to water is determined in a laboratory tank for sea water and water from several alkaline lakes ( $\mathrm{pH}=9.2-10)$. The kinetic fractionation constant for the sea water experiments showed no measurable temperature dependence and the average for eight experimental runs at $3.5^{\circ} \mathrm{C}$, $12.5^{\circ} \mathrm{C}$, and $20^{\circ} \mathrm{C}$ was $-2.4 \pm 2.0 \%$. The fractionation during invasion in alkaline lake water ranged from -2.5 to $-8 \%$ depending on the lake water and the degree of agitation. Most turbulence resulted in smaller fractionation. The larger fractionation for alkaline lake water than ocean water is attributed to reaction of $\mathrm{CO}_{2}$ with hydroxide ions in the surface boundary layer.

Major Professor(s): Broecker, Wallace S.

Department: Geochemistry

Principal Investigator(s): Broecker, Wallace S.

Program Area: Carbon, Climate, and Vegetation

\section{KEYWORDS: CARBON DIOXIDE, CARBON ISOTOPES, CHEMISTRY, FRACTIONATION, GASES, LAKES, OCEANS, TRACERS, TRANSPORT, WATER, WINDS}

\section{7}

Wei, Ching-Ling. 1985. Carbonate Chemistry of the North Pacific Ocean. M.S. Thesis, Oregon State University, 148 pages.

This thesis covers a wide area of the North Pacific Ocean, latitudinally from $10^{\circ}$ to $55^{\circ} \mathrm{N}$ and longitudinally from Japan to the U.S. coast. With two longitudinal cruises as the main data sources and selected literature data sets as supplementary data source, the distribution of physical and chemical properties in the North Pacific Ocean is presented. $\mathrm{AOU}, \mathrm{pH}$, total $\mathrm{CO}_{2}$, and nutrients (nitrate and phosphate) are interrelated parameters. Along our two longitudinal sections they all show a core structure underlying the salinity minimum layer. From these oxidation related parameters we obtain a conclusion that the subsurface water of the eastern North Pacific Ocean is older than that of the western North Pacific Ocean. Alkalinity, calcium, and silicate show a monotonically increasing trend with depth to the deepest sampling depth. The alkalinity data can be used as a water mass tracer. Different water masses which show their own mixing trends can be identified when the correlation of normalized alkalinity with temperature is scrutinized. The vertical distribution of the normalized alkalinity shows a maximum core at a depth of about $2500 \mathrm{~m}$ in the North Pacific Ocean. Not only the calcium carbonate dissolution but also the circulation in the deep and bottom layer plays a role in this normalized alkalinity maximum core. Our analysis of carbonate data shows that about $25 \%$ of the increase in total inorganic $\mathrm{CO}_{2}$ of deep water, after leaving from the Southern Ocean to the North Pacific, is contributed by inorganic $\mathrm{CaCO}_{3}$ dissolution. There is no significant difference of inorganic carbon/orgaric carbon ratio between our two sections. However, it was found that the eastern section has a higher total $\mathrm{TCO}_{2}$ input than that of the western section. The degree of saturation with respect to calcite and aragonite was calculated from all the available data sets. Mr. Ahmed Rushdi and Professor R.M. Pytkowicz are working on the effect of $\mathrm{Mg}$ on the formation and the properties of magnesian calcites. There are metastable forms of these compounds which may have been interpreted as stable ones in solubility determinations. Some revisions of degree of saturation may be called for in the future. Four selected cross-sections, three longitudinal and one latitudinal, show that a large volume of the North Pacific is undersaturated with respect to $\mathrm{CaCO}_{3}$. The saturation horizon generally shows a shoaling from the west to the east and from the south to the north in the North Pacific Ocean. It was found that lysocline falls on a depth much deeper (about $2500 \mathrm{~m}$ deeper) than the saturation horizon of calcite and several hundred meters shallower than the CCD (calcium carbonate compensation depth) depth. Our results support the kinetic point of view on the $\mathrm{CaCO}_{3}$ dissolution mechanisms. The direct approach on the fossil fuel increase signal in seawater is adopted in this thesis. A new set of preformed equations of alkalinity and total $\mathrm{CO}_{2}$ was obtained from a more updated GEOSECS data. Our results show that the penetration depth of fossil fuel $\mathrm{CO}_{2}$ is strongly related to the surface oceanographic circulation. The shallowest penetration depth is less than $300 \mathrm{~m}$ found in the eastern equatorial region where the upwelling prevails and the deeper penetration depth is deeper than $2000 \mathrm{~m}$ off Japan where an interaction of Oyashio and Kuroshio currents in found.

Major Professor(s): Chen, Chen-Tung A. Department: Oceanography Principal Investigator(s): Chen, Chen-Tung A. Program Area: Carbon, Climate, and Vegetation

KEYWORDS: CARBON CYCLE, CARBON DIOXIDE, CHEMISTRY, EMISSIONS, FOSSIL FUELS, METALS, NITROGEN SPECIES, OCEANS, ORGANICS, PHOSPHATE, SPATLAL DISTRIBUTION 
198

Wray, Susan Marks. 1985. Comparative Physiological

Ecology of Two Old Field Perennials, Aster pilosus and Andropogon vinginicus, under $\mathrm{CO}_{2}$ Enrichment and Drought Stress. M.S. Thesis, Duke University, 52 pages.

Aster pilosus Willdenow (aster, $\mathrm{C}_{3}$ photosynthetic pathway) dominates old fields two to three years after abandonment, but is replaced by Andropogon vinginicus L. (broomsedge, $\mathrm{C}_{4}$ photosynthetic pathway), which is more drought tolerant. $\mathrm{CO}_{2}$ enrichment decreases the severity of drought stress, and typically has a stronger effect on $\mathrm{C}_{3}$ than on $\mathrm{C}_{4}$ species. Differential responses of aster and broomsedge to drought stress and $\mathrm{CO}_{2}$ enrichment could change the rate of succession in old fields. These two species were grown in growth chambers at $26 / 20 \mathrm{C}$ day/night temperatures with a PPFD of $1000 \mu \mathrm{mol} \mathrm{sec}-1 / \mathrm{m}^{-2}$. Plants were subjected to a 2-wk drought at approximately 380,500 , or $650 \mu \mathrm{ll}^{-1}$ $\mathrm{CO}_{2}$. There were significant interactions of $\mathrm{CO}_{2}$ enrichment and drought stress on aster so that drought stress was less severe in plants grown with $\mathrm{CO}_{2}$ enrichment. Drought stressed asters with $\mathrm{CO}_{2}$ enrichment had greater leaf water potentials, higher photosynthetic rates, and higher total dry weights than plants grown at $380 \mu \mathrm{l} \mathrm{I}^{-1} \mathrm{CO}_{2}$. The response of broomsedge to drought was the same in all $\mathrm{CO}_{2}$ treatments and there were no significant interactions of $\mathrm{CO}_{2}$ enrichment and drought stress. The decreased severity of drought stress and the increased growth of aster with $\mathrm{CO}_{2}$ enrichment may increase its competitive abilities during droughts, allowing it to persist for longer periods during succession in abandoned fields.

Major Professor(s): Strain, Boyd R.

Department: Botany

Principal Investigator(s): Strain, Boyd R.

Program Area: Carbon, Climate, and Vegetation

KEYWORDS: C3 METABOLISM, C4 METABOLISM, CARBON DIOXTDE, COMPETITION, FERTILIZATION, PHOTOSYNTHESIS, SUCCESSION, VEGETATION, WATER STRESS, WATER USE

199

Wray, Susan Marks. 1987. Competitive Interactions of Two Old-Field Perennials, Aster pilosus and Andropogon virginicus under $\mathrm{CO}_{2}$ Enrichment. $P h D$. Dissertation, Duke University, 167 pages.

Differential response of species to $\mathrm{CO}_{2}$ enrichment may change future community structure in natural ecosystems. In old fields of the North Carolina Piedmont, aster (Aster pilosus Willd, $\mathrm{C}_{3}$ ) is usually the dominant perennial two years after abandonment. Broomsedge (Andropogon virginicus $\mathrm{L}_{\text {., }} \mathrm{C}_{4}$ ) outcompetes and replaces aster during the next several years. When grown individually, aster responds positively to $\mathrm{CO}_{2}$ enrichment whereas broomsedge does not. Thus it was hypothesized that the competitive interactions between these species would change if the atmospheric $\mathrm{CO}_{2}$ concentration was increased. Aster and broomsedge were grown in simplified de Wit replacement series experiments in the Duke Phytotron at 350,500 and $650 \mu l \mathrm{l}^{-1} \mathrm{CO}_{2}$. The suppression of broomsedge by aster was awways greater with $\mathrm{CO}_{2}$ enrichment so that broomsedge grown with aster had $69 \%$ less dry weight than in monoculture at $650 \mu 11^{-1}$ $\mathrm{CO}_{2}$. Aster had $49 \%$ more dry weight when grown with broomsedge than in monoculture at $650 \mu \mathrm{l} \mathrm{I}^{-1} \mathrm{CO}_{2}$. Broomsedge was more drought tolerant than aster and under ambient conditions had a higher water use efficiency. However, under water-limited conditions, broomsedge was not a stronger competitor than aster. With $\mathrm{CO}_{2}$ enrichment aster comprised $75 \%$ of total pot biomass under both water-limited and well-watered conditions. There could also be competition between established broomsedge and a secord generation of aster seedlings in old fields. In the Phytotron when broomsedge was grown for six weeks before aster emerged, aster seedlings did not suppress the growth of broomsedge even with $\mathrm{CO}_{2}$ enrichment. These studies have shown that competitive interactions between these old-field perennials change under $\mathrm{CO}_{2}$ enrichment when grown in a controlled environment. Future increases in atmospheric $\mathrm{CO}_{2}$ concentration may slow the rate of succession in old fields under both drought and nondrought conditions. However, aster will not necessarily eliminate broomsedge from the perennial herbaceous community as broomsedge ultimately will reach a size where competition with aster seedlings does not delay its growth. It is hoped that these studies will contribute to the understanding of the dynamics of community structure in the face of environmental change.

Major Professor(s): Strain, Boyd R.

Department: Botany

Principal Investigator(s): Strain, Boyd R.

Program Area: Carbon, Climate, and Vegetation

KEYWORDS: C3 METABOLISM, C4 METABOLISM, CARBON DIOXIDE, COMPETITION, FERTILIZATION, PHOTOSYNTHESIS, RESPIRATION, SUCCESSION, VEGETATION, WATER STRESS, WATER USE

200

Wuebbles, Donald James. 1983. A Theoretical Analysis of the Past Variations in Global and Atmospheric 
Composition and Temperature Structure. $P h D$. Dissertation, University of California at Davis, 162 pages.

Over the last decade, advances in observation techniques coupled with an improved understanding of atmospheric chemical and physical processes have demonstrated that concentrations are changing for a number of radiatively and chemically active trace gases. Many of the observed changes appear to be the result of human activities. Changing concentrations of these gases are of concern both because of their potential direct radiative effects on atmospheric temperature and climate and because of their potential effects on tropospheric and stratospheric ozone. This study attempts a comprehensive analysis of how recognized anthropogenic and natural influences may have affected the atmosphere since the beginning of the industrial age. Within this context, model results for past and present atmosphere are compared with available observations of relevant atmospheric parameters. This report also examines whether recognized anthropogenic influences are sufficient to explain recent measured trends in atmospheric ozone and temperature. An attempt is made to evaluate the chemical composition and temperature structure of the atmosphere before major human influence, termed the pre-industrial atmosphere. A comparison is made between the calculated pre-industrial and present atmospheres to determine whether the ozone and temperature distributions might have been substantially different before human activities influenced the global atmosphere. Results from this study suggest that man has altered the ozone distribution and temperature structure of the global atmosphere over this period. Increasing concentrations of $\mathrm{CO}_{2}, \mathrm{CH}_{4}, \mathrm{~N}_{2} \mathrm{O}$ and chlorocarbons, plus emissions of nitrogen oxides from aircraft, appear to be influencing the present atmosphere. The calculated pre-industrial (1850) atmosphere was found to be measurably different from the present atmosphere. Model calculated trends in ozone and temperature for the 1960s and 1970s are generally in agreement with the measured trends, but there are too many remaining theoretical and sampling uncertainties for causality to be established. The generally excellent comparison of observations with the calculated distribution of trace species lends confidence to the capability of current theory to represent atmospheric processes. The results presented here plus calculations studying potential anthropogenic influences on the future atmosphere suggest that total ozone measurements may not provide a very sensitive indication of the impact of human activities on the global atmosphere. Monitoring of changes in the distributions of ozone and temperature should be more useful.
Major Professor(s): Weare, Bryan C. Department: Atmospheric Sciences Principal Investigator(s): MacCracken, Michael C. Program Area: Carbon, Climate, and Vegetation

KEYWORDS: ATMOSPHERE, CARBON DIOXTDE, CLIMATE, EMISSIONS, HALOGENATED HYDROCARBONS, METHANE, NITROGEN SPECIES, OZONE, PRE-INDUSTRLAL ERA, SPATIAL DISTRIBUTION, TEMPERATURE

\section{1}

Youngblood, Debra A 1994. Further Development and Testing of a Bimodal Aerosol Dynamics Model. M.S. Thesis, Colorado State University, 151 pages.

A previously reported bimodal monodisperse aerosol model is further developed and tested. The starting point is the BImodal MOnoDisperse Aerosol Model (BIMODAM I) which was developed to model the formation of ammonium sulfate $\left(\left(\mathrm{NH}_{4}\right)_{2} \mathrm{SO}_{4}\right)$ particles from sulfuric acid $\left(\mathrm{H}_{2} \mathrm{SO}_{4}\right)$ vapor. The model follows the evolution of two monodisperse modes where each mode, $\mathrm{i}$, is characterized by a unique mean diameter and the number of particles with that mean diameter. The aerosol distribution is assumed to undergo typical atmospheric processes such as condensational growth, coagulation, nucleation, and deposition. In BIMODAM I, the effect of each process on the aerosol distribution is represented as a rate equation. The prognostic equations are coupled, so a variable time step differential equation solver is utilized to simultaneously solve the system of equations to predict the mass and number concentration in each mode. The diameter of each mode is diagnosed from the mass and number concentrations. In the first part of this work, two new parameterizations were developed for BIMODAM I. First, a condensation rate factor was developed to account for the lack of polydispersity in the model. Second, a criterion was developed which dictates when the two modes may be merged without generating large errors. In the second part of this work, a new version of the model (BIMODAM II) was developed to give the same accurate results as BIMODAM I without using the variable time step differential equation solver. A key development in BIMODAM II is a parameterization for the process of homogeneous nucleation. This parameterization is based on the approximation of the time-dependent nucleation rate with a triangular function; using this approach, only two parameters are needed to predict the total number of particles resulting from a nucleation event. The two parameters are correlated to chemical source rate and relative humidity. Therefore, prediction of the number concentration of particles resulting from a nucleation 
burst depends on knowing the relative humidity and determining the chemical source rate. This development has been shown to perform well in the presence and absence of preexisting particles and over short and long time scale simulations. Further developments in BIMODAM II include simple analytical solutions of the differential equations for coagulation and deposition. Using a mass balance equation, a simple solution was also derived to predict the amount of sulfuric acid in the vapor phase at any time during the simulation. From this calculation, the amount of mass in the aerosol phase is calculated by subtracting the amount in the vapor phase from the total amount of sulfuric acid produced during any given time step. By using the simplifications and parameterizations mentioned above, computational time is saved by eliminating the variable time stepping differential equation solver. This model is shown to perform well when compared against a simulation which uses a more detailed description of the aerosol size distribution.

Major Professor(s): Kreidenweis, Sonia

Department: Atmospheric Sciences

Principal Investigator(s): Kreidenweis, Sonia

Program Area: National Institute for Global

Environmental Change (NIGEC)

KEYWORDS: AEROSOLS, MODELS, SIZE DISTRIBUTION

\section{2}

Zaff, David Z 1994. A Dynamical Explanation for Longitude Dependent Ozone and Temperature Trends in the Northern Hemisphere Winter. M.S. Thesis, University of Arizona, 21 pages.

Ozone and temperature data are obtained from the Total Ozone Mapping Spectrometer (TOMS) on the Nimbus 7 satellite and Channel 4 of the Microwave Sounding Unit (MSU) on the NOAA operational satellites. January averages are analyzed separately via a multiple regression statistical model with dependences on a linear trend, the quasibiennial oscillation (QBO), and the solar cycle. Trends show that both data sets exhibit significant negative trends at middle to sub-polar latitudes occurring over Russia and the western Pacific, with smaller negative trends at mid-latitudes occurring over the eastern United States. Positive trends occur in the sub-polar latitudes over the Atlantic, although neither ozone nor temperature trends in this region are found to be statistically significant. The strongest negative trends are located in the same geographic area where climatological ozone and temperature are a maximum. A calculation of three year January ozone and temperature averages for 1980-82 and 1989-91 yields differences that are similar to the statistically derived ozone and temperature trends. These composite plots show a significant decrease in the wave 1 amplitude of both ozone and temperature, in agreement with the trends. A steady state ozone perturbation model under adiabatic and geostrophic conditions is applied to test whether changes in dynamics alone, represented by the geopotential height fields, can explain the observed longitude distribution of ozone trends. Similarly, the hydrostatic equation is used to study the longitude distribution of temperature. Results show that changes in the stationary wave pattern alone can explain the observed longitude dependence.

Major Professor(s): Hood, Lon L.

Department: Atmospheric Sciences Principal Investigator(s): Hood, Lon L. Program Area: Atmospheric Sciences

KEYWORDS: ATMOSPHERE, OZONE, TEMPORAL DISTRIBUTION

203

Zeng, Fanrong. 1994. A Large-Eddy Simulation Study of the Convective Boundary Layer in Complex Terrain: Implications for Subgrid-Scale Parameterizations in GCMs. M.S. Thesis, Rutgers University, 31 pages.

For the purpose of improving the parameterization of the planetary boundary layer (PBL) in atmospheric models, large-eddy simulations (LES) were used to study the statistical properties and the structure of turbulence in the PBL that develops in complex terrain. The impact of hill height, hill length, surface heat flux, atmospheric stability, and background wind were considered. As compared to a flat domain, a $400-\mathrm{m}$ high (40\%-slope) hill starts to exhibit noticeable influence on the different moments of most atmospheric variables, with a more pronounced impact on the higher moments. Wind speed, hill length, and surface heat flux all have at least some impact on the convective boundary layer (CBL). In particular, the structure and preferential location of the eddies is strongly affected by these parameters. A hill as small as $100 \mathrm{~m}$ high induces hill-valley circulations, which, however, are eliminated with a background wind as low as $2.5 \mathrm{~m} / \mathrm{s}$. This LES study indicates that only in very irregular terrain, with slopes larger than $20 \%$, the current CBL parameterizations of microscale turbulent fluxes need to be improved to represent correctly the atmospheric fluxes. Typically, such terrain is only found in mountainous regions. Since the mean surface sensible beat flux is the major surface forcing source for the CBL, the "mosaic-of-tiles" type of surface 
parameterization suggested by Avissar and Pielke seems appropriate for most continental areas.

Major Professor(s): Avissar, Roni

Department: Meteorology and Physical Oceanography Principal Investigator(s): Avissar, Roni

Program Area: Computer Hardware, Advanced

Mathematics, and Model Physics (CHAMMP)

\section{KEYWORDS: BOUNDARY LAYER, DIFFUSION, LAND SURFACE, TURBULENCE}

\section{4}

Zhang, Bing 1993. Use of Taylor Expansion in Computation of the Simplest Spectral Barotropic Vorticity Equation. M.S. Thesis, University of Maryland at College Park, 29 pages.

Time integration is the basic part of the computation of meteorologic forecast modeis, but the time step is constrained by stability consideration, CFL condition must be satisfied for linear problems. The time steps are very short for high frequency components, this makes the integration procedures extremely timeconsuming, especially for climate models. The current popular numerical integration scheme for time integration is three time-level leapfrog scheme which uses the first order derivative at the mid-level, we will refer this method as the regular leapfrog scheme. In this paper, a system of the simplest spectral barotropic vorticity equation in channel domain is experimentally computed by using Taylor's expansions of time dependent variables so that higher derivatives are included in computing the values at next time level. Taylor's expansion is applied for two computational schemes: one is "leapfrog" with the derivatives evaluated at the mid-level, the other is the two time-level forward scheme with the derivatives evaluated at level one, at which all variables values are considered as known, and the predicted outputs are given at level two. The experiment shows that on the average, when certain number of derivatives are included in the expansions, the integration time step can be more than 6 times of those given by the regular leapfrog scheme without losing any accuracy. This results tells us that it is possible to integrate the equations with a much higher time step by rewriting the forecasting equations in their Taylor's expansion forms. Although Taylor's expansion forms are usually much more complicated compared with the forms of the regular leapfrog scheme, time integration can still be fastened if each term in Taylor's expansion is assigned to one processor of the Massive Parallel Processors. The deal is the lose of simple expression form in exchange of the gaining of computational speed when MPP is used. In addition, the simple expansion form of the regular leapfrog scheme (several integration time steps are combined into one expression) is tested. Compared with Taylor's expansion forms, it will take about two orders magnitude higher computation times for the same increase of integration time step. This shows that the perspective of making use of Massive Parallel Processors with the use of Taylor's expansion forms are brighter.

Major Professor(s): Baer, Ferdinand Department: Meteorology Principal Investigator(s): Baer, Fcrdinand Program Area: Computer Hardware, Advanced Mathematics, and Model Physics (CHAMMP)

\section{KEYWORDS: ATMOSPHERE, CIRCULATION, METEOROLOGY, MODELS, PRESSURE, TAYLOR'S EXPANSION, TEMPORAL DISTRIBUTION}

\section{5}

Zhang, Qing 1990. Test of Transilient Turbulence Theory Against a Field Experiment. M.S. Thesis, University of Wisconsin - Madison, 88 pages.

A simple 1-dimension grid-point boundary-layer simulation model based on transilient turbulence theory is tested against BLX83 experiment data. Transilient coefficients are parameterized using a simplified form of the total kinetic energy (TKE) equation instead of Richardson numbers. The model is absolutely numerically stable. May 28,1983 , a cloudless day with sufficient measurements, was chosen as the case-study day. The early morning radiosonde sounding is used to prescribe the initial conditions. Surface heat and moisture flux from an aircraft and flux tower, and surface geostrophic wind, thermal wind and horizontal temperature gradient are computed from surface temperature, pressure, and wind data from portable automated mesonet (PAM) stations, and are used to prescribe the forcings and boundary conditions on the model. Subsidence calculated from horizontal divergence is prescribed at the top of the model. Simulated potential temperature and specific humidity profiles compare well with actual radiosonde and aircraft soundings. Modeled heat flux decreases linearly with height as expected. Moisture flux profiles show a maximum near the top of the mixed layer (ML), also expected. There is no explicit forecast equation for ML depth $z_{i}$ in the transilient model, yet the simulation exhibits a growing $M L$ with entrainment. Modeled $z_{i}$ is between radiosonde and aircraft soundings and lidar measurements. Modeled surface potential temperature and specific humidity evolution are close to the PAM II and radiosonde observations. A nonlocal spectral 
decomposition of the flux at different levels indicates that most contributions of the total flux at height $\mathbf{Z}$ are made by the eddies with size $Z$.

Major Professor(s): Stull, Roland B.

Department: Atmospheric and Oceanic Sciences

Principal Investigator(s): Stull, Roland B.

Program Area: Atmospheric Radiation Measurement (ARM)

\section{KEYWORDS: BOUNDARY LAYER, MIXED LAYER, MODELS, TURBULENCE}

\section{6}

Zhang, YingYi. 1992. Two Studies on the Sources and Reactions of Tropospheric Gases: Investigation of Emission of Tropospheric Gases in Biomass Burning and the Effects of Diurnal Variation of Photolysis Rates on Their Concentrations. M.S. Thesis, State University of New York at Stony Brook, 71 pages.

In May 1989, a major fire began in the Great Hinggan Forests in Heilongjiang province in Northeastern China and across the Black Dragon River in Siberia. A detailed investigation of the fire by Yang et al. (1987) suggested that the total area burned in China was about 2.8 million acres. Based on their information, this study estimates the release of $\mathrm{CO}_{2}$ and $\mathrm{CO}$ from this fire to be about $73 \mathrm{Tg} \mathrm{CO}-\mathrm{C}$ and $7.3 \mathrm{Tg} \mathrm{CO}-\mathrm{C}$, together with $0.84 \mathrm{Tg} \mathrm{CH} \mathrm{CH}_{4} \mathrm{C}, 0.85 \mathrm{Tg} \mathrm{NMHC}-\mathrm{C}, 0.35 \mathrm{Tg} \mathrm{H} \mathrm{H}_{2} \mathrm{H}$, and $0.027 \mathrm{Tg} \mathrm{N} \mathrm{N}_{2} \mathrm{O}-\mathrm{N}$. By comparing these values with estimated releases from tropical areas and emissions from fossil fuel combustion, we know that this big boreal forest fire contributed significantly to the total release of $\mathrm{CO}_{2}$ and $\mathrm{CO}$ and other trace gases to the atmosphere. Comparisons between two zerodimensional photochemical models have shown that the concentrations of many tropospheric species are very sensitive to photolysis rates of ozone, nitrogen dioxide and several other species by UV radiation on the 290 $400 \mathrm{~nm}$ region. An accurate calculation of the associated photolysis rates is essential in model descriptions of the troposphere, as is the diurnal variation of photolysis rates and their impact on the calculated concentrations of trace species in the troposphere. Using newly published, presently recommended absorption cross section and quantum yield data, updated photolysis rates for tropospheric species have been obtained. By comparing concentrations computed using diurnal variation of photolysis rates with concentrations derived using diurnally averaged calculation. this study showed the diurnal variation of photolysis rates is very important in determining the tropospheric concentrations of $\mathrm{NO}_{3}$ and $\mathrm{N}_{2} \mathrm{O}_{5}$.
Major Professor(s): Hameed, Sultan

Department: Marine Environmental Sciences Program Principal Investigator(s): Hameed, Sultan

Program Area: Carbon, Climate, and Vegetation

KEYWORDS: ATMOSPHERE, BIOMASS, COMBUSTION, EMISSIONS, GASES

207

Zhao, Weining 1990. The Relationship Between Precipitation and Temperature over the Continental United States. M.S. Thesis, Oregon Graduate Institute, Global Change Research Center, 125 pages.

There has been growing concern that if the earth warms up due to the increasing greenhouse effect of $\mathrm{CO}_{2}$ and other trace gases in the atmosphere, the patterns of rainfall will shift and greatly affect agricultural productivity and availability of fresh water. One way to study what might happen is to look at the relationship between precipitation and temperature in the past. Within the continental United States, there are extensive data of monthly precipitation and temperature records at over 1000 stations and spanning the last 100 years. Seven regions were defined in the United States based on the ecological and climatological considerations, including areas of major agricultural productivity such as the Corn Belt. This study investigated the relationship between temperature and precipitation over an 80-year period from 1905 to 1984 in the continental United States to see whether the climate tends to be wetter or dryer when it gets warmer. These past patterns might be indicators of future climate as the earth warms from increasing greenhouse effect. The correlation coefficients between precipitation and temperature have been computed for individual stations, for state averages and for regional averages for each month and each season of the year. The linear regression analysis has also been conducted on each region for each of the four seasons. Areas of both negative and positive precipitation-temperature correlations were found in the United States. Over most areas, summer precipitation and temperature are negatively correlated, which indicates that warm summers tend to be dryer and colder summers tend to be wetter. The only notable area where a significant positive correlation was found is south of the Great Lakes bounded in the east by the Appalachian mountains. The contribution to the total correlation from variations of various time-scales was also analyzed in terms of moving-average filtering technique. The correlation between precipitation and temperature were analyzed for three frequency bands - short (shorter than 5 years), medium (between 5 and 15 fifteen years), and long (longer than 15 years) cycles. Although both 
negative and positive precipitation-temperature correlations were found for all cycle bands, over most areas of the United States, significant correlation mainly occurs from variations of short and medium cycles.

Major Professor(s): Khalil, M. Aslam K. Department: Environmental Science and Engineering Principal Investigator(s): Rasmussen, R.A., and M.A.K. Khalil

Program Area: Carbon, Climate, and Vegetation

KEYWORDS: CLIMATE, NORTH AMERICA, PRECIPITATION, REGIONAL ANALYSIS, SPATIAL DISTRIBUTION, TEMPERATURE, TEMPORAL DISTRIBUTION

\section{8}

Zhong Min. 1994. The Greenhouse Effect in the Present Earth-Atmosphere Climate System. M.S. Thesis, State University of New York at Albany, 86 pages.

In recent years, the data from the Earth Radiation Budget Experiment (ERBE) provide the information to study the influences of the greenhouse gases and clouds in the Earth's climate. This is because the ERBE data can offer an unique opportunity to consider not only the radiative balances at the top of the atmosphere but also the clear sky radiative fluxes. The addition of these clear sky fields also permits one to consider the cloud radiative forcing properties. The purposes of this paper are: 1) to study the spacial and temporal characteristics of the greenhouse effect for clear sky and cloudy sky conditions using the ERBE and the observed sea surface temperature data; 2) to compare the Climate Community Model (CCM1) simulations of the greenhouse effect with the observations; and 3) to diagnose the individual contributions to the total greenhouse effect of atmospheric trace constituents. The Earth absorbs the shortwave radiation from the sun and emits the longwave radiation into the space. If there was no atmosphere, the longwave radiation from the Earth's surface would be the same as that at the top of the atmosphere. Due to the existence of water vapor, carbon dioxide, trace constituents and clouds, some of the longwave radiation will be trapped, thus decreasing the outgoing longwave radiation. The greenhouse effect is defined as the trapping of the longwave radiation by atmospheric gases and clouds. In this paper, we evaluate the clear sky greenhouse effect from the model simulations of CCM 1 and compare the results with the observed data over oceans. The results show that the distribution of the monthly mean greenhouse effect from the model simulation is very similar to that of the observational data. Both show the greenhouse effect has the maximum value of more than
$175 \mathrm{Wm}^{-2}$ in tropical region, and the value decreases toward the polar region where it reaches $25 \mathrm{Wm}^{-2}$ or less. Zonal mean profiles show small differences between the model simulation and observation for January and July. The global monthly average of the greenhouse effect from observations is also close to the model analysis. We conclude that the CCM1 with trace gases in it simulates the greenhouse very well for clear sky conditions. The interannual variability of the total greenhouse effect is found to be small, about 1-2 $\mathrm{Wm}^{-2}$. By using a one-dimensional radiative code from the CCM1, the values of the global mean greenhouse effect is calculated to be $136 \mathrm{Wm}^{-2}$ for July 1987 and 125 $\mathrm{Wm}^{-2}$ for January 1987. The model is also used to study the individual contributions of atmospheric constituents to the total greenhouse effect for clear sky conditions. Water vapor, carbon dioxide, ozone, and other trace gases account for $68.6 \%, 21.1 \%, 6.6 \%$, and $3.7 \%$ respectively for July, while they are $67.5 \%, 22.2 \%$, $6.3 \%$, and $4.0 \%$ respectively for January. The results also show that the greenhouse effect is dominated by the amount of the moisture content and its distribution. Clouds also play an important role in the climate system. Clouds absorb the longwave radiation from the Earth surface and emit it at the lower cloud top temperature. The net effect is to trap longwave radiation from the Earth's surface. The cloud longwave radiative forcing is defined as the difference between the clear sky greenhouse effect and the total greenhouse effect. We study the cloud longwave radiative forcing both using the model and the observational data. The model simulated patterns of the longitude-latitude distribution of the cloud longwave radiative forcing are in general agreement with those from observations. However, there are some discrepancies in the magnitude and the size of the region in which cloud radiative forcing occurs. We conclude that the cloud parameterization in the CCM1 captures the general features of the cloud longwave radiative forcing, but further improvements are warranted.

Major Professor(s): Wang, Wei-Chyung

Department: Atmospheric Science

Principal Investigator(s): Wang, Wei-Chyung

Program Area: Carbon, Climate, and Vegetation

KEYWORDS: CLIMATE, CLOUDS, GASES, MODELS, RADLATIVE PROCESSES

\section{9}

Zhong, Shiyuan. 1992. An Observational and Numerical Study of Sea/Land-Breeze Circulations in an Area of Complex Coastal Heating. Ph. D. Dissertation, Iowa State University, 154 pages. 
This dissertation presents an observational and a numerical study of sea/land-breeze circulations as well as a theoretical study on the boundary-layer turbulence parameterization. The sea/land-breeze circulation is a mesoscale response of the atmosphere to the inhomogeneities in heating between land and water surfaces. It is a very important meteorological phenomenon because it directly affects actual weather and climate as well as air pollution in coastal regions. Data from the Kennedy Space Center Atmospheric Boundary Layer Experiment have been used to examine the three-dimensional structure of the mesoscale Atlantic sea/land-breeze and small-scale riverbreeze circulations frequently occur over the area of Kennedy Space Center/Cape Canaveral (KSC/CC) where there exists irregular topographic features such as rivers and lagoons. Detailed characteristic features over a diurnal cycle of the circulations onset time, strength, depth, propagation speed, and both seaward and landward extensions, are documented. Some boundarylayer characteristics related to atmospheric diffusion including atmospheric stability, depth of the thermal internal boundary layer and its evolution with time, and turbulence mixing are also discussed. One of the most important environmental factors affecting the sea/landbreeze circulation is the large-scale synoptic forcing. Previous studies on this factor were all constrained by two factors: a) they were two dimensional in space with the assumption of uniformity in the direction along the coastline, which is idealistic in most coastal regions; and b) they were mostly theoretical, with little regard for geographic features that may strongly influence or dominate the flow. A three-dimensional numerical mesoscale model is used to study the effects of synoptic forcing on the sea/land-breeze circulation at $\mathrm{KSC} / \mathrm{CC}$ area. The sensitivity of mesoscale features to the largescale background flow is explored by examining the lowlevel convergence field, location, strength, and timing of maximum vertical motion; diurnal variation of depth of inflow layer and the thermal internal boundary layer; and the rotation of wind vector. Both of these studies may lead to not only an improved forecast of local weather and atmospheric diffusion of rocket exhausts at $\mathrm{KSC} / \mathrm{CC}$ area, but also to a better understanding of the physical mechanism of the thermally induced circulations, such as their dependence on the threedimensional coastal effects and the synoptic forcing. Boundary-layer turbulence parameterizations are essential for boundary-layer and mesoscale modeling. A new scheme for parameterizing the turbulent stress in terms of the mean wind profile is also presented in this dissertation. This new parameterization scheme is based on the balance of turbulence kinetic energy and is valid in a deeper layer than the constant-flux layer where the previous schemes all fail because of the violation of the fundamental assumption of constant turbulent fluxes.
This new scheme may have direct impact in boundarylayer and mesoscale modeling because it may improve the accuracy of solutions and also reduce the computation time by allowing a minimum number of vertical nodes needed to capture the sharp gradients near the low boundary.

Major Professor(s): Takle, Eugene S. Department: Geological and Atmospheric Sciences Principal Investigator(s): Takle, Eugene S. Program Area: Computer Hardware, Advanced Mathematics, and Model Physics (CHAMMP)

KEYWORDS: COASTAL ENVIRONMENT, LAND SURFACE, NORTH AMERICA, RIVERS, TURBULENCE, WINDS

210

Zhou, Chuan. 1994. Spectral Correction of the MultiFilter Rotating Shadowband Radiometer Shortwave Sensor. M.S. Thesis, State University of New York at Albany, 58+ pages.

The multifilter rotating shadowband radiometer (MFRSR) measures total shortwave irradiance with an unfiltered silicon photodiode. The largest error terms in pyranometer measurements, in general, are caused by angular response and temperature response imperfections. In the MFRSR the temperature is held at a constant value, and the angular response deviation from ideal is measured before deployment and measurements are corrected accordingly. The main error in silicon photodiode radiometry arises because of the mismatch of spectral responses between the ideal wavelength-independent response sensor and the wavelength- dependent response of the silicon cell. To evaluate this error, total horizontal, diffuse horizontal, and direct normal irradiance measurements made with an absolute cavity radiometer-calibrated thermopile pyrheliometer and tracking disk diffuse pyranometer are compared to the silicon response measurements made with an MFRSR. The root-mean-square errors for the MFRSR without spectral corrections are significantly improved compared with standard silicon cell pyranometer with a $60 \%$ improvement in direct normal and a $55 \%$ improvement in diffuse horizontal irradiance. The spectral corrections provide a relatively small additional improvement of 15 to $20 \%$ in the diffuse and total horizontal irradiances. Further, it is found that for five-minute measurements $40 \%, 30 \%$, and $20 \%$ of the remaining difference in direct normal, total horizontal, and diffuse horizontal irradiance measurements, respectively, arises from the difference in the time response of the silicon cell sensors (seconds) and thermopile sensors (seconds). Consequently, silicon 
cell pyranometry with root-mean-square errors of less that $10 \mathrm{~W} / \mathrm{m}^{2}$ in each component are possible.

\author{
Major Professor(s): Michaisky, Joseph, and Lee \\ Harrison \\ Department: Atmospheric Sciences
}

Principal Investigator(s): Michalsky, Joseph, and Lee

Harrison

Program Area: Atmospheric Radiation Measurement (ARM)

\section{KEYWORDS: MULTIFILTER ROTATING \\ SHADOWBAND RADIOMETER (MRSR), \\ RADLATIVE PROCESSES}

\section{1}

Zhuang, Yicheng, 1993. Radiative Forcing Due to Observed Changes in Tropospheric Ozone. M.S. Thesis, State University of New York at Albany, 84 pages.

Tropospheric ozone is observed to have increased at a rate of $10 \%$ per decade at the middle and high latitude in the Northern Hemisphere during the last two decades. This may be attributed to the increasing anthropogenic emissions of $\mathrm{NO}_{x} \mathrm{CO}, \mathrm{CH}_{4}$, etc. (WMO, 1991). Here, we use the observed and model-predicted tropospheric ozone trends to study their possible effect on radiative forcing, which is interpreted as a gain (positive) or loss (negative) of radiation energy for the surface-troposphere system as a whole. The radiative forcing caused by ozone changes is calculated as the changes in the net downward radiative flux at tropopause. Because the observed lower stratospheric ozone depletion may induce a cooling of the lower temperature, we use two types of treatment to calculate the radiative forcing: the first is the fixed temperature treatment, and the second is the fixed dynamical heating treatment, in which the temperature is determined under radiative equilibrium condition with constant dynamical heating. The observed ozone data were measured from seven ozonesonde stations in the Northern Hemisphere, while the model-calculated tropospheric ozone changes were provided from simulations using as two-dimensional tropospheric photochemical tracer transport model at University of Oslo, Norway. Tropospheric ozone increase would result in more absorption of both solar and terrestrial radiation, and therefore yields a warming of the troposphere-surface system. Our study showed that at the stations where there was a large tropospheric ozone increase in the last one to two decades, the fixedtemperature forcing caused by the tropospheric ozone trend was comparable to or even greater than the forcing caused by the stratospheric ozone depletion, thus indicating that the warming effect caused by the tropospheric ozone increase could be as significant as that caused by stratospheric ozone depletion. For example, in January at Payerne, the fixed-temperature forcing caused by the tropospheric ozone increase is $0.24 \mathrm{Wm}^{-2}$, more than twice the forcing caused by the stratospheric ozone depletion which is $0.11 \mathrm{Wm}^{-2}$. The fixed-dynamical heating forcing include an additional cooling effect of the troposphere-surface system caused by the decreased long wave radiation flux to the troposphere resulting from stratospheric temperature decrease in response to stratospheric ozone depletion. This additional cooling effect varies from $0.02 \mathrm{Wm}^{-2}$ to $0.32 \mathrm{Wm}^{-2}$, depending on the magnitude of the stratospheric ozone depletion. Consequently, compared with the fixed temperature treatment, the fixeddynamical heating treatment will calculate a relatively more important role of tropospheric ozone increase. Comparing the forcing induced by the observed ozone changes and $\mathrm{CO}_{2}$ increase during the last two decades, we find that the total ozone induced forcing can attribute substantially to the tropospheric ozone increase, which is comparable to or even exceeds the $\mathrm{CO}_{2}$ induced forcing. For example, in July at Hohenpeissenberg the fixed-temperature forcing $(0.57$ $\mathrm{Wm}^{-2}$ ) caused by ozone is more than twice of the forcing caused by $\mathrm{CO}_{2}$. It is therefore concluded that the increasing trend of tropospheric ozone may have significant climate implications. Changes of the tropospheric ozone for the period 1990-2025 are calculated from a two-dimensional photochemical model. Four cases are considered: (1). $\mathrm{CH}_{4}$ emissions increase by $10 \%$, (2). CO emissions increase by $10 \%$, (3). $\mathrm{NO}_{\mathrm{x}}$ emissions from ground sources increase by $10 \%$, and (4). $\mathrm{NO}_{\mathrm{x}}$ emissions from airplanes increase from $0.7 \mathrm{TgN} / \mathrm{yr}$ to $1.2 \mathrm{TgN} / \mathrm{yr}$. The maximum increase in the model-predicted ozone is $4 \%$ around $10 \mathrm{~km}$ for case 4. Consequently, the radiative forcing is also small ranging from $0.02 \mathrm{Wm}^{-2}$ to $0.19 \mathrm{Wm}^{-2}$, which is about $10-20 \%$ of the forcing caused by $\mathrm{CO}_{2}$ increase during the same time period. The much smaller ozone changes calculated for the next two decades are not consistent with the large observed increase for the past two decades. Therefore, there are two needs to address this issue: The first is to understand better the causes for the ozone increases and the second to continue improving the models for their representation of physical and chemical processes

Major Professor(s): Wang, Wei-Chyung

Department: Atmospheric Science

Principal Investigator(s): Wang, Wei-Chyung

Program Area: Carbon, Climate, and Vegetation

KEYWORDS: OZONE, RADIATIVE PROCESSES 
212

Zieman, Jonathan J. 1991. Tropospheric Carbonyl Compounds at Three Continental Sites: The Importance of Biogenic Hydrocarbons and Implications for the Oxidative Chemistry. Ph.D. Dissertation, University of Washington, 142 pages.

Concentration and stable isotopic measurements of tropospheric carbonyl compounds were made at three widely separated North American continental sites during 1989. The speciation and range of carbonyl compounds were compared to the few measurements reported for other similar sites. The first simultaneous measurements of glyoxal, hydroxyacetaldehyde, methylglyoxal, methyl vinyl ketone and methylacrolein were reported. The carbon isotopic determinations were the first reported using a chemical isotope dilution technique, as well as the only measurements to include more than formaldehyde. The relative importance of methane and biogenic and anthropogenic hydrocarbons in the cycling of reduced carbon compounds and the oxidative state of the tropospheric was discussed for each location. Biogenic nonmethane hydrocarbons were found to be ubiquitous and important components of the troposphere at all the sites. The high reactivity of the biogenic compounds (isoprene and terpenes) results in greater rates of free radical chain reaction propagation than for typical anthropogenic nonmethane hydrocarbons at a given concentration. Therefore, even at small concentrations, biogenic nonmethane hydrocarbons can have a large effect on tropospheric oxidation processes. Acetaldehyde, acetone and MEK were determined to have significant biogenic sources.

Major Professor(s): Zoller, William $\mathbf{H}$.

Department: Chemistry

Principal Investigator(s): Gaffney, Jeffrey S., and Nancy

A. Marley

Program Area: Atmospheric Sciences

KEYWORDS: HYDROCARBONS, REMOTE

SENSING, STABLE ISOTOPES 


\title{
MAJOR PROFESSOR INDEX
}

(numbers refer to citation numbers in the body of the bibliography, beginning on page 1 of this report)

\author{
Aber, John 180 \\ Adams, F. Gerard 159 \\ Albrecht, S.L. 97 \\ Allen, Leon H., Jr. 13, 21, 16, 97 \\ Aller, Robert C. 22 \\ Alofs, Darryl John 131 \\ Arya, S.P.S. 20 \\ Avery, Susan 6 \\ Avissar, Roni 29, 114, 203
}

Baer, Ferdinand 8, 24, 41, 163, 204

Barry, Roger G. 43, 132, 147, 191, 155

Benninger, Larry K. 195

Bianchi, Thomas S. 61

Birge, John R. 164

Biswas, P.K. 54, 128

Bowes, George E. 89

Bradley, Raymond S. 55, 107, 178

Broecker, Wallace S. 76, 80, 189, 196

Brook, George A. 177

Brown, Sandra 68

Brown, Wendell S. 18

Budd, W.F. 130

Cess, Robert D. 26, 48, 100, 105, 141, 186

Chen, Chen-Tung A. 119, 146, 197

Chen, T.-W. 181

Clark, William C. 44

Cotton, William 32

Curtin, T.B. 74

Davidovits, Paul 38, 84

Davidson, Cliff 71

DeAngelis, D.L. 101

DeYoung, Raymond 99

Dickinson, Robert E. 27

Ehleringer, James R. 30, 31, 50, 81

Ellingson, Robert G. 39, 75

Emanuel, Kerry A. 161

Falkowski, Paul G. 145

Few, Arthur 138

Fitzjarrald, David R. 121, 168

Frank, William 37

Gose, Earl E. 63

Hall, Anthony E. 3

Hall, Charles A.S. 57, 40 
Ham, J.M. 17

Hameed, Sultan 45, 103, 104, 148, 149, 182, 183, 206

Han, Qingyuan 25

Harris, Robert C. 62

Harrison, Lee 210

Harte, John 92, 179

Hellmers, Henry 12

Hobbs, Peter V. 2

Hoffert, Martin I. 11, 64, 83, 194

Holsen, Thomas M. 52

Hood, Lon L. 202

Jacoby, G. 36

Janowitz, Gerald S. 117, 156

Johnston, Harold 102

Jones, James W. 90,95

Jones, Pierce H. 166

Kammen, Daniel M. 1

Kao, C.-Y. J. 181

Kaplan, Stephen 99

Kaufman, Donald G. 134

Khalil, M. Aslam K. 122, 123, 125, 126, 136, 137, 207

Kirkham, M. B. 65, 127

Klink, John 35

Kreidenweis, Sonia 201

Kutzbach, John E. 106, 133

Lambert, Jerry R. 42

Larock, Bruce E. 165

Long, Austin 110

Lussenhop, John 91, 160

Marlow, William H. 34

Martin, Chris 53

Michalsky, Joseph 210

Miller, R. Michael 60

Moore, Berrien 193

Morgan, Hugh 59

Morrison, J. 49

Nathan, Terrance R. 115

Oechel, Walter C. 188

Oeschger, H. 96

Patterson, Robert P. 153

Pietrafesa, Leonard J. 111, 118, 129, 143, 156, 185

Raman, Sethu 4, 5, 10, 23, 28, 82, 87, 108

Randall, David A. 33, 78, 85, 174

Rennie, John 120

Repeta, Daniel J. 7

Reynolds, James F. 109

Rogers, Hugo H. 154

Sarmiento, Jorge L. 98, 140 
Sassen, Kenneth 116

Saxena, Vinod K. 19, 73, 79, 167, 192

Schlesinger, Michael 56, 93, 94, 135, 144, 157

Schoeberl, Mark 138

Shaw, P.T. 185

Sherr, Barry F. 187

Siegenthaler, U. 96

Smith, Jeffrey L. 139

Smith, Ronald B. 169

Soong, Su-Tsai 9

Stamnes, Knut 86

Stephens, Graeme L. 51, 175

Stone, Peter H. 66

Strain, Boyd R. 47, 72, 112, 124, 150, 158, 162, 172, 173, 190, 198, 199

Street, Robert L. 142

Stuiver, Minze 184

Stull, Roland B. 171, 176, 205

Takahashi, Taro 70

Takle, Eugene S. 209

Trent, Tony A. 113

Vankat, John L. 15, 77

Wang, Wei-Chyung 46, 208, 211

Weare, Bryan C. 67,200

Whillans, Ian M. 88

Wigley, T.M.L. 170

Williams, Earle 14

Wofsy, Steven C. 58, 69

Zachariah, G.L. 95

Zobler, Leonard 151

Zoller, William H. 152, 212 



\section{UNIVERSTTY INDEX}

(numbers refer to citation numbers in the body of the bibliography, beginning on page 1 of this report)

Arizona State University 53

Auburn University 154

Boston College 38, 84

Carnegie Mellon University 71

Clemson University 42

Colorado State University $32,33,51,78,85,174,175,201$

Columbia University $36,70,76,80,151,189,196$

Cornell University 40

Duke University $12,47,72,112,124,150,158,162,172,173,190,198,199$

Harvard University 44, 58, 69

Illinois Institute of Technology 52

Iowa State University 209

Kansas State University $17,65,127$

Lamar University 61

Massachusetts Institute of Technology 7, 14, 66, 161

Miami University $15,35,59,77,134$

New Mexico State University at Las Cruces 181

New York University 11, 64, 83, 194

North Carolina State University $4,5,10,19,20,23,28,49,73,74,79,82,87,108,109,111,117$, $118,129,143,153,156,167,185,192$

Ohio State University 88

Oregon Graduate Institute, Global Change Research Center 122, 123, 125, 126, 136, 137, 207

Oregon State University 93, 119, 135, 144, 146, 187, 197

Pennsylvania State University 37

Princeton University $1,98,140$

Rice University 138

Rutgers University 29, 114, 203

San Diego State University 188

South Dakota School of Mines and Technology 25

Stanford University 142

State University of New York at Albany 46, 121, 168, 208, 210, 211

State University of New York at Stony Brook 22, 26, 45, 48, 100, 103, 104, 105, 141, 145, 148, $149,182,183,186,206$

State University of New York at Syracuse 57

Texas A\&M University 34

Tuskegee University 54,128

University of Alaska - Fairbanks 86

University of Arizona 27, 110, 202

University of Bern 96

University of California at Berkeley $92,102,179$

University of California at Davis 9, 67, 115, 165, 200

University of California at Riverside 3

University of Chicago 60 
116

University of Colorado $6,43,132,147,155,191$

University of East Anglia 170

University of Florida 13, 16, 21, 89, 90, 95, 97, 166

University of Georgia 177

University of Idaho 113

University of Illinois at Chicago $63,91,160$

University of Illinois at Urbana-Champaign 56, 68, 94, 157

University of Maryland at College Park 8, 24, 39, 41, 75, 163, 204

University of Massachusetts 55, 107, 178

University of Melbourne 130

University of Michigan 99, 164

University of Missouri - Pola 131

University of New Hampshire 18, 62, 180, 193

University of North Carolina at Chapel Hill 195

University of Pennsylvania 159

University of Tennessee 101,120

University of Utah $30,31,50,81,116$

University of Washington 2,152, 184, 212

University of Wisconsin - Madison 106, 171, 133, 176, 205

Washington State University 139

Woods Hole Oceanographic Institution 7

Yale University 169 


\section{PRINCIPAL INVESTIGATOR INDEX}

(numbers refer to citation numbers in the body of the bibliography, beginning on page 1 of this report)

Acock, Basil 42, 53, 113

Allen, Leon H., Jr. 13, 16, 21, 53, 89, 90, 95, 97, 113, 166

Aller, J.Y. 22

Aller, R.C. 22

Avissar, Roni 29, 114, 203

Baer, Ferdinand 8, 24, 41, 163, 204

Barry, Roger G. 147,191

Benninger, Larry K. 195

Bianchi, Thomas S. 61

Biswas, P.K. 54, 128

Bolton, Harvey, Jr. 139

Bradley, Raymond S. 55, 107, 155, 178

Broecker, Wallace S. 76, 80, 189, 196

Brook, George A. 177

Brown, Sandra 68

Cess, Robert D. 26, 100, 105, 141, 186

Chen, Chen-Tung A. 119, 146, 197

Clark, William C. 44

Cochran, J.K. 22

Cushman, Robert M. 35

Davidovits, Paul 38, 84

Diaz, Henry F. 43, 155

Dickinson, Robert E. 27

Edmonds, James A. 159

Eglinton, Timothy I. 7

Ehleringer, James R. 30, 31, 50, 81

Ellingson, Robert G. 39, 75

Emanuel, Kerry A. 161

Emanuel, W.R. 101, 120

Falkowski, Paul G. 145

Farrell, Michael P. $15,59,77,134$

Fitzjarrald, David R. 121,168

Fung, Inez 36, 151

Gaffney, Jeffrey S., 52, 152, 212

Gage, Ken 6

Gates, W. Lawrence $67,93,135$

Hall, Anthony E. 3

Hall, Charles A.S. 40

Hameed, Sultan 45, 48, 103, 104, 148, 149, 182, 183, 206

Han, Qingyuan 25

Harrison, Lee 210

Hoffert, Martin I. 64, 83, 194

Hood, Lon L. 202 
Kammen, Daniel M. 1

Kanciruk, Paul 35

Kao, C.-Y. Jim 181

Khalil, M.A.K $\quad$ 122, 123, 125, 126, 207

Kimball, Bruce A. 53, 113

Kirkham, M.B. 65,127

Kreidenweis, Sonia 201

Kutzbach, John E. 106, 133

Lee, C. 22

Lee, Robert L. 165

Long, Austin 110

MacCracken, Michael C. 66,200

Marley, Nancy A. 52, 152, 212

Marlow, William H. 34

Michalsky, Joseph 210

Miller, R. Michael $60,91,160$

Moore, Berrien 18, 62, 180, 193

Oechel, Walter C. 188

Owensby, C.E. 17

Penner, Joyce E. 9, 142

Pietrafesa, Leonard J. 4, 10, 20, 28, 49, 74, 87, 111, 117, 118, 129, 143, 156, 185

Porch, William M. 32

Radok, Uwe 130

Raman, Sethu 5, 23, 82, 108

Randall, David A. 33, 78, 85, 174

Rasmussen, R.A., 122, 123, 125, 126, 207

Repeta, Daniel J. 7

Reynolds, James F. 109

Rogers, Hugo H. 153, 154

Rogers, Lee E., 139

Rotman, Douglas A. 115

Sarmiento, Jorge L. 98,140

Sassen, Kenneth 116

Saxena, Vinod K. 19, 73, 79, 167, 192

Schlesinger, Michael 56, 94, 144, 157

Schwartz, Stephen E. 11

Sherr, Barry F. 187

Siegenthaler, U. 96

Smith, Ronald B. 169

Stamnes, Knut 86

Stephens, Graeme L. 51, 175

Strain, Boyd R. 12, 47, 72, 112, 124, 150, 158, 162, 172, 173, 190, 198, 199

Stull, Roland B. 171, 176, 205

Takahashi, Taro 70

Takle, Eugene S. 209

Toon, Owen B. 2

Wang, Wei-Chyung 46, 208, 211

Washington, Warren M. 132 
Wesely, Marvin L. 63

Westphal, Douglas L. 2

Wigley, T.M.L. 170

Williams, Allen 131

Williams, Earle 14

Wofsy, Steven C. 58, 69

Wohlpart, A. 37, 57, 69, 71, 88, 92, 99, 136, 137, 138, 164, 179, 184

Wuebbles, Donald J. 102 



\section{PROGRAM AREA INDEX}

(numbers refer to citation numbers in the body of the bibliography, beginning on page 1 of this report)

Atmospheric Radiation Measurement (ARM) 2, 5, 6, 8, 23, 24, 33, 75, 82, 108, 116, 163, 171, $175,176,181,205,210$

Atmospheric Sciences 9, 11, 34, 38, 63, 79, 84, 102, 115, 142, 152, 165, 167, 202, 212

Carbon, Climate, and Vegetation $12,13,16,17,18,21,26,35,36,40,42,43,45,46,47,48,53$, $54,55,56,62,64,65,66,67,68,70,72,76,80,83,85,89,90,93,94,95,96,97,98,100$, $101,103,104,105,106,109,110,112,113,119,120,122,123,124,125,126,127,128,130$, $132,133,135,140,141,144,146,147,148,149,150,151,153,154,155,157,158,159,162$, $166,170,172,173,174,178,180,182,183,186,188,189,190,191,193,194,196,197,198$, $199,200,206,207,208,211$

Computer Hardware, Advanced Mathematics, and Model Physics (CHAMMP) 27, 29, 41, 78, $114,161,203,204,209$

Ecosystems Function and Response $30,31,50,60,81,91,139,160$

Graduate Fellowships for Global Change 37, 57, 69, 71, 88, 92, 99, 136, 137, 138, 164, 179, 184

Information $15,35,59,77,134$

Marine Transport $4,7,10,20,22,28,49,74,87,111,117,118,129,143,156,185,187,195$

National Institute for Global Environmental Change (NIGEC) 1, 3, 14, 19, 25, 44, 51, 58, 61, 69, $73,107,121,168,169,177,192,201$

Oceans 145

Quantitative Links $32,39,86,131$

Terrestrial Transport 52 



\section{KEYWORD INDEX}

(numbers refer to citation numbers in the body of the bibliography, beginning on page 1 of this report)

Absorption 39

Acidity 44, 167

Aerosols 2, 19, 34, 35, 71, 79, 102, 123, 125, 167, 192, 201

Africa 1, 193

Aggregates 91

Agriculture 68, 90

Air quality 99,152

Alkalinity 80, 194

Antarctica 88, 147, 167

Arctic 107, 188

Asia 55, 87, 104, 178

Atmosphere $4,9,12,13,20,21,23,28,29,35,38,40-43,49,56,58,62,66,67,70,82,84,87,89$, $90,95,97,108,114,115,121-123,125,126,137,141,144,147,155,157,159,162,166$, $169,170,172,186,190,200,202,204,206$

Bacteria 7, 97, 187

Biomass 13, 47, 54, 57, 70, 91, 95, 162, 172, 190, 206

Biomes 151

Biosphere 58, 62, 70, 101, 147, 151

Boundary layer 2, 6, 20, 23, 28, 32, 37, 49, 87, 108, 121, 123, 176, 181, 203, 205

C3 metabolism 17, 47, 124, 127, 162, 198, 199

C4 metabolism 17, 47, 124, 127, 150, 162, 198, 199

Capillarity 34

Carbohydrates 7, 13, 54, 89, 95, 127, 162

Carbon cycle 7, 30, 31, 40, 50, 58, 64, 65, 68, 70, 76, 96, 101, 119, 140, 147, 151, 158, 180, 194, 197

Carbon dioxide 3, 12, 13, 15, 17, 21, 36, 40, 47, 53, 54, 56, 58, 65, 70, 72, 76, 80, 83, 89, 90, 93-95, $97,101,109,110,112,113,119,124-126,128,147,150,153,154,158,159,162,166$, $172-174,184,188-190,194,196-200$

Carbon isotopes 70, 80, 96, 102, 110, 184, 189, 195, 196

Carbon monoxide 9, 123, 137

Carbon use 72

Cellulose 54

Charcoal 177

Chemistry $9,19,38,79,84,119,122,123,131,137,146,167,189,192,195-197$

Circulation 4, 18, 23, 28, 32, 41, 43, 49, 66, 74, 82, 87, 98, 108, 111, 115, 117, 118, 129, 143, 146, $155,156,185,189,194,204$

Climate $4,5,8,10,19,20,23,24,27,28,33,36,43,44,49,53,56,62,64,73,77,78,82,83$, $85-87,90,92-94,101,103,106-108,125-127,132,133,135,144,149,155,157,159,161$, $163,164,170,174,177-179,181,183,184,191-193,200,207,208$

Cloud chamber 131

Clouds $2,19,25,26,33,37,51,73,75,79,82,86,87,100,108,116,123,125,131,137,144,167$, $175,176,181,192,208$

Coastal environment 4, 28, 35, 87, 108, 117, 118, 129, 134, 143, 156, 167, 185, 209

Colloids 52 
Colonization 160

Combustion 45, 206

Competition 47, 60, 158, 198, 199

Condensation 2, 10, 19, 34, 73, 79, 131, 167

Convection 10, 33, 37, 56, 85, 125, 155, 161, 181

Databases 15, 35, 77, 134

Decomposition 62

Degradation 7

Deposition 9, 44, 71

Deserts 30, 31, 50, 81

Diagenesis 22

Diatoxanthin 145

Diffusion 32, 58, 62, 70, 87, 96, 102, 194, 203

Discrete dipole approximation (DDA) 175

Disturbance 57, 120, 178

Droplets 73, 84

Economics 159, 164

Ecotypes 150

Electron transport capacity 112

El Nino - Southern Oscillation (ENSO) 36, 41, 132, 147, 155, 183

Emissions 11, 38, 45, 61-63, 69, 70, 73, 79, 96, 99, 102, 136, 142, 159, 164, 180, 192, 197, 200, 206

Energy balance 86

Energy transport 67

Energy use 159

Environmental growth chambers 166

Enzymes 21, 89

Equatorial region 106, 146

Estuaries 195

Europe 55, 170, 178

Evaporation 10, 82, 90

Evolution 47

Extratropics 5, 41

Fertilization $3,12,13,36,47,54,72,76,89,90,95-97,112,113,124,128,150,153,154,158,162$, $172,173,188,190,198,199$

Fish 143

Flow 88

Fluorescence 145

Forests $40,57,68,69,101,120,121,168,180$

Fossil fuels 45, 73, 79, 197

Fourier Amplitude 29

Fractionation 196

Fuel 54

Fulvic acids 52

Fungi 53, 60, 91, 112, 160

Gases 46, 62, 102, 157, 164, 186, 196, 206, 208

Genetics 50

Geology 106

Glaciology 130 
Grasslands 63, 160

Greenland 184

Growth and development $3,12,13,16,21,30,31,47,50,53,72,81,92,97,109,113,127,128$, $150,153,154,158,162,172,173,188,190$

Halogenated hydrocarbons $125,137,200$

Halogen species 38, 84, 102, 195

Heat flux 4-6, 24, 29, 82, 93, 94, 121, 126, 129, 163

Heat stress 3

Henry's Law 38

Holocene 43, 177

Humic acids 52, 61

Hydrocarbons 9, 69, 212

Hydrology 143, 193

Hydrolysis 38

Hydroxyl radical 9, 122, 123, 137

Ice $62,88,147,175,184,191$

Ice Age 106, 122, 123, 133

Intercellular concentrations 124

Intertropical Convergence Zone (ITCZ) 70

Introduced species 172,173

Islands 68, 181

Lakes 58, 80, 107, 191, 196

Land surface 20, 29, 32, 82, 87, 114, 176, 193, 203, 209

Land use $20,40,68,76,180$

Latin America 40

Leaves $13,16,21,30,31,50,53,81,89,90,95,109,128,153,162,168$

Marine environment 2, 7, 23, 28, 49, 51, 87, 145, 181

Mass 18

Metabolism 89

Metals 22, 96, 119, 146, 167, 189, 195, 197

Meteorology 204

Methane 9, 58, 61, 62, 123, 125, 136, 137, 200

Microbes 91

Microphysics 2, 19, 51, 79, 87, 108, 192

Midlatitudes 69

Mixed layer 171, 189, 194, 205

Models 8-11, 15, 16, 20, 24, 25, 27, 29, 40, 48, 56, 57, 62, 70, 71, 73, 78, 82, 83, 85-87, 90, 93-96, $101-103,106,108,111,115,117,118,122,123,125,126,132,133,135,137,140,144,147$, $149,151,157,159,161,163-166,169,170,174,179,181,185,187,189,192-194,201,204$, 205,208

Momentum 4, 6, 126, 156

Morphology 113, 160

Mortality 50, 120

Multifilter Rotating Shadowband Radiometer (MRSR) 210

News media 59

Nighttime 122, 123, 127

Nitrogen cycle $42,62,76,139,142,187$

Nitrogen species 9, 62, 97, 98, 102, 125, 137, 139, 142, 182, 192, 194, 197, 200 
North America 22, 43, 55, 58, 61, 68, 107, 120, 148, 170, 177, 181, 185, 191, 207, 209

North Atlantic Oscillation 149

Northern Hemisphere 36, 55, 69, 107

Oceans $4,18,22,23,28,37,49,67,70,74,83,87,93,94,96,98,108,111,117-119,129,140,146$, $147,156,157,170,185,189,194,196,197$

Organics $22,40,61,63,68,69,91,140,197$

Oxygen 98, 119, 140, 189, 194

Ozone 9, 25, 39, 44, 58, 102, 109, 200, 202, 211

Particulates 2, 19, 73, 79, 131, 140, 167, 175

Partitioning 102

Pastures 68

Peat 177

Permafrost 136

Peroxyacetyl nitrates 152

$\mathrm{pH} 80$

Phosphate 22, 89, 95, 112, 194, 197

Phosphorus 140

Photosynthesis $21,30,31,50,58,72,81,95,112,124,150,151,158,168,173,188,190,198,199$

Plankton 7, 145

Pleistocene Epoch 47

Policy $1,44,159,164$

Pollen 43, 177

Prairies 17, 65, 91

Precipitation 5, 27, 30, 31, 43, 50, 55, 61, 62, 81, 87, 103, 104, 108, 126, 155, 178, 193, 207

Pre-industrial era 47, 123, 200

Pressure 23, 28, 74, 126, 156, 170, 204

Productivity $65,101,133$

Product release assays (PRA) 187

Program management 59

Proteins 128

Protists 187

Puerto Rico 68

Pyrgeometer 75

Radiative processes $8,24-26,35-37,39,46,48,51,56,66,75,83,85-87,102,105,108,123,125$, $137,141,144,157,161,163,168,169,174,181,190,192,208,210,211$

Radio Acoustic Sounding System (RASS) 6

Recovery 57, 120

Reflectance $2,19,25,48,49,51,73,100,125,168$

Regional analysis 55, 73, 101, 152, 178, 192, 207

Remobilization 22

Remote sensing 5, 49, 51, 152, 175, 180, 181, 212

Reproduction 3, 81

Respiration 58, 72, 95, 124, 127, 150, 151, 158, 173, 199

Reynolds stresses 165

Ribulose bisphosphate 21

Risk 44

Rivers 22, 129, 193, 195, 209

Roots 53, 60, 91, 112, 128, 154, 160 
Rubisco 112

Runoff 129, 155, 193

Salinity $18,81,98,129,189$

Sap 17

Scattering $25,116,175$

Scavenging 182

Schumann resonance 14

Sea floor 64

Sea level 35, 64, 117, 130, 134, 156

Sediments 7, 22, 107, 177, 189, 195

Seeds 13, 128

Shade 158

Shrub-steppe 139

Silica 98, 189

Size distribution 201

Soils $16,29-31,40,42,50,62,65,68,76,81,82,90,91,114,124,136,154,179,193$

Solar energy 1

Sound 77

South America 22, 58, 155, 180, 193

Soviet Union 55

Spatial distribution $4,11,20,27,62,81,82,122,123,135,139,146,150,156,169,170,173,185$, 191, 197, 200, 207

Stable isotopes 91,212

Stomates 90, 128

Storms 4, 5, 10, 23, 28, 35, 36, 57, 108, 120, 132, 155

Streams 88

Strontium-90102

Structure 120

Subalpine environment 179

Subtropics 57, 68, 169

Succession 198, 199

Sulfur species $11,38,45,73,79,157,167,182,192$

Sunshine 148

Surface layer $43,147,171$

Surging 130

Taylor's expansion 204

Teleconnections 149

Temperature $16,18,21,35,37,39,43,53,62,82,89,90,92,125-127,129,147,157,159,168,169$, $178,179,188,189,191,194,200,207$

Temporal distribution 4, 11, 22, 27, 36, 41, 43, 50, 55, 62, 69, 85, 102-104, 121-123, 135, 139, 147, 148, 155-157, 168-170, 178, 181, 182, 185, 191, 202, 204, 207

Terrestrial environment 70, 101, 151

Tides 74, 117, 156

Tracers 70, 94, 96, 102, 107, 119, 189, 196

Trajectories 138

Transformation 11

Transpiration 16, 17, 81, 90, 188

Transport 9, 11, 66, 140, 194, 196 
Transportation 99

Tree rings $36,43,92,110$

Tropics 5, 10, 18, 37, 40, 58, 115, 180, 193

Tundra 58, 101

Turbulence 6, 29, 58, 87, 108, 114, 121, 165, 181, 203, 205, 209

Urban environment 20,71, 79

Vapor pressure 16, 34

Vegetation $3,12,13,16,17,21,29-31,42,47,50,53-55,65,72,81,82,89,90,92,95,97,110$, $112-114,120,124,127,128,150,153,154,158,162,172,173,177,188,190,198,199$

Virtual impactor 131

Volcanoes 35, 36, 125, 157

Water 16, 18, 19, 62, 65, 78, 81, 167, 179, 192, 193, 196

Water quality 52

Water stress $12,16,30,31,42,50,61,81,109,124,153,154,162,190,198,199$

Water use $16,50,90,153,188,190,198,199$

Water vapor $5,37,39,82,124,161,168,169$

Waves $43,66,74,115,117,185$

Wetlands 61, 62, 79

Winds $5,6,33,37,49,58,71,82,87,111,115,117,118,121,126,129,138,143,147,156,171$, 196,209

Yield 13, 97 